A SAÚDE DO IDOSO EM MARINGÁ:

ANÁLISE DO PERFIL DE SUA MORBI-MORTALIDADE

THAIS AIDAR DE FREITAS MATHIAS

São Paulo

2002 


\section{A SAUUDE DO IDOSO EM MARINGÁ: \\ ANÁLISE DO PERFIL DE SUA MORBI-MORTALIDADE}

\section{THAIS AIDAR DE FREITAS MATHIAS}

Tese de Doutorado apresentada ao Departamento de Epidemiologia da Faculdade de Saúde Pública da Universidade de São Paulo para obtenção do Grau de Doutor.

Área de concentração: Epidemiologia.

Orientadora: Prof ${ }^{\mathrm{a}}$. Dr ${ }^{\mathrm{a}}$. Maria Helena Prado de Mello Jorge

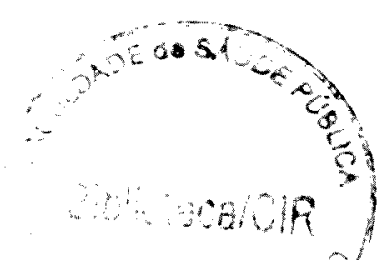


Autorizo, exclusivamente para fins acadêmicos e científicos, a reprodução total ou parcial desta tese por processos fotocopiadores. Assinaturas thas Mden de Juv aolin Data: A foil 2002

4218012002 dic 


\section{AGRADECIMENTOS}

Agradeço à Professora $\mathrm{Dr}^{\mathrm{a}}$ Maria Helena Prado de Mello Jorge, cuja dedicação e incentivo foram essenciais para a elaboração deste trabalho.

Agradeço aos meus colegas do Departamento de Enfermagem da Universidade Estadual de Maringá pelo estímulo, ao Roberto pelas informações cedidas e a $\mathrm{Dr}^{\mathrm{a}}$ Cassia Maria Buchalla pelas orientações na compatibilização dos diagnósticos.

À minha família que me acompanha e me ampara sempre.

À CAPES (Coordenação de Aperfeiçoamento de Pessoal de Nível Superior) pela bolsa de estudo concedida. 


\section{RESUMO}

Objetivo: O objetivo deste estudo foi conhecer a situação de saúde de idosos residentes em Maringá-PR, por meio da análise da mortalidade segundo sexo, idade e causa básica de óbito e da morbidade hospitalar segundo sexo, idade, diagnóstico principal de internação, média de permanência e tipo de saída. Material e Método: População idosa, neste estudo, refere-se às pessoas com 60 anos e mais de idade. Para a mortalidade o período analisado foi de 1979 a 1998, agrupado em quatro triênios: 1979/81, 1984/86, 1990/92 e 1996/98 e os dados foram obtidos do Sistema de Informações de Mortalidade do Ministério da Saúde. Para a morbidade hospitalar o período analisado foi de 1995 a 1998 e os dados foram obtidos do Sistema de Informações Hospitalares do SUS. As informações sobre população referem-se aos censos demográficos com estimativas para os anos intercensitários. Os indicadores de mortalidade e morbidade foram apresentados por capítulos, agrupamentos ou diagnósticos mais freqüentes, codificados segundo a Classificação Internacional de Doenças, $9^{\mathrm{a}}$ e $10^{\mathrm{a}}$ Revisões. Os dados foram analisados através de medidas de proporção e taxas de mortalidade e morbidade hospitalar. Resultados: Entre 1979 e 1998 a população idosa residente em Maringá aumentou e houve queda na estimativa do risco de morte, mais importante para as mulheres. As causas mais freqüentes de óbito foram as doenças do aparelho circulatório, neoplasias e doenças do aparelho respiratório. Os coeficientes de mortalidade por doenças do aparelho circulatório e doenças infecciosas e parasitárias diminuíram e por doenças do aparelho respiratório, neoplasias e doenças endócrinas, nutricionais e metabólicas aumentaram. Em 1998 houve 163,5 internações por 1000 habitantes idosos com valores maiores para as idades mais avançadas. As doenças do aparelho circulatório, respiratório e digestivo foram as mais importantes com mais de $70 \%$ das saidas hospitalares no período estudado. A média de permanência foi de 4,4 dias e o coeficiente de mortalidade hospitalar foi de 6,5 óbitos para cada 100 internações. Entre os diagnósticos de internação mais freqüentes as doenças do sistema nervoso, do aparelho geniturinário, do aparelho respiratório e digestivo foram as que apresentaram maior relação hospitalização/óbito. Conclusões: $O$ aumento da longevidade é uma conquista e a velhice deve ser considerada como uma etapa da vida que deve ser desfrutada com qualidade. É preciso implementar na comunidade ações de promoção à saúde mais 
agressivas direcionadas aos riscos de óbito, principalmente por doenças cardiovasculares, neoplasias e doenças respiratórias crônicas. Por isso os serviços de saúde, considerados, dependendo do atendimento, co-responsáveis por complicações e mortes precoces no idoso, devem estar preparados para oferecer atenção em quantidade e qualidade suficientes para essa população.

Descritores: Mortalidade, Idoso, Morbidade Hospitalar, Estatísticas de Saúde. 


\section{ABSTRACT}

Objective: The main purpose of this study was to know the health condition of the elderly population resident in Maringá-PR, by means of the mortality and hospital morbidity analysis according to sex, age and underlying cause of death and main diagnosis of hospital admission, for the hospital morbidity. Material and Method: In this study aged population was considered people 60 years and over. The period for the mortality analysis ranged from 1979 to 1998 grouped in triennials: 1979/81, 1984/86, 1990/92 and 1996/98 and data were obtained from the Mortality Information System of the Brazilian Ministry of Health. Hospital morbidity was studied from 1995 to 1998 and data was obtained from the Hospital Information System of the National Health System. Other variables for the hospital discharges analysis such as length of stay and mortality rate were studied. The population was estimated from the national demographic census. Mortality and morbidity rates were presented by chapters or more frequent diagnoses and underlying cause of death and main diagnosis of hospital admission were codified by the International Classification of Diseases, $9^{\text {th }}$ and $10^{\text {th }}$ Revisions. Data were analyzed by proportion measures, mortality and morbidity rates. Results: From 1979 to 1998 the aged population in Maringá has increased and the estimated mortality rate has decreased, more importantly for women. During all the studied period the leading causes of death were circulatory diseases, neoplasms and respiratory diseases. The mortality rates for circulatory diseases, infectious and parasitc diseases and digestive diseases have decreased and the respiratory diseases, neoplasms and endocrine, nutritional and metabolic diseases and immunity' disorders, have increased. In 1998 the hospitalization rate was 163.5 admissions per 1000 inhabitants aged 60 and over and they were higher for more advanced ages. From 1995 to 1998 the circulatory, respiratory and digestive diseases were the more frequent diagnoses with more the $70 \%$ from all hospital admissions. The hospital admissions have increased in the period, more importantly in the hospitals outside the municipality of Maringá. The average length or stay was 4.4 days and the hospital mortality rate was 6.5 deaths per 100 admissions. Among the more frequent diagnoses of hospital admissions, the rate hospitalization/death was higher for the nervous system diseases, genitourinary diseases, respiratory and digestive diseases. Conclusions: The increase in life 
expectancy is a victory and the ageing must be considered as a time of life that has to be enjoyed and enjoyed with quality. It is important that strategies of care are implemented and more aggressive activities of health promotion are addressed to the major risks of death, mainly for cardiovascular diseases, malignant neoplasms and chronic respiratory diseases. The health services that may be considered coresponsible for complications and premature deaths among aged people, depending on the attention offered, must be prepared to offer attention with enough quantity and quality for that population.

Descriptors: Mortality, Elderly, Hospital Morbidity, Health Statistics. 


\section{SUMÁRIO}

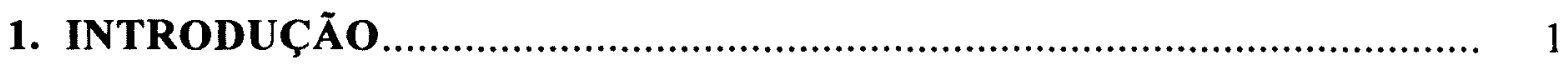

1.1 A transição epidemiológica e demográfica .......................................... 3

1.2 Envelhecimento e desigualdade ...................................................... 5

1.3 Envelhecimento e saúde ................................................................... 8

1.4 Estudos de mortalidade ................................................................. 10

1.5 Estudos de morbidade .................................................................. 12

1.6 As estatísticas de saúde. Importância e qualidade dos dados ..................... 13

1.6.1 Mortalidade ......................................................................... 13

1.6.2 Morbidade hospitalar .......................................................... 16

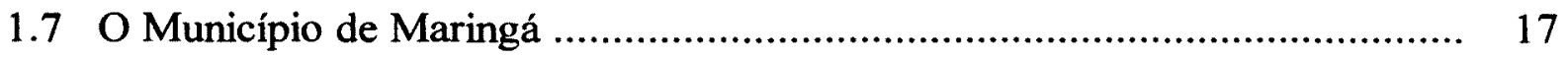

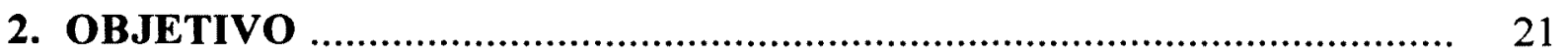

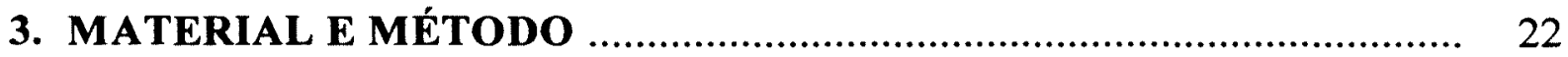

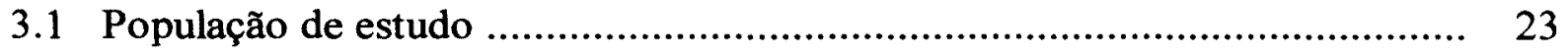

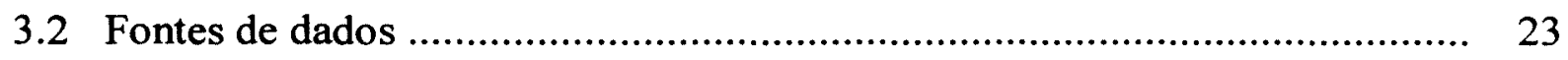

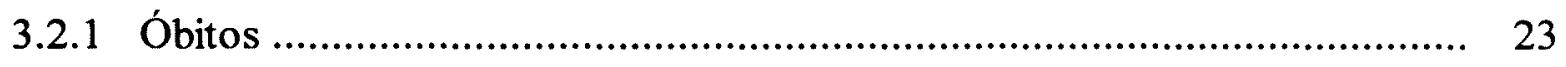

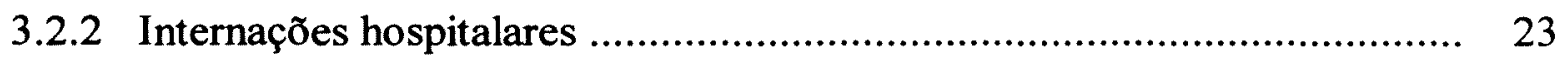

3.2.3 População .............................................................................. 24

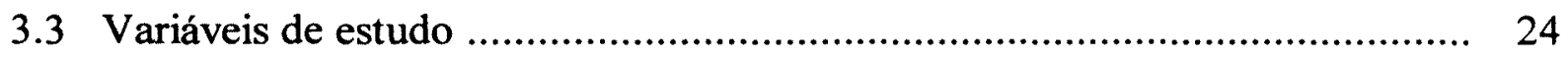

3.3.1 Mortalidade ............................................................................ 24

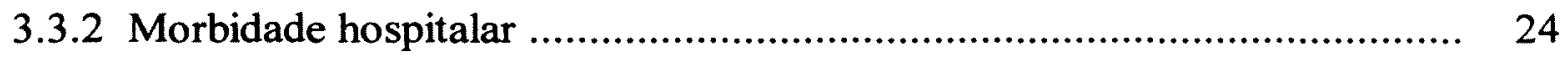

3.4 Procedimentos de análise .............................................................. 24

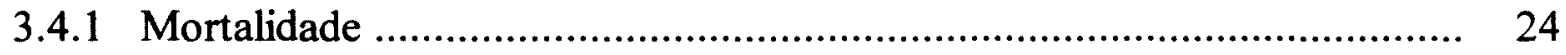

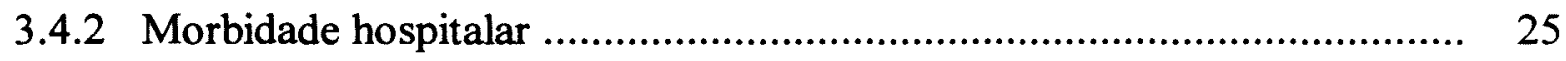

3.5 Medidas utilizadas ....................................................................... 26

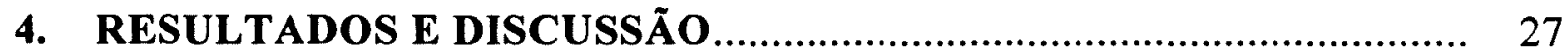

4.1 Evolução da população do Município de Maringá .................................... 28

4.2 Mortalidade em idosos no período de 1979 a 1998 ............................... 31

4.2.1 Considerações sobre a qualidade do banco de dados de mortalidade em Maringá 
4.2.2 Mortalidade em idosos segundo sexo e idade ........................................ 37

4.2.3 Mortalidade em idosos segundo causas ............................................... 45

- Doenças do aparelho circulatório ............................................................... 48

- Doença cerebrovascular .................................................................... 52

- Doença isquêmica do coração .................................................................... 58

- Outras formas de doenças do coração ......................................................... 64

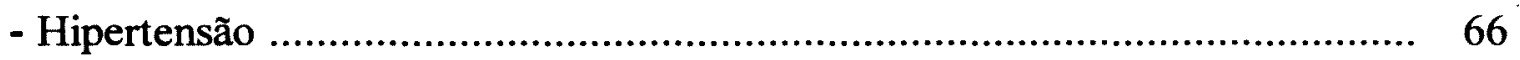

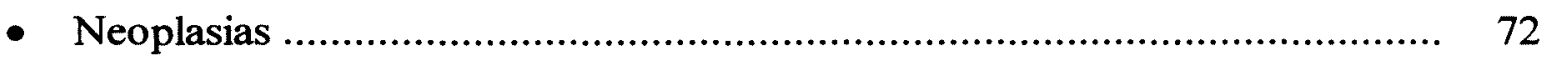

- Doenças do aparelho respiratório ................................................................. 83

- Doenças endócrinas, nutricionais e metabólicas …………………………....... 89

- Doenças do aparelho digestivo ................................................................. 95

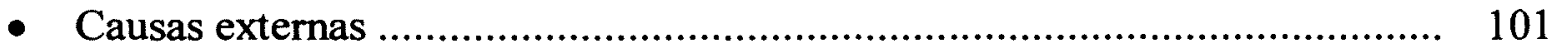

- Algumas doenças infecciosas e parasitárias .................................................. 108

4.3 Morbidade hospitalar em idosos no período de 1995 a $1998 \ldots \ldots \ldots \ldots \ldots \ldots \ldots . . . . . . . .117$

4.3.1 Morbidade hospitalar em idosos segundo sexo e idade ........................... 118

4.3.2 Morbidade hospitalar em idosos segundo diagnóstico principal de internação ....................................................................................... 122

4.3.3 Morbidade hospitalar em idosos segundo duração média da

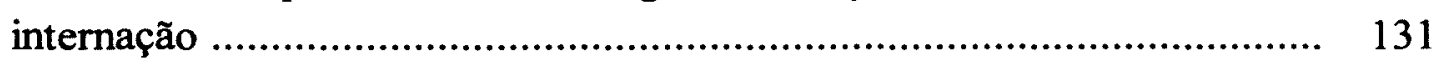

4.3.4 Morbidade hospitalar em idosos segundo tipo de saída 138

4.3.5 Morbidade hospitalar em 1998 e mortalidade em idosos no triênio 1996-1998

5. CONSIDERAÇÕES FINAIS............................................................. 153

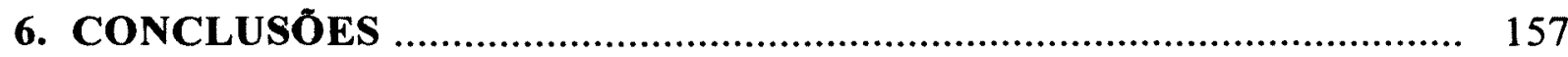

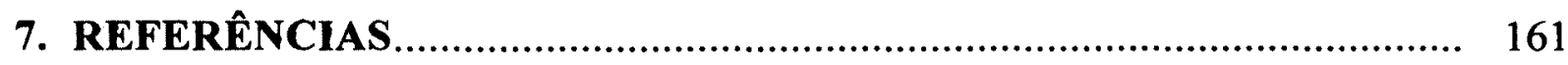

8. ANEXOS 
1. INTRODUÇÃO 
O processo de envelhecimento da população é um fenômeno que vem sendo observado e amplamente divulgado através de estudos que evidenciam variações na sua composição por idade e em indicadores como os coeficientes de mortalidade geral, infantil, expectativa de vida, entre outros.

A preocupação mundial a princípio, era o aumento populacional, principalmente em regiões menos desenvolvidas, conseqüência da fase inicial da transição demográfica caracterizada pela queda da mortalidade, sem no entanto ter ainda iniciado a queda da natalidade. As discussões levavam a conclusões catastróficas como o eventual esgotamento de recursos materiais, além da discussão em relação a um limite suportável de população para que não houvesse perigo de guerras e outras calamidades.

Com as transformações econômicas e sociais iniciam-se importantes modificações no comportamento demográfico das populações, que vêm ocorrendo em ritmo diferenciado nas diversas regiões do mundo. Para os países desenvolvidos, a queda da natalidade e da mortalidade por doenças infecciosas e o conseqüente aumento da expectativa de vida vêm ocorrendo há muito, resultado da elevação do nível de vida da população, urbanização adequada das cidades, melhoria nutricional, dos níveis de higiene pessoal, das condições sanitárias, ambientais e de trabalho (PATARRA 1990).

Ao contrário do que ocorreu no mundo desenvolvido, onde essas mudanças têm sido registradas em várias décadas, esse impacto foi muito mais acentuado nos países em desenvolvimento, sendo um fenômeno de pouco mais de vinte ou trinta anos. As alterações da estrutura etária da população somente seriam observadas após muitos anos, se fossem depender apenas da queda da mortalidade. No entanto, a fecundidade registrou quedas significativas a partir dos anos 60, principalmente nos países da América Latina e Leste da Ásia (MARANGONE CAMARGO 1988). A partir de então, evidenciam-se os primeiros sinais de mudança nas estruturas etárias, diminuindo gradativamente o peso relativo das coortes mais jovens, dando lugar a um aumento na participação dos grupos de idades mais avançadas.

Assim, conforme assinalado por PATARRA (1990), a questão demográfica hoje, é uma estrutura etária em rápida transformação e que, em função do crescimento 
diferenciado de seus grupos etários resulta em demandas sociais específicas, principalmente as relativas à saúde.

\subsection{A transição epidemiológica e demográfica}

A queda nos índices de mortalidade, em especial da mortalidade infantil, associada à queda nos índices de fecundidade resultou em aumento na esperança de vida trazendo implicações e alterações no quadro de morbi-mortalidade da população, onde as doenças de caráter crônico-degenerativos, comuns às pessoas idosas, ganharam um peso cada vez maior frente àquelas de caráter agudo, mais comumente observadas na população infantil.

O conceito de transição epidemiológica segundo OMRAN (1971) diz respeito à uma evolução lenta e gradual dos problemas de saúde que de alta incidência e prevalência das doenças infecciosas passam a se caracterizar por um predomínio de doenças não-infecciosas, as cardiovasculares, neoplasias e outras doenças crônicas. Tais mudanças, ocorridas a longo prazo em uma população específica, são acompanhadas por transformações demográficas, sociais e econômicas. É um conceito dinâmico que, segundo FRENK e col. (1991) é resumido em duas direções básicas. A primeira seria a da predominância das doenças infecciosas, associadas com carências primárias de nutrição, abastecimento de água e habitação, para a predominância das doenças crônico-degenerativas, causas externas e transtornos mentais. A segunda direção seria o deslocamento da carga principal de mortes e doenças dos grupos de idade mais jovens para os de idade mais avançada, conseqüência do aumento da expectativa de vida e do grau de exposição a fatores de risco associados aos processos crônicos de morbidade. Os autores afirmam que tal conceito é imprescindível para que se compreendam as características presentes e futuras da dinâmica demográfica e da situação de saúde da população que implicam, entre outros fatores, em um deslocamento da mortalidade como primeiro plano substituído pela morbidade como força predominante.

Esse processo começa a ser observado em países desenvolvidos a partir da segunda metade do século XIX e foi acompanhado por um aumento progressivo da 
esperança de vida ao nascer que de 30 a 40 anos, no início do século $\mathrm{XX}$, passou para algo em torno de 80 anos em épocas recentes (BARRETO e col. 1993).

Segundo a Organização Panamericana da Saúde (OPS/OMS 1990), a população mundial cresce a uma taxa anual de $1,7 \%$ enquanto a população de 60 anos e mais de idade cresce $2,5 \%$ sendo que, mais de $80 \%$ desse incremento ocorre nos países em desenvolvimento onde a taxa de crescimento anual é 3 vezes maior do que nos países desenvolvidos. Para a América Latina, em 1955, a esperança de vida ao nascer era de 51,2 anos enquanto que, segundo projeções, será de 72,8 anos em 2025, ou seja, 21,6 anos a mais de vida.

Outra forma de observar o aumento da idade da população consiste em examinar o índice de envelhecimento que mede a proporção de pessoas de 60 anos e mais para cada 100 crianças menores de 15 anos de idade. No Brasil, conforme discutido por MELLO JORGE e GOTLIEB (2000), a relação idoso/criança revela um lento envelhecimento da população, visto que, de 1940 a 1996 passou de 5,6 para 17 idosos para cada 100 crianças de até 15 anos de idade. Esse indicador chegará a 58 em 2020 e a 74 em 2025 e em quase todos os países da região das Américas deverá haver uma duplicação nesse indice nas próximas duas décadas, fenômeno que representará uma mudança populacional sem precedentes (Anonymus 2000).

A literatura sistematicamente tem ressaltado as importantes mudanças nos niveis e padrões de comportamento reprodutivo da população brasileira. Entre 1940 e 1960, houve um ganho de 10 anos na esperança de vida do brasileiro, resultante exclusivamente do declínio da mortalidade, uma vez que o número médio de filhos por mulher se manteve em todo período igual a 6,2. Já no período entre 1940 e 1980 a esperança de vida ao nascer subiu de 41,5 para 60 anos e a mortalidade infantil declinou de 168, para 88 óbitos por mil nascidos vivos. A partir de então, a queda no ritmo de crescimento da população foi resultado do decréscimo da fecundidade pois, o censo demográfico de 1980 indicava expressiva redução desse indicador na década de 70 , da ordem de $24,5 \%$, em todas as regiões do Brasil e com ritmo mais elevado para o Centro Sul. O número médio de filhos por mulher caiu de 6,2 em 1960 para 5,6 em 1970 e 4,5 em 1980. Essa última queda de quase 20\%, segundo BERQUÓ e LEITE (1988) significou uma fenômeno sem precedentes que ocorreu tanto na zona urbana como rural e em todas regiões do país. Mais recentemente, para o ano de 1998, o 
número médio de filhos por mulher foi estimado em 2,2 e a esperança de vida ao nascer chegou a 67,2 anos (OPS 1998).

Com esse quadro, considerando que a fecundidade é o fator de maior influência sobre o crescimento vegetativo e envelhecimento da população e também, os niveis já relativamente baixos de mortalidade e reduzida expressão da migração internacional (OLIVEIRA e FELIX 1995), estão colocadas as condições determinantes para o aumento do número de idosos na sociedade.

Tal situação, favorável ao envelhecimento populacional, tem levado à necessidade de serem feitas constantes revisões das projeções demográficas como a das Nações Unidas que apontavam, para o Brasil, para o ano de 2025, um percentual de $10,9 \%$ de idosos de 60 anos e mais de idade e que passou para $14 \%$ em nova estimativa de 1984. De fato, como ressaltam BERQUÓ e LEITE (1988) enquanto a população brasileira crescia a uma taxa anual média de $2,9 \%$ ao ano, no período de 1960-1970, era de 4,3\% o crescimento anual de idosos. Já para o período seguinte, o crescimento anual caía para $2,5 \%$ e crescia para $5 \%$ a taxa correspondente à população com 65 anos e mais de idade.

Somado ao maior crescimento existe o aumento da longevidade na população idosa. Entre os óbitos da população brasileira com 65 anos e mais de idade, em 1980, apenas $11,4 \%$ dos homens e $18,5 \%$ das mulheres faleciam com 85 anos e mais de idade. Em 1995 esses percentuais foram de 16,1 e 24,8\% para homens e mulheres, respectivamente (VASCONCELOS 1998).

O Brasil, considerado "um país de jovens", chega ao século XXI com uma perspectiva de envelhecimento da população, devendo situá-lo entre as nações do mundo com o maior número de idosos (B́AETA e CRUZ 1988) com um significado muito maior do que apenas indicadores estatísticos, pois resulta em profundas transformações na sociedade para um futuro próximo.

\subsection{Envelhecimento e desigualdade}

A transição epidemiológica, como afirmam FRENK e col. (1991) não ocorreu de igual forma nos diferentes grupos sociais e regiões geográficas da América Latina. Ao contrário, exacerbaram-se as desigualdades principalmente as relativas à saúde que 
não estão presentes somente entre os países, mas também dentro deles, o que parece ser a explicação para a natureza prolongada da transição em algumas regiões. Segundo os autores, as populações pobres e rurais continuam em desvantagem pois, embora seja um ponto que merece maiores investigações, é essa a população que apresenta maior diversidade de doenças.

Desde a década de 60 vêm se processando no Brasil profundas mudanças sociais, econômicas e políticas. $\mathrm{O}$ aumento da produção industrial, a migração maciça de áreas rurais para os grandes centros urbanos, a queda na fertilidade, na mortalidade infantil, na mortalidade por doenças infecciosas e aumento da esperança de vida além da importante inserção da mulher na força de trabalho, contribuíram para grandes transformações na sociedade (LESSA 1994). Essas mudanças ocorreram de forma heterogênea no país o que resultou em marcantes diferenças no aspecto epidemiológico e de exposição da população aos fatores de risco para as doenças não transmissíveis e consequentemente, em perfil de morbimortalidade distinto. Essas disparidades são freqüentes e estão presentes até mesmo nos limites de um único espaço social, independentemente da região do país (LESSA 1994).

Para o Brasil, a redução dos níveis de indicadores como a mortalidade geral e mortalidade infantil, segundo OLIVEIRA e FELIX (1995), foi resultado mais direto da presença imperiosa do Estado como executor de medidas de ampliação de redes de assistência à saúde, da expansão dos sistemas de saneamento básico por um lado e do combate à doença, da erradicação das doenças infecciosas, medidas terapêuticas, da expansão da medicalização, vacinação, acompanhamento materno-infantil e reidratação, de outro. Entretanto, tais medidas não foram acompanhadas com igual magnitude de melhora nos aspectos de natureza socio-econômica, renda, de condições nutricionais e habitacionais e do exercício dos direitos sociais, fatores que concorrem para a persistência e tendência de aumento das desigualdades em nosso meio (OLIVEIRA e FELIX 1995).

Embora tenha havido queda na mortalidade geral e infantil os desniveis regionais na década de 80 ainda persistiram. Na Região Sudeste por exemplo, a expectativa de vida aumentou 27 anos entre 1940 e 1984, enquanto que na Região Nordeste subiu apenas 17 anos e a mortalidade infantil era mais do que o dobro da observada nas regiões Sul e Sudeste (OLIVEIRA e FELIX 1995). Em outro estudo, 
PATARRA (1995) afirma que a Região Nordeste foi e continua sendo a mais discriminada em avanços no controle da mortalidade e no diferencial de expectativa de vida. Ainda, em análise ampla, MONTEIRO e col. (1997) descrevem detalhadamente a evolução de indicadores das Regiões do Brasil entre 1986 e 1996 e concluem que houve melhora para todas as regiões mas, em menor intensidade para as Regiões Norte e Nordeste rural, existindo uma tendência de aumento das desigualdades mostrada por essa disparidade nos indicadores.

Como resultado dessas disparidades as modificações na estrutura etária brasileira não ocorrem de modo simultâneo em todos os segmentos sociais. Devido aos diferenciais nas taxas de fecundidade por estrato de renda, o crescimento vegetativo da população de menor renda tem sido cerca de duas vezes o da população de renda mais elevada, fazendo com que os grupos mais pobres apresentem, sistematicamente, maior percentual de crianças e jovens e o estrato de maior renda, maior percentual de idosos (DUCHIADE 1995). Além das disparidades regionais, assim como em outros países de industrialização recente, a transição demográfica no Brasil está se dando em tempo relativamente curto, sem o suporte do desenvolvimento econômico e social que venha responder às exigências do novo perfil demográfico e epidemiológico que se anuncia (RAMOS e col. 1987).

Ao ritmo diferenciado e às diferenças no processo de envelhecimento entre os países e dentro deles, soma-se a heterogeneidade dentro da própria população de idosos. O mito de que "todas as pessoas idosas são iguais" é contestado pela Organização Panamericana da Saúde (OPAS/OMS 1999) que discute, desde as diferenças de origem étnica e cultural, residência em regiões mais ou menos desenvolvidas, zonas urbana ou rural, até as diferenças de hábitos na infância ou idade adulta, nível sócio-econômico e de escolaridade. Esses fatores têm influência tanto na expectativa de vida da comunidade como na própria qualidade de vida e de saúde na velhice. Reconhecer e administrar a falta de eqüidade e a desigualdade existentes no processo de envelhecimento se apresentam, para a sociedade, como o principal desafio do século que se inicia. 


\subsection{Envelhecimento e saúde}

O novo perfil demográfico somado aos fatores ambientais negativos como a poluição ambiental, crises sociais e econômicas, hábitos como fumo, hiperalimentação e o estresse da vida moderna vêm determinando mudanças no comportamento da morbi-mortalidade na população. A incidência de doenças cardiovasculares, de certos tipos de câncer e distúrbios como o diabetes, principalmente na idade adulta vêm aumentando, mesmo em países subdesenvolvidos (VERAS e col. 1987). O incremento da prevalência de doenças crônico degenerativas com problemas de saúde de longa duração afeta a qualidade de vida, pois aumenta o tempo médio de incapacidade no indivíduo. Para muitos países, ditos subdesenvolvidos, o problema é mais grave pois como destacado, além de conviverem com a realidade da desigualdade social, com problemas de saneamento, infra-estrutura e doenças infecto-contagiosas deparam-se também com patologias de maior complexidade e que absorvem grandes quantidades de recursos materiais e humanos.

Em países da América Latina o atendimento e o reconhecimento das necessidades da população idosa têm sido, em geral, muito limitados em razão de fatores que, segundo a Organização Panamericana da Saúde (OPS/OMS 1990) têm origem histórica, ideológica e social que influenciam nos processos políticos de decisão. A existência de opiniões questionando as politicas de atenção à terceira idade como uma minoria não produtiva são alguns dos fatores que podem dificultar ou retardar o avanço das políticas públicas voltadas ao idoso. As ações de saúde têm se concentrado e com êxito, na demanda dos grupos mais jovens da população, proporcionalmente mais importantes, em especial a atenção materno-infantil e controle de doenças infecciosas. Já as pessoas de idade avançada, com problemas crônicos de saúde, que requerem atenção contínua, têm tradicionalmente sido atendidas por suas famílias ou por algumas instituições e têm tido acesso restrito a tratamentos e a serviços e profissionais especializados (OPS/OMS 1990).

Como orientação da Organização Panamericana da Saúde (OPS/OMS 1990), as intervenções relacionadas ao envelhecimento devem ter por objetivo assegurar ao idoso o prolongamento da vida o quanto possível com manutenção da capacidade funcional, fisica, mental e de qualidade aceitável. É necessário que, além da 
acessibilidade aos serviços, exista a flexibilidade para reconhecer situações que estão em constante mudança, procurando atender à população idosa de maneira integral, com provisão de serviços sociais, condições de trabalho, de moradia, seguridade, alimentação, transporte e recreação.

Nesse sentido, descrever e conhecer características da população idosa, como suas necessidades, padrão de consumo de medicamentos, acesso e utilização dos serviços de saúde e, principalmente, os perfis de mortalidade e morbidade é tarefa imprescindível, se o objetivo for atender às recomendações acima citadas. É preciso que, para cada região, sejam conhecidas as condições de saúde e doença da população para que as ações sejam melhor direcionadas. Uma das formas de se conhecer a saúde das comunidades é a análise ou o estudo dos perfis de mortalidade e morbidade.

Os estudos de mortalidade e morbidade segundo idade, sexo, lugar e tempo permitem comparações evidenciando aspectos detalhados do comportamento desses indicadores que propiciam tanto a geração de hipóteses causais, como servem de base técnica para subsidiar o desencadeamento de ações de controle. Devido às desigualdades regionais, esses estudos podem contribuir para que as decisões, quer seja em relação à políticas sociais, habitação, atendimento à saúde ou outras, estejam subsidiadas em dados que traduzam a real situação da comunidade. A descrição dessa realidade em nível local faz-se necessária, principalmente porque com o conhecimento atual, pode-se melhor compreender características presentes e futuras da saúde na sociedade.

Acresce que a mortalidade, além de atuar como causa no processo de envelhecimento populacional é também diretamente influenciada pelo seu efeito. Por isso o perfil da mortalidade em adultos e idosos vai determinar a estrutura etária, a distribuição da população idosa, particularmente a participação relativa dos idosos jovens e dos idosos velhos e, consequentemente, definir as principais características do processo de envelhecimento (PALLONI 1997).

Cabe aqui comentar a dificuldade de se encontrar um critério que permita distinguir um indivíduo idoso de um não idoso. A definição de pessoa idosa é mais complexa do que a simples demarcação de uma idade limite. $\mathrm{O}$ que seria um indivíduo idoso ou um indivíduo velho? Os valores que referendam esse juízo dependem de características específicas de cada sociedade em particular (CAMARANO e col. 
1999). Existem as características biológicas, os traços psicológicos e também o contexto sociocultural e histórico que são fatores igualmente importantes para uma possível definição de idoso. Mesmo com o grande avanço científico acerca do envelhecimento, não contamos ainda com uma concepção consensual e definitiva desse processo natural que toma parte no curso da vida das pessoas (ANDRADE 2001). Entretanto tal discussão, embora de extrema relevância para a abordagem do envelhecimento populacional não será aprofundada neste estudo.

Por outro lado, do ponto de vista científico e para os formuladores de políticas públicas é necessário a distinção dos indivíduos para que se possa classificá-los como pertencentes ou não a uma categoria. $O$ caráter biológico da velhice, ou a senilidade pode demarcar um padrão de declínio de determinadas características físicas ou o momento em que o indivíduo pode ser considerado idoso, ou ainda, aquele indivíduo que tem idade típica da velhice. Nesse caso é demandado que se estabeleça uma idade limite que separe as pessoas idosas das não idosas (CAMARANO e col. 1999), que no caso deste estudo foi de 60 anos e mais de idade.

\subsection{Estudos de mortalidade}

Nos países industrializados a preocupação com a atenção e bem estar do idoso não é recente e características dessa fração da população têm sido amplamente estudadas e divulgadas. Análises sobre causas de morte têm demonstrado que, em 1986, nos Estados Unidos, as principais causas entre os idosos acima de 65 anos eram as doenças do coração, câncer e doença cerebrovascular, com percentuais de $41,6 \%$, 20,7\% e 8,7\%, respectivamente (ROSENBERG e col. 1991).

A doença isquêmica do coração é a principal causa de morte nos paises industrializados, responsável por $30 \%$ de todas as mortes em cada ano. Entretanto, existe uma tendência de declínio na mortalidade por esta causa nos Estados Unidos que, segundo BEAGLEHOLE (1990) não é devida a modismos em diagnósticos ou procedimentos na codificação das causas de óbito, mas a uma tendência real de queda.

Outro estudo, ainda nos Estados Unidos, revelou que, de 1940 a 1970 houve um crescimento da mortalidade por câncer e doenças do aparelho circulatório em 
idosos de 70 a 89 anos mas, após 1970, a tendência da última causa foi de queda (SMITH 1998).

Para o Brasil, estudos de mortalidade vêm evidenciando a crescente importância das doenças crônicas como as cardiovasculares e os neoplasmas malignos. Resultados de estudo realizado para anos próximos a 1980 mostram que os neoplasmas no Brasil representavam, para o sexo masculino, taxa de mortalidade (por 100.000 habitantes) de 87,8 e para o sexo feminino de 70,6, que foram consideradas baixas se comparadas às taxas da Bélgica (213,3 para o sexo masculino) e Dinamarca (136,5 para o sexo feminino) (ESCOLA NACIONAL DE SAÚdE PÚBLICA/FUNDAÇÃO OSWALDO CRUZ 1991).

Em análise do perfil de mortalidade no período de 1979 a 1988, ROUQUAYROL e col. (1993) relatam queda das doenças infecciosas e parasitárias e o aumento proporcional das doenças cardiovasculares, câncer e causas externas. $O$ coeficiente de mortalidade (por 100.000 habitantes) por doenças infecciosas, baixou de 63,2 para 34,7 no período. Por outro lado, as doenças do aparelho circulatório, neoplasmas e causas externas tiveram seus coeficientes aumentados de 154,4 para 168,$6 ; 50,0$ para 57,4 e 56,4 para 69,6 respectivamente, para os dois anos citados. Para o triênio 1993/1995 as principais causas de óbito em idosos foram as doenças do aparelho circulatório, neoplasias e doenças do aparelho respiratório (MELLO JORGE e GOTLIEB 2000).

Estudo do perfil de mortalidade por doenças cardiovasculares na Região Metropolitana do Recife, em 1991, mostrou que as doenças do aparelho circulatório foram a primeira causa de óbito $(25,6 \%)$ com destaque para as cerebrovasculares e doença isquêmica do coração. Para o conjunto da população as doenças cardiovasculares vitimaram mais as mulheres e em idades mais avançadas. Para os homens em idades mais jovens as doenças isquêmicas do coração, particularmente o infarto agudo do miocárdio foram as que mais ocorreram (CARVALHO e BRANCO 1996). 


\subsection{Estudos de morbidade}

Outro aspecto de grande relevância é o estudo da morbidade como indicador da situação de saúde, particularmente para a população idosa que, em geral, é acometida simultaneamente por várias patologias e requer atenção especial.

Os padrões de morbidade para a população em geral apresentam importantes diferenças em relação ao que tem sido observado para as taxas de mortalidade. Segundo BARRETO e CARMO (1994) persistem altas taxas de prevalência para algumas doenças infecciosas, com reintrodução e recrudescimento de algumas delas como a dengue e cólera, esta última recentemente introduzida na Região Sul. Por outro lado, as doenças imunopreveniveis vêm apresentando tendência constante de queda. Para as doenças crônico-degenerativas, os resultados de inquéritos isolados realizados para algumas patologias em algumas regiões ou municipios são as informações disponíveis, pois não existem sistemas para o registro desses agravos no Brasil, de forma sistemática. As doenças passíveis de notificação compulsória e as comunicações de acidentes de trabalho são algumas das informações colhidas de forma direta em todo o país, além dos dados relativos ao universo das ocorrências ambulatoriais e internações hospitalares (Sistema de Informações da Demanda Ambulatorial, SIA-SUS e Sistema de Informações Hospitalares, SIH-SUS).

Nesse contexto, destacam-se as informações hospitalares, em especial as internações. As estatísticas de morbidade hospitalar são informações fundamentais que, quando analisadas, agregadas às informações de outros serviços que compõem o sistema de assistência à saúde, refletem as condições de vida e saúde da população, além de permitirem a avaliação da assistência que se proporciona, a estrutura dos serviços de saúde e a política médico assistencial (LAURENTI e BUCHALLA 1985).

Em análise da morbidade hospitalar no Estado de São Paulo, para o ano de 1980, em todas as fontes de financiamento, FERREIRA e FARIA (1986) destacam que as causas de internação mais freqüentes em pessoas de 60 a 69 e 70 anos e mais foram as doenças do aparelho circulatório, respiratório e neoplasias. Em hospitais de Ribeirão Preto, no ano de 1988, GERMANO NETO (1991) constatou que $75 \%$ das hospitalizações em pessoas com 60 anos e mais foram devidas às doenças dos aparelhos circulatório, respiratório, digestivo, neoplasias malignas e lesões e 
envenenamentos. Os homens idosos tiveram maior risco de hospitalização do que as mulheres idosas (coeficientes de 264,1 e 241,1 por 1000 habitantes, respectivamente). Dois terços dessas hospitalizações foram financiados pelo setor público e foram também internações mais longas do que as financiadas por seguros saúde e particulares. Em outro estudo, CASELLI (1998) analisou a situação do idoso no meio hospitalar do Município de São Carlos, constatando que 18,4\% das internações no ano de 1996 ocorreram para pessoas acima de 60 anos de idade, mais freqüentemente por doenças cardiovasculares e do aparelho respiratório.

Estudo das internações em hospitais da Região do Vale do Paraíba no Estado de São Paulo, realizado por LEBRÃO (1994), descreve mudanças no perfil de morbidade no período de 1975 e 1988. A autora destaca modificações importantes nos diagnósticos principais de internação que no início do período se caracterizavam por alta proporção de internações por doenças infecciosas e parasitárias e doenças do aparelho respiratório e no final houve remanejamento para outras causas, com crescimento importante das doenças do aparelho circulatório. Outra conclusão importante do estudo refere-se à elevação da idade média dos pacientes atribuída ao envelhecimento da população.

\subsection{As estatísticas de saúde. Importância e qualidade dos dados}

\subsubsection{Mortalidade}

$\mathrm{O}$ interesse em conhecer o número de óbitos fez com que, no final do século XVI surgissem as famosas tabelas mortuárias de Londres, quando da epidemia de peste que assolava a Europa. Posteriormente, essas tabelas permitiram conhecer a distribuição dos óbitos segundo características importantes como sexo e idade. Graunt, considerado pai das estatísticas de mortalidade e Farr no século XIX mostraram, através de seus estudos, a importância dos óbitos infantis, da sobremortalidade masculina e a relação entre saneamento, situação econômica, diferenciais regionais e mortalidade (MELLO JORGE e GOTLIEB 1998). A partir de então, os estudos de mortalidade passam a ser uma importante ferramenta e preferencialmente utilizada para conhecer e descrever as características de saúde das populações. 
As estatísticas de mortalidade representam uma das mais valiosas fontes de informação em saúde, além de constituírem o mais tradicional e um dos mais eficientes métodos para avaliação do estado de saúde das populações (LAURENTI 1991). Esses dados são, muitas vezes, para muitas regiões do país, a única fonte disponível seja para análise epidemiológica e planejamento ou na vigilância da freqüência de doenças cuja mortalidade é significativa, como as neoplasias, afecções cardiovasculares e acidentes.

As informações sobre mortalidade estão disponíveis através do Sistema de Informações em Mortalidade (SIM), do Ministério da Saúde, que as obtém diretamente da Declaração de Óbito (DO), com busca ativa dos dados realizada pelos municípios. Quanto às causas, são codificadas de acordo com as regras internacionalmente estabelecidas pela Organização Mundial da Saúde. Vale enfatizar que a implantação do SIM, em 1975, representou um grande avanço na produção de informações sobre a mortalidade no país. Com a utilização de um formulário padronizado e individualizado para o registro dos dados, a DO (Anexo 1), houve a possibilidade de se obter, para todo território nacional, estatísticas de melhor qualidade e com a vantagem da possibilidade de comparação entre as regiões e entre os países (BALDIJÃO 1992).

Hoje é possível obter dados de mortalidade para os municípios brasileiros armazenados em CD-ROM distribuído pelo Centro Nacional de Epidemiologia, CENEPI, da Fundação Nacional de Saúde/MS. Essa nova forma de apresentação e também sua disseminação via internet nas páginas do Ministério da Saúde têm possibilitado a pesquisadores e instituições interessadas o conhecimento, análise e divulgação das informações. Além da indiscutível contribuição à comunidade e aos serviços de saúde, a utilização mais democrática dos dados sobre mortalidade é uma maneira de fortalecer o SIM.

Entretanto, sempre que as estatísticas de mortalidade são utilizadas, questionamentos são feitos a respeito da confiabilidade apresentada por elas. Apesar das disposições legais relativas à obrigatoriedade do registro dos óbitos, sabe-se que ainda existem falhas, tanto na cobertura ou na quantidade, como no preenchimento adequado da DO ou da qualidade. Assim, conhecer a qualidade dos dados é componente inicial para qualquer análise, sendo necessário que se tenha uma idéia básica do que esperar dos dados (BECKER 1991). 
Em 1985, os dados do SIM representavam $80 \%$ dos óbitos estimados para o Brasil que era de aproximadamente um milhão de óbitos/ano. Os óbitos que não eram registrados em cartório ou a não cobertura de todos os municípios pelo SIM resultaram em 20\% de sub-registro (MELLO JORGE 1990). Existe, entretanto, uma heterogeneidade desse comportamento evidenciado por um considerável sub-registro para as regiões Norte e Nordeste.

Em avaliação dos dados de mortalidade no período de 1979 a 1989, PAULA e col. (1994) concluem que, para o Brasil, os percentuais de população coberta com informação regular nunca foram inferiores a $83 \%$ o que é conseguido graças às altas coberturas alcançadas pelas regiões Sul e Sudeste. Da mesma forma, o percentual de municípios que apresentam coleta regular das DO é mais estável para os estados situados nessas regiões, como o Estado do Paraná que apresentava em 1979, 97\% e em 1989, 99\% de municípios com informação regular para mortalidade.

A avaliação da qualidade da informação na DO é feita ainda, através da proporção de óbitos em causas mal definidas, ou seja, aquelas inscritas no capítulo XVI da CID-9 (OMS 1985), (Sinais, sintomas e afeç̧ões mal definidas) e XVIII da CID-10 (OMS 1998), (Sintomas, sinais e achados anormais de exames clínicos e de laboratório não classificados em outra parte).

O Brasil, em 1979, teve $20 \%$ de óbitos nesse capítulo baixando para $18,2 \% \mathrm{em}$ 1990, sendo que, para alguns Estados como São Paulo, Rio de Janeiro, Rio Grande do Sul as proporções eram inferiores a 10\% em 1990 enquanto que, todos os estados do Nordeste apresentavam proporções superiores a 30\% (VASCONCELOS 1996). De acordo com publicação do MS/OPAS/OMS (MINISTÉRIO DA SAÚDE 1997), em 1997 era de $15,1 \%$ a participação relativa das causas mal definidas no Brasil.

A proporção de óbitos por causas mal definidas para pessoas idosas foi analisada por MELLO JORGE e GOTLIEB (2000) que encontraram variações desde $67 \%$ no Estado da Paraíba no triênio 1979-1981, até 1,7\% no Distrito Federal em 1993-1995. Para a Região Sul esse percentual foi de $11,1 \%$ no sexo masculino e de $11,7 \%$ no feminino, no triênio 1993-1995.

Em análise realizada para o Estado do Paraná, RIBAS e DAVANSO (1996) concluem que, o percentual de óbitos por causas mal definidas declinou de $17,7 \%$ no triênio 1979-1981 para 12,6\% em 1990-1992 e dado recente mostra que, para 1997 
esse percentual foi de 9,8\% (MINISTÉRIO DA SAÚDE 1997). Os autores ressaltam que a variação desses dados é bastante expressiva nos diferentes municípios sendo os situados no norte do Estado os que têm informações consideradas muito boas.

\subsubsection{Morbidade hospitalar}

É de amplo conhecimento que existem restrições às estatisticas produzidas pelos registros hospitalares. São seletivas por se tratarem de dados relativos às doenças graves e parciais pois apenas parte desse contingente é conhecido. Existe, ainda, a impossibilidade de se calcularem coeficientes, pois não se conhece a população de risco e portanto essas informações não serão representativas da morbidade da coletividade (LEBRÃO 1997). Ainda, a unidade de análise nos arquivos de dados no SIH-SUS refere-se às internações e não aos indivíduos, podendo existir desta forma, uma superestimação da prevalência de certas doenças que requerem internações sucessivas. Mesmo com essas restrições, as estatísticas hospitalares são o único registro sistemático de informações de morbidade, com a vantagem de conterem diagnósticos mais precisos resultantes de modernas técnicas e testes de laboratório disponíveis e refletirem o segmento mais custoso do sistema de saúde.

Em âmbito nacional, os hospitais e profissionais contratados pelo SUS cobram da Previdência Social os serviços prestados ao paciente através do formulário Autorização de Internação Hospitalar (AIH), caracterizando-se como um sistema de remuneração fixa por procedimentos aceitos como "realizáveis pela rede de assistência hospitalar" (LEVCOVITZ e PEREIRA 1993). A informatização desse formulário constitui um banco de dados processado pelo SIH-SUS que o coloca à disposição do usuário seja via Internet ou em CD-ROM. Como o setor público é o maior financiador das hospitalizações, responsável pela assistência médico hospitalar a aproximadamente $80 \%$ da população brasileira, sua análise significa conhecer a grande maioria das internações no Brasil (LEVCOVITZ e PEREIRA 1993).

Da mesma forma que as informações de mortalidade, observações devem ser feitas no que concerne à qualidade das informações contidas nas AIH. Parece ser o diagnóstico de internação a variável de menor confiabilidade o que é atribuído, entre outros fatores, à finalidade contábil do formulário que pode levar os hospitais a 
selecionarem diagnósticos que permitem melhor remuneração. Entretanto, análise de confiabilidade de diagnósticos das AIH desenvolvida por VERAS e MARTINS (1994) no Rio de Janeiro mostrou que, em geral, os resultados naquele município foram melhores do que se esperava para o banco de dados SIH-SUS observando que, de preferência, os diagnósticos sejam analisados de forma mais agregada. Análise semelhante foi realizada para as internações ocorridas em 1992 no Município de Maringá-PR, concluindo igualmente, que melhor confiabilidade foi encontrada para os diagnósticos mais freqüentes e quando estes foram analisados segundo agrupamentos e capítulos da Classificação Internacional de Doenças (MATHIAS e SOBOLL 1998).

\subsection{O Município de Maringá}

Maringá é um município de porte médio, situado no noroeste do Estado do Paraná com 288.465 habitantes (FIBGE 2001). Foi fundada em 1947 como Distrito do Município de Mandaguari e, em 1951, a cidade adquiria sua autonomia sendo elevada à categoria de município.

Surgida no período de ouro do ciclo do café apresenta, hoje, diversificada produção agrícola composta de soja, algodão, milho, cana-de-açúcar, trigo e grande produtor do bicho-da-seda. É uma região que polariza uma vasta área de influência por seu estratégico posicionamento físico e territorial, tornando-se ponto de convergência de importantes rodovias federais e estaduais. Destacam-se também, os setores industriais de alimentação, confecção, agro-indústria e metal-mecânico. Em função da rede migratória, a cidade forma um meio cultural múltiplo com uma colônia japonesa exercendo importante influência' na comunidade, além das colônias árabe, portuguesa, alemã e italiana (PREFEITURA MUNICIPAL DE MARINGÁ 1997). Centro populacional importante, é polo de atração comercial, educacional e médico assistencial, apresentando características singulares como centro de uma rica região do Estado do Paraná.

Por pertencer a uma região do Estado do Paraná colonizada mais recentemente Maringá apresentou até 1991 uma população de idosos inferior à do Brasil e igualou à do Estado do Paraná em 1980 (Tabela 1). Segundo os resultados da contagem populacional de 1996 (FIBGE 1998) 7,9\% de residentes em Maringá tinha 60 anos e 
mais de idade. Considerando que Maringá foi fundada em 1947, pode-se concluir que houve um rápido envelhecimento da população, provavelmente, ultrapassando o Brasil nos próximos anos.

Maringá é sede da 15 Regional de Saúde e dispõe de 23 Núcleos Integrados de Saúde com especialidades básicas e duas unidades de pronto atendimento. Conta com uma rede de 5 hospitais gerais privados, um filantrópico e um hospital público universitário, totalizando 231 leitos disponíveis ao SUS. Por ser um município polo de atração, os recursos de saúde nele concentrados atendem também expressiva demanda regional.

$\mathrm{O}$ atendimento ao adulto e ao idoso nas unidades básicas de saúde é feito por consultas médicas oferecidas por clínicos gerais além de procedimentos como vacinação, curativos e disponibilidade de medicamentos para as doenças mais freqüentes, como hipertensão e diabetes. Algumas unidades desenvolvem atendimentos sistematizados ao diabético e ao hipertenso com atividades paralelas envolvendo a equipe de profissionais disponível.

Tabela 1 - População (\%) de 60 anos e mais, segundo o ano, Brasil, Paraná e Maringá.

\begin{tabular}{ccccccc}
\hline \multicolumn{7}{c}{ ANO } \\
\hline Local & 1950 & 1960 & 1970 & 1980 & 1991 & 1996 \\
\hline Brasil & 4,3 & 4,7 & 5,0 & 6,1 & 7,4 & 7,9 \\
Paraná & 3,4 & 3,4 & 3,7 & 5,3 & 6,8 & 7,6 \\
Maringá & $\ldots$ & 3,5 & 3,8 & 5,3 & 6,9 & 7,9 \\
\hline
\end{tabular}

(...) Dado não disponível.

Fonte: IBGE 1953, FIBGE 1960, FIBGE 1970.

Em face ao apresentado justifica-se este trabalho que descreve os aspectos da saúde da população idosa residente em Maringá através de sua morbi-mortalidade, pretendendo também contribuir para elaboração de programas de saúde, já que para isso é importante o conhecimento das necessidades das comunidades em regiões menores ou mais homogêneas.

Quanto às críticas aos bancos de dados oficiais disponíveis é importante o reconhecimento de que estes representam o resultado de um esforço conjunto que tem 
a participação desde de médicos e legistas que preenchem a DO, dos profissionais que igualmente preenchem as $\mathrm{AIH}$, das pessoas ou órgãos que inserem esses dados no sistema, das autoridades institucionais de saúde até das universidades e pesquisadores que trabalharam para aprimorar e colocar à disposição essas informações. As limitações que porventura ainda existam, no que diz respeito à utilização e qualidade dos dados e aprimoramento da informação, não invalidam o esforço na análise dos seus resultados. Cabe também aos usuários interpretá-las, conhecer suas limitações e contribuir para melhorá-las, quantitativa e qualitativamente (MELLO JORGE 1990). 


\section{OBJETIVO}


Analisar o perfil de saúde dos idosos residentes no Município de Maringá-PR, por meio da:

$1^{\circ}$ - Análise do comportamento da mortalidade no período de 1979 a 1998 segundo sexo, idade e causa básica de óbito.

$2^{\circ}$ - Análise da morbidade hospitalar entre 1995 e 1998, segundo sexo, idade, diagnóstico de internação, média de permanência e tipo de saída. 
3. MATERIAL E MÉTODO 


\subsection{População de estudo}

O critério para definição de população idosa adotado foi o da idade cronológica, embora seja indiscutível que esse não representa critério suficiente para classificar o indivíduo em "idoso" já que é uma categoria populacional socialmente constituída (OPS/OMS 1990; CAMARANO e col. 1999). Não obstante às restrições no critério de idade e ainda que vários estudos venham adotando o limite inicial de 65 anos, optou-se por estudar a coorte etária de 60 anos e mais, conforme acordado na Assembléia Mundial sobre Envelhecimento realizada em Viena em 1982, que estabeleceu 60 anos como idade limite ou inicial da etapa do envelhecimento (OPS/OMS 1990).

\subsection{Fontes de dados}

\subsection{1 Óbitos}

Os dados de óbitos de residentes em Maringá com 60 anos e mais de idade foram obtidos do SIM que congrega informações provenientes da DO (Anexo 1) em forma de CD-ROM (MINISTÉRIO DA SAÚDE 1998). O banco de dados relativo aos óbitos complementares do ano de 1997 e o relativo ao ano de 1998 foi cedido diretamente pelo CENEPI pois à época da análise não havia sido publicado o banco oficial definitivo em CD-ROM (Anexo 2).

\subsubsection{Internações hospitalares}

Os dados de internações hospitalares para idosos residentes em Maringá foram obtidos do SIH-SUS apresentados em CD-ROM para o período de 1995 a 1998 (MINISTÉRIO DA SAÚDE 1998). As internações de 1998 apresentadas em 1999, por não estarem disponíveis no momento da análise, foram obtidas diretamente do CENEPI/MS. Dados de internação de anos anteriores embora existam, não foram utilizados por não haver a informação sobre o município de residência, campo que passou a ser preenchido a partir de 1995. 


\subsubsection{População}

As informações sobre população foram obtidas dos Anuários Estatísticos da Fundação Instituto Brasileiro de Geografia e Estatística (IBGE) referentes aos Recenseamentos Gerais de 1980 (FIBGE 1982), 1991 (FIBGE 1993) e contagem populacional de 1996 (FIBGE 1998). Para os anos intercensitários foram utilizadas estimativas elaboradas pelo Núcleo de Estudos de População da UNICAMP (NEPO 1999) (Anexo 3).

\subsection{Variáveis de estudo}

\subsubsection{Mortalidade}

- Sexo, idade e causa básica de óbito, definida como: "a doença ou a lesão que iniciou a sucessão de eventos mórbidos que levou diretamente à morte ou as circunstâncias do acidente ou violência que produziram a lesão fatal" (OMS 1985).

\subsubsection{Morbidade hospitalar}

- Sexo, idade, diagnóstico principal (diagnóstico principal que motivou a internação), tempo de permanência (duração da internação em dias) e tipo de saída (alta ou óbito).

\subsection{Procedimentos de análise}

\subsubsection{Mortalidade}

Os óbitos foram identificados nos bancos de dados a partir do código do município de residência e da idade registrados na DO extraídos do CD-ROM (MINISTÉRIO DA SAÚdE 1998).

A análise da mortalidade foi feita agrupando-se os óbitos e população em quatro triênios: 1979/1981, 1984/1986, 1990/1992 e 1996/1998, buscando com isso atenuar as possíveis flutuações aleatórias nos óbitos e variações na estimatịa da população. 
A idade foi desagregada em intervalos de cinco anos (60 a 64, 65 a 69, 70 a 74,75 a 79, 80 a 84 e 85 anos e mais de idade) e, para algumas causas cujo número de óbitos era pequeno a idade foi agrupada em intervalos maiores (60 a 69, 70 a 79 e 80 anos e mais de idade).

As causas analisadas foram as causas básicas de óbito segundo sexo e idade e foram estudadas de acordo com os Capítulos da CID e alguns agrupamentos ou diagnósticos mais freqüentes. No período de 1979 a 1995 as causas de óbito foram codificadas segundo as regras de classificação da $9^{a}$ Revisão da CID (OMS 1985) e a partir de 1996 segundo a 10 $10^{\mathrm{a}}$ Revisão (OMS 1993). O banco de dados do SIM, como já comentado, tem como referência as DO que são preenchidas pelos médicos e codificadas pela equipe do setor de epidemiologia da Secretaria Municipal de Saúde.

É importante salientar que, com início da utilização de uma nova revisão, podem ocorrer eventuais mudanças na tendência da mortalidade por determinadas causas devido ao surgimento de novas doenças ou por haver transferência de uma determinada doença ou agrupamento de um capítulo para outro ou ainda, por uma doença com apenas uma categoria passar a ser representada por um agrupamento (várias categorias) (GRASSI e LAURENTI 1998; SANTO 2000). Portanto foi necessário estabelecer correspondência dos códigos dos diagnósticos por capítulo, agrupamentos ou categorias com as adaptações devidas.

\subsubsection{Morbidade hospitalar}

Fizeram parte do estudo todas as internações de idosos residentes em Maringá ocorridas em 1995, 1996, 1997 e 1998, constantes no banco SIH-SUS (MINISTÉRIO DA SAÚDE 1995, 1996, 1997 e 1998), sendo selecionadas as AIH do tipo "1" (normal). As internações referentes aos transtornos mentais e comportamentais não foram incluídas no estudo por apresentarem características de atendimento e de internação específicas.

Foi estudado o diagnóstico principal, ou seja, aquele que gerou a internação e que é previamente codificado na própria instituição ou hospital de origem segundo as normas da CID. Assim como para os óbitos, para a análise da morbidade hospitalar foi 
estabelecida correspondência dos diagnósticos principais de internação das duas classificações, $9^{\mathrm{a}}$ e $10^{\mathrm{a}}$.

\subsection{Medidas utilizadas}

A morbi-mortalidade foi analisada através das medidas de proporção e taxas avaliadas no tempo, de modo a fornecer um perfil adequado para ações que possam vir a ser tomadas no setor de atenção à saúde. Com relação às causas, os dados foram apresentados por capítulos, agrupamentos ou diagnósticos mais freqüentes. 
4. RESULTADOS E DISCUSSÃO 


\subsection{Evolução da população do Município de Maringá}

Em breve análise das pirâmides populacionais de Maringá (Gráfico 1) puderam ser observadas modificações importantes na estrutura etária, fenômeno que acompanha as mudanças que vêm ocorrendo no restante do país.

Gráfico 1 - Pirâmides populacionais do Município de Maringá-PR, 1979 e 1998.
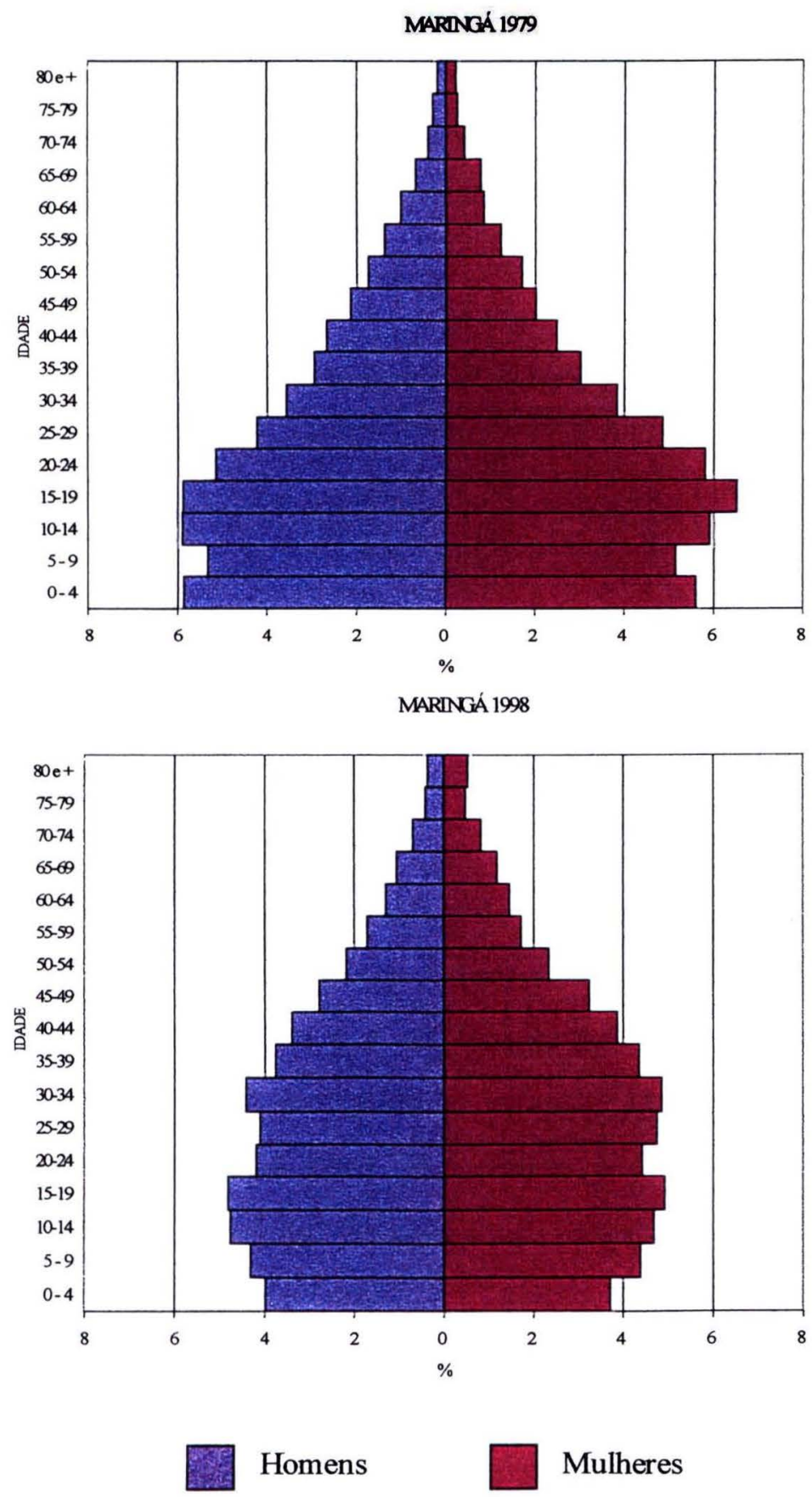

Fonte: NEPO/Unicamp 1999. 
A primeira pirâmide já mostra alguns traços dos resultados da queda da mortalidade infantil, mas ainda reflete características de uma população jovem. A pirâmide de 1998 com contornos bem menos afunilados evidencia, além dos resultados da queda da mortalidade infantil, também da mortalidade geral e nítida queda da natalidade resultando na menor participação de menores de 5 anos, contornos mais homogêneos nos grupos etários de até 34 anos e também, aumento relativo de pessoas com 60 anos e mais de idade.

O envelhecimento populacional pode ser melhor observado com a distribuição percentual da população por faixas de idade (Tabela 2 ). Houve queda de $23,4 \%$ no grupo de até 14 anos de idade, acréscimo de 7,7\% da população adulta e importante crescimento da população idosa que passou de $5,1 \%$ para $8,4 \%$, diferença relativa de $62,7 \%$ entre 1979 e 1998.

Tabela 2 - População (\%) residente em Maringá-PR, segundo idade e diferença percentual, 1979 e 1998.

\begin{tabular}{crcc}
\hline Idade & 1979 & 1998 & $\begin{array}{c}\text { Diferenca (\%) } \\
1979 / 1998\end{array}$ \\
\hline $0-14$ & 33,7 & 25,8 & $-23,4$ \\
$15-59$ & 61,2 & 65,9 & 7,7 \\
60 e mais & 5,1 & 8,3 & 62,7 \\
\hline Total & 100 & 100 & - \\
\hline
\end{tabular}

Fonte: NEPO/Unicamp 1999.

SOUZA e col. (1996) em análise de indicadores demográficos de Maringá, no período de 1980 a 1991, constataram redução expressiva da natalidade que passou de 28,6 para 21,9 nascidos vivos por mil habitantes, redução da ordem de $23,4 \%$ no período de onze anos. A mortalidade infantil, igualmente, apresentou tendência declinante passando de 37,8 para 14,4 óbitos por mil nascidos vivos. Os autores comentam que, sem estabelecer relação de determinação, é provável que a expansão dos serviços de saúde que, de 4 unidades básicas, em 1982, passou para 24, em 1989, explique, em parte, a tendência observada.

Em análise do grupo de pessoas acima de 60 anos de idade observou-se que, proporcionalmente, o número de mulheres idosas cresceu mais do que o de homens idosos $(74 \%$ contra $56,9 \%)$ e que, em relação ao total de idosos, a participação relativa da faixa etária de 60 a 69 anos decresceu $(6,7 \%$ para homens, 7,8\% para 
mulheres) aumentando daí a participação dos idosos mais velhos, principalmente os de 80 anos e mais de idade que tiveram sua participação relativa acrescida de $33,3 \%$ para homens e de $34,1 \%$ para mulheres (Tabela 3 ).

Tabela 3 - População idosa (\%) residente em Maringá-PR, segundo ano, idade e sexo, 1979 e 1998.

\begin{tabular}{cccc}
\hline Idade & 1979 & 1998 & $\begin{array}{c}\text { Diferenca (\%) } \\
1979 / 1998\end{array}$ \\
\hline \multicolumn{4}{c}{ Homens } \\
\hline $60-69$ & 65,7 & 61,3 & $-6,7$ \\
$70-79$ & 27,1 & 29,1 & 7,4 \\
80 e mais & 7,2 & 9,6 & 33,3 \\
Total & 5,1 & 8,0 & 56,9 \\
\hline \multicolumn{5}{c}{ Mulheres } \\
\hline $60-69$ & 64,0 & 59,0 \\
70-79 & 27,2 & 29,2 & $-7,8$ \\
Total & 8,8 & 11,8 & 3,4 \\
\multicolumn{4}{c}{8,7} \\
\hline 60 e mais & 5,0 & 74,0 \\
\hline
\end{tabular}

Fonte: NEPO/Unicamp 1999.

Ainda que de forma resumida, estas são as principais alterações que vêm acontecendo na estrutura etária da população salientando que, provavelmente, nos próximos 20 ou 30 anos, caso as atuais tendências permaneçam, a estrutura etária da população de Maringá poderá ter atingido certo equilíbrio apresentando características de populações de países desenvolvidos. Se por um lado tal realidade deve ser almejada e festejada, por outro, novos desafios são acrescentados especificamente os voltados às necessidades das pessoas idosas. Para isso, necessariamente, devem ser conhecidas as características de saúde dessa parcela da população o que neste trabalho foi feito, indiretamente, através da análise de indicadores de morbimortalidade, como está descrito a seguir. 


\subsection{Mortalidade em idosos no período de 1979 a 1998}

\subsubsection{Considerações sobre a qualidade do banco de dados de mortalidade em Maringá}

Com referência à quantidade de óbitos RIBAS e DAVANSO (1996) analisaram os dados divulgados pelo Ministério da Saúde e IBGE, para o Estado do Paraná sendo constatado que as diferenças entre os dois sistemas mantiveram-se pequenas no período de 1979 a 1990. Com exceção dos anos de 1980 e 1990 o total de óbitos disponibilizados pelo IBGE foi pouco maior que o do MS, com uma relação MS/IBGE mínima de 98,17 para o ano de 1979.

Em relação à qualidade, análise prévia dos dados registrados nas DO para todos os óbitos de residentes em Maringá, no período de 1979 a 1995, foi constatado que, de maneira geral, houve significativa melhora das informações de mortalidade (MATHIAS e MELLLO JORGE 2001). Para as variáveis demográficas a informação foi considerada boa visto que, em nenhum ano do período, o não preenchimento ultrapassou $0,7 \%$ para a variável idade e $0,3 \%$ para a variável sexo. Tal qualidade pode ser atribuída à coleta das DO nos hospitais do município que é feita semanalmente por profissionais da Secretaria de Saúde orientados a não deixar nenhum campo do documento em branco. A codificação das informações é feita por profissional treinado que, em caso de dúvida, solicita ao médico declarante esclarecimentos sobre o óbito. A análise da variável causa básica do óbito mostrou que o percentual de óbitos por sintomas, sinais e afeç̧ões mal definidas foi, em 1979, 7,5\% caindo para 3,5\% em 1995 sendo que, os óbitos sem assistência médica representaram $60 \%$ caindo para $12,4 \%$ nos dois anos, respectivamente, o que mostra melhora importante na qualidade dos dados para o conjunto dos óbitos no município.

Sabe-se que, com o avançar da idade, aumenta a proporção de óbitos por causas mal definidas (CUNHA e AIDAR 2000) o que é explicado, dentre outros motivos, pela dificuldade de identificação da causa básica que iniciou o processo mórbido, visto o complexo encadeamento de causas em pessoas idosas (VASCONCELOS 1996; LESSA 1998d).

Quando a distribuição dos óbitos segundo o diagnóstico ou causa básica é analisada, os resultados devem ser observados com alguma cautela. Os diagnósticos codificados nos atestados de óbito não são necessariamente precisos e essa precisão 
ou qualidade pode variar ao longo do tempo, sendo resultado de deficiências no seu preenchimento, por limitação do conhecimento médico, erros de diagnóstico ou ainda, erros na codificação das causas (CHOR e col. 1995). Em relação a essas considerações, cada causa tem, em maior ou menor proporção, possibilidade de variações ao ser diagnosticada em função da região, das equipes médicas, recursos diagnósticos presentes, acesso da população aos serviços de saúde, entre outros.

Em todo o período estudado o valor relativo das causas mal definidas girou em torno de 6,6\% no triênio 1996-1998 e 10\% no triênio 1990-1992. Nos quatro triênios, na maioria das vezes, os percentuais ficaram abaixo de $10 \%$, com manutenção para o sexo feminino e queda de $9,7 \%$ para o masculino (Tabela 4 ).

A queda na mortalidade proporcional por causas mal definidas foi de $5,7 \%$ que, a princípio, pode parecer pequena para um período de vinte anos, mas deve ser considerado que o percentual de 7,0\%, no primeiro triênio, já não era alto e que também, houve tendência de aumento no meio do período (Tabela 4). As variações resultaram em tendência de queda da concentração de óbitos por causas mal definidas em idades mais jovens e conseqüente aumento nas idades avançadas. Esse fato foi mais evidente no sexo feminino para o qual, aproximadamente $41 \%$ dos óbitos ocorreu na faixa de 85 anos e mais de idade (Gráfico 2).

Em relação ao local de ocorrência merece destaque a distribuição dos óbitos segundo o sexo. Para os óbitos por sintomas, sinais e afecções mal definidas, no sexo feminino, os locais mais freqüentes foram o domicílio e o hospital e para o sexo masculino apareceu, além desses, a via pública e outros locais (Tabela 5). No triênio 1996-1998, por exemplo, 20 óbitos (11,8\% do total dos óbitos por causas mal definidas) foram declarados como ocorridos em via pública, dos quais 16 (80\%) no sexo masculino. Poder-se-ia esperar um percentual de causas desconhecidas ainda menor se os óbitos ocorridos no hospital (21 no último triênio) tivessem sido melhor investigados e codificados, considerando maior facilidade de exames diagnósticos em ambiente hospitalar.

Houve concentração de óbitos por morte sem assistência médica e outras causas mal definidas e as não especificadas de mortalidade, morte súbita de causa desconhecida e senilidade, chamando atenção o incremento de óbitos devido à morte sem assistência médica e senilidade com $360,2 \%$ e $79,4 \%$, respectivamente (Tabela $6)$. 
Tabela 4 - Óbitos em idosos por sintomas, sinais e afecções mal definidas, segundo sexo e idade, por triênios, Maringá-PR, 1979-1998. ( $\mathrm{n}^{\circ}$ e \%*).

\begin{tabular}{|c|c|c|c|c|c|c|c|c|c|}
\hline Triênios & \multicolumn{2}{|c|}{$1979-1981$} & \multicolumn{2}{|c|}{ 1984-1986 } & \multicolumn{2}{|c|}{ 1990-1992 } & \multicolumn{2}{|c|}{ 1996-1998 } & $\begin{array}{c}\text { Diferença (\%) } \\
\text { 1979/81- } \\
\text { 1996/98 }\end{array}$ \\
\hline \multicolumn{10}{|c|}{ Masculino } \\
\hline Idade & $\mathrm{n}^{\mathrm{o}}$ & $\%$ & $\mathrm{n}^{\mathrm{o}}$ & $\%$ & $\mathrm{n}^{\mathrm{o}}$ & $\%$ & $\mathrm{n}^{\mathrm{o}}$ & $\%$ & $\%$ \\
\hline $60-69$ & 14 & 5,4 & 28 & 8,9 & 53 & 12,2 & 29 & 5,9 & 9,3 \\
\hline $70-79$ & 25 & 8,6 & 26 & 8,4 & 34 & 8,4 & 26 & 5,0 & $-41,9$ \\
\hline 80 e mais & 10 & 7,4 & 21 & 10,3 & 29 & 10,1 & 37 & 9,1 & 23,0 \\
\hline Total & 49 & 7,2 & 75 & 9,1 & 116 & 10,3 & 92 & 6,5 & $-9,7$ \\
\hline \multicolumn{10}{|c|}{ Feminino } \\
\hline $60-69$ & 11 & 7,2 & 6 & 2,9 & 18 & 7,7 & 12 & 4,3 & $-40,3$ \\
\hline $70-79$ & 12 & 5,7 & 12 & 5,5 & 25 & 7,6 & 21 & 5,1 & $-10,5$ \\
\hline 80 e mais & 12 & 8,2 & 25 & 13,2 & 41 & 12,9 & 45 & 9,9 & 20,7 \\
\hline Total & 35 & 6,8 & 43 & 7,0 & 84 & 9,5 & 78 & 6,8 & - \\
\hline \multicolumn{10}{|c|}{ Total } \\
\hline $60-69$ & 25 & 6,1 & 34 & 6,6 & 71 & 10,7 & 41 & 5,3 & $-13,1$ \\
\hline $70-79$ & 37 & 7,4 & 38 & 7,2 & 59 & 8,0 & 47 & 5,0 & $-32,4$ \\
\hline 80 e mais & 22 & 7,8 & 46 & 11,7 & 70 & 11,6 & 82 & 9,5 & 21,8 \\
\hline Total & 84 & 7,0 & 118 & 8,2 & 200 & 10,0 & 170 & 6,6 & $-5,7$ \\
\hline
\end{tabular}

*Percentual calculado em relação ao total de óbitos em cada faixa de idade e sexo.

Gráfico 2 - Distribuição percentual de óbitos em idosos por sintomas sinais e afecções mal definidas, segundo sexo e idade, por triênios, Maringá-PR, 1979-1998.

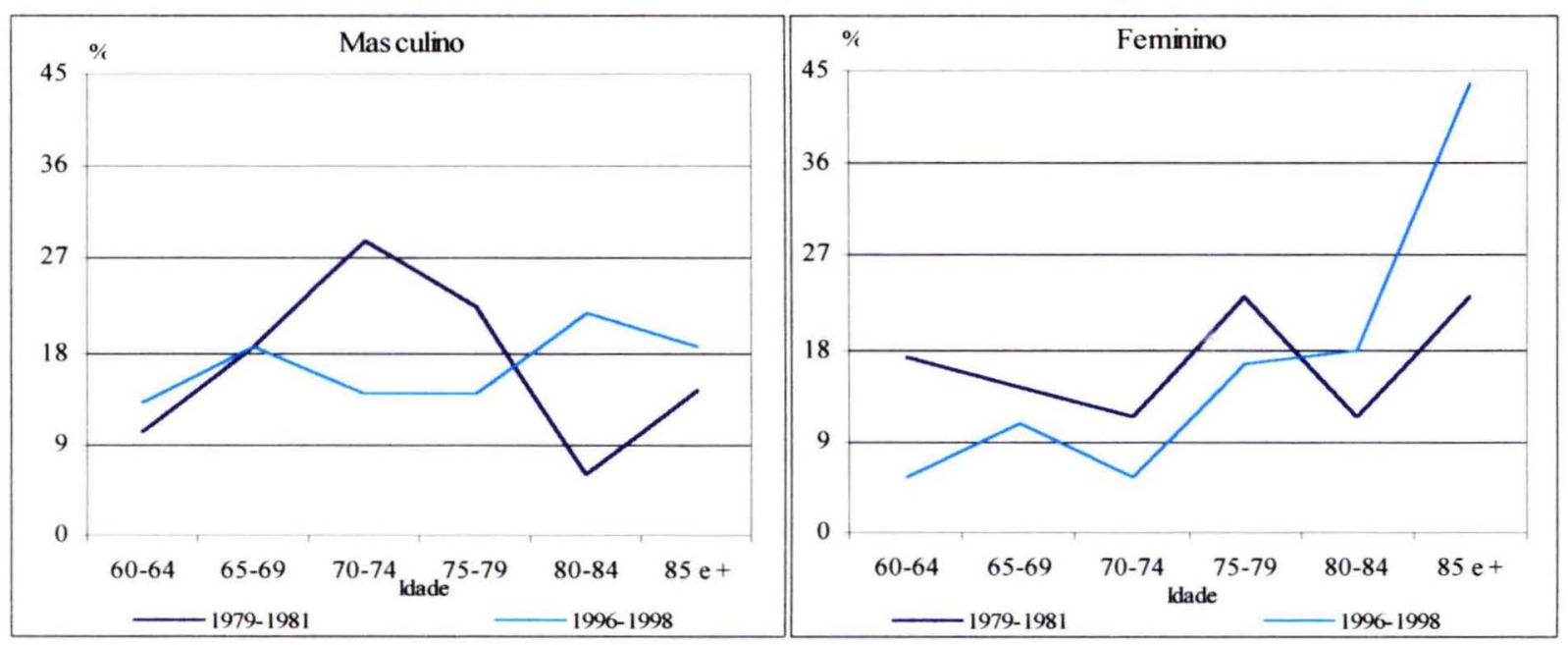


Tabela 5 - Óbitos em idosos por sintomas, sinais e afecções mal definidas, segundo sexo e local de ocorrência, por triênios, Maringá-PR, 1979-1998. (nº \%).

\begin{tabular}{|c|c|c|c|c|c|c|c|c|}
\hline & \multicolumn{2}{|c|}{ 1979-1981 } & \multicolumn{2}{|c|}{$1984-1986$} & \multicolumn{2}{|c|}{ 1990-1992 } & \multicolumn{2}{|c|}{ 1996-1998 } \\
\hline \multicolumn{9}{|c|}{ Masculino } \\
\hline Local & $n^{\circ}$ & $\%$ & $\mathrm{n}^{\circ}$ & $\%$ & $\mathrm{n}^{\circ}$ & $\%$ & $n^{\circ}$ & $\%$ \\
\hline Hospital & 6 & 12,2 & 9 & 12,0 & 24 & 20,7 & 9 & 9,8 \\
\hline Via pública & - & & 1 & 1,3 & 5 & 4,3 & 16 & 17,4 \\
\hline Domicílio & 34 & 69,4 & 50 & 66,7 & 77 & 66,4 & 58 & 63,0 \\
\hline Outro & 6 & 12,2 & 15 & 20,0 & 10 & 8,6 & 8 & 8,7 \\
\hline Ignorado & 3 & 6,2 & - & - & - & - & 1 & 1,1 \\
\hline Total & 49 & 100 & 75 & 100 & 116 & 100 & 92 & 100 \\
\hline \multicolumn{9}{|c|}{ Feminino } \\
\hline Hospital & 5 & 14,3 & 9 & 20,9 & 11 & 13,1 & 12 & 15,4 \\
\hline Via pública & - & & - & - & - & - & 4 & 5,1 \\
\hline Domicílio & 30 & 85,7 & 30 & 69,8 & 69 & 82,1 & 59 & 75,6 \\
\hline Outro & - & - & 4 & 9,3 & 4 & 4,8 & 3 & 3,9 \\
\hline Ignorado & - & - & - & - & - & - & - & - \\
\hline Total & 35 & 100 & 43 & 100 & 84 & 100 & 78 & 100 \\
\hline \multicolumn{9}{|c|}{ Total } \\
\hline Hospital & 11 & 13,1 & 18 & 15,3 & 35 & 17,5 & 21 & 12,3 \\
\hline Via pública & - & - & 1 & 0,8 & 5 & 2,5 & 20 & 11,8 \\
\hline Domicílio & 64 & 76,2 & 80 & 67,8 & 146 & 73,0 & 117 & 68,8 \\
\hline Outro & 6 & 7,1 & 19 & 16,1 & 14 & 7,0 & 11 & 6,5 \\
\hline Ignorado & 3 & 3,6 & - & - & - & - & 1 & 0,6 \\
\hline Total & 84 & 100 & 118 & 100 & 200 & 100 & 170 & 100 \\
\hline
\end{tabular}

Para o período de 1979 a 1995 MELLO JORGE e GOTLIEB (2000) encontraram para o Brasil e Regiões aumento no percentual de óbitos sem assistência médica em relação ao total de óbitos por causas mal definidas. Segundo as autoras, à medida que programas com objetivo de aumentar a captação de óbitos são implementados, a qualidade da informação tende a baixar gerando, provavelmente, DO com causas mal definidas aumentando, a princípio, a quantidade para posteriormente haver aprimoramento na qualidade.

ROSENBERG e col. (1991) comentam que existem algumas razões para que a qualidade da informação de óbitos seja inferior em idades mais avançadas. Uma possibilidade reside no fato de que, em pessoas mais jovens as condições de saúde e a história médica tenham maior possibilidade de serem agudas e estejam melhor 
associadas com o óbito gerando diagnósticos ou causas de óbito declarados de forma mais completa. Para os óbitos em idosos mais velhos, principalmente com quadros crônicos de longa duração o atestado de óbito teria maior chance de ser preenchido com menor precisão pelo menor conhecimento, pelo médico, da história do falecido e também devido à possibilidade de menor quantidade de informações como exames laboratoriais complementares.

Tabela 6 - Óbitos em idosos por sintomas, sinais e afeç̧ões mal definidas, segundo diagnósticos, por triênios, Maringá-PR, 1979-1998. ( $\mathrm{n}^{\mathrm{O}}$ e \%).

\begin{tabular}{|c|c|c|c|c|c|c|c|c|c|}
\hline Diagnósticos & \multicolumn{2}{|c|}{$1979-1981$} & \multicolumn{2}{|c|}{$\begin{array}{r}1984-1986 \\
n^{\circ}\end{array}$} & \multicolumn{2}{|c|}{ 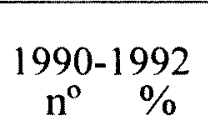 } & \multicolumn{2}{|c|}{$\begin{array}{c}1996-1998 \\
n^{\circ} \% \\
\end{array}$} & $\begin{array}{l}\text { Diferença } \\
1979 / 1981- \\
1996 / 1998 \\
\end{array}$ \\
\hline Outras causas mal definidas & 45 & 53,5 & 51 & 43,2 & 42 & 21,0 & 55 & 32,4 & $-39,4$ \\
\hline Morte sem assistência & 7 & 8,3 & 52 & 44,1 & 94 & 47,0 & 65 & 38,2 & 360,2 \\
\hline \multicolumn{10}{|l|}{ Morte súbita de causa } \\
\hline Desconhecida & 21 & 25,0 & - & - & 9 & 4,5 & 10 & 5,9 & $-76,4$ \\
\hline Senilidade & 11 & 13,1 & 15 & 12,7 & 55 & 27,5 & 40 & 23,5 & 79,4 \\
\hline Total & 84 & 100 & 118 & 100 & 200 & 100 & 170 & 100 & \\
\hline
\end{tabular}

Em relação aos óbitos por senilidade, outros estudos revelam seu aumento na população idosa. ROTHENBERG e KOPLAN (1990) reportaram que os óbitos por demência senil aumentaram nos Estados Unidos desde 1975 da mesma forma que o aumento na mortalidade por doença de Alzheimer. Os autores explicam que, em relação à doença de Alzheimer, o aumento parece real e não devido à mudanças na prática de codificação dos diagnósticos pois, entre outras razões, vem ocorrendo concomitante ao acréscimo dos óbitos por senilidade naquele país.

SMITH (1998) comenta, também para os Estados Unidos, que os diagnósticos que poderiam ser atribuídos, de alguma forma à senilidade ou estados de demência, se tornaram cada vez mais comuns como causa de óbitos em idosos. Em 1950, aproximadamente $0,3 \%$ dos óbitos entre 70 e 74 anos e $2,8 \%$ entre 85 e 89 anos de idade eram atribuídos ao estado de demência. Em 1990 esse percentual já havia aumentado para $1,6 \%$ e $3,1 \%$, para as faixas de idade, respectivamente.

É ainda discutido que, em idades avançadas nenhuma causa de morte possa parecer óbvia, sobretudo quando várias patologias de longa duração estão prı́sentes 
somando-se, ainda, ao fenômeno do progressivo declínio das funções fisiológicas no idoso (KOHN 1982). Neste caso a verdadeira causa de morte em grande parte da população idosa, seria o próprio envelhecimento. Por outro lado a "velhice" não é uma causa de morte freqüente ou aceitável já que as informações clínicas e testes diagnósticos laboratoriais não são avaliados para conduzir a um diagnóstico de "velhice" ou "senilidade". KOHN (1982) conclui que a siíndrome da velhice poderia ser considerada como uma doença fatal, ou seja, quando a morte em indivíduos muito debilitados da população idosa não pudesse ser devida a nenhum processo mórbido que causasse o óbito em pessoas adultas, esta causa de morte deveria ser atestada como "senilidade". De fato, segundo SMITH (1998) "idade avançada" já foi um diagnóstico aceito no atestado de óbito em 1900 quando 2,5\% dos óbitos eram atribuídos a ela e $8 \%$ ocorridos em pessoas entre 80 a 89 anos. Porém, o que é recomendado, é que os médicos descrevam causas específicas de morte e reservem o uso dos códigos das mal definidas para óbitos onde não existe informação disponível sobre sua causa (ARMSTRONG e col. 1995).

Ainda, no que diz respeito às possíveis razões da utilização das causas mal definidas, segundo ARMSTRONG e col. (1995), existe uma relação entre estes e os óbitos por doença isquêmica do coração. Os autores relatam que a doença isquêmica do coração ocorre, com freqüência, de forma súbita e também em indivíduos sem acompanhamento médico prévio, o que resulta em escassa informação disponível para a causa de morte e codificação no atestado de óbito, além do fato de que, algumas causas como arritmia cardíaca não serem detectáveis em autópsias. Embora essas observações sejam referentes a estudo em população americana adulta, é possível que parte dos óbitos em idosos residentes em Maringá classificados como sintomas, sinais e afeç̧ões mal definidas tenham ocorrido por doença isquêmica do coração considerando, além da dificuldade ou da não existência da prática da autópsia em nosso meio, no caso de óbito por causas naturais, também a possibilidade da falta de acesso do idoso aos serviços de saúde.

Essa breve análise, além de subsidiar a discussão sobre a qualidade das informações utilizadas neste estudo, acrescenta outras questões importantes ao tema da saúde do idoso como o aumento dos óbitos em via pública que, no caso das mulheres, poderia ser chamado de surgimento já que não havia sido registrado nenhum caso nos três primeiros triênios e, em 1996-1998, ocorreram 4 cásos. O 
aumento dos óbitos sem assistência médica e por senilidade pode ser apenas reflexo do envelhecimento populacional ou revelar dificuldade de acesso da população idosa aos ambulatórios e hospitais do município ou ainda, falta de empenho dos profissionais em buscar informações que completem com clareza todos os dados exigidos na DO. Porém, a busca de respostas para essas questões, embora de suma importância, extrapola os objetivos deste estudo. Mesmo que percentuais acima de $10 \%$ de óbitos por causas mal definidas tenham sido observados constatou-se que ocorreram em alguns triênios e nas idades mais avançadas, o que é de certa forma esperado. Acredita-se portanto na qualidade do banco de dados, considerando tanto percentuais reduzidos de óbitos por causas mal definidas como também o fato da análise ter sido feita para o universo dos eventos e para um período longo de tempo.

\subsubsection{Mortalidade em idosos segundo sexo e idade}

À medida que aumenta a população de 60 anos e mais os óbitos também são deslocados para idades cada vez mais avançadas e, no Município de Maringá, a mortalidade proporcional em idosos mostrou uma elevação crescente nas duas últimas décadas, passando de $43,2 \%$ para $60,8 \%$ e mais acentuadamente no sexo feminino. No último triênio mais da metade dos óbitos $(56,3 \%)$ no sexo masculino e dois terços $(67,4 \%)$ no sexo feminino ocorreram em pessoas de 60 anos e mais de idade (Tabela 7).

A mortalidade proporcional teve maior acréscimo na faixa de 80 anos e mais com aumentos relativos importantes de $100,1 \%$ para o sexo masculino e de $95,6 \%$ para o feminino seguidos de longe pela faixa de 60 a 69 anos para o sexo masculino $(28,3 \%)$ e 70 a 79 anos para o feminino (24\%) (Tabela 7$)$.

Essas variações resultaram em modificações na estrutura da mortalidade proporcional, principalmente para o sexo feminino. Assim, observou-se para o último triênio, que a proporção de óbitos aumentou para todas as idades e principalmente a partir de 80 anos que passou a ser a faixa de idade com maior mortalidade proporcional. Para o sexo masculino embora a diferença entre as percentagens nas faixas de idade tenha diminuído, a mortalidade proporcional manteve a mesma estrutura que apresentava no início do período, qual seja, com maior número de óbitos, ainda para as faixas de idade até 79 anos (Gráfico 3). 
Tábela 7 - Mortalidade proporcional em idosos, segundo sexo e idade, por triênios, Maringá-PR, 1979-1998.

\begin{tabular}{|c|c|c|c|c|c|}
\hline \multicolumn{6}{|c|}{ Triênios } \\
\hline Idade & 1979-1981 & 1984-1986 & 1990-1992 & 1996-1998 & $\begin{array}{c}\text { Diferença (\%) } \\
\text { 1979/81-1996/98 }\end{array}$ \\
\hline \multicolumn{6}{|c|}{ Masculino } \\
\hline $60-69$ & 15,2 & 15,7 & 19,4 & 19,5 & 28,3 \\
\hline $70-79$ & 17,2 & 15,6 & 18,2 & 20,7 & 20,3 \\
\hline 80 e mais & 8,0 & 10,2 & 12,8 & 16,1 & 100,3 \\
\hline Total & 40,5 & 41,5 & 50,4 & 56,3 & 39,0 \\
\hline \multicolumn{6}{|c|}{ Feminino } \\
\hline $60-69$ & 14,2 & 17,2 & 16,2 & 16,5 & 16,2 \\
\hline $70-79$ & 19,6 & 18,2 & 23,0 & 24,3 & 24,0 \\
\hline 80 e mais & 13,6 & 15,9 & 22,2 & 26,6 & 95,6 \\
\hline Total & 47,4 & 51,4 & 61,4 & 67,4 & 42,2 \\
\hline \multicolumn{6}{|c|}{ Total } \\
\hline Total & 43,2 & 45,2 & 54,7 & 60,8 & 40,7 \\
\hline
\end{tabular}

* Percentual calculado em relação ao total de óbitos na população em cada sexo.

A Tabela 8 mostra que, para os dois sexos, houve declínio da proporção de óbitos até 79 anos e aumento a partir de 80 anos de idade, chegando a uma variação positiva de $55,3 \%$ e de $74,8 \%$ no sexo masculino e feminino a partir de 85 anos de

Gráfico 3 - Mortalidade proporcional em idosos, segundo sexo e idade, por triênios, Maringá-PR, 1979-1998.

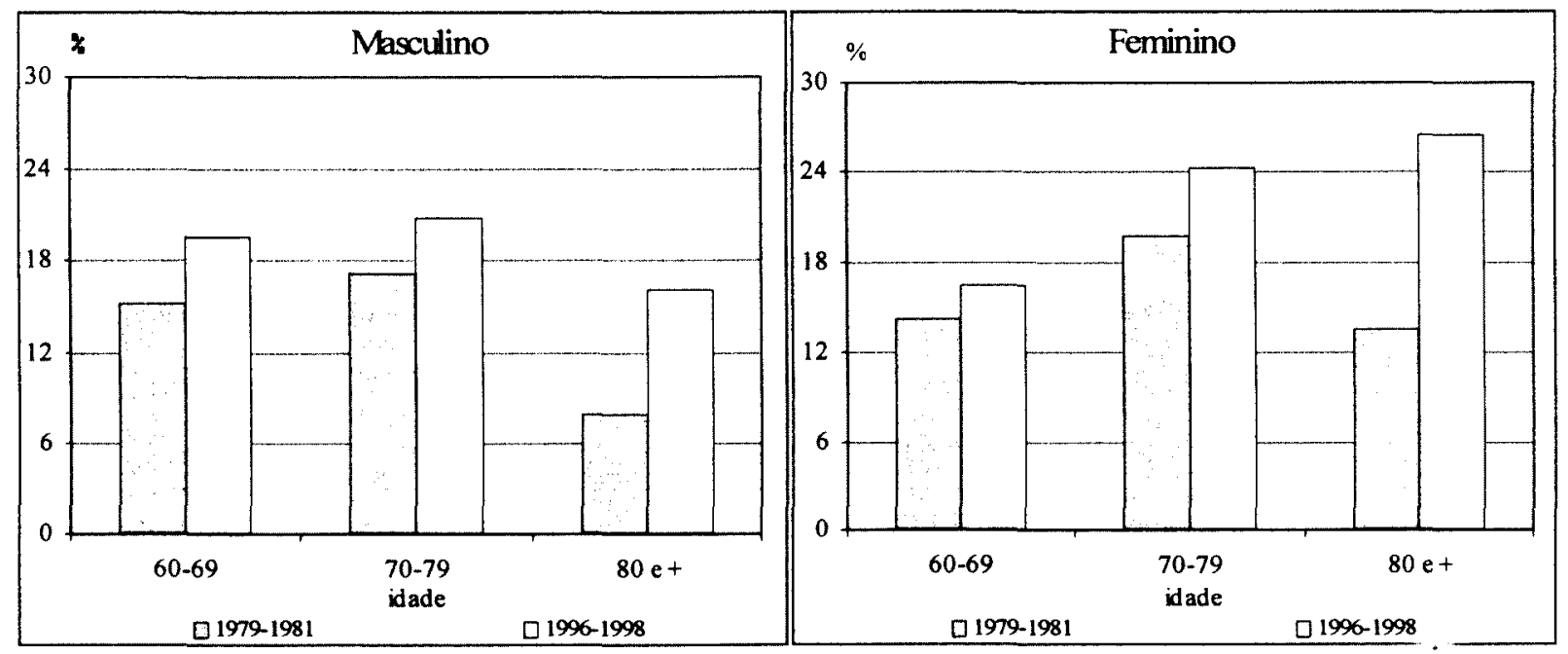


idade. A diferença relativa evidencia maior queda nos percentuais para o sexo feminino que variaram de $12,3 \%$ entre 70 e 74 anos e $20,6 \%$ entre 65 e 69 anos. Para o sexo masculino o declínio na mortalidade proporcional foi menor entre 65 e 69 anos $(8,3 \%)$ e maior entre 75 e 79 anos $(15 \%)$.

Por outro lado, o acréscimo de $35,1 \%$ e de $55,3 \%$ de óbitos entre 80 e 84 e 85 anos e mais, no sexo masculino, não foi suficiente para a aproximação das estruturas de mortalidade pois, já no início do período a mortalidade proporcional apresentava situação mais favorável para o sexo feminino, com maior concentração de óbitos nas idades mais avançadas (Gráfico 3). Embora com tendência de declínio nas idades mais jovens e aumento nas idades de 80 anos e mais, os óbitos no sexo masculino, no último triênio, ainda se concentraram nas faixas de idade mais jovens.

Essas variações podem ser melhor observadas no Gráfico 4 que mostra as curvas relativas à mortalidade proporcional de idosos do sexo masculino de até 79 anos que em todo o período estudado, foram sempre superiores à de idades acima de 80 anos.

No sexo feminino a tendência de queda da mortalidade proporcional entre 60 e 69 foi mais evidente "empurrando" os óbitos para as idades mais elevadas. Em todo o período o número de óbitos foi sempre menor na faixa de 60 a 64 anos com aumento constante dos percentuais após 80 anos de idade, chegando no final do período, o peso relativo dos óbitos na faixa de 85 anos e mais a superar todas as outras faixas e representar mais do que o dobro dos óbitos de 60 a 64 anos de idade.

Situação contrária ocorreu com o coeficiente de mortalidade, que declinou $15,2 \%$, observando-se queda para ambos os sexos mas mais importante para o feminino. A taxa de mortalidade para os homens idosos reduziu 12,1\% passando de 52,3 para 46 óbitos por mil habitantes e entre as mulheres a redução foi de $17 \%$, passando de 38,5 para 32 óbitos por mil habitantes, do primeiro para o último triênio, respectivamente (Tabela 8). Os coeficientes de mortalidade para a população masculina idosa foram sempre mais elevados que para a feminina, em todos os grupos etários, em todos os triênios (Tabela 8, Gráfico 5).

Interessante observar que de 1979 a 1998 os coeficientes de mortalidade permaneceram praticamente os mesmos para os homens de 60 a 64, com queda de apenas $7 \%$ enquanto que, para as mulheres a queda foi de $27,9 \%$ e ainda, o risco de morrer em idosos com mais de 85 anos teve maior aumento no sexo feminino 
$(10,9 \%)$ do que no masculino $(2 \%)$. Os ganhos mais importantes no declínio dos riscos de morrer para os homens ocorreram no intervalo de 65 a 79 anos e para as mulheres de até 84 anos (Tabela 8).

Tabela 8 - Distribuição dos óbitos e coeficientes de mortalidade em idosos (por 1000 hab.), segundo sexo e idade, por triênios, Maringá-PR, 1979-1998. (nº e \%).

\begin{tabular}{|c|c|c|c|c|c|c|c|c|c|c|c|c|c|c|}
\hline \multirow{3}{*}{\begin{tabular}{l|} 
Triennios \\
Idade
\end{tabular}} & \multicolumn{3}{|c|}{$1979-1981$} & \multicolumn{3}{|c|}{ 1984-1986 } & \multicolumn{3}{|c|}{ 1990-1992 } & \multicolumn{3}{|c|}{ 1996-1998 } & \multicolumn{2}{|c|}{$\begin{array}{l}\text { Diferença (\%) } \\
\text { 1979/81-1996/98 }\end{array}$} \\
\hline & \multicolumn{14}{|c|}{ Masculino } \\
\hline & $n^{o}$ & $\%$ & coef & $\mathrm{n}^{\circ}$ & $\%$ & coef & $\mathrm{n}^{\mathrm{o}}$ & $\%$ & coef & $\mathrm{n}^{\mathrm{o}}$ & $\%$ & coef & $\%$ & coef \\
\hline $60-64$ & 125 & 18,2 & 24,3 & 137 & 16,5 & 21,0 & 193 & 17,1 & 22,3 & 238 & 16,8 & 22,6 & $-11,0$ & $-7,0$ \\
\hline $65-69$ & 133 & 19,4 & 38,7 & 176 & 21,3 & 39,5 & 240 & 21,3 & 39,4 & 253 & 17,8 & 29,8 & $-8,3$ & $-23,0$ \\
\hline $70-74$ & 154 & 22,5 & 73,8 & 169 & 20,4 & 59,2 & 206 & 18,3 & 49,9 & 282 & 19,8 & 50,3 & $-11,6$ & $-31,8$ \\
\hline $75-79$ & 137 & 20,0 & 93,3 & 142 & 17,1 & 75,7 & 200 & 17,8 & 79,5 & 242 & 17,0 & 72,0 & $-15,0$ & $-22,8$ \\
\hline $80-84$ & 78 & 11,4 & 126,6 & 119 & 14,4 & 143,0 & 149 & 13,2 & 124,2 & 218 & 15,4 & 118,9 & 35,1 & $-6,1$ \\
\hline $85 \mathrm{e}+$ & 58 & 8,5 & 174,2 & 85 & 10,3 & 185,2 & 138 & 12,3 & 205,4 & 187 & 13,2 & 177,6 & 55,3 & 2,0 \\
\hline Total & 685 & 57,2 & 52,3 & 828 & 57,4 & 48,7 & 1126 & 56,1 & 48,4 & 1420 & 55,2 & 46,0 & - & $-12,1$ \\
\hline \multicolumn{15}{|c|}{ Feminino } \\
\hline $60-64$ & 61 & 11,9 & 13,6 & 93 & 15,1 & 14,9 & 99 & 11,2 & 10,8 & 116 & 10,1 & 9,8 & $-15,1$ & $-27,9$ \\
\hline $65-69$ & 92 & 18,0 & 23,1 & 113 & 18,4 & 22,3 & 134 & 15,2 & 19,8 & 165 & 14,3 & 17,3 & $-20,6$ & $-25,1$ \\
\hline $70-74$ & 104 & 20,3 & 47,3 & 96 & 15,6 & 31,5 & 163 & 18,5 & 36,1 & 205 & 17,8 & 31,2 & $-12,3$ & $-34,0$ \\
\hline $75-79$ & 108 & 21,1 & 75,0 & 122 & 19,9 & 59,1 & 167 & 19,0 & 53,2 & 210 & 18,3 & 53,1 & $-13,7$ & $-29,2$ \\
\hline $80-84$ & 82 & 16,0 & 115,0 & 89 & 14,5 & 85,6 & 137 & 15,6 & 83,8 & 199 & 17,3 & 80,1 & 8,1 & $-30,3$ \\
\hline $85 e+$ & 65 & 12,7 & 138,0 & 101 & 16,5 & 154,2 & 181 & 20,5 & 183,6 & 256 & 22,2 & 153,1 & 74,8 & 10,9 \\
\hline Total & 512 & 42,8 & 38,5 & 614 & 42,6 & 33,9 & 881 & 43,9 & 33,7 & 1151 & 44,8 & 32,0 & - & $-16,9$ \\
\hline \multicolumn{15}{|c|}{ Total } \\
\hline $60-64$ & 186 & 15,5 & 19,3 & 230 & 16,0 & 18,0 & 292 & 14,5 & 16,4 & 354 & 13,8 & 15,9 & $-11,0$ & $-17,6$ \\
\hline $65-69$ & 225 & 18,8 & 30,3 & 289 & 20,0 & 30,4 & 374 & 18,6 & 29,1 & 418 & 16,3 & 23,2 & $-13,3$ & $-23,4$ \\
\hline $70-74$ & 258 & 21,6 & 60,2 & 265 & 18,4 & 49,9 & 369 & 18,4 & 42,7 & 487 & 18,9 & 40,0 & $-12,5$ & $-33,6$ \\
\hline $75-79$ & 245 & 20,5 & 84,2 & 264 & 18,3 & 79,5 & 367 & 18,3 & 64,9 & 452 & 17,6 & 61,8 & $-14,1$ & $-26,6$ \\
\hline $80-84$ & 160 & 13,4 & 120,4 & 208 & 14,4 & 124,2 & 286 & 14,3 & 100,9 & 417 & 16,2 & 96,6 & 20,9 & $-19,8$ \\
\hline $85 \mathrm{e}+$ & 123 & 10,3 & 153,0 & 186 & 12,9 & 205,4 & 319 & 15,9 & 192,4 & 443 & 17,2 & 162,6 & 67,0 & 6,3 \\
\hline Total & 1197 & 100 & 45,4 & 1442 & 100 & 41,1 & 2007 & 100 & 40,6 & 2571 & 100 & 38,5 & & $-15,2$ \\
\hline
\end{tabular}

*Percentual calculado em relação ao total de óbitos em idosos. 
Gráfico 4 - Distribuição percentual dos óbitos em idosos segundo sexo e idade, por triênios, Maringá-PR, 1979 -1998.
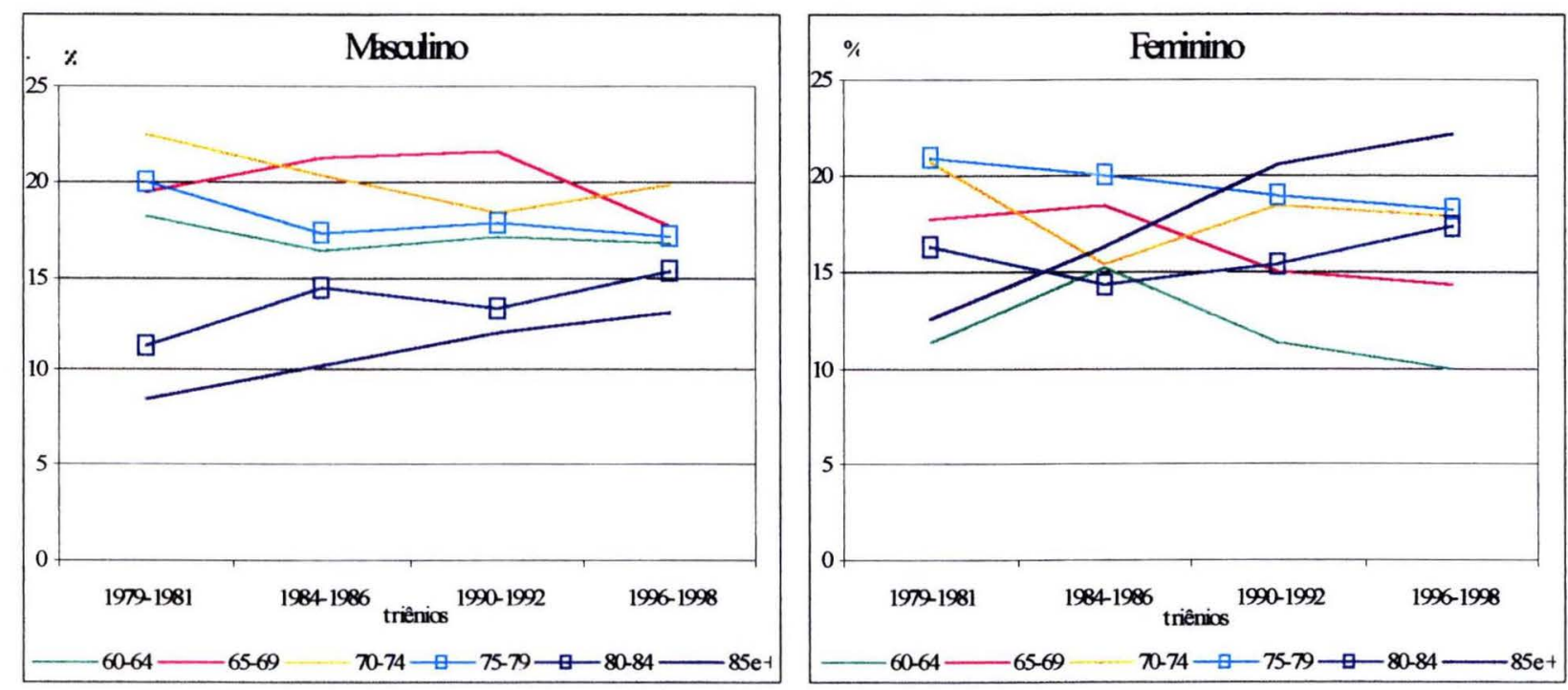

Com relação ao diferencial dos coeficientes de mortalidade por sexo, o Gráfico 6 evidencia alguns aspectos importantes. $O$ primeiro é a nítida queda da sobremortalidade masculina à medida que avança a idade. $O$ segundo é que a sobremortalidade masculina aumentou no período, em todas as idades, com exceção do segmento de 85 anos e mais (Gráfico 6, Tabela 8) para o qual houve queda de $7,9 \%$. Chamou atenção o aumento da sobremortalidade masculina nos idosos jovens de 60 a 64 anos $(29,1 \%)$ e nos de 80 a 84 anos $(34,5 \%)$.

Gráfico 5 - Coeficientes de mortalidade em idosos (por 1000 hab.) segundo sexo e idade, por triênios, Maringá-PR, 1979-1998.
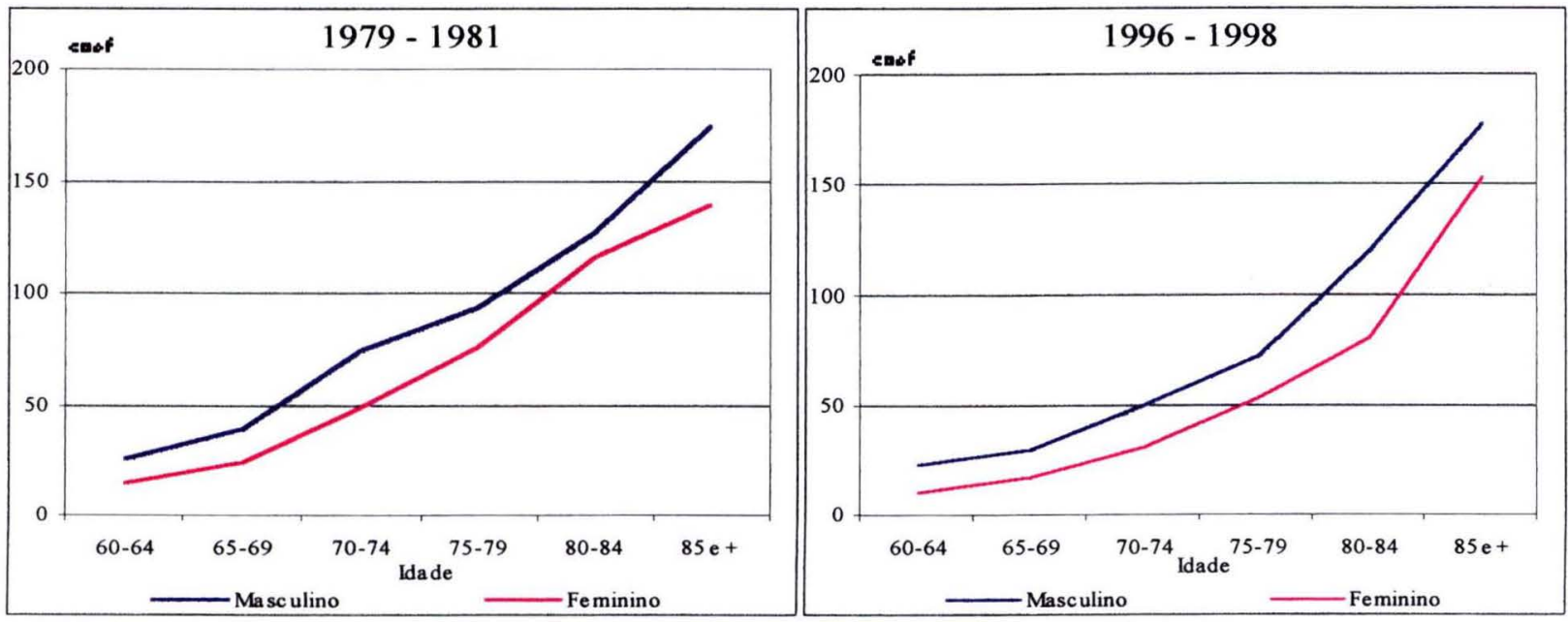
Os resultados relativos, tanto às variações da mortalidade proporcional, dos coeficientes e do aumento da sobremortalidade masculina são descritos também para outras localidades. Entre 1980 e 1995 para a população brasileira, houve um aumento de $68 \%$ para o sexo masculino e de $75, \%$ para o feminino na faixa de 80 anos e mais de idade (MELLO JORGE e GOTLIEB 2000). YAZAKI (1988) em análise da mortalidade em idosos do Município de São Paulo descreve que o aumento da proporção de óbitos entre 1940 e 1984 se deveu mais ao sexo feminino e aos grupos de 70 a 79 e 80 anos e mais de idade.

A evolução da mortalidade proporcional em idosos no Município de Botucatu foi analisada por RUIZ (1996) que encontrou, para o período de 1970 a 1993, acréscimo de $47 \%$ para os homens e $63 \%$ para as mulheres e que a mortalidade proporcional, em 1993, era de 58,3\% e $77,8 \%$ respectivamente. Ainda, a mortalidade proporcional da população acima de 60 anos do Município do Rio de Janeiro era de 51,6\% em 1983 e passou para 54,9\%, em 1994 (PARAHYBA 1997).

Para o Estado do Rio Grande do Norte FORMIGA e col. (1996) e para a população brasileira VASCONCELOS (1998) e CAMARANO e col. (1999) encontraram resultados semelhantes e concluem que, além do aumento da participação relativa dos óbitos na população idosa, está havendo um adiamento da morte para as idades cada vez mais avançadas e de forma mais acelerada no sexo feminino.

Gráfico 6 - Razão de coeficientes de mortalidade em idosos, entre os sexos, segundo idade, por triênios, Maringá-PR, 1979-1998.

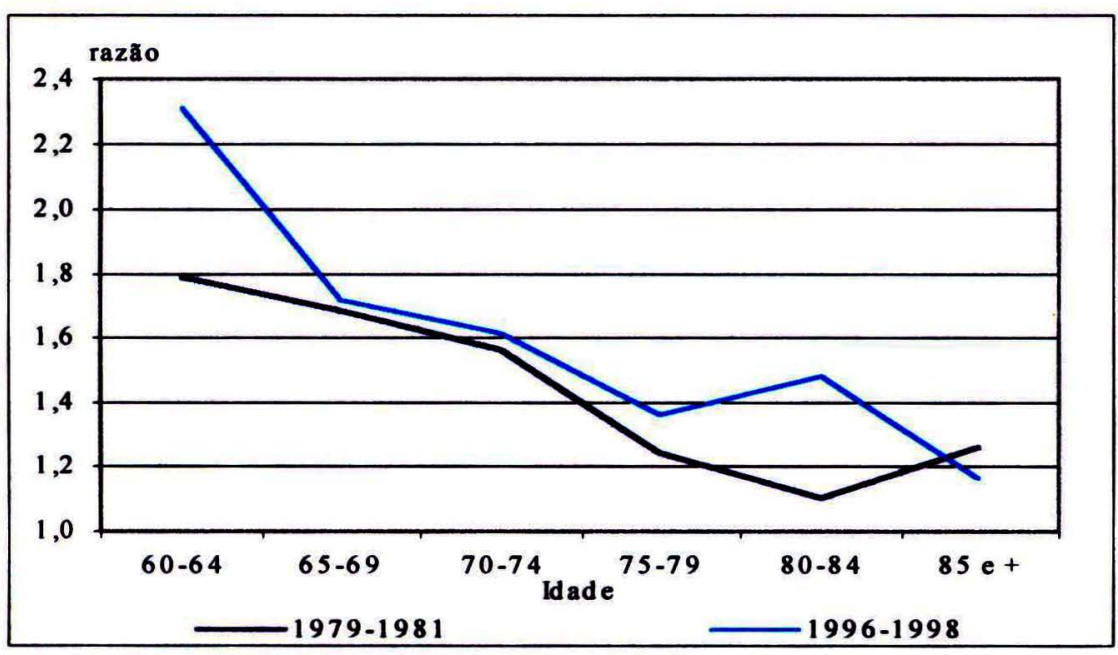


De acordo com CAMARANO e col. (1999) a sobrevida nas idades mais avançadas é elevada na população brasileira, com valor próximo ao de países desenvolvidos. Segundo os autores isso ocorre, pois a mortalidade infantil no Brasil é elevada, o que influencia sobremaneira a expectativa de vida, já que aquelas pessoas que sobrevivem às más condições de vida, ganham anos de vida nas idades que se seguem. Ultrapassado determinado limite de idade a sobrevida se eleva e, no Brasil, no ano de 1996, chegou a 13,2 anos para os homens e a 16,9 anos para as mulheres que atingiam 65 anos de idade.

Uma explicação plausível para a desaceleração da mortalidade em pessoas idosas, segundo HORIUCHI e WILMOTH (1997), pode ser devida à heterogeneidade da população, já que aqueles que são mais vulneráveis aos riscos de mortalidade tendem a morrer nas idades mais jovens e os sobreviventes tendem a ser mais saudáveis, "pressionando" os coeficientes de mortalidade das idades avançadas para valores decrescentes. Segundo os autores, essa hipótese da heterogeneidade é consistente com seus resultados que mostram queda nos coeficientes para todas as principais causas de morte.

Outra possibilidade que poderia explicar, em parte, a queda da mortalidade ou queda do risco de morte nas idades mais avançadas é apresentada por ELO e PRESTON (1996). Em estudo realizado nos Estados Unidos, com dados do início da década de 80 , os autores demonstram que existe diferença significativa no risco de óbito de acordo com a escolaridade, mesmo controlando pelo fator sócio-econômico, ou seja, ocorre uma relação inversa entre nível de escolarização e coeficiente de mortalidade, mais importante em homens do que em mulheres e na idade adulta economicamente ativa. $\mathrm{O}$ que os autores comentam e sugerem é que, à medida que essa coorte da população adulta com maior nível educacional substitua a atual coorte de 65 anos ou mais de idade menos escolarizada a mortalidade tende a diminuir, já que o nivel de escolaridade é "fator protetor" do óbito.

Aspecto interessante encontrado neste estudo foi a diferença na magnitude dos coeficientes entre os sexos e esse fenômeno tem sido estudado em muitos países para décadas recentes.

É fato conhecido que a maioria dos indicadores tradicionais de saúde mostra diferenças entre os sexos, sobretudo a ocorrência de sobremortalidade masculina em praticamente todas as idades, com exceção, quase sempre, das idades mais avançadas, 
acima de 75 ou 80 anos e para a quase totalidade das causas de óbito (LAURENTI e col. 1998). Com isso, independentemente da causa, a maior mortalidade no sexo masculino em todas as idades resulta em um excesso de população feminina nas idades mais avançadas fazendo com que a sobremortalidade masculina seja menor (LAURENTI e FONSECA 1976).

UEMURA e PISA (1988) em estudo da mortalidade por doenças cardiovasculares em vários países, afirmam que, em geral, as tendências de queda observadas foram mais favoráveis para as mulheres do que para os homens, consequentemente as diferenças entre os sexos aumentaram. No sexo masculino a mortalidade por todas as causas é aproximadamente 2 vezes a do sexo feminino havendo variações quando cada diagnóstico é analisado separadamente. O diferencial por sexo é particularmente grande na mortalidade por doenças isquêmicas do coração que, segundo os autores chega a ser 3 vezes maior para os homens e para a doença cerebrovascular era menor que 2. A diferença na mortalidade entre os sexos tem se agravado nas últimas décadas devido ao aumento do risco de morte para os homens, principalmente nos adultos jovens, em razão das causas externas e Aids.

ZHANG e col. (1995) analisaram a tendência da razão de coeficientes de mortalidade por sexo descrevendo a diferença desse indicador entre os triênios 19551957 e 1987-1989, para 30 países. Os autores encontraram aumento da sobremortalidade masculina na grande maioria deles, mesmo naqueles com crescimento do coeficiente geral de mortalidade como a Hungria ou com declínio, como o Japão. Concluem que o aumento da sobremortalidade masculina não está, necessariamente, correlacionada com o nível de mortalidade (com a magnitude do coeficiente geral de mortalidade) e seu comportamento em determinada região e que existem riscos similares afetando a mortalidade nos dois sexos em uma determinada população, mas que atuam de diferentes formas, ou seja, sempre que mudanças na mortalidade ocorrem, elas são mais favoráveis para as mulheres do que para os homens.

Conforme afirmam LAURENTI e col. (1998), sem dúvida, alguns componentes biológicos explicam a sobremortalidade masculina mas, por outro lado, os comportamentos específicos do homem e da mulher resultado dos fatores culturais e sociais, explicam essa diferença e devem ser considerados ao se caracterizar e analisar a saúde masculina e feminina. 
KITAGAWA (1977) comenta que é consenso geral que os fatores biológico e ambiental são tão interdependentes que é praticamente impossivel determinar separadamente a sua influência na mortalidade. Analisa que os maiores aumentos das diferenças de mortalidade entre os sexos são atribuídos às pessoas com mais de 50 anos e que as doenças cardiovasculares e neoplasias foram as causas de morte responsáveis pelos maiores aumentos. Acrescenta também, que o hábito de fumar contribuiu largamente para o diferencial de óbitos entre os sexos, ou seja, as doenças consideradas como conseqüências do hábito de fumar como as doenças do coração, câncer do pulmão e bronquite são, aparentemente, as maiores responsáveis pela deterioração da mortalidade nos homens idosos.

\subsubsection{Mortalidade em idosos segundo causas}

A análise da mortalidade em idosos segundo causas conhecidas aponta para um perfil característico dessa faixa de idade com as doenças do aparelho circulatório, neoplasias, aparelho respiratório como as mais importantes mantendo a ordem de importância durante o período (Tabela 9). Entretanto, ainda que as principais causas tenham permanecido as mesmas, algumas mudanças foram observadas, como a tendência de queda no peso relativo das doenças do aparelho circulatório que mesmo se mantendo como a principal causa de óbito, tiveram declínio de $23,6 \%$ entre os triênios extremos. Por outro lado, houve aumento de $43,2 \%$ no percentual de óbitos por neoplasias e de $118,6 \%$ por doenças do aparelho respiratório. Entre outras variações a partir da quarta causa, destacam-se as doenças das glândulas endócrinas, que não estavam entre as cinco mais freqüentes e aparecem no último triênio, no quarto posto, com $4,7 \%$ do total de óbitos e as doenças infecciosas, com queda de $32,6 \%$, não aparecem mais entre as principais causas no final do período (Tabela 9).

A estrutura da mortalidade por sexo apresentou semelhanças quanto aos grupos de causas mais freqüentes, mas apresentou diferenças em relação a sua proporção em cada sexo. No triênio 1996-1998 as doenças do aparelho circulatório, digestivo e as doenças das glândulas endócrinas eram as mais importantes nos óbitos no sexo feminino e as neoplasias, doenças do aparelho respiratório e causas externas, no sexo masculino (Tabela 9). 
Tabela 9 - Mortalidade proporcional em idosos, segundo causa e sexo, por ordem de importância e por triênios, Maringá-PR, 1979-1998.

\begin{tabular}{|c|c|c|c|c|c|c|c|c|c|}
\hline \multirow{2}{*}{\multicolumn{2}{|c|}{$\begin{array}{c}\text { Triênio } \\
\text { Sexo Posto }\end{array}$}} & \multicolumn{2}{|c|}{$1979-1981$} & \multicolumn{2}{|c|}{$1984-1986$} & \multicolumn{2}{|c|}{$1990-1992$} & \multicolumn{2}{|c|}{ 1996-1998 } \\
\hline & & causa & $\%$ & causa & $\%$ & causa & $\%$ & Causa & $\%$ \\
\hline \multirow{7}{*}{ Masc } & $1^{\circ}$ & oulatót & & 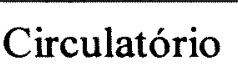 & 44,9 & rio & 44,5 & & 39,8 \\
\hline & $2^{\circ}$ & Neoplasias & 13,3 & Neoplasias & 15,2 & Neoplasias & 17,0 & Neoplasias & 20,2 \\
\hline & $3^{\circ}$ & Respir/digest & 7,0 & Respiratório & 8,6 & Respiratório & 11,2 & & 13,2 \\
\hline & $4^{\circ}$ & Externas & 4,7 & Externas & 5,9 & Externas & 5,4 & & 4,8 \\
\hline & $5^{\circ}$ & Infecciosas & 4,5 & & 5,6 & & 3,2 & & 4,3 \\
\hline & $6^{\circ}$ & Endócrinas & 1,8 & Infecciosas & 3,5 & Endócrinas & 3,0 & & 3,4 \\
\hline & $7^{\circ}$ & SN/Genitur & 1,3 & End & 3,4 & Infec & 2,5 & & 1,8 \\
\hline \multirow{7}{*}{ Fem } & $1^{\circ}$ & & & & & & 46 & & \\
\hline & $2^{\circ}$ & Neoplasias & 11,3 & & 14,5 & Neoplasias & 13,6 & & 15,1 \\
\hline & $3^{\circ}$ & Infecciosas & & & & & 10 & & 12,5 \\
\hline & $4^{\circ}$ & Respiratório & & & 5,5 & & & & 6,3 \\
\hline & $5^{\circ}$ & Digest & & & 4,7 & & & & 5,0 \\
\hline & $6^{\circ}$ & Endócr & & & 4,4 & & & & 3, \\
\hline & $7^{\circ}$ & Externas & 3,1 & Endócrinas & 4,2 & Infe & 3,2 & Inieccio & 2,7 \\
\hline \multirow{7}{*}{ Total } & $1^{\circ}$ & & & & & & & & \\
\hline & $2^{o}$ & Neoplasias & 12,5 & Neoplasias & 14,9 & Neoplasias & 15,5 & Neoplasias & 17,9 \\
\hline & $3^{\circ}$ & Respiratório & & & 7,6 & & 10,7 & & 12,9 \\
\hline & $4^{\circ}$ & Digestivo & 5,5 & Externas & 5,3 & Externas & & Endócrinas & 4,7 \\
\hline & $5^{\circ}$ & Infecciosas & 4,6 & Digestivo & 5,2 & Endócrinas & 4,3 & Digestivo & \\
\hline & $6^{\circ}$ & Externas & 4,0 & Infecciosas & 4,4 & Digestivo & 3,6 & Externas & 4. \\
\hline & $7^{\circ}$ & Endócrinas & & Endócrinas & 3,7 & Infecciosas & 2,8 & Infecciosas & \\
\hline
\end{tabular}

$\mathrm{O}$ aumento da mortalidade proporcional por neoplasias foi maior no sexo masculino (51,9\% contra $33,6 \%$ no sexo feminino), mas o aumento na participação das doenças do aparelho respiratório foi maior no feminino (177,8\% contra $88,6 \%$ no sexo masculino). Para as doenças do aparelho digestivo a tendência foi inversa, com queda de $38,6 \%$ para o sexo masculino e acréscimo de $42,9 \%$ para o feminino. Mesmo que as diferenças relativas tenham sido calculadas entre os dois triênios extremos é importante salientar que as tendências de declínio ou acréscimo 
observadas na mortalidade proporcional, para as principais causas ocorreram, com pequenas variações, nos 4 triênios.

A Tabela 10 apresenta os dez diagnósticos mais freqüentes segundo o sexo, para os dois triênios extremos. Mais uma vez chama a atenção a similaridade do perfil de mortalidade por causas para os dois sexos, sendo o coeficiente sempre maior no

Tabela 10 - Mortalidade proporcional em idosos, segundo diagnósticos mais freqüentes e sexo, por ordem de importância e triênios, Maringá-PR, 1979-1998.

\begin{tabular}{|c|c|c|c|c|}
\hline & \multicolumn{2}{|c|}{$1979-1981$} & \multicolumn{2}{|c|}{ 1996-1998 } \\
\hline posto & Masculino & Feminino & Masculino & Feminino \\
\hline $1^{\circ}$ & $\begin{array}{c}\text { Cerebrovasculares } \\
(22,3)\end{array}$ & $\begin{array}{c}\text { Cerebrovasculares } \\
(26,2)\end{array}$ & $\begin{array}{c}\text { Cerebrovasculares } \\
(14,2)\end{array}$ & $\begin{array}{c}\text { Cerebrovasculares } \\
(13,3)\end{array}$ \\
\hline $2^{\circ}$ & $\begin{array}{l}\text { Isquêmicas } \\
(14,9)\end{array}$ & $\begin{array}{l}\text { Isquêmicas } \\
(18,2)\end{array}$ & $\begin{array}{l}\text { Isquêmicas } \\
(10,2)\end{array}$ & $\begin{array}{l}\text { Out. for. dça. coraç. } \\
(11,8)\end{array}$ \\
\hline $3^{\circ}$ & $\begin{array}{l}\text { Out. for. dça. coraç. } \\
(8,5)\end{array}$ & $\begin{array}{l}\text { Out. for. dça. coraç. } \\
(10,2)\end{array}$ & $\begin{array}{l}\text { Neo ap. digestivo } \\
(7,8)\end{array}$ & $\begin{array}{l}\text { Isquêmicas } \\
(11,2)\end{array}$ \\
\hline $4^{\circ}$ & $\begin{array}{l}\text { Neo ap. digestivo } \\
(4,8)\end{array}$ & Neo ap. digestivo & $\begin{array}{c}\text { DPOC } \\
(7,7)\end{array}$ & $\begin{array}{l}\text { Neo ap. digestivo } \\
(6,6)\end{array}$ \\
\hline $5^{\circ}$ & $\begin{array}{l}\text { DPOC } \\
(4,4)\end{array}$ & $\begin{array}{l}\text { Diabetes } \\
(2,5)\end{array}$ & $\begin{array}{l}\text { Out. for dça. coraç. } \\
(7,6)\end{array}$ & $\begin{array}{c}\text { DPOC } \\
(6,5)\end{array}$ \\
\hline $6^{\circ}$ & $\begin{array}{c}\text { Doença de Chagas } \\
\qquad(2,3)\end{array}$ & $\begin{array}{l}\text { Doença de Chagas } \\
\text { Art. arter. e capilares }\end{array}$ & $\begin{array}{c}\text { Hipertensão } \\
(4,2)\end{array}$ & $\begin{array}{l}\text { Hipertensão } \\
(5,2)\end{array}$ \\
\hline $7^{\circ}$ & $\begin{array}{l}\text { Pneumonia; } \\
\text { Neo.órg.Intratoráxicos } \\
\text { Hipertensão } \\
(2,2)\end{array}$ & $\begin{array}{c}\text { DPOC } \\
(2,1)\end{array}$ & $\begin{array}{c}\text { Neo. } \\
\text { órg.Intratoráxicos } \\
(3,9)\end{array}$ & $\begin{array}{c}\text { Diabetes } \\
(5,0)\end{array}$ \\
\hline $8^{\circ}$ & $\begin{array}{l}\text { Acid. de transporte } \\
\text { Doença card. pulm. } \\
\text { e da circul. pulmonar } \\
(2,0)\end{array}$ & $\begin{array}{l}\text { Hipertensão } \\
(2,0)\end{array}$ & $\begin{array}{c}\text { Pneumonia } \\
(3,8)\end{array}$ & $\begin{array}{c}\text { Pneumonia } \\
(4,1)\end{array}$ \\
\hline $9^{\circ}$ & $\begin{array}{c}\text { Doenças do } \\
\text { intestino } \\
(1,8)\end{array}$ & $\begin{array}{c}\text { Pneumonia } \\
(1,8)\end{array}$ & $\begin{array}{c}\text { Neoplasia de } \\
\text { próstata } \\
(3,1)\end{array}$ & $\begin{array}{c}\text { Art. arter. e capilares } \\
\text { Quedas } \\
(1,8)\end{array}$ \\
\hline $10^{\circ}$ & $\begin{array}{c}\text { Neoplasia de próstata } \\
\qquad(1,6)\end{array}$ & $\begin{array}{c}\text { Doença card. pulm. e } \\
\text { da circul. pulmonar } \\
(1,2)\end{array}$ & $\begin{array}{c}\text { Diabetes } \\
(2,5)\end{array}$ & $\begin{array}{c}\text { Neoplasia de mama } \\
\qquad(1,7)\end{array}$ \\
\hline
\end{tabular}


masculino do que no feminino. Ressalta-se porém, que algumas causas ou aparecem somente no sexo masculino ou somente no feminino. Assim, no primeiro triênio as neoplasias malignas dos órgãos intratorácicos e os acidentes de transporte estão presentes somente entre as dez principais causas no sexo masculino e o diabetes e as doenças das artérias arteríolas e capilares, no feminino. Em relação às modificações observou-se que a doença de Chagas já não está entre as principais causas de óbito no final do período e que o diabetes $(2,5 \%)$ aparece para o sexo masculino e as quedas $(1,8 \%)$ e a neoplasia de mama $(1,7 \%)$, para o feminino.

\section{- Doenças do aparelho circulatório}

As doenças do aparelho circulatório constituem-se em um conjunto de afecções com etiologias e manifestações clínicas diversas de grande importância na estrutura de morbimortalidade em todos os países (LOTUFO e LOLIO 1995). Enquanto que a redução da mortalidade por doenças infecciosas e parasitárias entre 1930 e 1985 , no Brasil, foi de $471 \%$, apenas as doenças cardiovasculares e as neoplasias aumentaram $208 \%$ e $322 \%$, respectivamente, no mesmo período (LESSA 1994). Para a população brasileira na década de 80 houve aumento do coeficiente de mortalidade por doenças cardiovasculares de $13,3 \%$ e em 1991 estas representavam a primeira causa de morte sendo responsáveis por, aproximadamente, $34 \%$ dos óbitos no país (MINISTÉRIO DA SAÚDE 1993).

Segundo LESSA (1994), as projeções indicam que, com a esperada duplicação da população idosa nos próximos anos no Brasil, as doenças não transmissíveis juntamente com as causas externas serão responsáveis por $74 \%$ de todos os óbitos no ano de 2020.

Para Maringá também as doenças do aparelho circulatório são as causas mais freqüentes de óbitos na população idosa mas, os dados deste estudo indicaram que houve redução de $22,3 \%$ na mortalidade proporcional, no sexo masculino e de $25,4 \%$ no feminino. A redução nos coeficientes de mortalidade foi de $31,7 \%$ e $37,8 \%$ para homens e mulheres, respectivamente (Anexo 4).

A Tabela 11 mostra como os percentuais dos diagnósticos mais importantes entre as doenças do aparelho circulatório se comportaram nos triênios estudados. Mesmo com algumas oscilações houve queda na participação das cerebrovasculares e 
isquêmicas e incremento nas outras formas de doenças do coração e hipertensão, mudanças observadas com maior intensidade no sexo feminino.

Tabela 11 - Óbitos em idosos, por doenças do aparelho circulatório, segundo diagnósticos e sexo, por triênios, Maringá-PR, 1979-1998. (nº e \%).

\begin{tabular}{|c|c|c|c|c|c|c|c|c|c|}
\hline \multicolumn{10}{|c|}{ MASCULINO } \\
\hline \multirow[b]{2}{*}{ Diagnósticos } & \multicolumn{2}{|c|}{$1979-1981$} & \multicolumn{2}{|c|}{$1984-1986$} & \multicolumn{2}{|c|}{$1990-1992$} & \multicolumn{2}{|c|}{$1996-1998$} & \multirow{2}{*}{$\begin{array}{l}\text { Diferença } \\
79 / 81-96 / 98\end{array}$} \\
\hline & $\mathrm{n}^{\mathbf{o}}$ & $\%$ & $\mathrm{n}^{\mathbf{o}}$ & $\%$ & $\mathrm{n}^{\mathbf{o}}$ & $\%$ & $\mathrm{n}^{\mathbf{o}}$ & $\%$ & \\
\hline Cerebrovasc & 153 & 43,6 & 158 & 42,4 & 240 & 47,9 & 202 & 35,7 & $-18,1$ \\
\hline Isquêmicas & 102 & 29,0 & 124 & 33,3 & 90 & 18,0 & 145 & 25,7 & $-11,4$ \\
\hline Out.f.do.cora. & 58 & 16,5 & 33 & 8,9 & 98 & 19,5 & 108 & 19,1 & 15,8 \\
\hline Hipertensão & 15 & 4,3 & 29 & 7,8 & 37 & 7,4 & 59 & 10,4 & 141,9 \\
\hline Art.art.e capi & 6 & 1,7 & 14 & 3,8 & 16 & 3,2 & 32 & 5,7 & 235,3 \\
\hline D.circ.pulm & 14 & 4,0 & 11 & 3,0 & 15 & 3,0 & 13 & 2,3 & $-42,5$ \\
\hline Demais & 3 & 0,9 & 3 & 0,8 & 5 & 1,0 & 6 & 1,1 & 22,2 \\
\hline Total & 351 & 100 & 372 & 100 & 501 & 100 & 565 & 100 & - \\
\hline \multicolumn{10}{|c|}{ FEMININO } \\
\hline & \multicolumn{2}{|c|}{$1979-1981$} & \multicolumn{2}{|c|}{$1984-1986$} & \multicolumn{2}{|c|}{$1990-1992$} & \multicolumn{2}{|c|}{$1996-1998$} & Diferença \\
\hline Diagnósticos & $\mathrm{n}^{\mathbf{o}}$ & $\%$ & $\mathrm{n}^{\circ}$ & $\%$ & $\mathrm{n}^{\mathbf{o}}$ & $\%$ & $\mathrm{n}^{\mathbf{o}}$ & $\%$ & $79 / 81-96 / 98$ \\
\hline Cerebrovasc & 134 & 43,2 & 121 & 38,9 & 155 & 37,5 & 153 & 29,4 & $-31,9$ \\
\hline Isquêmicas & 93 & 30,0 & 97 & 31,2 & 103 & 24,9 & 129 & 24,8 & $-17,3$ \\
\hline Out.f.do.cora. & 52 & 16,8 & 51 & 16,4 & 95 & 23,0 & 136 & 26,1 & 55,4 \\
\hline Hipertensão & 10 & 3,2 & 21 & 6,7 & 30 & 7,3 & 60 & 11,5 & 259,4 \\
\hline Art.art.e capi & 12 & 3,9 & 4 & 1,3 & 11 & 2,7 & 21 & 4,0 & 2,6 \\
\hline D.circ.pulm & 6 & 1,9 & 14 & 4,5 & 9 & 2,2 & 10 & 1,9 & - \\
\hline Demais & 3 & 1,0 & 3 & 1,0 & 10 & 2,4 & 12 & 2,3 & 130,0 \\
\hline Total & 310 & 100 & 311 & 100 & 413 & 100 & 521 & 100 & - \\
\hline \multicolumn{10}{|c|}{ TOTAL } \\
\hline \multirow[b]{2}{*}{ Diagnósticos } & \multicolumn{2}{|c|}{$1979-1981$} & \multicolumn{2}{|c|}{$1984-1986$} & \multicolumn{2}{|c|}{$1990-1992$} & \multicolumn{2}{|c|}{$1996-1998$} & Diferença \\
\hline & $\mathrm{n}^{\mathbf{0}}$ & $\%$ & $\mathrm{n}^{\mathbf{o}}$ & $\%$ & $\mathrm{n}^{\mathbf{0}}$ & $\%$ & $\mathrm{n}^{\mathbf{0}}$ & $\%$ & $79 / 81-96 / 98$ \\
\hline Cerebrovasc & 287 & 43,5 & 279 & 40,8 & 395 & 43,2 & 355 & 32,7 & $-24,8$ \\
\hline Isquêmicas & 195 & 29,5 & 221 & 32,4 & 193 & 21,1 & 274 & 25,2 & $-14,6$ \\
\hline Out.f.do.cora. & 110 & 16,6 & 84 & 12,3 & 193 & 21,1 & 244 & 22,5 & 35,5 \\
\hline Hipertensão & 25 & 3,8 & 50 & 7,3 & 67 & 7,3 & 119 & 11,0 & 189,5 \\
\hline Art.art.e capi & 18 & 2,7 & 18 & 2,6 & 27 & 3,0 & 53 & 4,9 & 81,5 \\
\hline D.circ.pulm & 20 & 3,0 & 25 & 3,7 & 24 & 2,6 & 23 & 2,1 & $-30,0$ \\
\hline Demais & 6 & 0,9 & 6 & 0,9 & 15 & 1,7 & 18 & 1,6 & 77,8 \\
\hline Total & 661 & 100 & 683 & 100 & 914 & 100 & 1086 & 100 & - \\
\hline
\end{tabular}


Essas mudanças podem ser melhor examinadas na Tabela 12 quando a mortalidade é analisada considerando o total de óbitos em idosos. Assim como vem sendo descrito para outras regiões do Brasil (LOLIO e LAURENTI 1986; LOLIO e col. 1995; LOTUFO 1993; LESSA e col. 1996) também foi observado para Maringá

Tabela 12 - Mortalidade proporcional e coeficientes de mortalidade em idosos (por 100.000 hab.), por doenças do aparelho circulatório, segundo diagnóstico e sexo, por triênios, Maringá-PR, 1979-1998.

\begin{tabular}{|c|c|c|c|c|c|c|c|c|c|c|}
\hline \multicolumn{11}{|c|}{ MASCULINO } \\
\hline & \multicolumn{2}{|c|}{ 1979-1981 } & \multicolumn{2}{|c|}{ 1984-1986 } & \multicolumn{2}{|c|}{ 1990-1992 } & \multicolumn{2}{|c|}{ 1996-1998 } & \multicolumn{2}{|c|}{\begin{tabular}{|r|} 
Diferença (\%) \\
1979/81 - 1996/98 \\
\end{tabular}} \\
\hline Diagnósticos & $\%$ & coef & $\%$ & coef & $\%$ & coef & $\%$ & coef & $\%$ & coef \\
\hline Cerebrovascular & \multicolumn{2}{|l|}{22,3} & 19,1 & 929,1 & \multicolumn{2}{|c|}{$21,3 \quad 1031,9$} & 14,2 & 654,8 & $-36,3$ & $-44,0$ \\
\hline Isquêmica & 14,9 & 779,4 & 15,0 & 729,2 & 8,0 & 387,0 & 10,2 & 470,0 & $-31,5$ & $-39,7$ \\
\hline Out.f.do.cora. & 8,5 & 443,2 & 4,0 & 194,0 & 8,7 & 421,4 & 7,6 & 350,1 & $-10,6$ & $-21,0$ \\
\hline \multirow[t]{2}{*}{ Hipertensão } & 2,2 & 114,6 & 3,5 & 170,5 & 3,3 & 159,1 & 4,2 & 191,3 & 90,9 & 66,9 \\
\hline & \multicolumn{10}{|c|}{ FEMININO } \\
\hline & \multicolumn{2}{|c|}{$1979-1981$} & \multicolumn{2}{|c|}{ 1984-1986 } & \multicolumn{2}{|c|}{ 1990-1992 } & \multicolumn{2}{|c|}{ 1996-1998 } & \multicolumn{2}{|c|}{\begin{tabular}{|c|} 
Diferença (\%) \\
1979/81 - 1996/98 \\
\end{tabular}} \\
\hline Diagnósticos & $\%$ & coef & $\%$ & coef & $\%$ & coef & $\%$ & coef & $\%$ & coef \\
\hline Cerebrovascular & \multicolumn{2}{|c|}{$26,2 \quad 1008,0$} & 19,7 & 669,0 & 17,6 & 592,3 & 13,3 & 424,9 & $-49,2$ & $-57,8$ \\
\hline Isquêmica & 18,2 & 699,6 & 15,8 & 536,3 & 11,7 & 393,6 & 11,2 & 358,3 & $-38,5$ & $-48,8$ \\
\hline \multirow{2}{*}{$\begin{array}{l}\text { Out.f.do.cora. } \\
\text { Hipertensão }\end{array}$} & 10,2 & 391,2 & 8,3 & 282,0 & 10,8 & 363,0 & 11,8 & 377,7 & 15,7 & $-3,5$ \\
\hline & 2,0 & 75,2 & 3,4 & 116,1 & 3,4 & 114,6 & 5,2 & 166,6 & 160,0 & 121,5 \\
\hline \multicolumn{11}{|c|}{ TOTAL } \\
\hline & 1979 & -1981 & 1984 & -1986 & 1990 & -1992 & 1996. & 1998 & \begin{tabular}{|r} 
Difere \\
$1979 / 8$ \\
\end{tabular} & $\begin{array}{r}\text { aça (\%) } \\
1996 / 98 \\
\end{array}$ \\
\hline Diagnósticos & $\%$ & coef & $\%$ & coef & $\%$ & coef & $\%$ & coef & $\%$ & coef \\
\hline Cerebrovascular & 24,0 & 1087,9 & 19,3 & 795,0 & 19,7 & 799,2 & 13,8 & 531,0 & $-42,5$ & $-51,2$ \\
\hline Isquêmicas & 16,3 & 739,2 & 15,3 & 629,8 & 9,6 & 390,5 & 10,7 & 409,8 & $-34,4$ & $-44,6$ \\
\hline Out.f.do.cora. & 9,2 & 417,0 & 5,8 & 239,4 & 9,6 & 390,5 & 9,5 & 365,0 & 3,3 & $-12,5$ \\
\hline Hipertensão & 2,1 & 94,8 & 3,5 & 142,5 & 3,3 & 135,6 & 4,6 & 178,0 & 119,0 & 87,8 \\
\hline
\end{tabular}

*Percentual calculado em relação ao total de óbitos em cada sexo.

que a mortalidade proporcional por doenças cerebrovasculares e doenças isquêmicas do coração decresceu com uma diferença de 42,5\%, 34,4\% entre os dois triênios extremos. Por outro lado, houve aumento da hipertensão que embora com participação relativa pequena, passou de $2,1 \%$ para $4,6 \%$ assumindo, praticamente, a mesma importância que as doenças infecciosas representavam no início da década de 
80. O declínio na mortalidade proporcional por doenças cerebrovasculares, isquêmicas, assim como o acréscimo observado para a hipertensão foram maiores para o sexo feminino. Para as outras formas de doenças do coração houve queda de $10,6 \%$ para o sexo masculino e acréscimo de 15,7\% para o feminino (Tabela 12), podendo sugerir a migração de um diagnóstico para outro o que será discutido adiante.

O comportamento dos coeficientes de mortalidade foi semelhante ao da mortalidade proporcional, ou seja, de queda para as doenças cerebrovasculares $(51,2 \%)$, doenças isquêmicas $(44,6 \%)$ e outras formas de doenças do coração $(12,5 \%)$ e aumento para hipertensão (87,8\%). A queda foi mais evidente para as mulheres nos coeficientes de mortalidade por doença cerebrovascular e doença isquêmica assim como o aumento dos coeficientes para hipertensão. No último triênio a estimativa dos riscos de óbito por doença cerebrovascular, doença isquêmica do coração e hipertensão continuam maiores para o sexo masculino enquanto que para outras formas de doenças do coração, para o feminino (Tabela 12). De fato, para esta última causa, embora os coeficientes tenham decrescido para ambos os sexos, o declínio foi maior para o masculino $(21 \%)$ do que para o feminino $(3,5 \%)$ ficando como segundo diagnóstico mais importante entre as doenças do aparelho circulatório para as mulheres e continuando em terceiro lugar para os homens (Tabela 9).

Em relação à transição no perfil de mortalidade na população, as doenças isquêmicas do coração vêm assumindo maior importância como causa de óbito, substituindo as doenças cerebrovasculares. Segundo LESSA e col. (1996), existe uma tendência de inversão nas causas de morte com as cerebrovasculares passando para segundo plano, como vem ocorrendo no Brasil para as regiões e capitais melhor situadas social e economicamente (Sul e Sudeste). Nas regiões menos desenvolvidas as doenças cerebrovasculares continuam com diferença importante em relação às isquêmicas do coração o que pode caracterizar as diferenças regionais e geográficas. Dados sobre mortalidade para o Brasil indicam que, para o ano de 1994, excluindo-se as causas mal definidas, as doenças cerebrovasculares representaram 11,3\% do total de óbitos contra 9,3\% das doenças isquêmicas e em relação às doenças do aparelho circulatório as cerebrovasculares contribuíram com $33,9 \%$ contra $28 \%$ das isquêmicas do coração (LESSA 1998b). 
LOTUFO (1993) descreve a tendência da mortalidade por doenças cardiovasculares e conclui que o Estado de São Paulo apresentou transição mais acelerada do que o restante do país com um padrão de mortalidade diferenciado, com predomínio das doenças isquêmicas do coração sobre as doenças cerebrovasculares, determinado tanto pela urbanização e adoção de estilos de vida ocidentais, como também pela composição étnica da população paulista.

No Município paulista de Botucatu esse fenômeno foi também observado para os óbitos na população idosa onde a doença cerebrovascular e a doença isquêmica do coração inverteram de posição. No ano de 1970 a mortalidade proporcional para as cerebrovasculares e isquêmicas era de $22,58 \%$ e $17,97 \%$ e em $1993,10,47 \%$ e $14,48 \%$, respectivamente (RUIZ 1996).

$O$ que pode ser observado na análise da mortalidade proporcional da população idosa de Maringá é, provavelmente, o início desse processo de inversão ou transição, com queda na diferença ou aproximação dos valores relativos e coeficientes de mortalidade por doenças cerebrovasculares e doenças isquêmicas do coração. De fato, embora no final do período, a mortalidade proporcional por doenças cerebrovasculares seja ainda maior do que por doenças isquêmicas do coração $(13,8 \%$ contra $10,7 \%$ ), a diferença entre elas, do primeiro para o último triênios, reduziu de 7,7 para 3,1 pontos percentuais (Tabela 12 ).

\section{- Doença cerebrovascular}

Mesmo tendo sua importância diminuída a doença cerebrovascular continua sendo a principal causa de morte na população idosa residente em Maringá (Tabela 10). No primeiro triênio, $24 \%$ de todos os óbitos foram por doença cerebrovascular e no último, sua participação relativa decresceu $42,5 \%$ representando $13,8 \%$ dos óbitos. Em relação ao sexo, houve uma mudança importante pois, no início do periodo a doença cerebrovascular tinha uma participação relativa maior nes óbitos do sexo feminino (26,2\% contra $22,3 \%$ no masculino) e no final, com decréscimo mais expressivo no sexo feminino a mortalidade proporcional passou a ser maior no sexo masculino (14,2\% contra $13,3 \%$ no sexo feminino) (Tabela 12$)$.

A análise mais detalhada da doença cerebrovascular por sexo e faixas de idade mostra que houve um ligeiro deslocamento dos óbitos, das idades mais jovens para as 
mais avançadas que, para o último triênio, para o sexo masculino concentraram-se entre 65 e 74 e para o feminino entre 75 e 84 anos (Gráfico 7). A queda dos coeficientes ocorreram para ambos os sexos e em todas as idades e mantiveram, praticamente, a mesma tendência no início e no final do período que foi de aumento à medida que aumentou a idade (Gráficos 8 e 9).

A idade é um importante fator de risco para a doença cerebrovascular, pois por volta de 80 a $98 \%$ de todos os óbitos ocorrem em pessoas acima de 55 anos e mesmo entre os idosos o risco de morrer cresce com a idade (KALACHE e ABODERIN 1995).

Muito embora a queda na mortalidade por doença cerebrovascular tenha sido observada em muitas regiões e países, não necessariamente tem havido a mesma redução na sua incidência. Para o Município de Salvador, em 1980, foi verificado que as incidências variaram entre 5,3 por 100.000 habitantes de 15 a 24 anos a 1952,3 por 100.000 homens e 1560,4 por 100.000 mulheres, a partir de 65 anos de idade (LESSA 1998b).

Gráfico 7 - Distribuição percentual dos óbitos em idosos por doença cerebrovascular segundo sexo e idade, por triênios, Maringá-PR, 1979-1998.
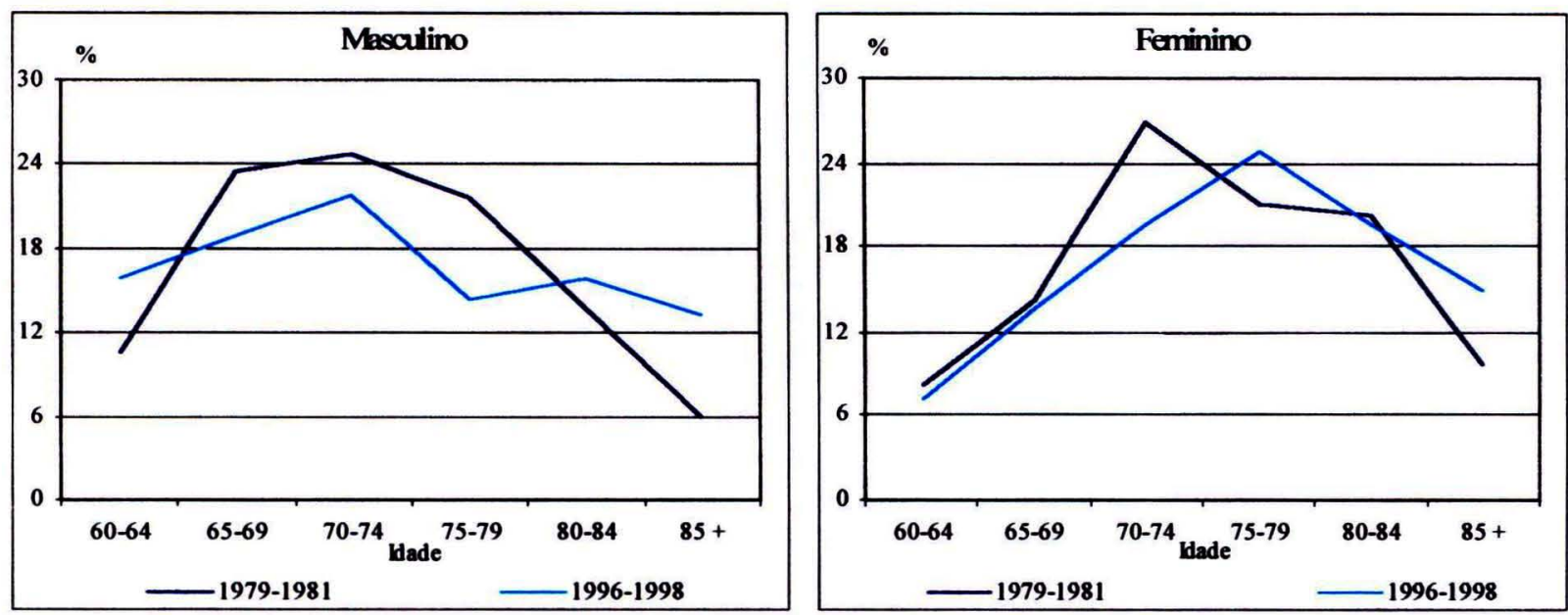

Com o aumento da mortalidade proporcional para os idosos poder-se-ia esperar um substancial aumento nas taxas de mortalidade por doenças cerebrovasculares, já que a incidência de casos é maior nas idades mais avançadas. $O$ que se observou no entanto foi que, paralelamente ao aumento da população idosa 
houvè um declínio das taxas de mortalidade por doenças cerebrovasculares na população maringaense.

Estudo desenvolvido por UEMURA e PISA (1988), para o período de 1950 a 1985, mostrou que, para muitos países, houve um decréscimo consistente desde o início dos anos 50, que ocorreu mais rapidamente na segunda metade do período. A queda relativa nas taxas de mortalidade foi maior que $50 \%$ no Japão (67\%), Austrália (55\%), Estados Unidos (55\%) e Israel (52\%) para os homens e maior que $60 \%$ para as mulheres no Japão (66\%) e Malta (68\%). Em outros países entretanto, durante o segundo período do estudo, houve importante aumento no risco de morrer por doenças cerebrovasculares como na Polônia (68\% nos homens e 38\% nas mulheres), Hungria (54\% nos homens e $24 \%$ nas mulheres) e República Democrática Alemã (48\% nos homens e $40 \%$ nas mulheres) (UEMURA e PISA 1988).

Nos Estados Unidos resultados do Minnesota Heart Survey mostraram que os coeficientes de mortalidade por doença cerebrovascular caíram mais de $\mathbf{5 0 \%}$ durante o período de 1960 a 1990 , enquanto que a pressão arterial média na população também declinou e o tratamento antihipertensivo entre 1973 e 1987 aumentou (McGOVERN e col. 1992) e para o Canadá STOKES e LINDSAY (1996) também demonstraram queda nos coeficientes desde meados da década de 60 .

Gráfico 8 - Coeficientes de mortalidade em idosos (por 100.000 hab.), por doença cerebrovascular, segundo sexo e idade, por triênios, Maringá-PR, 1979-1998.
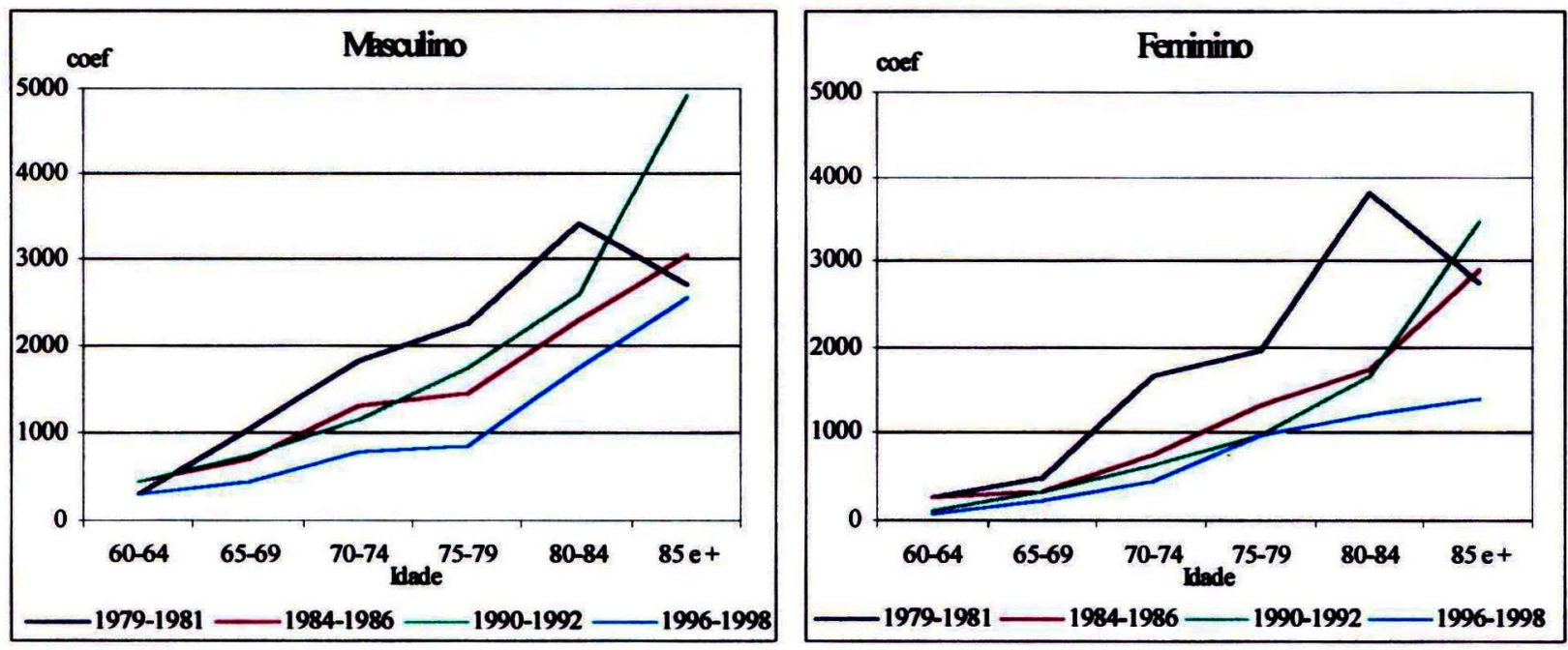

Em análise da tendência dos coeficientes de mortalidade por doenças cardiovasculares no Estado de São Paulo, no período de 1970 a 1989 LOTUFO 
(1993) encontrou que as taxas para as doenças cerebrovasculares não se alteraram nas idades mais jovens mas tiveram significativo descenso para a faixa de idade acima de 60 anos, em ambos os sexos. $O$ autor comenta que o declínio observado para o Estado de São Paulo foi o menor se comparado com o de outros países e ficou em situação intermediária com os países do Leste Europeu. $O$ fato de não ter havido nenhuma melhora nos coeficientes de mortalidade nas idades mais jovens é atribuído pelo autor, à maior prevalência nessa faixa de idade, da hemorragia subaracnoídea com maior letalidade por seus determinantes genéticos menos preveníveis. A análise do declínio nas idades acima de $\mathbf{6 0}$ anos encontrado no estudo não é tarefa fácil pois envolve desde a falta de informação sobre o tipo de acidente vascular cerebral que determinou o óbito, modificações na qualidade do preenchimento da declaração de óbito, até ao controle da hipertensão arterial e melhora na assistência médica dispensada ao paciente (LOTUFO 1993).

Em Maringá, conforme pode ser visualizado no Gráfico 8, as curvas referentes aos triênios 1979-1981 e 1996-1998 mostraram distâncias importantes entre sí, ou declínios na estimativa do risco, maiores nas idades intermediárias. Foi possível ainda perceber a sobremortalidade masculina nos dois triênios extremos salvo a partir de $\mathbf{8 0}$ anos no primeiro e de 75 a 79 anos no último, para as quais os coeficiente de mortalidade foram ligeiramente superiores para o sexo feminino (Gráfico 9).

Gráfico 9 - Coeficientes de mortalidade em idosos (por 100.000 hab.) por doença cerebrovascular segundo triênios, sexo e idade, Maringá-PR, 1979-1998.

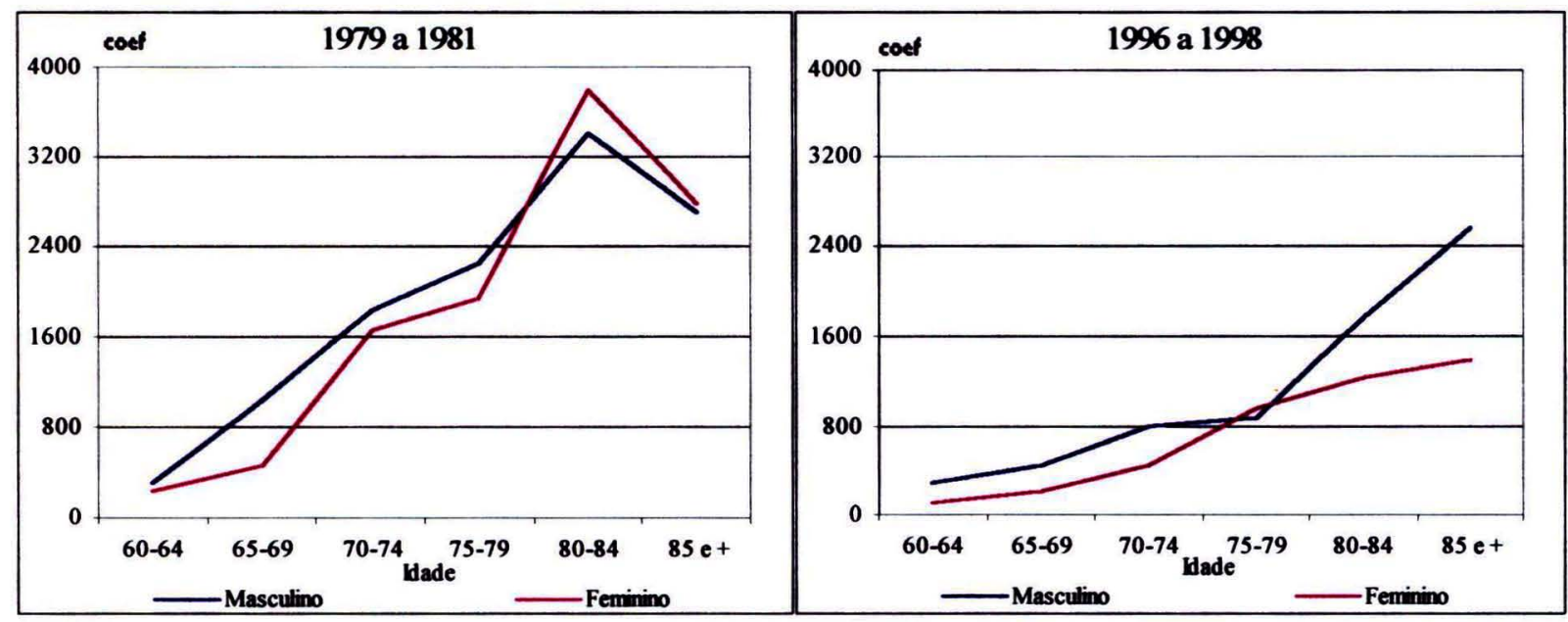


As discussões a respeito das causas que diretamente têm contribuído para a queda na mortalidade por doença cerebrovascular envolvem alguns fatores como a importância do tratamento antihipertensivo, que tem registrado incremento, pelo menos em comunidades onde existem estudos que acompanham tais variáveis. No que diz respeito à gravidade, os acidentes vasculares cerebrais do tipo hemorrágico são sempre os mais graves e, segundo LESSA (1998a) a hipertensão arterial não tratada, não controlada, ou mesmo desconhecida do paciente está presente em cerca de $100 \%$ dos casos.

Entretanto, uma das conclusões do Minnesota Heart Survey diz respeito ao tratamento antihipertensivo que teria um efeito pequeno na queda das taxas de mortalidade por doença cerebrovascular, já que o uso de medicamentos explica apenas parte do declínio da média da pressão arterial na população (JACOBS e col. 1992). O potencial do tratamento antihipertensivo ainda não foi alcançado na comunidade em estudo, pois 3 entre 10 pessoas hipertensas continuam sem tratamento e ainda, o intervalo de tempo entre o primeiro diagnóstico e o início do tratamento ainda pode ser diminuído, fazendo com isso melhorar a relação entre níveis pressóricos e mortalidade por derrame cerebral (JACOBS e col. 1992). Por outro lado as causas da queda na média da pressão arterial observada em nível populacional, mesmo com o aumento registrado no tratamento antihipertensivo, ainda não estão bem elucidadas. $\mathrm{O}$ aumento das atividades físicas, o melhor controle de peso, a queda no consumo de álcool e sal são fatores relevantes que merecem ser pesquisados.

Existem evidências de que a prevalência do hábito de fumar tem declinado desde 1964 nos Estados Unidos (JACOBS e col. 1992). Então, se o hábito de fumar é significativamente relacionado com o derrame cerebral, o seu declínio pode também, ter influenciado diretamente o declínio nas taxas de mortalidade. Indo mais além, se existe a constatação de que o hábito de fumar está também, relacionado com o grau de escolaridade, seria importante explorar a relação do nível socioeconômico e mortalidade por derrame cerebral (JACOBS e col. 1992). Outra possibilidade relatada no Minnesota Heart Survey é a queda na média dos níveis séricos de colesterol total na população observada entre 1973 e 1987 que pode ter relação, mesmo que pequena, na redução da mortalidade por derrames tromboembolíticos. 
O fato de ter havido redução na mortalidade por doenças do coração nas últimas décadas pode ter, indiretamente, contribuído para o declínio na mortalidade por doença cerebrovascular. Segundo WOLF (1990) e BENJAMIN e col. (1992), a fibrilação atrial, o infarto do miocardio, a função ventricular esquerda reduzida podem gerar formação de trombose cardíaca resultando em acidente vascular cerebral. LOTUFO (1993) acrescenta que, embora esse impacto deva ser melhor avaliado, a utilização de drogas anti-agregantes plaquetárias como o ácido acetilsalicílico após os episódios isquêmicos cerebrais transitórios tornou-se popular entre os médicos, como prevenção primária concorrendo também, para influenciar na história natural da doença.

É possivel que todos esses fatores possam ser extrapolados para a população idosa de Maringá se for considerado que as tendências de tratamento, técnicas de diagnóstico e condutas médicas são similares. Por outro lado as conclusões acerca da tendência observada devem ser cautelosas, principalmente no que diz respeito à magnitude das mudanças observadas considerando que as doenças crônicas no idoso interagem entre si e de maneira complexa. Outro dado importante que foi observado, é que para Maringá, houve aumento do risco de óbito por hipertensão, principalmente no sexo feminino (Tabela 12). Seria então possível que parte da queda observada, tanto na mortalidade por doenças cerebrovasculares como para a doença isquêmica do coração e outras formas de doença do coração fosse atribuída à migração de diagnósticos para a hipertensão ou também, que a melhora no atendimento médico, maior disponibilidade de tecnologia diagnóstica, ter repercutido no conhecimento mais completo sobre cada patologia com possibilidade de diagnosticá-las com maior segurança.

De qualquer maneira a queda na mortalidade por doença cerebrovascular deve ser considerada uma grande conquista e um ganho para a população idosa mas, em relação à sua saúde o problema ainda persiste considerando as conseqüências de um acidente vascular cerebral, pois elas representam das mais importantes causas de incapacidades em países desenvolvidos. Estima-se que entre 20 e $30 \%$ dos sobreviventes terão seqüelas importantes e que apenas 25 a $50 \%$ destes serão capazes de andar sem necessitar de ajuda (KALACHE e ABODERIN 1995).

SHAHAR e col. (1995) avaliaram a sobrevida de pacientes hospitalizados por acidente vascular cerebral nos anos de 1980, 1985 e 1990. Os resultados mostiaram 
que houve aumento na sobrevida nos dois períodos analisados, 28 dias e 2 anos após o evento. Tanto para os homens como para as mulheres o risco de morrer dentro dos 2 anos após o acidente vascular cerebral foi aproximadamente $40 \%$ menor em 1990 do que em 1980. Esses resultados foram surpreendentes, pois segundo os autores, aparentemente, não existiu nenhum avanço importante no tratamento do derrame cerebral durante a década de 80 . O que ocorreu foi um incrível aumento no uso da tecnologia de imagens, da introdução da tomografia computadorizada que rapidamente se tornou uma importante ferramenta diagnóstica para avaliar pacientes que apresentavam desordens neurológicas levando a uma melhora indiscutível no diagnóstico dos tipos dos eventos ocorridos e à melhor orientação terapêutica. As razões para a queda na mortalidade então, segundo os pesquisadores, podem ser atribuídas ao melhor cuidado dispensado ao paciente com derrame cerebral, pois os óbitos após um derrame são freqüentemente causas de seqüelas como embolia pulmonar ou broncopneumonia e também por possíveis doenças cardíacas que o paciente pudesse, concomitantemente, apresentar. Essas condições foram provavelmente melhor administradas e prevenidas em 1990 do que em 1980 (WOLF 1990; SHAHAR e col. 1995).

Além disso é possível que tenha havido mudança da historia natural do acidente vascular cerebral que poderia estar se tornando uma doença menos grave. Os mesmos fatores de risco que provavelmente contribuíram para a queda na mortalidade podem também ter resultado em melhor prognóstico para as pessoas que tiveram um acidente vascular cerebral (WOLF 1990; SHAHAR e col. 1995). De qualquer forma o declínio da mortalidade aponta para o provável aumento na prevalência das incapacidades relativas ao acidente vascular cerebral nas próximas décadas, principalmente se essa queda é resultado do tratamento dos casos incidentes sem contudo, serem implementados esforços na prevenção primária da doença (elevado consumo de sal e gorduras saturadas, controle da hipertensão arterial e obesidade).

\section{- Doença isquêmica do coração}

No Brasil, em todas as regiões, a doença isquêmica do coração é importante causa de óbito onde persistem altas taxas de mortalidade apesar do declínio que vem sendo observado em algumas capitais de áreas metropolitanas. A forma mais 
conhecida de doença isquêmica, o infarto agudo do miocárdio, é predominante em homens, mas nas mulheres a angina do peito é a causa mais freqüentemente encontrada (LOTUFO 1998a; LOTUFO 1998b).

A mortalidade proporcional por doença isquêmica do coração, em Maringá, no primeiro triênio foi maior entre 60 e 64 e 75 e 79 anos mas no último houve queda importante para as mesmas idades, de $28,4 \%$ para $18,6 \%$ e de $23,5 \%$ para $17,2 \%$, respectivamente (Gráfico 10). Por causa dessas modificações a distribuição no último triênio apresentou uma linha de tendência mais uniforme com maior concentração dos óbitos nos idosos mais jovens e declínio nas idades mais avançadas. No sexo feminino a distribuição percentual dos óbitos não apresentou tendência de queda em idades mais avançadas. $\mathrm{O}$ que se observa, para os dois triênios extremos é uma maior flutuação dos óbitos que, no último triênio, concentraram-se nas faixas de 70 a 74 anos $(24, \%)$ e 85 anos e mais de idade (20,9\%).

Gráfico 10 - Distribuição percentual de óbitos em idosos, por doença isquêmica do coração, segundo sexo e idade, por triênios, Maringá-PR, 1979-1998.
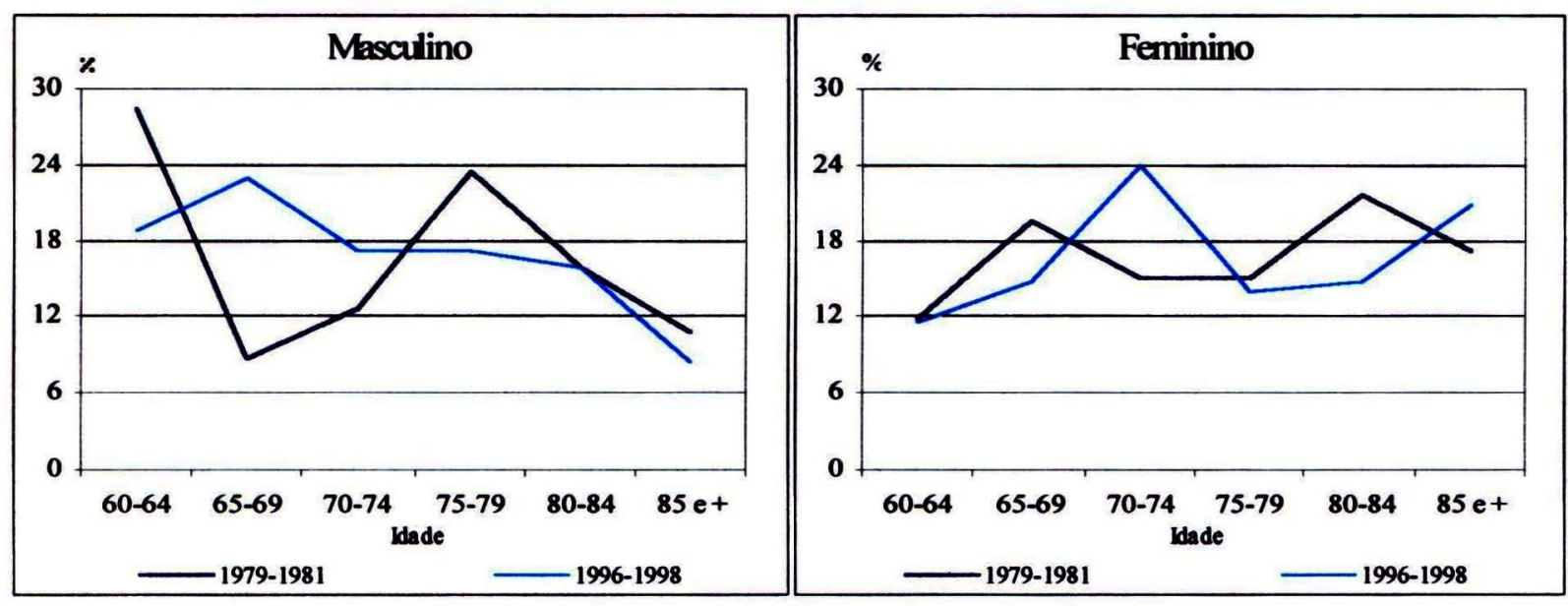

Considerando ainda apenas as curvas relativas aos triênios extremos pode-se observar que as taxas de mortalidade para os homens só não decresceram na faixa de 65 a 69 anos, ao passo que para as mulheres o declínio foi observado para todas as idades (Gráfico 11). As quedas mais expressivas foram registradas para os idosos mais velhos em ambos os sexos. O Gráfico 12 mostra que, além da queda, a estimativa do risco de mortalidade por doença isquêmica do coração - teve comportamento semelhante para homens e mulheres com aumento das taxas com a 
idade. Existe entretanto, uma leve tendência de maior risco para os homens jovens (60-64 anos) e para as mulheres idosas ( 85 anos e mais).

Gráfico 11 - Coeficientes de mortalidade em idosos (por 100.000 hab.), por doença isquêmica do coração, segundo sexo e idade, por triênios, Maringá-PR, 1979-1998.

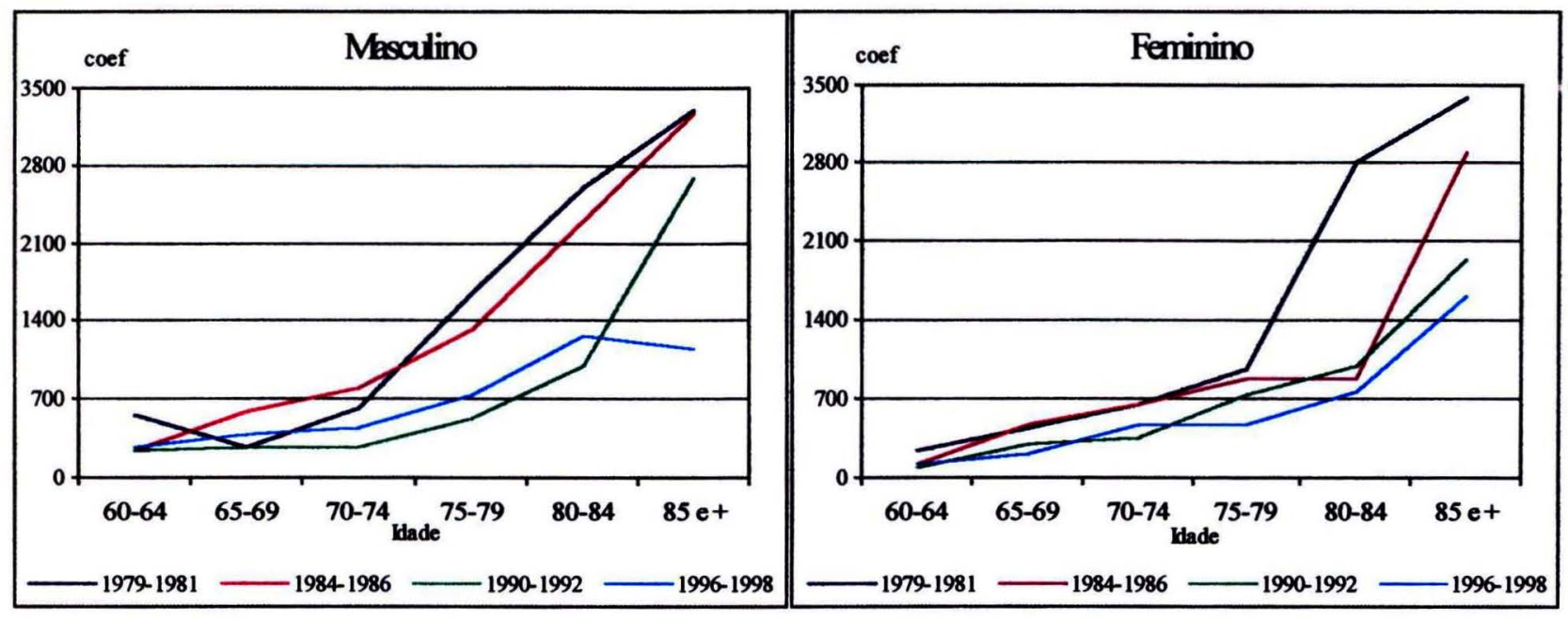

A tendência descendente dos coeficientes de mortalidade nas doenças isquêmicas do coração teve início no final da década de 60 para países como os Estados Unidos, Canadá, Australia, Japão e outros da Europa Ocidental, o que aponta para a possibilidade de estar ocorrendo uma diminuição de incidência do infarto agudo do miocárdio na população (LOLIO e LAURENTI 1986).

Gráfico 12 - Coeficientes de mortalidade em idosos (por 100.000 hab.), por doença isquêmica do coração, segundo triênios, sexo e idade, Maringá-PR, 1979-1998.
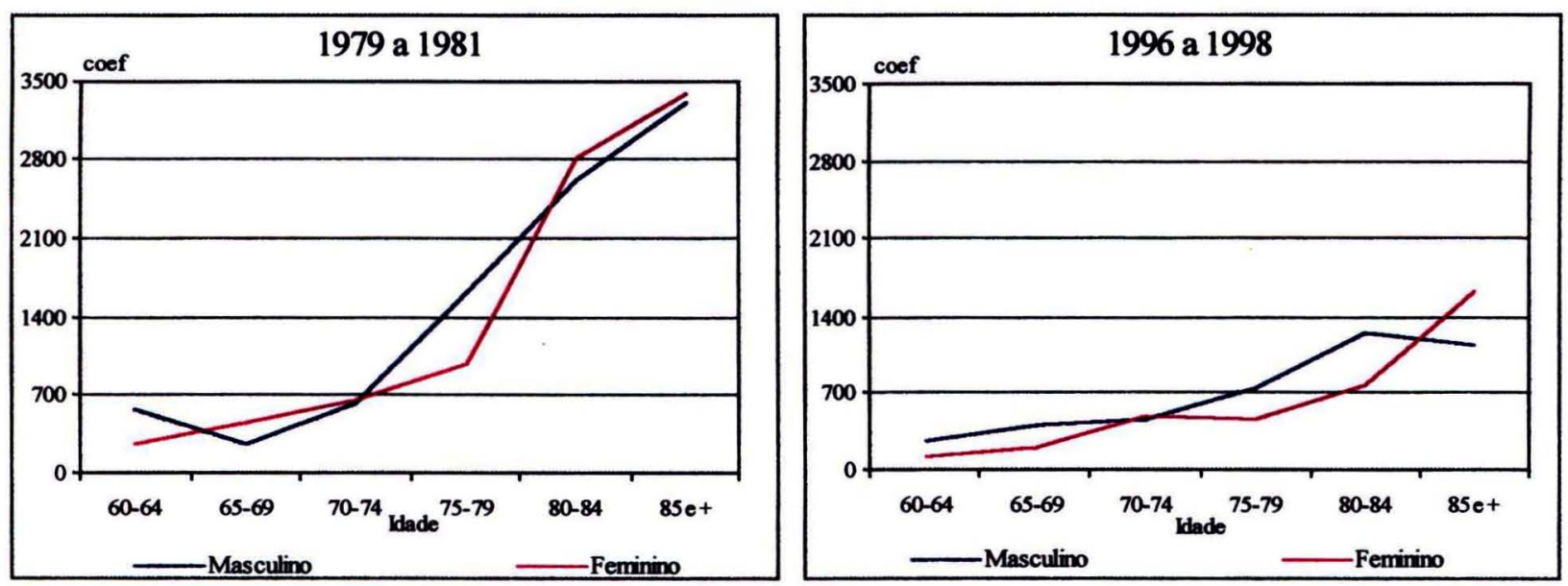
No Brasil, após 1976, a mortalidade por doença isquêmica do coração começou a declinar nas capitais de áreas metropolitanas tanto entre os homens como entre as mulheres. Para o Município de São Paulo no periodo de 1976 a 1983 houve declínio consistente dos coeficientes de mortalidade com tendência contínua observada em todas as idades, após os 20 anos, com redução de $16,8 \%$ nos homens e 27,4\% nas mulheres (LOLIO e LAURENTI 1986).

Em estudo realizado para a população idosa de Botucatu-SP entre 1970 e 1993 também foi constatado decréscimo nos coeficientes de mortalidade que ocorreram com maior intensidade para as pessoas acima de 70 anos de idade para ambos os sexos (RUIZ 1996).

Para o Município de Goiânia a tendência dos coeficientes de mortalidade por doença isquêmica do coração no período de 1980 a 1994 foi de estabilidade até a faixa de 65 a 74 anos e a partir dos 75 anos de idade houve claro declínio para ambos os sexos (MORAES e col. 2000). Mesmo assim, segundo LOTUFO (1998b) as cidades brasileiras têm altas taxas de mortalidade por doenças isquêmicas do coração, principalmente entre as mulheres, quando comparados aos valores de países da Europa e dos Estados Unidos.

SIMONS (1989) em comparação internacional das taxas de mortalidade por doença isquêmica do coração mostrou que, com poucas exceções, em muitos países tem ocorrido queda desse indicador para os "idosos jovens" (65 a 74 anos) e para os "idosos velhos" (75 anos ou mais). Ainda que, em alguns momentos, tenha sido observada melhora expressiva para os "idosos velhos" o que, segundo o autor, é um resultado inesperado e de difícil explicação, as vantagens estão sendo compartilhadas tanto para os segmentos mais jovens como para os mais velhos da população.

Em Maringá os coeficientes de mortalidade em idosos, no último triênio, apresentaram valores maiores para o sexo masculino com exceção de 70 a 74 anos e 85 anos e mais de idade cujo risco foi maior para as mulheres (472,1 contra 445,8 óbitos por 100.000 habitantes de 70 a 74 anos e 1614,8 contra 1139,6 óbitos por 100.000 habitantes de 85 anos e mais).

No Brasil a diferença entre homens e mulheres vítimas de doença coronariana é das menores. Segundo LOTUFO (1998a) tal fato decorre das altas taxas de mortalidade entre as mulheres e não das taxas reduzidas entre os homens. Essa afirmação corrobora conclusão sobre os mitos relativos às doenças cardiovascuiares 
descritos por LAURENTI e BUCHALLA (2001). Os autores comentam que estudos clínicos e epidemiológicos mostram claramente que a doença isquêmica do coração não é doença fundamentalmente do homem mas que ocorre também, de maneira significativa entre as mulheres. A idéia arraigada na população de que esse grupo de doenças incide mais em homens pode também contribuir para que as mulheres subestimem alguns sintomas específicos, impedindo que se faça diagnóstico precoce.

Os três principais fatores de risco para a doença isquêmica são a hipercolesterolemia, o tabagismo e a hipertensão. O determinante principal para a hipercolesterolemia é o consumo de gorduras de origem animal, a alta ingestão de ácidos graxos saturados de qualquer origem e o aumento do peso médio de uma população (LOTUFO 1998a).

Para SIMONS (1989) a queda na mortalidade por doença isquêmica do coração nos grupos de idade mais jovens parece ser atribuída mais à redução da incidência da doença do que à redução do número de casos fatais. Para o grupo dos idosos, segundo o autor, embora estudos de fatores de risco nessa população em particular devam ser feitos, a explicação pode estar na melhora dos níveis de colesterol plasmáticos, hábitos alimentares e hábito de fumar.

SMITH (1998) comenta que a divulgação dos resultados de estudos sobre fatores de risco para doenças isquêmicas do coração, como o de Framingham, influenciaram na mudança de estilos de vida e nas intervenções terapêuticas levando à redução da mortalidade por esta causa.

GOLDMAN e COOK (1984) afirmam que $60 \%$ do declínio da mortalidade por doença isquêmica do coração observado para os Estados Unidos entre 1968 e 1976 , foram resultado de mudanças no estilo de vida, sobretudo na redução nos níveis de colesterol sérico e no controle do tabagismo, enquanto que $40 \%$ foram decorrentes de intervenções médicas específicas sobre estas doenças.

Não existem estudos em relação à história natural da doença e da diminuição da prevalência dos fatores de risco especificamente para a população idosa em nosso meio, portanto ainda não se conhece com precisão, a participação dos fatores envolvidos na determinação do declínio da mortalidade por doença isquêmica do coração. Entretanto, é possível supor que os estudos que demonstram a queda nos níveis de colesterol sérico e da prevalência do tabagismo e ainda, da melhoria da assistência médica ao infartado possam ser extrapolados para a população idosia de 
Maringá que também apresentou nesses vinte anos, nítida queda na estimativa do risco de óbito.

Embora o risco de morrer por doenças cardiovasculares tenha diminuído, outro comportamento vem sendo observado quando a tendência da mortalidade é descrita para período mais recente. LOTUFO (2000) levanta uma importante discussão a respeito da mortalidade por doenças cardiovasculares, em especial da doença isquêmica do coração. $O$ autor apresenta resultados sobre mortalidade em adultos de 40 a 79 anos de idade residentes em áreas metropolitanas do Brasil no período de 1979 a 1998 . Enquanto as taxas por doenças cerebrovasculares vinham mostrando tendências de queda, mesmo no final do período, as relativas às doenças isquêmicas parece que atingiram um limite a partir do qual não têm mostrado evidência de queda. Pode-se dizer que os coeficientes de mortalidade para idosos residentes em Maringá tiveram comportamento semelhante. A mortalidade por doença cerebrovascular segue tendência de queda, mesmo na década de 90, mas para a doença isquêmica do coração, a partir de 1992, as taxas de mortalidade sinalizam para uma tendência estacionária, principalmente no sexo feminino (Gráfico 13). Outra

Gráfico 13 - Coeficientes de mortalidade em idosos (por 100.000 hab.), por doença cerebrovascular e doença isquêmica do coração, segundo sexo e ano, Maringá-PR, 1979-1998.

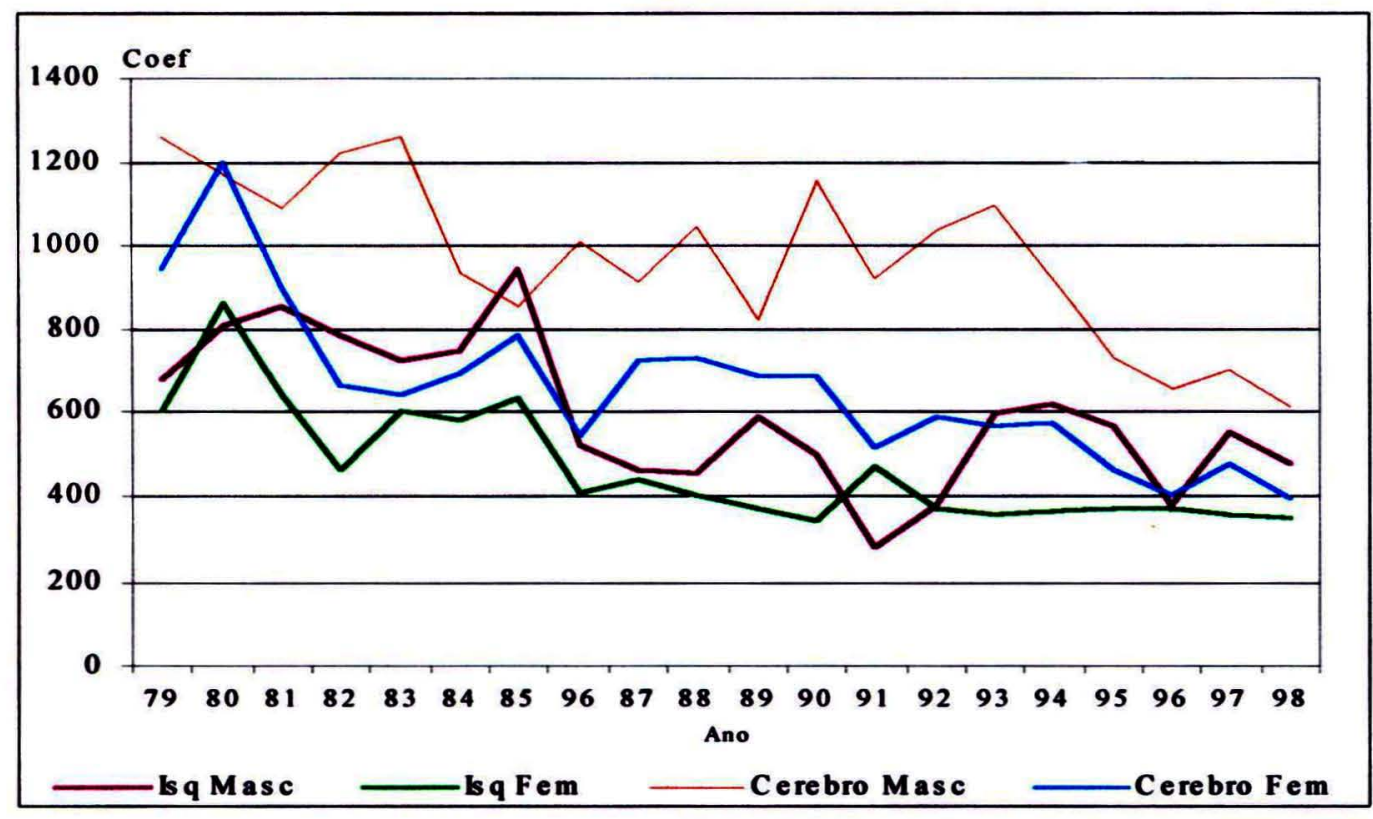


série histórica sobre mortalidade por doença isquêmica do coração em Juiz de ForaMG, apresentada por OLIVEIRA e col. (1999) também mostrou que, a partir de 1990, existe uma nítida inversão da tendência de declínio dos coeficientes para ambos os sexos.

LOTUFO (2000) comenta que, paralelamente ao quadro de queda na mortalidade por doença cardiovascular observada no Brasil, outros estudos vêm mostrando que houve um importante aumento na prevalência da obesidade. Segundo MONTEIRO e col. (2000) a obesidade na população brasileira (índice de massa corporal maior ou igual a $30 \mathrm{~kg} / \mathrm{m}^{2}$ ) aumentou de $2,4 \%$ para $6,9 \%$ para homens e de 7\% para 12,5\% para mulheres, no periodo de 1973-1974 a 1996.

Como conseqüência da obesidade, considerada hoje uma epidemia, ocorre o crescimento da prevalência do diabetes que passou de 4,9\% em 1990 para $6,5 \%$ em 1998 nos Estados Unidos (MOKDAD e col. 2000).

A desaceleração na tendência de queda na mortalidade por doença isquêmica do coração para a população brasileira (LOTUFO (2000) observada também para a população idosa de Maringá poderia refletir em parte, o crescimento da obesidade e do diabetes. Se assim for ou a epidemia da obesidade é controlada ou poderemos assistir, além do aumento da prevalência do diabetes provavelmente, uma inversão na tendência da mortalidade por doenças isquêmicas do coração.

\section{- Outras formas de doenças do coração}

A mortalidade proporcional por outras formas de doenças do coração (CID-9: 420-429 e CID-10: 130-I52) tais como as cardiomiopatias e a insuficiência cardíaca tiveram um pequeno aumento de $3,3 \%$, passando de $9,2 \%$ para $9,5 \%$ do total de óbitos em idosos (Tabela 12). Em relação ao sexo, era a terceira causa de óbito para os homens e mulheres com $8,5 \%$ e $10,2 \%$ do total, respectivamente, no primeiro triênio mas no último passaram a ser a quinta causa mais freqüente para os homens com 7,6\% a segunda para as mulheres com $11,8 \%$ do total de óbitos (Tabela 10). No primeiro triênio os óbitos concentraram-se entre 60 e 74 anos, no sexo masculino, com $27,6 \%$, e entre 70 e 79 anos, no feminino, com $32,7 \%$ e, no último triênio houve aumento da concentração de óbitos nas idades mais avançadas, mais evidente no sexo feminino (Gráfico 14). 
Gráfico 14 - Distribuição percentual dos óbitos em idosos por outras formas de doenças do coração, segundo sexo e idade, por triênios, Maringá-PR, 1979-1998.

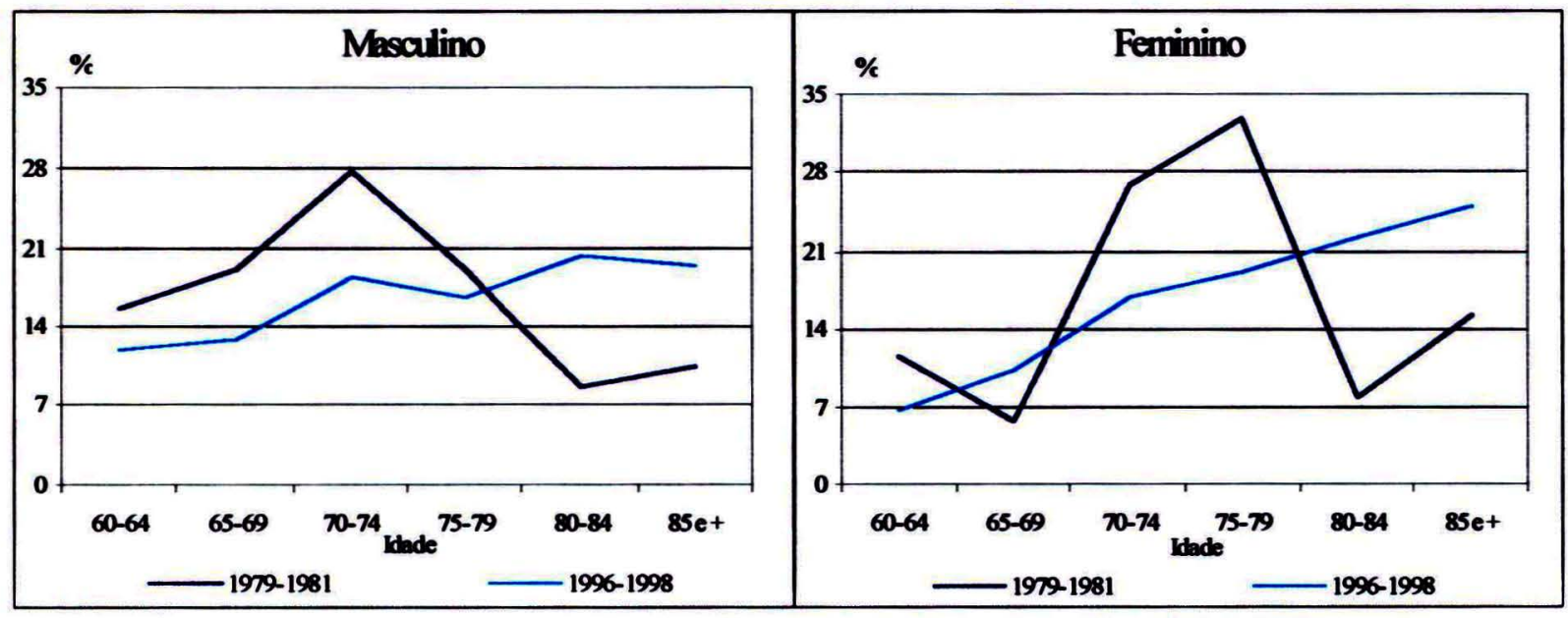

A estimativa do risco de morrer caiu para os dois sexos, mas com maior intensidade no masculino (21\% contra 3,5\% no feminino) (Tabela 12). O Gráfico 15 mostra que para ambos os sexos, houve menor oscilação dos coeficientes no último triênio evidenciando uma curva de mortalidade mais linear em relação às idades, ou seja, assim como para as outras causas os riscos de mortalidade são maiores à medida que avançou a idade. $O$ Gráfico 16 ilustra bem esse comportamento no último triênio com curvas quase justapostas para homens e mulheres. Houve queda na estimativa do risco de morrer para homens de até 79 anos e aumento a partir de 80 anos de idade.

Gráfico 15 - Coeficientes de mortalidade em idosos (por 100.000 hab.) por outras formas de doenças do coração, segundo sexo e idade, por triênios, Maringá-PR, 19791998.
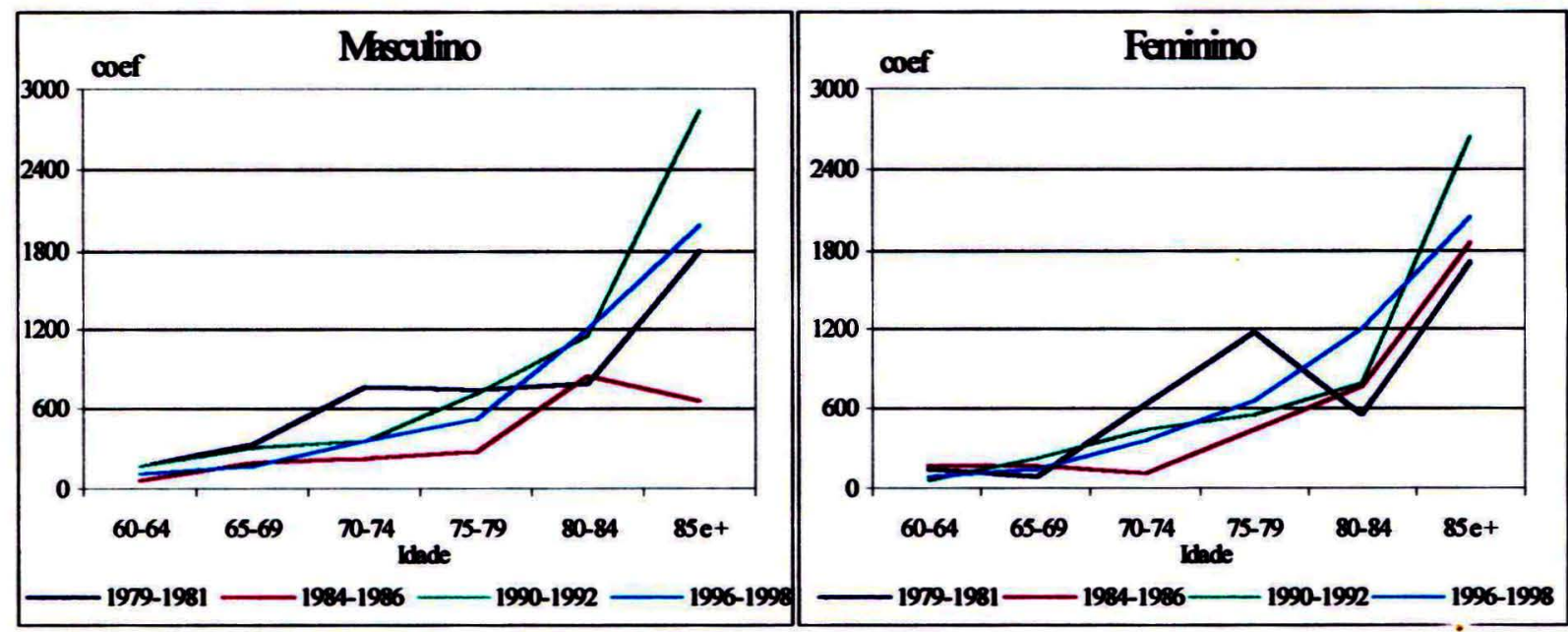
Para às mulheres a queda mais importante ocorreu na faixa de 75 a 79 e aumento, também, a partir de 80 anos de idade, refletindo a mudança da concentração dos óbitos das idades mais jovens para as mais avançadas.

Resultados semelhantes foram descritos por SUTHERLAND e col. (1990), em análise da mortalidade proporcional para os Estados Unidos, entre 1950 e 1986, onde foi encontrado queda no percentual de óbitos por doença isquêmica do coração e aumento nos óbitos por outras formas de doença do coração particularmente na faixa de 85 anos e mais de idade. Segundo os autores essa tendência pode ser explicada por aumentos em patologias definidas previamente como insuficiência cardíaca, transtornos da condução e cardiomiopatia, além do fator idade, que está associado a doenças do coração ainda não identificadas. Uma possibilidade poderia estar relacionada a alterações teciduais resultando em degeneração do miocardio. É possível também que tenha havido uma melhor definição nas causas de óbito e modificação no modo de preenchimento da declaração de óbito.

Gráfico 16 - Coeficientes de mortalidade em idosos (por 100.000 hab) por outras formas de doenças do coração, segundo triênios, sexo e idade, Maringá-PR, 19791998.
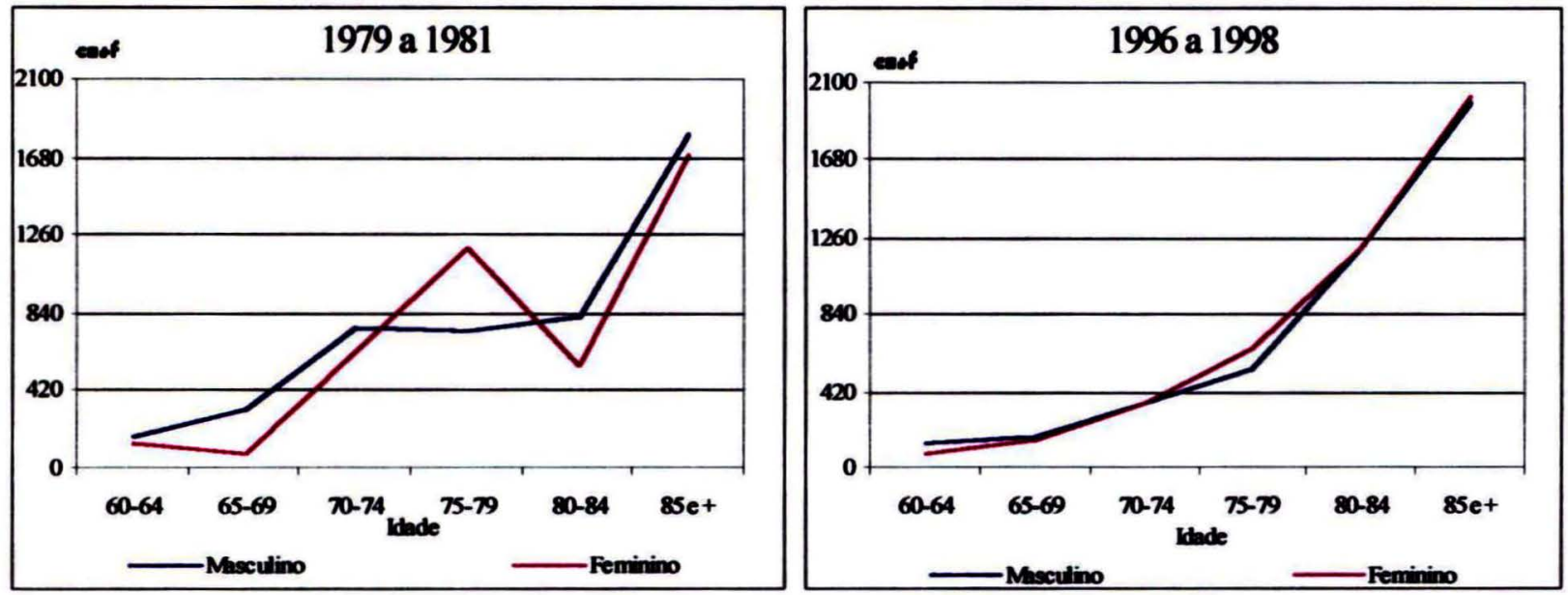

\section{- Hipertensão}

A hipertensão arterial se considerada como causa isolada, é a doença mais freqüente na população adulta em todo mundo industrializado e em países em desenvolvimento, sobretudo em áreas urbanas (LESSA 1998a). 
Estudo sobre fatores de risco para doenças crônicas no Município de São Paulo, em 1987, revelou que na população de 15 a 59 anos $15,8 \%$ dos homens e $7,8 \%$ das mulheres foram considerados hipertensos (REGO e col. 1990); para o Município de Pelotas $18,3 \%$ dos homens e $21,2 \%$ mulheres de 20 a 69 anos eram hipertensos (PICCINI e VICTORA 1994) e em Porto Alegre foi estimada uma prevalência na população acima de 18 anos de 13,1\% em homens e 12,1\% em mulheres (FUCHS e col. 1994). Para o Município de Araraquara, em 1987, LOLIO (1990) encontrou 32\% de hipertensos do sexo masculino e $25,3 \%$ do sexo feminino para a população de 15 a 74 anos e AYRES (1991), em Piracicaba, encontrou prevalência de 33\% nos homens e $32 \%$ nas mulheres acima de 15 anos destacando que entre eles apenas $10 \%$ estavam usando medicamentos.

Segundo LESSA (1998a) não existe nenhum estudo que possibilite qualquer inferência sobre a prevalência da hipertensão arterial para o Brasil pois os que existem não retratam os atributos da população, considerando que as macrorregiões apresentam-se social e economicamente extremamente heterogêneas com desigualdades importantes em vários indicadores de saúde. Mas, após análise dos estudos existentes para regiões do Brasil LESSA (1998a) afirma que a prevalência da hipertensão arterial é elevada, estando muitas vezes entre 20 e $30 \%$.

Por outro lado a hipertensão arterial, como causa de morte, já não é tão importante como no passado devido ao reconhecimento de sua associação com a maioria das doenças cardiovasculares que nesses casos têm prioridade na codificação (LESSA 1998a). Nos Estados Unidos por exemplo, é de apenas 3\% a participação da hipertensão no total dos óbitos (KANNEL 1992). Para o Brasil, em 1979, essa participação foi de 2,39\% para pessoas acima de 15 anos de idade (LAURENTI 1983) e, para o ano de 1988 foi de 2,8\% (LESSA 1998a).

Em Maringá houve um acréscimo no percentual de mortes e nos coeficientes de mortalidade por hipertensão como está disposto na Tabela 13. Esta análise foi feita com intervalos de idade maiores devido ao pequeno número de óbitos.

No triênio 1996-1998 a mortalidade proporcional por hipertensão era apenas $4,6 \%$ do total de óbitos mas, em relação ao primeiro triênio, esse percentual representou um aumento de $87,8 \%$, período em que era a sétima causa mais importante com $2,1 \%$ dos óbitos. As variações, tanto na mortalidade proporcional como nos coeficientes ocorreram para os dois sexos, mas foram bem thiais 
importantes para o sexo feminino. Até 1992 a mortalidade proporcional era semelhante entre os sexos, mas devido ao acréscimo observado entre os triênios extremos, mais significativo no sexo feminino (160\% contra $90 \%$, no sexo masculino) a diferença aumentou e a hipertensão é hoje mais freqüente para os óbitos em mulheres idosas (Tabela 13).

Tabela 13 - Mortalidade proporcional e coeficientes de mortalidade em idosos (por 100.000 hab.), por hipertensão, segundo triênios e sexo, Maringá-PR, 1979-1998.

\begin{tabular}{c|cc|cc|cc}
\hline & \multicolumn{2}{|c|}{ Masculino } & \multicolumn{2}{c|}{ Feminino } & \multicolumn{2}{c}{ Total } \\
\cline { 2 - 7 } Triênio & $\%$ & coef & $\%$ & coef & $\%$ & coef \\
\hline $1979-1981$ & 2,2 & 114,6 & 2,0 & 75,2 & 2,1 & 94,8 \\
$1984-1986$ & 3,5 & 170,5 & 3,4 & 116,1 & 3,5 & 142,5 \\
$1990-1992$ & 3,3 & 159,1 & 3,4 & 114,6 & 3,3 & 135,6 \\
$1996-1998$ & 4,2 & 191,3 & 5,2 & 166,6 & 4,6 & 178,0 \\
\hline $\begin{array}{c}\text { Diferença } \\
\text { (\%) 1996/1998-1979/1981 }\end{array}$ & 90,9 & 66,9 & 160,0 & 121,5 & 119,0 & 87,8 \\
\hline
\end{tabular}

A concentração dos óbitos segundo faixa etária foi maior no grupo de 60 a 79 com tendência de queda para idosos com 80 anos e mais de idade no sexo masculino (Gráfico 17). Observou-se queda da mortalidade proporcional para a faixa de 60 a 69 anos, para o sexo masculino e entre 70 e 79 para o feminino. Os coeficientes de

Gráfico 17 - Distribuição percentual de óbitos em idosos por hipertensão, segundo sexo e idade, por triênios, Maringá-PR, 1979-1998.

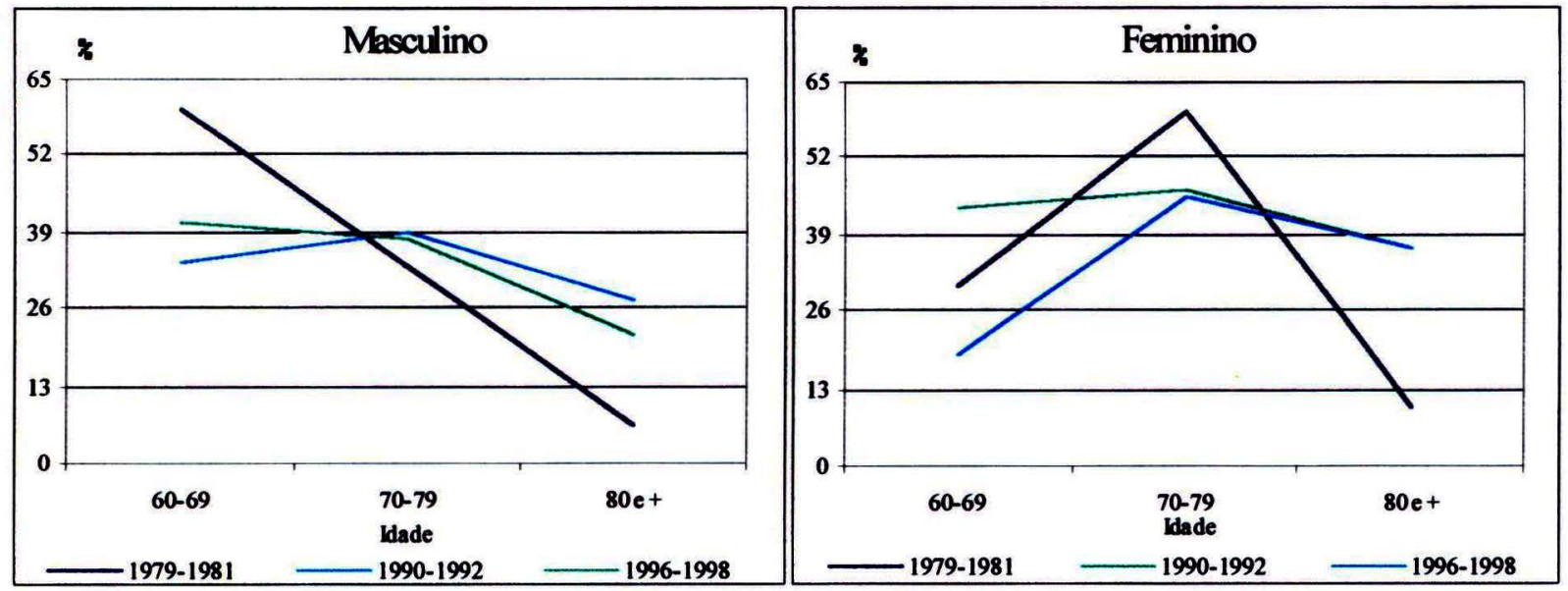


mortalidade foram sempre superiores no sexo masculino, nos quatro triênios estudados, embora o aumento tenha sido mais expressivo no feminino (121,5\% contra 70\% no masculino) (Tabela 13).

O Gráfico 18 deixa claro o aumento da estimativa do risco com a idade. Para os idosos de 60 a 69 anos houve pouca variação no risco de morrer por hipertensão para os quatro triênios, que ficou em torno de 104 óbitos por 100.000 habitantes idosos do sexo masculino e de 35,4 a 51,6 óbitos por 100.000 habitantes do feminino. Foi a partir de 80 anos, em ambos os sexos, que o risco teve importante aumento, de $425 \%$ para os homens e de $526,6 \%$ para as mulheres.

Gráfico 18 - Coeficientes de mortalidade em idosos (por 100.000 hab.), por hipertensão, segundo sexo e idade, por triênios, Maringá-PR, 1979-1998.

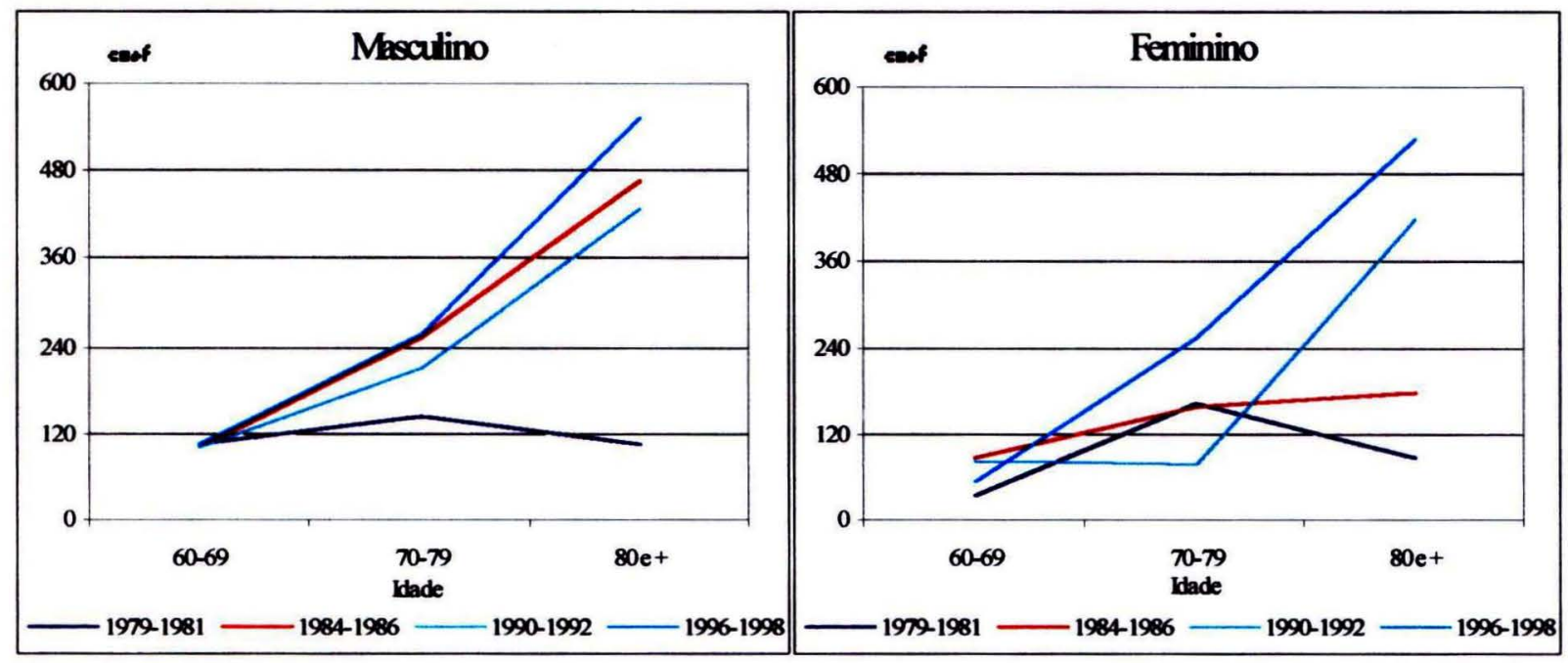

Embora estudos mostrem que a prevalência da hipertensão arterial seja maior para os homens, a mortalidade proporcional no Município de São Paulo, ao contrário, mostrou ser maior para as mulheres, em todas as idades (LAURENTI 1983) o que não foi encontrado para a população idosa de Maringá, com exceção dos óbitos acima de 80 anos de idade, cuja mortalidade proporcional foi maior para o sexo feminino. Observando os dados da Tabela 13 constata-se que a sobremortalidade masculina caiu de 1,5 para 1,1 no período.

Uma das possibilidades que levaria ao aumento da mortalidade proporcional e dos coeficientes de mortalidade por hipertensão, poderia ser atribuída à adoção da $10^{\mathrm{a}}$ Revisão da CID para codificação das causas de óbito, iniciada no ano de $1996 \mathrm{em}$ Maringá. Entretanto, observando os Gráficos 17 e 18 percebe-se que essas 
modificações já vinham ocorrendo no triênio 1990-1992 período ainda, sob vigência da $9^{a}$ Revisão da CID.

Como a literatura aponta para uma queda constante nesses indicadores nas últimas décadas (LAURENTI 1983; LOTUFO 1993) é possível então, que o comportamento da mortalidade por hipertensão não seja homogêneo para todos os grupos populacionais. De fato, como ressalta LAURENTI (1983) a mortalidade por hipertensão aumenta com a idade chegando, para a população com 65 a 74 anos, ser 100 ou mais vezes a da população de 25 a 34 anos de idade.

Assim, a tendência de aumento dos indicadores de mortalidade encontrada para os idosos residentes em Maringá pode refletir características particulares da população estudada e também possíveis modificações no modo do preenchimento da declaração de óbito. Como a uniformidade das práticas diagnósticas e do preenchimento dos atestados de óbito nas duas décadas estudadas não está garantida, é possível de alguma maneira, a sua influência nas mudanças observadas tanto para a hipertensão arterial, como para as outras causas de morte.

Importante salientar que os estudos de mortalidade por hipertensão como causa básica de morte trazem resultados que refletem apenas parte da realidade, pois o fato de ter alta prevalência na população limita sua escolha como causa básica de morte (LUTUFO 1993). Segundo LAURENTI (1983) a hipertensão nem sempre é selecionada como causa básica da morte, ainda que seja informada no atestado de óbito fazendo com que a mortalidade por esta causa esteja sempre subestimada pois, as disposições de codificação e de seleção de diagnóstico não lhe dão prioridade quando existe, conjuntamente, outras patologias registradas, como é o caso do infarto do miocardio, coronariopatia aterosclerótica e qualquer tipo de acidente vascular cerebral. As estatísticas de óbito refletem então, aqueles casos em que a hipertensão apresentou complicações como a cardiopatia hipertensiva ou as complicações renais e consequentemente o óbito. Assim, quando se pretende conhecer a magnitude da hipertensão arterial como patologia associada, a análise da mortalidade por causas múltiplas seria mais adequada, considerando que, nas sociedades ocidentais, a sua prevalência aumenta com a idade (LAURENTI 1983; LOLIO 1990; BOSHUIZEN e col. 1998).

O aumento da prevelência da hipertensão arterial com a idade é um fenômeno ainda não muito bem esclarecido, se é resultado de processo patológico.com 
necessidade de tratamento ou se faz parte do processo natural do envelhecimento. De qualquer forma segundo BOSHUIZEN e col. (1998) o tratamento anti-hipertensivo nos idosos acima de 85 anos de idade é indicado para a prevenção de incapacidades, já que parte do declínio da incidência e da mortalidade por doenças cardiovasculares depende do controle da hipertensão arterial.

Para melhor compreensão do comportamento dos indicadores foi feita análise da mortalidade por outras formas de doenças do coração, hipertensão e doença isquêmica do coração em um mesmo grupo, o grupo das doenças do coração, conforme sugere LOTUFO (1993). O autor recomenda que as causas sejam analisadas também em conjunto, devido à grande proporção de indivíduos que morrem tendo como causa básica "insuficiência cardíaca" ou "miocardiopatia" como conseqüência do infarto do miocárdio associado à hipertensão, o que pode indicar o binômio "doença isquêmica coronariana - hipertensão arterial". Para esta análise a febre reumática ativa e a doença reumática crônica do coração não foram consideradas pois o número de óbitos com essas causas foi muito pequeno.

Para o conjunto das doenças do coração foi observado que houve redução da participação relativa dos óbitos por doenças isquêmicas e aumento da participação das outras formas de doenças do coração e da hipertensão (Tabela 14). Esse fato pode ocorrer devido à migração dos óbitos por doença isquêmica do coração para as outras formas de doenças do coração e para a hipertensão. Os dados da Tabela 13 mostram que se essa migração acontece ela é mais provável para o sexo feminino, cuja diferença relativa entre os triênios extremos foi maior, tanto na mortalidade proporcional como no coeficiente de mortalidade.

Tabela 14 - Distribuição percentual de óbitos em idosos por doenças do coração, segundo diagnósticos e sexo, por triênios, Maringá-PR, 1979-1998.

\begin{tabular}{lccccccccccc}
\hline & & & & & & & & & & \multicolumn{4}{c}{ Diferença (\%) } \\
\hline \multicolumn{1}{c}{ Diagnósticos } & M & F & M & F & M & F & M & F & M & F \\
\hline Isquêmicas & 58,3 & 60,0 & 66,7 & 57,4 & 40,0 & 45,2 & 46,6 & 39,7 & $-20,1$ & $-33,8$ \\
Outras d. coração & 33,1 & 33,5 & 17,7 & 30,2 & 43,6 & 41,7 & 34,4 & 41,8 & 3,9 & 24,8 \\
Hipertensão & 8,6 & 6,5 & 15,6 & 12,4 & 16,4 & 13,1 & 19,0 & 18,5 & 121,0 & 184,6 \\
\hline
\end{tabular}


Situação inversa foi encontrada por LOTUFO (1993) para o Estado de São Paulo, no período de 1970 a 1989, onde houve queda na mortalidade proporcional e nos coeficientes, tanto por outras formas de doenças do coração como por hipertensão. Para o conjunto das doenças do coração houve aumento do peso relativo da doença isquêmica do coração e queda das outras formas de doenças do coração e da hipertensão. Para o risco de óbito por hipertensão, naquele estado, o autor afirma que a queda pode ter sido motivada pelo seu controle mais efetivo, resultado do maior acesso do paciente ao atendimento médico e ao arsenal terapêutico o que, por sua vez, facilitou a definição do diagnóstico e melhorou o preenchimento da DO.

Existe atualmente o reconhecimento de que, durante o século passado, teve início uma grande epidemia relacionada à ocorrência e ao óbito de doenças cardiovasculares que começou a diminuir no final da década de 60 e continua a diminuir até hoje (ROTHENBERG e KOPLAN 1990). Assim, na análise de tendência da mortalidade por doenças cardiovasculares é muito importante que também seja examinado se as mudanças observadas em uma determinada causa poderiam ser explicadas por mudanças em outras, devido às variações no uso dos diagnósticos (OSLER e col. 1996).

O fato em sí, ou seja, a existência de queda na mortalidade por doenças cardiovasculares é amplamente aceito, mas as causas desse fenômeno ainda motivam debates, particularmente pela falta de coleta sistemática de informação sobre a incidência desse grupo de doenças na população. Acredita-se entretanto, que a redução da estimativa do risco de morrer seja devido a uma combinação de fenômenos tais como a queda na prevalência dos fatores de risco, a melhoria no atendimento médico a essas patologias e o aumento na utilização de tecnologias diagnósticas e terapêuticas reduzindo a letalidade e aumentando a sobrevida dos pacientes (ROTHENBERG e KOPLAN 1990; NICHOLLS e col. 1993).

\section{- Neoplasias}

As neoplasias representam hoje, no Brasil, na mortalidade geral a segunda ou terceira causa com $10 \%$ dos óbitos, em média, na maioria das capitais (LATORRE 1997). Para a população masculina a expansão da mortalidade por câncer só perde 
para o aumento das mortes por acidentes e violências e, entre as mulheres é a que mais cresce (FONSECA 1995).

Em Maringá os óbitos em idosos por neoplasias continuam ocupando, desde o início do período, a segunda causa de óbito mais freqüente $(12,5 \%$ e $17,9 \%$ no primeiro e último triênios, respectivamente), mas com queda de $23,6 \%$ na mortalidade proporcional por doenças do aparelho circulatório e aumento de $43,2 \%$ por neoplasias, houve uma aproximação nos valores relativos dessas duas principais causas, que no primeiro triênio tinham uma diferença de 42,7 pontos percentuais e no último caiu para 24,3 pontos percentuais (Tabela 9). O aumento na mortalidade proporcional foi mais expressivo para o sexo masculino $(51,9 \%)$ do que para o feminino (33,6\%). No que concerne à idade e para o sexo masculino, os valores relativos mantiveram-se praticamente a mesma tendência do início do período com os óbitos concentrando-se até os 79 anos e diminuindo em seguida. No sexo feminino a distribuição dos óbitos é semelhante e mesmo com queda da importância dos óbitos de 65 a 74 anos e aumento a partir de 80 anos de idade, os valores relativos mantiveram-se mais altos nas idosas mais jovens (Gráfico 19). O Gráfico 20 evidencia que a estimativa do risco de morrer por câncer cresceu continuamente com

Gráfico 19 - Distribuição percentual dos óbitos em idosos, por neoplasias, segundo sexo e idade, por triênios, Maringá-PR, 1979-1998.

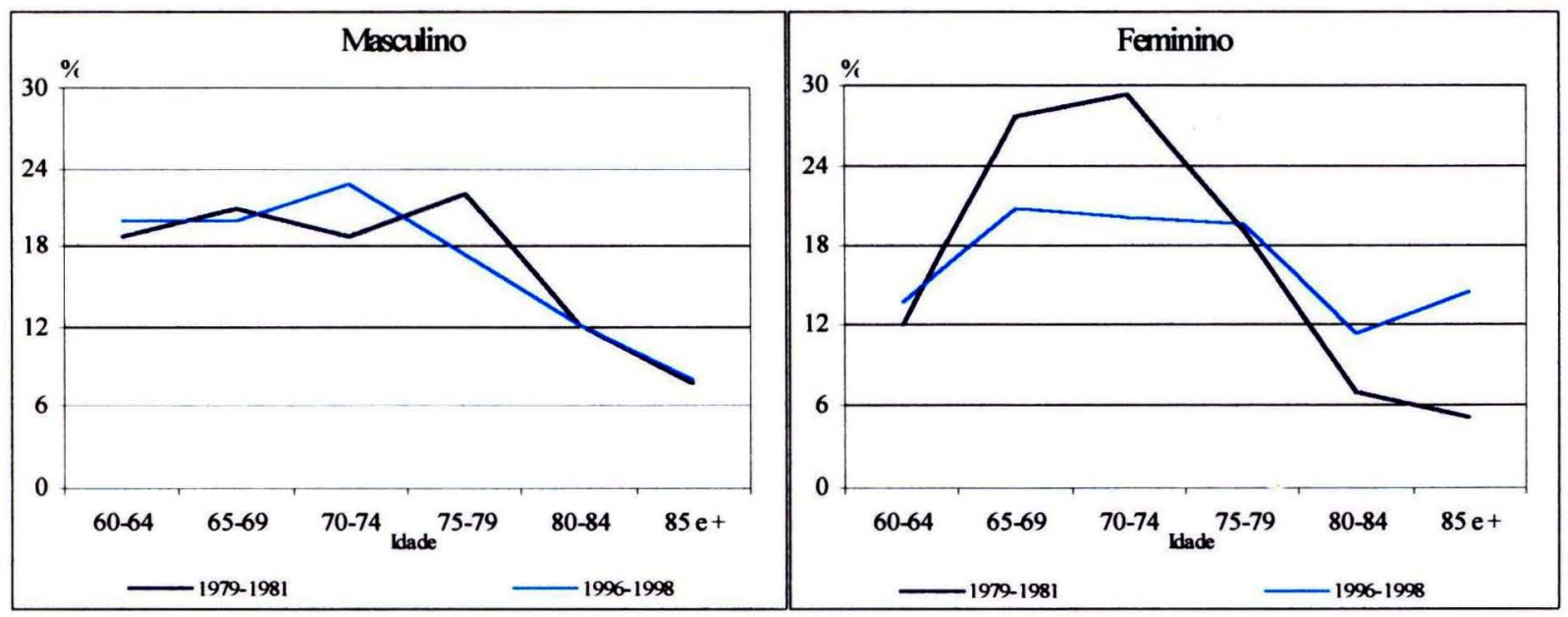

a idade tanto para os homens como para as mulheres. Considerando apenas as linhas relativas ao primeiro e último triênios observou-se que o aumento nas estimativaś do 
risco de morrer por neoplasias, para o sexo masculino, ocorreu em todas as faixas de idade de maneira mais ou menos uniforme. O mesmo não ocorreu para o sexo feminino, registrando pequena queda entre 70 e 74 anos e aumento acima de 80 anos de idade. Foi constante o acréscimo nos coeficientes, para o sexo feminino, que entre 80 a 84 anos passaram de 561,0 para 805,5 e de 85 anos e mais passaram de 636,9 para 1495,2 óbitos, para cada 100.000 habitantes, do primeiro para o último triênio, respectivamente.

A sobremortalidade masculina aumentou de 1,6 para 1,9, mas devido ao incremento de óbitos no sexo feminino, nas idades mais avançadas, a sobremortalidade diminuiu nessas faixas de idade de 3,2 para 2,4, de 80 a 84 anos e de 3,3 para 1,5, acima de 85 anos de idade, do primeiro para o último triênio, o que pode ser melhor visualizado no Gráfico 21 .

Gráfico 20 - Coeficientes de mortalidade em idosos (por 100.000 hab.) por neoplasias, segundo sexo e idade, por triênios, Maringá-PR, 1979-1998.

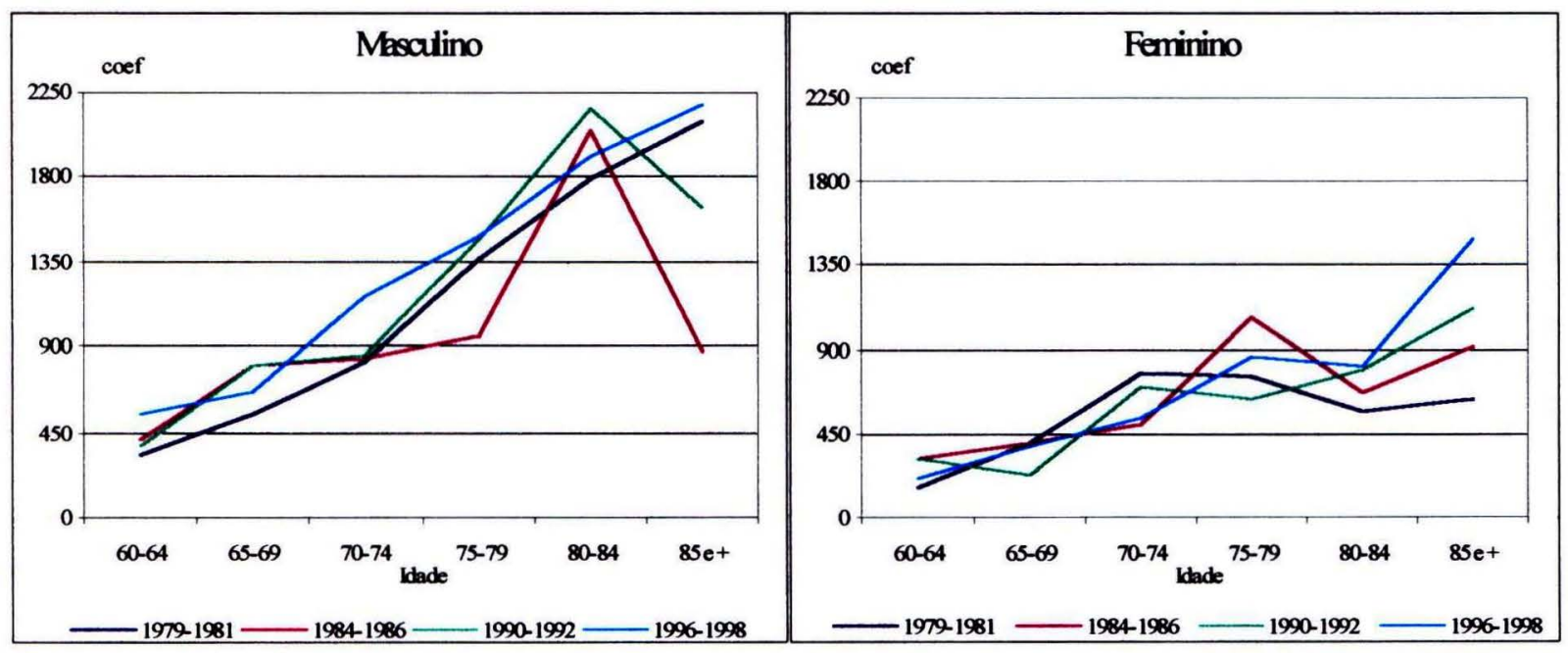

As Tabelas 15, 16 e 17 apresentam os valores relativos e os coeficientes de mortalidade referentes aos principais tipos de câncer, segundo o sexo. As principais modificações para o sexo masculino foram observadas para as neoplasias de estômago, pulmão e próstata que, apesar de continuarem as três localizações anatômicas mais freqüentes, mudaram sua ordem de importância. A mortalidade proporcional por neoplasia de estômago teve variação negativa de $13,4 \%$ entre os triênios extremos, passando de primeiro para terceiro lugar (de $16,4 \%$ para $14,2 \%$.dos 
óbitos); a neoplasia de pulmão aumentou 70,5\% subindo de $3^{\circ}$ para $2^{\circ}$ posto (de $8,8 \%$ para $15 \%$ dos óbitos) e, finalmente, a neoplasia de próstata que, com aumento de $27,4 \%$, passou a ser a localização anatômica mais freqüente (de $12,1 \%$ no primeiro triênio, para 15,3\%, no último) (Tabela 15).

Gráfico 21 - Coeficientes de mortalidade em idosos (por 100.000 hab.), por neoplasias, segundo triênios, sexo e idade, Maringá-PR, 1979-1998.

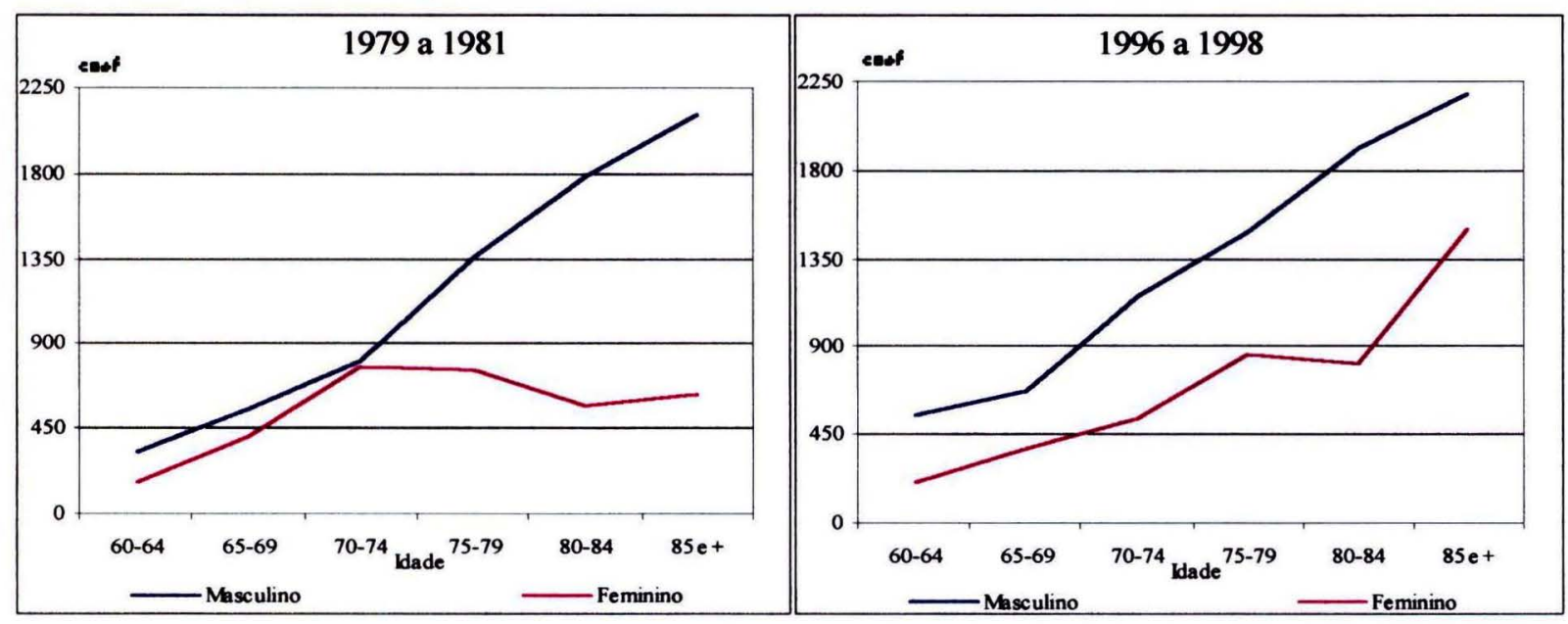

Tabela 15 - Distribuição dos óbitos em idosos por neoplasias, no sexo masculino, segundo principais localizações anatômicas e triênios, Maringá-PR, 1979-1998. (nº e

$\%)$.

\begin{tabular}{|c|c|c|c|c|c|c|c|c|c|}
\hline \multirow[b]{2}{*}{ Localizações } & \multicolumn{2}{|c|}{$1979-1981$} & \multicolumn{2}{|c|}{ 1984-1986 } & \multicolumn{2}{|c|}{ 1990-1992 } & \multicolumn{2}{|c|}{ 1996-1998 } & \multirow{2}{*}{\begin{tabular}{|l|} 
Diferença (\%) \\
$1979 / 81-1996 / 98$ \\
\end{tabular}} \\
\hline & $n^{\circ}$ & $\%$ & $\mathrm{n}^{\circ}$ & $\%$ & $n^{\circ}$ & $\%$ & $\mathrm{n}^{\circ}$ & $\%$ & \\
\hline Próstata & 11 & 12,1 & 12 & 9,5 & 24 & 12,6 & 44 & 15,3 & 26,4 \\
\hline Pulmão & 8 & 8,8 & 18 & 14,3 & 27 & 14,1 & 43 & 15,0 & 70,5 \\
\hline Estômago & 15 & 16,4 & 31 & 24,6 & 46 & 24,1 & 41 & 14,2 & $-13,4$ \\
\hline Cólon / reto & 7 & 7,7 & 7 & 5,5 & 6 & 3,1 & 18 & 6,3 & $-18,2$ \\
\hline Pâncreas & 6 & 6,6 & 4 & 3,2 & 9 & 4,7 & 18 & 6,3 & $-4,5$ \\
\hline Esôfago & 2 & 2,2 & 4 & 3,2 & 22 & 11,5 & 13 & 4,5 & 104,5 \\
\hline Bexiga & 4 & 4,4 & 6 & 4,8 & 7 & 3,7 & 10 & 3,5 & $-20,5$ \\
\hline Out. local. & 32 & 35,2 & 41 & 32,5 & 47 & 24,6 & 90 & 31,4 & $-10,8$ \\
\hline s/ especificação* & 6 & 6,6 & 3 & 2,4 & 3 & 1,6 & 10 & 3,5 & $-47,0$ \\
\hline TOTAL & 91 & 100 & 126 & 100 & 191 & 100 & 287 & 100 & - \\
\hline
\end{tabular}

*Neoplasias de localização e de natureza não especificadas. 
Para o sexo feminino sobressairam-se, no início do período, o câncer de estômago, colo do útero, colon/reto e pâncreas e no final, o de estômago continuou em primeiro lugar $(13,2 \%)$, vindo em segundo o câncer de cólon/reto $(12,1 \%)$ e em terceiro, o câncer de mama (11\%) (Tabela 17). A mortalidade proporcional por câncer do estômago declinou para os dois sexos, mais no feminino $(30,5 \%)$ que no masculino $(13,4 \%)$ e por câncer de pulmão aumentou $70,5 \%$ para o masculino e $85,3 \%$ para o feminino (Tabelas 15 e 16 ).

Tabela 16 - Distribuição dos óbitos em idosos por neoplasias, no sexo feminino, segundo principais localizações anatômicas e triênios, Maringá-PR, 1979-1998.(nº e $\%$ ).

\begin{tabular}{|c|c|c|c|c|c|c|c|c|c|}
\hline \multirow[b]{2}{*}{ Localizações } & \multicolumn{2}{|c|}{$1979-1981$} & \multicolumn{2}{|c|}{$1984-1986$} & \multicolumn{2}{|c|}{ 1990-1992 } & \multicolumn{2}{|c|}{ 1996-1998 } & \multirow{2}{*}{$\begin{array}{l}\text { Diferença (\%) } \\
1979 / 81-1996 / 98 \\
\end{array}$} \\
\hline & $n^{\circ}$ & $\%$ & $\mathrm{n}^{\mathbf{o}}$ & $\%$ & $\mathrm{n}^{\mathrm{o}}$ & $\%$ & $\mathrm{n}^{\mathbf{o}}$ & $\%$ & \\
\hline Estômago & 11 & 19,0 & 10 & 11,2 & 19 & 15,8 & 23 & 13,2 & $-30,5$ \\
\hline Cólon / reto & 5 & 8,6 & 3 & 3,4 & 17 & 14,2 & 21 & 12,1 & 40,7 \\
\hline Mama & 3 & 5,2 & 12 & 13,5 & 15 & 12,5 & 19 & 10,9 & 109,6 \\
\hline Pâncreas & 5 & 8,6 & 5 & 5,6 & 2 & 1,7 & 15 & 8,6 & - \\
\hline Pulmão & 2 & 3,4 & 6 & 6,7 & 12 & 10,0 & 11 & 6,3 & 85,3 \\
\hline Colo do útero* & 7 & 12,1 & 11 & 12,4 & 9 & 7,5 & 8 & 4,6 & $-62,0$ \\
\hline Bexiga & 3 & 5,2 & 5 & 5,6 & - & - & 6 & 3,5 & $-32,7$ \\
\hline Esôfago & 2 & 3,4 & 5 & 5,6 & 4 & 3,3 & 1 & 0,6 & $-82,4$ \\
\hline Out. local. & 15 & 25,9 & 28 & 31,5 & 32 & 26,7 & 62 & 35,6 & 37,5 \\
\hline s/ especificação** & 5 & 8,6 & 4 & 4,5 & 10 & 8,3 & 8 & 4,6 & $-46,5$ \\
\hline TOTAL & 58 & 100 & 89 & 100 & 120 & 100 & 174 & 100 & - \\
\hline
\end{tabular}

*Incluído "neoplasia do útero porção não especificada"

**Neoplasias de localização e de natureza nâo especificadas.

A estimativa do risco de mortalidade no sexo masculino, aumentou para todos os tipos de câncer apresentados, principalmente para o câncer de esôfago, pulmão e próstata que tiveram variação positiva de $175,7 \%, 128 \%$ e $69,6 \%$, respectivamente. Mesmo com essas modificações as neoplasias com maiores riscos de óbito para os homens idosos no último triênio, continuaram a de próstata, pulmão e estômago (Tabela 17, Gráfico 22). Entretanto o estômago já não é a localização mais freqüente entre os óbitos por câncer, nos homens, devido ao importante acréscimo nos coeficientes do câncer de próstata e de pulmão. 
Para as mulheres apesar da redução de $22,8 \%$ no risco de morrer por câncer de estômago essa localização continuou com o coeficiente mais elevado, 63,9 óbitos para cada 100.000 habitantes, no último triênio, vindo a seguir o câncer de cólon/reto, mama e pâncreas com 58,3, 52,8 e 41,7 óbitos por 100.000 habitantes, respectivamente (Tabela 17 , Gráfico 22 ).

O aumento expressivo na estimativa do risco de mortalidade por câncer de mama nas mulheres $(133,6 \%)$ fez com que, de quinta passasse a ser a terceira localização anatômica mais freqüente e o câncer do colo do útero de segunda localização passou a ser a sexta no final do período, com risco de 22,2 óbitos por 100.000 habitantes (Tabela 17). É importante comentar que parte do acréscimo em alguns tipos de câncer observado neste estudo pode ter ocorrido em função da queda nas taxas de mortalidade por neoplasias de localização ou de natureza não especificadas, de aproximadamente $30 \%$ para o sexo masculino e $41 \%$ para o feminino (Tabela 17).

Tabela 17 - Coeficientes de mortalidade em idosos (por 100.000 hab.), por neoplasias, segundo principais localizações anatômicas, sexo e triênios, Maringá-PR, 1979-1998.

\begin{tabular}{|c|c|c|c|c|c|c|c|c|c|c|}
\hline \multirow{2}{*}{$\begin{array}{l}\text { Triênios } \\
\text { Localizações }\end{array}$} & \multicolumn{2}{|c|}{$1979-1981$} & \multicolumn{2}{|c|}{ 1984-1986 } & \multicolumn{2}{|c|}{ 1990-1992 } & \multicolumn{2}{|c|}{ 1996-1998 } & \multicolumn{2}{|c|}{$\begin{array}{c}\text { Diferença (\%) } \\
\text { 1979/81-1996/98 }\end{array}$} \\
\hline & $\mathrm{M}$ & $\mathrm{F}$ & $\mathrm{M}$ & $\mathrm{F}$ & $\mathrm{M}$ & $\mathrm{F}$ & $\mathrm{M}$ & $F$ & $\mathrm{M}$ & $\mathrm{F}$ \\
\hline Próstata & 84,1 & - & 70,6 & - & & - & & - & 69,6 & - \\
\hline Pulmão & 61,1 & 15,0 & 105,8 & 33,2 & 116,1 & 38,2 & 139,4 & 30,5 & 128,0 & 103,3 \\
\hline Estômago & 114,6 & 82,8 & 182,3 & 55,3 & 197,8 & 72,6 & 132,9 & 63,9 & 16,0 & $-22,8$ \\
\hline Cólon/reto & 53,5 & 37,6 & 41,2 & 16,6 & 25 , & 65,0 & 58 & 58,3 & 9,1 & 55,1 \\
\hline Pâncreas & 45,8 & 37,6 & 23,5 & 27,6 & 38,7 & 7,6 & 58,3 & 41,7 & 27,3 & 10,9 \\
\hline Esôfago & 15,3 & 15,0 & 23,5 & 27,6 & 94,6 & 15,3 & 42,1 & 2,8 & 175,7 & $-81,3$ \\
\hline Colo do útero* & - & 52,7 & - & 60,8 & - & 34,4 & - & 22,2 & - & $-57,9$ \\
\hline Mama & - & 22,6 & - & 66,3 & - & 57,3 & - & 52,8 & - & 133,6 \\
\hline Bexiga & 30,6 & 22,6 & 35,3 & 27,6 & 30,1 & - & 32,4 & 16,7 & 6,1 & $-26,2$ \\
\hline Outras localizaç̃es & 244,5 & 112,8 & 241,1 & 182,5 & 202,1 & 122,3 & 291,7 & 188,9 & 19,3 & 52,6 \\
\hline S/ especificação** & 45,8 & 37,6 & 17,6 & 23,5 & 12,9 & 38,2 & 32,4 & 25,9 & $-29,3$ & $-40,9$ \\
\hline TOTAL & 695,3 & 436,3 & 740,9 & 492,1 & 821,3 & 458,6 & 930,3 & 482,2 & 33,8 & 10,8 \\
\hline
\end{tabular}

*Incluído "neoplasia do útero porção não especificada"

**Neoplasias de localização e de natureza não especificadas. 
As neoplasias não constituem entidade nosológica única, mas referem-se a um grupo de doenças diferentes entre si, com possibilidades terapêuticas e preventivas distintas (FONSECA 1995) e apresentam grande variabilidade na sua incidência e mortalidade nas regiões geográficas, tendo em vista suas diferentes etiologias e fatores de risco (ESCOLA NACIONAL DE SAÚDE PÚBLICA 1991).

O padrão de mortalidade das neoplasias segundo ROTHENBERG e KOPLAN (1990) não é tão bem reconhecido como o das doenças cerebrovasculares e cardiovasculares, que têm apresentado contínua queda nos coeficientes desde final dos anos 60, devendo-se ao fato do câncer não representar uma única doença, mas ser um termo utilizado para um conjunto de processos neoplásicos.

Gráfico 22 - Coeficientes de mortalidade em idosos (por 100.000 hab.) por neoplasias, segundo sexo e localização anatômica, por triênios, Maringá-PR, 19791998.
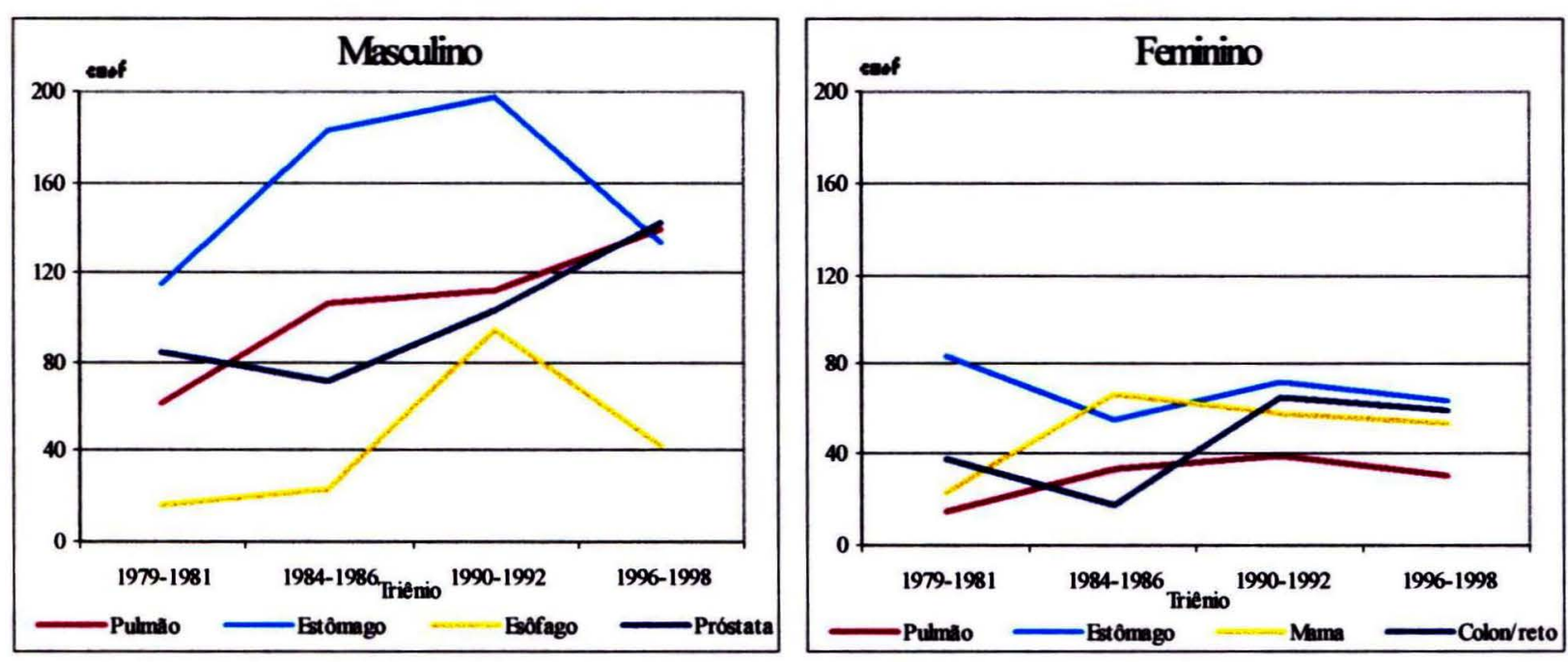

Segundo o Instituto Nacional do Câncer dos Estados Unidos existem mais de 1300 tipos de câncer classificados por localização, tipo de célula e virulência. No entanto, ROTHENBERG e KOPLAN (1990) afirmam que se for considerada como uma doença única as taxas de mortalidade nos Estados Unidos, entre 1976 e 1985 aumentaram, principalmente a partir de 55 anos de idade. Os autores atribuem esse aumento ao câncer do pulmão, que consideram uma epidemia que, para os homens iniciou nos anos 30 e para as mulheres 20 ou 30 anos depois. Parece que, para os homens, essa epidemia alcançou o ponto máximo em 1985 ao passo que para as mulheres ainda continua crescendo, registrando 4,8\% de aumento entre 1976 e 1985 . 
Os autores afirmam que entre as neoplasias se o câncer de pulmão for excluído, as taxas de mortalidade ajustadas por idade apresentaram tendência declinante nos últimos anos.

Por outro lado, em algumas regiões os coeficientes por câncer de pulmão têm registrado queda, como na Inglaterra e País de Gales, entre homens de 35 a 84 anos e mulheres de 35 a 69 anos e nos Estados Unidos em homens de 35 a 44, mas no Japão e na França houve aumento em todas as faixas de idade (MENDONÇA e TEIXEIRA 1998).

Para os Estados Unidos tem sido observado que tanto as taxas de incidência como as de mortalidade têm decrescido. Segundo ROSENTHAL (1998), entre 1990 e 1994, os óbitos por câncer de pulmão, em homens e por câncer de próstata caíram $1,4 \%$ e $0,5 \%$ ao ano, respectivamente. Em relação ao câncer de colon/reto houve queda de $1,9 \%$ para homens e 1,5\% para mulheres e o câncer de mama feminino também diminuiu $1,8 \%$ ao ano. $O$ autor afirma que para as mulheres a taxa de mortalidade por câncer de pulmão continua a apresentar tendência de aumento.

Entre os tipos de câncer que apresentaram tendência mundial ao declínio, em todas as idades, o que mais se destaca é o de estômago e o câncer cérvico-uterino. Para o câncer do estômago as razões ainda não estão bem explicadas mas pode ser resultado das melhoras nas condições de vida da população, da mudança de hábitos alimentares e da substituição do sal e da defumação pela refrigeração na conservação dos alimentos (FONSECA 1995; MENDONÇA e TEIXEIRA 1998). Já, para o câncer cérvico-uterino as quedas registradas em países da América do Norte e Europa, podem ser explicadas pela expansão dos programas preventivos (MENDONÇA e TEIXEIRA 1998).

Contudo, mesmo representando um tipo de câncer facilmente prevenível e detectável nas suas fases iniciais, a taxa de mortalidade por câncer cérvico-uterino no Brasil, não apresentou tendência declinante entre 1979 e 1995, conservando valores altos e estáveis o que leva a acreditar que para algumas regiões, prevalecem serviços de saúde precários não atendendo à mulheres com vistas à detecção precoce e prevenção (MELLO JORGE e GOTLIEB 2000). Quanto menos desenvolvida é uma área o risco de mortalidade por câncer de colo de útero supera o risco por câncer de mama e o contrário ocorre para regiões economicamente mais desenvolvidas, para as 
quais, a mortalidade por câncer de mama é maior do que por câncer do colo de útero (MELLO JORGE e GOTLIEB 2000).

As quedas nos coeficientes por câncer do estômago, esôfago e colo de útero e aumento por câncer de mama, no sexo feminino, foram tendências coerentes com a epidemiologia do câncer que associa a neoplasia de mama às regiões com melhores condições de vida mostrando, de certa forma, o estágio de desenvolvimento da região de Maringá.

A mortalidade proporcional por câncer de estômago diminuiu para ambos os sexos e o coeficiente diminuiu apenas para o sexo feminino (Tabelas 15, 16, 17 e Gráfico 22). Ressalta-se no entanto que, embora o comportamento do coeficiente para o sexo masculino tenha sido de acréscimo até o terceiro triênio, observou-se em seguida importante declínio (Tabela 17, Gráfico 22). Mesmo com essa redução entre os triênios 1990-1992 e 1996-1998, o resultado entre os triênios extremos ainda foi de aumento de $16 \%$ na estimativa do risco para homens idosos (Tabela 17). Esse mesmo comportamento foi também observado para o câncer do esôfago, cujo risco cresceu até o terceiro triênio mas declinou no último, com resultado final de acréscimo de $175,7 \%$, tendência mostrada no Gráfico 22 . É possível que para o homem idoso, a desaceleração da tendência de aumento da estimativa do risco por câncer de estômago e esôfago do terceiro para o último triênio, esteja sinalizando o início de um processo de queda para essa população em Maringá, o que já vem sendo observado para algumas regiões do país (LATORRE 1997).

O câncer de próstata vem aumentando sua participação na mortalidade representando importante causa de óbito em homens de 60 anos e mais de idade residentes em Maringá, pois com acréscimo de $70 \%$ no coeficiente passou a ser a principal localização anatômica. Para o Brasil MELLO JORGE e GOTLIEB (2000) descrevem situação análoga. $O$ coeficiente de mortalidade por câncer de próstata apresentou aumento da ordem de $70 \%$ no periodo de 1979 a 1995, passando de terceira para segunda localização anatômica mais freqüente, de 4 para 6,8 óbitos por 100.000 homens. Para o Rio Grande do Sul, no mesmo período, houve acréscimo de $31 \%$ na mortalidade proporcional e $30 \%$ no coeficiente de mortalidade, para todas as idades, fazendo com que de quarta, passasse a ser a segunda localização mais freqüente no risco de morrer na população masculina (HALLAL 2000). 
Segundo LAURENTI e col. (1998), para países da Região das Américas as taxas de mortalidade por neoplasia maligna de próstata vêm aumentando a partir de 55 anos de idade, sendo este aumento mais acentuado a partir dos 65 anos. No Brasil a taxa de mortalidade passou de 5,6 para 9,6 óbitos por 100.000 homens de 15 anos e mais de idade. Uma das explicações aventadas é que a expansão e melhoria das técnicas de diagnósticos precoce podem ter conduzido à maior detecção desta neoplasia em especial, suposição que pode ser aplicada para outros tipos de neoplasia. Além da idade, que é o único fator de risco para o câncer de próstata para o qual não há dúvidas, têm sido relatadas associações entre a incidência e ingestão de gorduras e carne vermelha (LAURENTI e col. 1998) mas para a prevenção é fundamental o diagnóstico precoce facilitado através da dosagem do PSA (Antígeno Prostático Específico) preconizado após os 50 anos de idade.

O câncer de mama é uma importante causa de morte entre as mulheres e vem aumentando sua participação relativa a partir de 25 anos de idade. Segundo CUNHA (1998) alcançou valores expressivos nas mortes de mulheres de 35 anos e mais até as idades avançadas chegando a representar mais de $23 \%$ dos óbitos por neoplasias no grupo de 35 a 54 anos de idade, no Brasil, em 1995. Para as mulheres com mais de 65 anos, de 9,37\% em 1980, passou para 11,21\% em 1995 do total de óbitos por neoplasias, sendo nesse último ano a primeira causa mais freqüente de morte por neoplasias.

Embora tenham sido registrados aumentos nas taxas de mortalidade por câncer de mama para algumas regiões da população brasileira (FONSECA 1995) em outros países industrializados como os Estados Unidos, Canadá, Áustria, Alemanha e Inglaterra as quedas observadas têm sido atribuídas, principalmente, ao incremento da utilização de exames de mamografia, com diagnóstico precoce e novos tratamentos (METTLIN 1999). Nos Estados Unidos, entre 1990 e 1994 houve queda significativa, principalmente em mulheres mais jovens com média de 1,8\% ao ano (GREENLEE e col. 2000).

$\mathrm{O}$ aumento na estimativa do risco de morrer por câncer de pulmão foi tão importante para os homens como para as mulheres $(128 \%$ e $103,3 \%$, respectivamente) o que, no caso das mulheres, é consistente com a explosão do hábito de fumar por elas adquirido. 
Sabe-se que o câncer de pulmão se expressa, principalmente na velhice e, segundo MORAES (1997) os óbitos em brasileiros, no ano de 1992, concentraram-se em pessoas após os 60 anos de idade. Nas últimas décadas o aumento da mortalidade entre as mulheres é atribuído a sua progressiva incorporação ao mercado de trabalho e à assimilação de hábitos e costumes até então predominantemente masculinos, como o tabagismo.

Situação inversa tem sido registrada em alguns países como nos Estados Unidos onde tem sido observada queda de 1 a $2 \%$ ao ano, de fumantes, mas que, segundo ROTHENBERG e KOPLAN (1990) permanece com taxas preocupantes pois é crescente o número de mulheres jovens que adquirem o hábito de fumar. Os autores comentam que mesmo com os progressos, o hábito de fumar continua sendo o fator de risco isolado mais importante para doenças crônicas na população. No Brasil as previsões são alarmantes para a mortalidade feminina por câncer de pulmão pois estudo realizado na cidade de São Paulo evidenciou aumento de mais de $50 \%$, entre 1971 e 1987 na proporção de mulheres fumantes (REGO e col. 1990).

Conforme MORAES (1997) à velhice somam-se outros fatores de importância como a dificuldade de tratamento do câncer nessa fase da vida, já que a maioria das pesquisas exclui os pacientes com mais de 65 ou 70 anos de idade por causa da gravidade dos efeitos colaterais. Em decorrência o encaminhamento do paciente a centros especializados costuma ser menos criterioso do que para os adultos e jovens, sendo muito comum que muitos velhos tenham o diagnóstico de câncer já na fase avançada da doença. $O$ autor vai mais além, dizendo que esses aspectos contribuem para que entre os velhos a dor devida ao câncer seja uma ocorrência comum, já que ela caracteriza, com algumas exceções, um quadro clínico de câncer avançado. Segundo esse autor calcula-se que $40 \%$ dos pacientes portadores de dor crônica, não cirúrgica devida ao câncer, dela não se aliviem por conta de submedicação, o que se detecta especialmente entre pacientes idosos.

Os fatores que mais influenciaram nas mudanças positivas aqui descritas têm sido debatidos, ou se são devidos aos cuidados com prevenção, detecção precoce, ou as terapêuticas mais agressivas que vêm sendo adotadas em relação às neoplasias. Quaisquer que sejam as principais causas das tendências favoráveis de queda, o desafio deve ser aceito e devem ser somados esforços no sentido de se manter e melhorar ainda mais essas estatísticas (ROSENTHAL 1998). 


\section{- Doenças do aparelho respiratório}

As doenças do aparelho respiratório, durante todo o periodo, foram a terceira causa mais freqüente de óbitos em idosos mas houve aumento da mortalidade proporcional de 118,6\% (Tabela 9) e da estimativa do risco de $84 \%$ (Tabela 18). Entre as doenças do aparelho respiratório destacaram-se a doença pulmonar obstrutiva crônica e a pneumonia que, juntas, representaram $91,5 \%$ e $85,8 \%$ do total de óbitos no grupo, no primeiro e últimos triênios, respectivamente (Tabela 18).

Tabela 18 - Óbitos ( $\mathrm{n}^{\mathrm{0}}$ e \%) e coeficientes de mortalidade em idosos (por 100.000 hab.), por doenças do aparelho respiratório, segundo principais diagnósticos e sexo, por triênios, Maringá-PR, 1979-1998.

\begin{tabular}{|c|c|c|c|c|c|c|c|c|c|c|c|c|c|c|}
\hline \multicolumn{15}{|c|}{ MASCULINO } \\
\hline \multirow[b]{2}{*}{ Diagn } & \multicolumn{3}{|c|}{$1979-1981$} & \multicolumn{3}{|c|}{$1984-1986$} & \multicolumn{3}{|c|}{$1990-1992$} & \multicolumn{3}{|c|}{$1996-1998$} & \multicolumn{2}{|c|}{ Diferença(\%) } \\
\hline & $\mathrm{n}^{\mathrm{o}}$ & $\%$ & coef & $\mathrm{n}^{\mathbf{o}}$ & $\%$ & coef & $n^{\mathbf{0}}$ & $\%$ & coef & & $\%$ & coef & $0 /$ & \\
\hline & 30 & 62,4 & & 50 & 70,4 & 294,0 & 84 & 66,7 & & 108 & 57,7 & & & \\
\hline & 5 & 31,3 & & 12 & 16,9 & 70,6 & 32 & 25,4 & 7,6 & 54 & 28,9 & & & \\
\hline & - & 62 & & 9 & & 52,9 & 10 & 7,9 & & 25 & 13,4 & & & \\
\hline & & 100 & & 71 & & 417.5 & 126 & 100 & & 187 & 100 & & & 5,3 \\
\hline \multicolumn{15}{|c|}{ FEMININO } \\
\hline \multirow[b]{2}{*}{ Diagn } & \multicolumn{3}{|c|}{$1979-1981$} & \multicolumn{3}{|c|}{$1984-1986$} & \multicolumn{3}{|c|}{$1990-1992$} & \multicolumn{3}{|c|}{$1996-1998$} & \multicolumn{2}{|c|}{ Diferença(\%) } \\
\hline & $\mathrm{n}^{\mathbf{o}}$ & $\%$ & coef & $\mathrm{n}^{\mathbf{9}}$ & $\%$ & coef & $\mathrm{n}^{\mathbf{o}}$ & $\%$ & coef & & $\%$ & coef & & \\
\hline & 11 & 170 & & 16 & 42,1 & 88,5 & 44 & 49,4 & & 75 & 52,1 & & 8,9 & 516 \\
\hline & 9 & 9,1 & & 17 & & 94,0 & 39 & 43,8 & & 47 & 32,6 & & & 2, \\
\hline & 3 & 121 & & 5 & 13,2 & 27,6 & 6 & 6,8 & 22,9 & 22 & 15,3 & 61,1 & 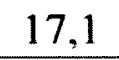 & 170. \\
\hline & 23 & 100 & & 38 & 100 & 210,1 & 89 & 100 & 340,1 & 144 & 100 & & & 1 \\
\hline \multicolumn{15}{|c|}{ OTAL } \\
\hline \multirow[b]{2}{*}{ Diagn } & \multicolumn{3}{|c|}{$1979-1981$} & \multicolumn{3}{|c|}{$1984-1986$} & \multicolumn{3}{|c|}{$1990-1992$} & \multicolumn{3}{|c|}{$1996-1998$} & \multicolumn{2}{|c|}{ Diferença(\%) } \\
\hline & $\mathrm{n}^{\mathbf{0}}$ & $\%$ & coef & $n^{\mathbf{o}}$ & $\%$ & coef & $\mathrm{n}^{0}$ & $\%$ & coef & $\mathrm{n}^{\mathbf{0}}$ & $\%$ & coef & & coel \\
\hline DPOC & 41 & 57,7 & 155,4 & 66 & 60,6 & 188,1 & 128 & 59,5 & 259,0 & 183 & 55,3 & 273,7 & $-4,3$ & 76,1 \\
\hline & 24 & 33,8 & & 29 & 26,6 & 82,6 & 71 & 33,0 & 143,7 & 101 & 30,5 & 151,1 & & 66,1 \\
\hline & 6 & 8,5 & 22,7 & 14 & 12,8 & 39,9 & 16 & 7,5 & 32,4 & 47 & 14,2 & 70,3 & 68,0 & 209,1 \\
\hline Total & 71 & 100 & 269,1 & 109 & 100 & 310,6 & 215 & 100 & 435,0 & 331 & 100 & 495,1 & & 84, \\
\hline
\end{tabular}

*DPOC: Doença pulmonar obstrutiva crônica

A mortalidade proporcional e o coeficiente de mortalidade por doença pulmonar obstrutiva crônica aumentaram 111,8\% e 76,1\% (Tabela 10), nesta c:dem, destacando-se que essa variação foi mais influenciada pelo aumento dos indicadores 
no sexo feminino, cuja diferença foi de $209,5 \%$ para a mortalidade proporcional e de $151,6 \%$ para o coeficiente (Tabela 19). Tais variações foram responsáveis pela mudança de sétimo $(2,1 \%)$ para quinto diagnóstico mais freqüente $(6,5 \%)$ de óbito em mulheres (Tabela 10).

Tabela 19 - Mortalidade proporcional* e coeficientes de mortalidade em idosos (por 100.000 habitantes), por doença pulmonar obstrutiva crônica, segundo sexo, por triênios, Maringá-PR, 1979-1998.

\begin{tabular}{|c|c|c|c|c|c|c|c|c|c|}
\hline \multirow{3}{*}{ Sexo } & \multicolumn{6}{|c|}{ Mortalidade proporcional } & \multirow{2}{*}{\multicolumn{3}{|c|}{ Coeficientes }} \\
\hline & & & I & & & & & & \\
\hline & $n^{0}$ & $\%$ & $n^{\circ}$ & $\%$ & $n^{0}$ & $\%$ & $\mathbf{M}$ & $\mathrm{F}$ & $\mathrm{T}$ \\
\hline $1979-1981$ & 30 & 4,4 & 11 & 2,1 & 41 & 3,4 & 229,2 & 82,8 & 155,4 \\
\hline $1984-1986$ & 50 & 6,0 & 16 & 2,6 & 66 & 4,6 & 294,0 & 88,5 & 188,1 \\
\hline $1990-1992$ & 84 & 7,5 & 44 & 5,0 & 128 & 6,4 & 361,2 & 168,1 & 259,0 \\
\hline $1996-1998$ & 108 & 7,5 & 75 & 6,5 & 183 & 7,1 & 350,1 & 208,3 & 273,7 \\
\hline $\begin{array}{c}\text { Diferença (\%) } \\
1979 / 81 \text {-1996/98 }\end{array}$ & - & 70,5 & - & 209,5 & - & 111,8 & 52,7 & 151,6 & 76,1 \\
\hline
\end{tabular}

*Percentual calculado em relação ao total de óbitos em idosos.

A distribuição percentual dos óbitos por doença pulmonar obstrutiva crônica mostraram que, no sexo masculino, os óbitos eram mais freqüentes entre 65 e 69 anos (26,7\%), no primeiro triênio e, no último, houve um adiamento para a faixa de 75 a

Gráfico 23 - Distribuição dos óbitos em idosos, por doença pulmonar obstrutiva crônica, segundo triênios, sexo e idade, Maringá-PR, 1979-1998.
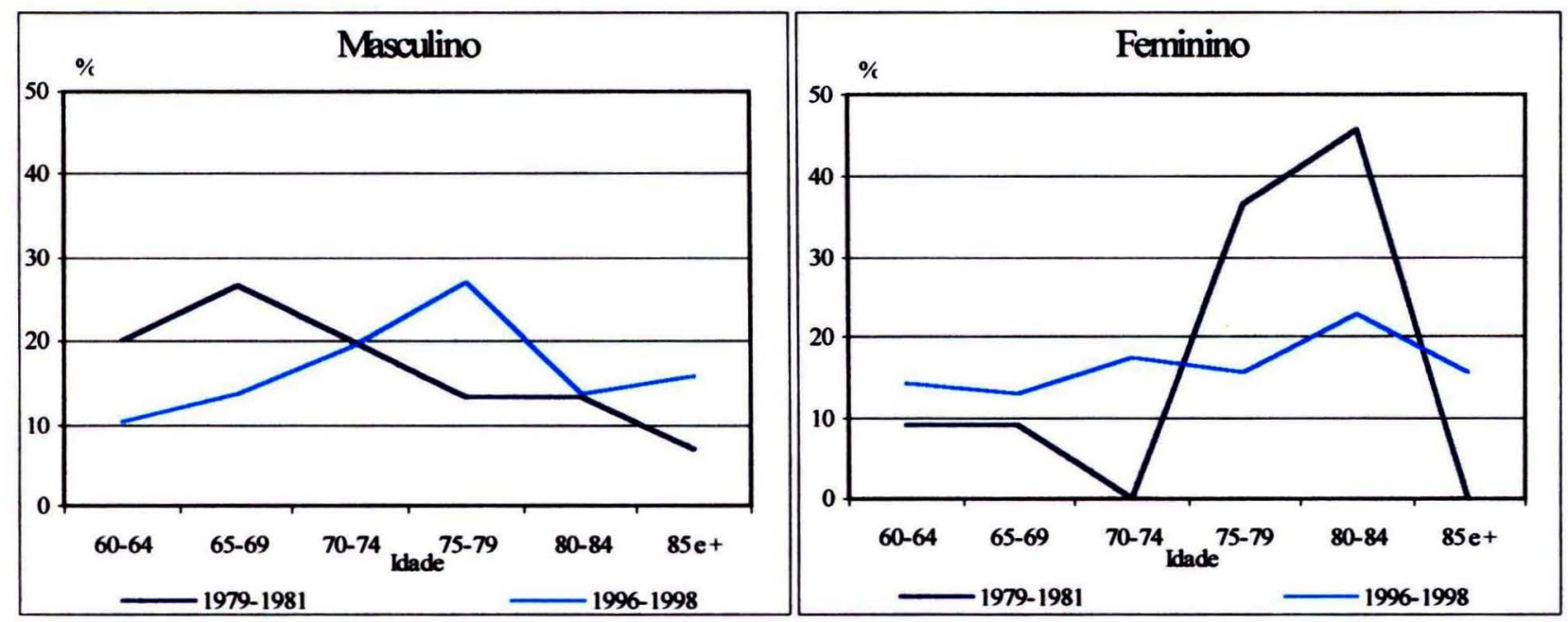
79 anos (26,9\%) (Gráfico 23). Para o sexo feminino foram observadas variações mais importantes devido à não ocorrência de óbitos no primeiro triênio, nas faixas de idade de 70 a 74 anos e 85 anos e mais de idade.

Em relação aos coeficientes de mortalidade, o Gráfico 24 indica taxas ascendentes em relação à idade, para os dois sexos e mais altas para o sexo masculino. Considerando os dois triênios extremos, observou-se que, para os homens, o risco de morrer por doença pulmonar obstrutiva crônica teve acréscimo importante a partir de 80 anos de idade. Na faixa dos mais idosos, de 85 anos e mais, o coeficiente de mortalidade de 600,6 passou para 1614,4 óbitos por 100.000 habitantes. O Gráfico 25 facilita a visualização da sobremortalidade masculina, principalmente nas idades mais avançadas cuja razão de risco, no último triênio, foi de 2,8 para a faixa de 75 a 79 anos e de 2,3 para a faixa de 85 anos e mais de idade.

Gráfico 24 - Coeficientes de mortalidade em idosos (por 100.000 hab.) por doença pulmonar obstrutiva crônica, segundo triênios, sexo e idade, Maringá-PR, 1979-1998.
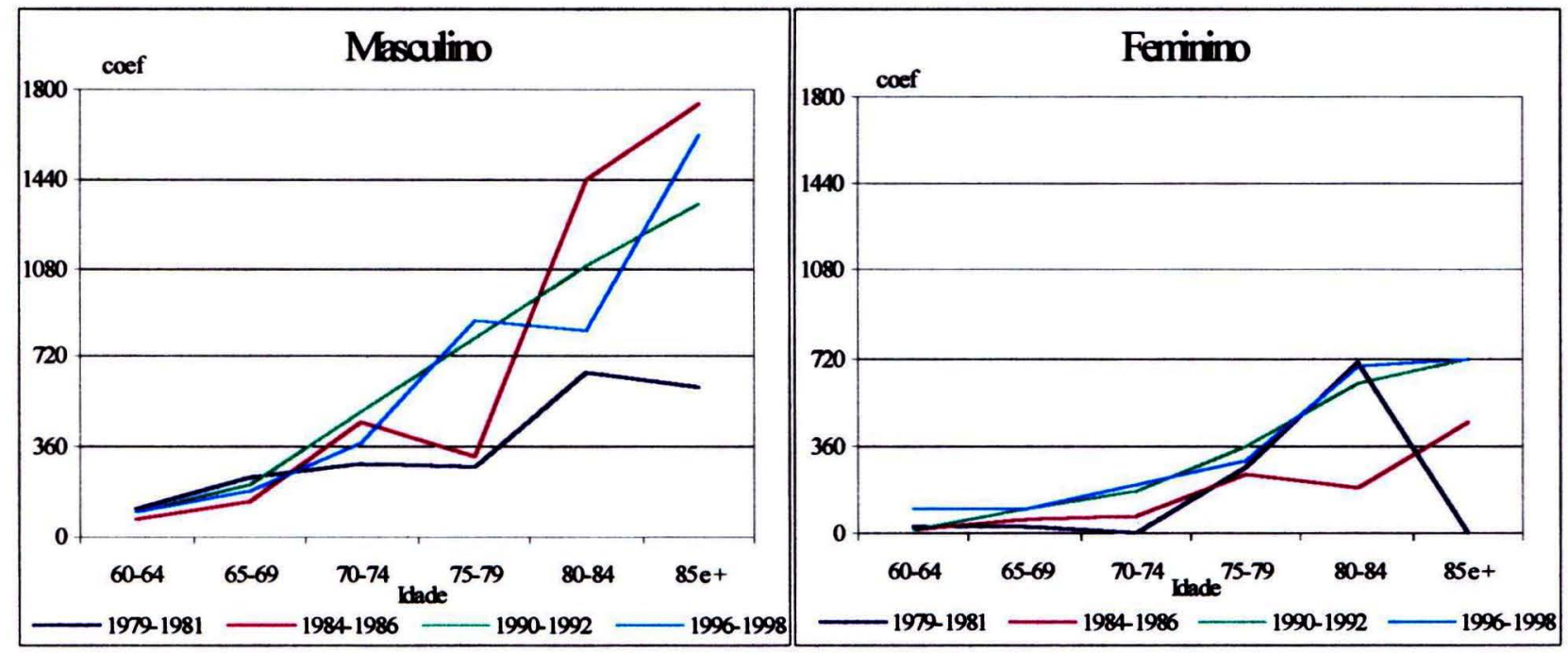

A mortalidade proporcional por pneumonia aumentou de $2 \%$ no primeiro triênio para 3,9\% no último, um acréscimo de $95 \%$ (Tabela 20) e os óbitos se concentraram nas idades mais elevadas, para ambos os sexos como mostra o Gráfico 26. No que concerne aos coeficientes os Gráficos 27 e 28 destacam que não existiu praticamente, nenhuma diferença, entre os sexos, até 74 anos de idade mas, a 
sobremortalidade masculina começa a ficar evidente a partir de 75 anos, fato observado nos dois triênios extremos.

Assim como para a doença pulmonar obstrutiva crônica, para a pneumonia os indicadores apresentaram nítida ascensão e com aumentos mais importantes para o sexo feminino (Tabela 20). Mesmo assim, esse aumento não foi suficiente para que o risco de morrer por doenças do aparelho respiratório ficasse maior nas mulheres, pois a sobremortalidade masculina ainda prevalece, $2,2 \mathrm{em}$ 1979-1981 e 1,5 em 1996-1998 Anexo 4).

Gráfico 25 - Coeficientes de mortalidade em idosos (por 100.000 hab.), por doença pulmonar obstrutiva crônica, segundo triênios, sexo e idade, Maringá-PR, 1979-1998.
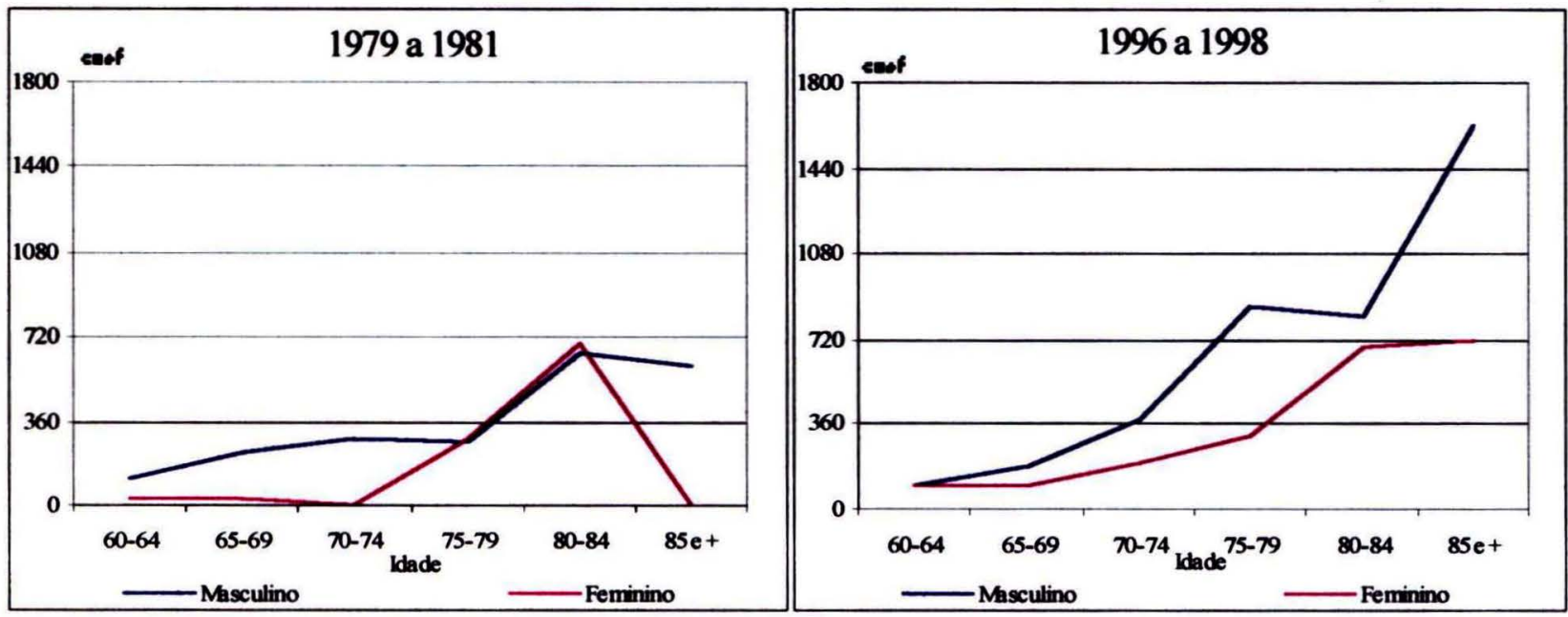

Tabela 20 - Mortalidade proporcional* e coeficientes de mortalidade em idosos (por 100.000 hab.), por pneumonia, segundo sexo, por triênios, Maringá-PR, 1979-1998.

\begin{tabular}{|c|c|c|c|c|c|c|c|c|c|}
\hline \multirow[b]{2}{*}{ Sexo } & \multicolumn{6}{|c|}{ Mortalidade proporcional } & \multirow{2}{*}{\multicolumn{3}{|c|}{ Coeficientes }} \\
\hline & $\mathbf{N}$ & & $\mathbf{F}$ & & 1 & & & & \\
\hline Triênios & $\mathrm{n}^{\mathbf{o}}$ & $\%$ & $\mathrm{n}^{\mathbf{0}}$ & $\%$ & $\mathrm{n}^{\mathbf{o}}$ & $\%$ & $\mathbf{M}$ & $\mathbf{F}$ & $\mathrm{T}$ \\
\hline $1979-1981$ & 15 & 2,2 & 9 & 1,8 & 24 & 2,0 & 114,6 & 67,7 & 91,0 \\
\hline $1984-1986$ & 12 & 1,4 & 17 & 2,8 & 29 & 2,0 & 70,6 & 94,0 & 82,6 \\
\hline $1990-1992$ & 32 & 2,8 & 39 & 4,4 & 71 & 3,5 & 137,6 & 149,0 & 143,7 \\
\hline $1996-1998$ & 54 & 3,8 & 47 & 4,1 & 101 & 3,9 & 175,0 & 130,5 & 151,1 \\
\hline $\begin{array}{c}\text { Diferença (\%) } \\
1979 / 81 \text {-1996/98 }\end{array}$ & - & 72,7 & - & 27,8 & - & 95,0 & 52,7 & 92,8 & 66,0 \\
\hline
\end{tabular}

* Percentual calculado em relação ao total de óbitos em idosos. 
Para o Brasil, conforme relatado por MELLO JORGE e GOTLIEB (2000) as doenças do aparelho respiratório foram também as que mais cresceram como causa de óbito em idosos e de maneira mais importante para as mulheres. De 1979 a 1995 a mortalidade proporcional teve uma variação positiva de $58,7 \%$, para o sexo masculino e de $64,1 \%$, para o feminino e para a região Sul os acréscimos foram de $65,2 \%$ e de $69,6 \%$, para os dois sexos, respectivamente.

Gráfico 26 - Distribuição dos óbitos em idosos por pneumonias, segundo sexo e idade, por triênios, Maringá-PR, 1979-1998.

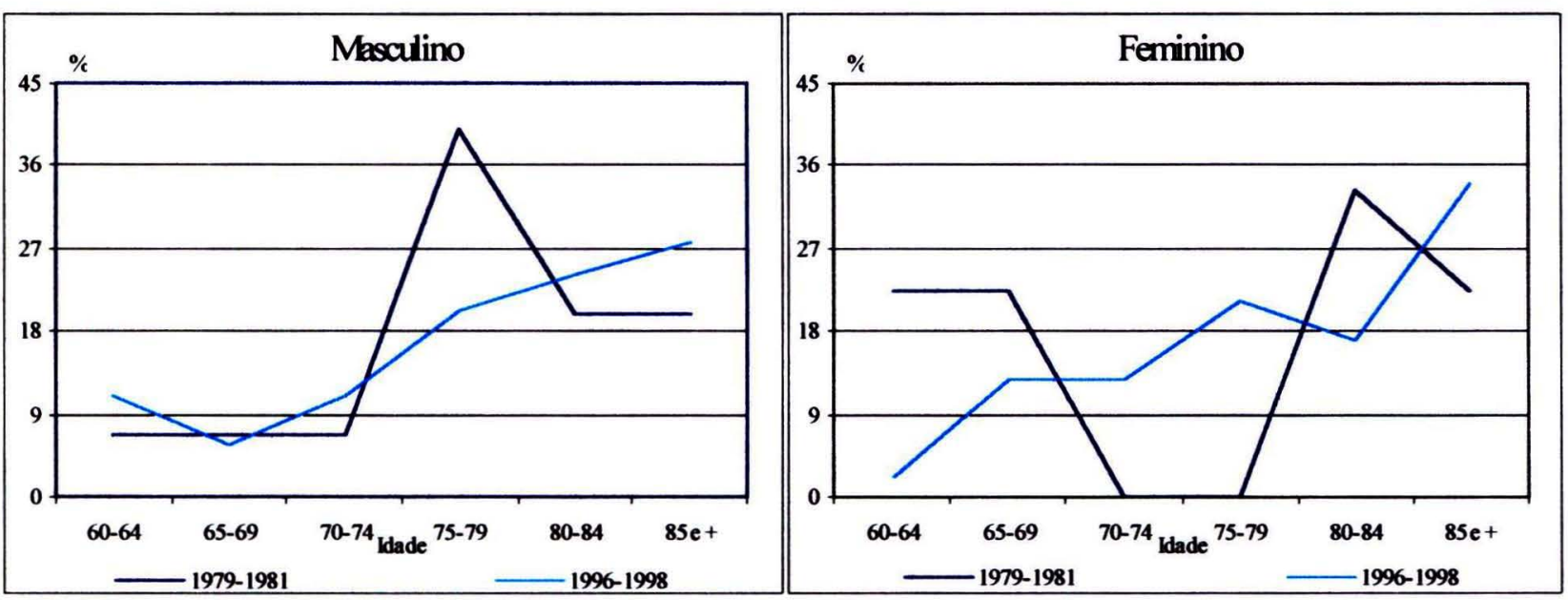

Gráfico 27 - Coeficientes de mortalidade por penumonias em idosos (por 100.000 hab.), segundo sexo e idade, por triênios, Maringá-PR, 1979-1998.
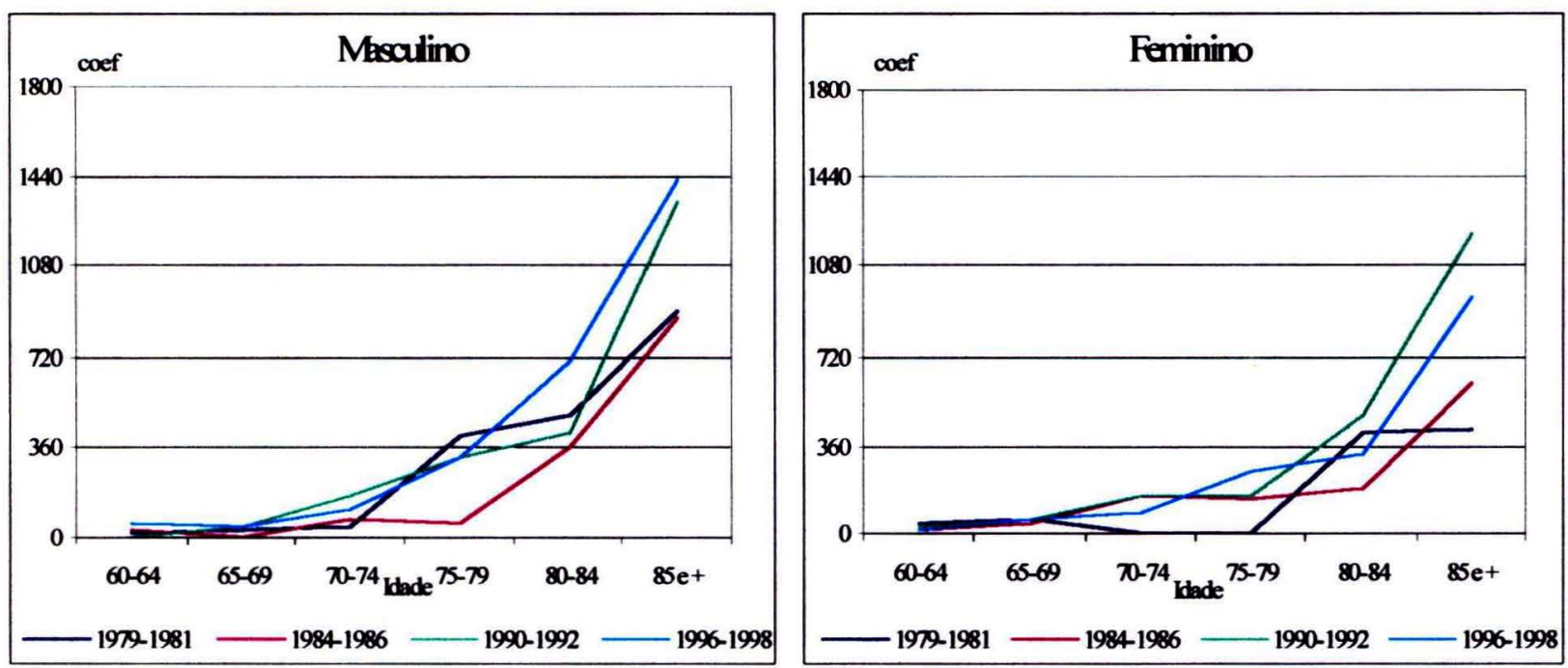
No Município do Rio de Janeiro, entre 1983 e 1994, PARAHYBA (1997) também encontrou sobremortalidade masculina por doenças do aparelho respiratório em idosos e os coeficientes tiveram maior acréscimo para idosos de 80 anos e mais de idade, para os dois sexos e o grupo de idade menos afetado foi o de 60 a 69 anos.

Para as doenças pulmonares obstrutivas crônicas, no Brasil, em 1988 o risco de óbito em pessoas com mais de 20 anos de idade era maior para os homens, em todas as regiões do país. As Regiões Sul e Sudeste apresentavam as mais elevadas taxas de mortalidade pois, apesar das baixas temperaturas e mudanças bruscas de temperatura não serem considerados fatores de risco é nessas regiões que predominam os maiores oscilações climáticas que podem ser fatores precipitantes de episódios mórbidos (LESSA 1998b).

Gráfico 28 - Coeficientes de mortalidade por penumonias em idosos (por 100.000 hab.), segundo triênios, sexo e idade, Maringá-PR, 1979-1998.
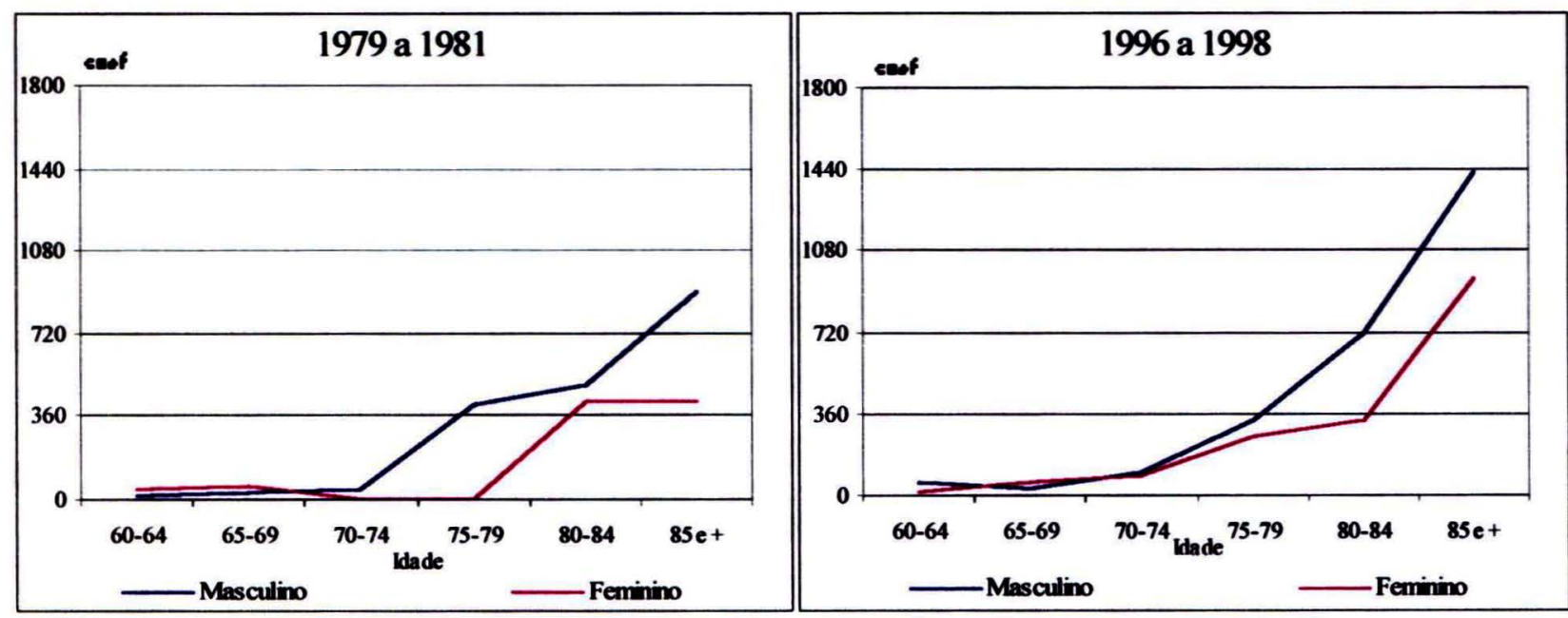

Nos Estados Unidos, entre 1950 e 1990 SMITH (1998) relata que o percentual de óbitos por pneumonia entre pessoas de 70 e 74 anos permaneceu o mesmo, entre 2 e $3 \%$, mas houve um salto de $2 \%$ para $6 \%$ na mortalidade proporcional entre 85 e 89 anos.

VILKMAN e col. (1997) afirmam que a doença pulmonar obstrutiva crônica, juntamente com asma e a pneumonia constituem a terceira causa mais importante de óbitos na Europa. Os dados clínicos e de altas hospitalares sobre pacientes portadores de doença pulmonar obstrutiva crônica indicam que aqueles que precisam de 
tratamento com hospitalização são considerados gravemente doentes. A análise da mortalidade em um grupo de pacientes entre 60 e 69 anos após sua primeira hospitalização por doença pulmonar obstrutiva crônica indicou um prognóstico ruim, principalmente para os homens.

As doenças pulmonares obstrutivas crônicas abrangem, basicamente, duas patologias de origem não-infecciosa, com graus diversificados de severidade: a bronquite crônica e o enfisema. Os fatores de risco mais importantes são o tabagismo, a exposição à poluição ambiental, relacionada ou não à ocupação e ainda, fatores genéticos ou história pregressa de doença pulmonar na infância. Mas de todos esses fatores, o tabagismo parece ser o mais grave e sua prevenção não constitui tarefa fácil. As estratégias de prevenção das doenças pulmonares crônicas são dirigidas para grupos considerados de alto risco, como os fumantes, trabalhadores de indústrias poluidoras do ar e populações residentes em áreas geográficas com poluição atmosférica além do permitido por lei (LESSA 1998b).

Segundo BROWN (1993) a prevenção da pneumonia em idosos envolve, a princípio, orientação quanto aos prejuízos do hábito de fumar e em pacientes hospitalizados é importante a observação do posicionamento do paciente além de evitar alimentação à noite. A vacinação contra o vírus influenza é recomendada para pessoas acima de 65 anos especialmente aquelas com capacidade pulmonar prejudicada, com problemas pulmonares crônicos além dos idosos institucionalizados.

Parte importante dos óbitos por pneumonia e doenças pulmonares crônicas pode envolver agentes infecciosos. Tem sido demonstrado que ocorre com a idade uma importante perda na capacidade imunológica e mais rapidamente nos mais idosos. A ascensão no risco de morrer pode então demonstrar a maior vulnerabilidade e fragilidade do idoso principalmente a partir de 80 anos de idade (HORIUCHI e WILMOTH 1997).

\section{- Doenças endócrinas, nutricionais e metabólicas}

As doenças endócrinas, nutricionais e metabólicas ocuparam o sétimo posto no primeiro triênio, com $2,4 \%$ e no último subiram para o quarto posto com $4,7 \%$ dos óbitos em idosos, significando um acréscimo de $95,8 \%$ na sua importância. No sexo 
masculino a mortalidade proporcional teve um acréscimo de $88,9 \% \quad(1,8 \%$ no primeiro e $3,4 \%$ no último triênio) e no sexo feminino de $90,9 \%$ (3,3\% no primeiro e $6,3 \%$ no último triênio) (Tabela 9 e Anexo 4). A estimativa do risco no início do período, para o sexo masculino, era de 91,7 enquanto que para o feminino era de 127,9 óbitos por 100.000 habitantes idosos. No decorrer do tempo o acréscimo foi maior para os homens $(69,7 \%)$ do que para as mulheres $(58,5 \%)$ (Tabela 21$)$.

Tabela 21 - Óbitos ( $n^{\circ}$ e \%) e coeficientes de mortalidade em idosos (por 100.000 hab.), por doenças endócrinas, nutricionais e metabólicas, segundo principais diagnósticos e sexo, por triênios, Maringá-PR, 1979-1998.

\begin{tabular}{|c|c|c|c|c|c|c|c|c|c|c|c|c|c|}
\hline \multicolumn{14}{|c|}{ MASCULINO } \\
\hline \multirow[b]{2}{*}{ Diagnósticos } & \multicolumn{3}{|c|}{$1979-1981$} & \multicolumn{2}{|c|}{$1984-1986$} & \multicolumn{3}{|c|}{$1990-1992$} & \multicolumn{3}{|c|}{$1996-1998$} & \multicolumn{2}{|c|}{ Diferença $(\%)$} \\
\hline & $\mathrm{n}^{\mathbf{0}}$ & $\%$ & coef & $\mathrm{n}^{\mathrm{o}} \quad \%$ & coef & $\mathrm{n}^{\mathrm{o}}$ & $\%$ & coef & $\mathrm{n}^{\mathrm{o}}$ & $\%$ & coef & $\%$ & coef \\
\hline Diabetes & 6 & 50,0 & 45,8 & 1864,2 & 105,8 & 26 & 76,5 & 111,8 & 35 & 72,9 & 113,5 & 45,8 & 147,8 \\
\hline Def. nutricion & 3 & 25,0 & 22,9 & 17,9 & 29,4 & 7 & 20,6 & 30,1 & 10 & 20,8 & 32,4 & $-16,8$ & 41,5 \\
\hline Demais & 3 & 25,0 & 22,9 & $5 \quad 17,9$ & 29,4 & 1 & 2,9 & 4,3 & 3 & 6,3 & 9,7 & $-61,2$ & $-57,6$ \\
\hline Total & 12 & 100 & 91,7 & 100 & 164,6 & 34 & 100 & 146,2 & 48 & 100 & 155,6 & - & 69,7 \\
\hline \multicolumn{14}{|c|}{ FEMININO } \\
\hline \multirow[b]{2}{*}{ Diagnósticos } & \multicolumn{3}{|c|}{$1979-1981$} & \multicolumn{2}{|c|}{$1984-1986$} & \multicolumn{3}{|c|}{$1990-1992$} & \multicolumn{3}{|c|}{$1996-1998$} & \multicolumn{2}{|c|}{ Diferença(\%) } \\
\hline & $\mathrm{n}^{\mathbf{o}}$ & $\%$ & coef & $\mathrm{n}^{\mathbf{0}} \quad \%$ & coef & $\mathrm{n}^{\mathbf{0}}$ & $\%$ & coef & $\mathrm{n}^{\mathbf{0}}$ & $\%$ & coef & $\%$ & coef \\
\hline Diab & 13 & 76,5 & 97,8 & 76,9 & 110,6 & 46 & 88,5 & 175,8 & 57 & 78,0 & 158,3 & 2,1 & 61,9 \\
\hline Def. nutricion & 1 & 5,9 & 7,5 & 3,9 & 5,5 & 4 & 7,7 & 15,3 & 8 & 11,0 & 22,2 & 86,4 & 196,0 \\
\hline Demais & 3 & 17,6 & 22,6 & 519,2 & 27,6 & 2 & 3,8 & 7,6 & 8 & 11,0 & 22,2 & 37,5 & 1,8 \\
\hline Total & 17 & 100 & 127,9 & 100 & 143,7 & 52 & 100 & 198,7 & 73 & 100 & 202,7 & - & 58,5 \\
\hline \multicolumn{14}{|c|}{ TOTAL } \\
\hline \multirow[b]{2}{*}{ Diagnósticos } & \multicolumn{3}{|c|}{$1979-1981$} & \multicolumn{2}{|c|}{$1984-1986$} & \multicolumn{3}{|c|}{$1990-1992$} & \multicolumn{3}{|c|}{$1996-1998$} & \multicolumn{2}{|c|}{ Diferença(\%) } \\
\hline & $\mathrm{n}^{\mathbf{0}}$ & $\%$ & coef & $\mathrm{n}^{\mathbf{0}} \%$ & coef & $\mathrm{n}^{\mathbf{o}}$ & $\%$ & coef & $\mathrm{n}^{\mathbf{0}}$ & $\%$ & coef & $\%$ & coef \\
\hline Diabetes & 19 & 65,5 & 72,0 & 3870,4 & 108,3 & 72 & 83,7 & 145,7 & 92 & 76,0 & 137,6 & 16,0 & 91,1 \\
\hline Def. nutricion & 4 & 13,8 & 15,2 & 11,1 & 17,1 & 11 & 12,8 & 22,3 & 18 & 14,9 & 26,9 & 8,0 & 77,4 \\
\hline Demais & 6 & 20,7 & 22,7 & $10 \quad 18,5$ & 28,5 & 3 & 3,5 & 6,1 & 11 & 9,1 & 16,5 & $-56,0$ & $-27,3$ \\
\hline Total & 29 & 100 & 109,9 & 100 & 153,9 & 86 & 100 & 174,0 & 121 & 100 & 181,0 & - & 65,0 \\
\hline
\end{tabular}

Mesmo que o número de óbitos por doenças endócrinas, nutricionais e metabólicas em idosos não seja muito expressivo e exista variação no período estudado, para melhor observação, a Tabela 21 apresenta os principais diagnósticos nesse grupo segundo sexo e triênios. A grande maioria dos óbitos foi devidó ao 
diabetes mellitus observando que, $65,5 \% ; 70,4 \% ; 83,7 \%$ e $76 \%$ foram por essa causa, nos quatro triênios, respectivamente. Em segundo lugar aparecem as deficiências nutricionais com 13,8\%, 11\%, 12,8\% e 14,9\% nos quatro triênios, respectivamente. $\mathrm{O}$ coeficiente de mortalidade por diabetes mellitus aumentou de 72 para 137,6 óbitos por 100.000 habitantes idosos e assim como na mortalidade proporcional, foi maior para o sexo masculino com uma diferença relativa de $147,8 \%$ contra $61,9 \%$ no sexo feminino, entre os triênios extremos. Enquanto que, para a maioria das causas de óbito fica evidente a sobremortalidade masculina, para o diabetes mellitus, embora a diferença tenha diminuído é o sexo feminino o que detém ainda, as taxas mais elevadas.

O comportamento do diabetes mellitus em relação às faixas de idade mostra que a proporção de óbitos é maior nas idades mais jovens (Tabela 22 e Gráfico 29).

Tabela 22 - Óbitos ( $\mathrm{n}^{\mathrm{o}}$ e \%) e coeficientes de mortalidade em idosos (por 100.000 habitantes), por diabetes mellitus, segundo sexo e idade, por triênios, Maringá-PR, 1979-1998.

\begin{tabular}{|c|c|c|c|c|c|c|c|c|c|c|c|c|}
\hline \multicolumn{13}{|c|}{ MASCULINO } \\
\hline & \multicolumn{3}{|c|}{ 1979-1981 } & \multicolumn{3}{|c|}{$1984-1986$} & \multicolumn{3}{|c|}{$1990-1992$} & \multicolumn{3}{|c|}{ 1996-1998 } \\
\hline Idade & $\mathrm{n}^{\mathrm{o}}$ & $\%$ & coef & $\mathrm{n}^{\mathbf{o}}$ & $\%$ & coef & $\mathrm{n}^{\mathrm{o}}$ & $\%$ & coef & $\mathrm{n}^{\mathbf{o}}$ & $\%$ & coef \\
\hline $60-69$ & 3 & 50,0 & 35,0 & 9 & 50,0 & 81,9 & 11 & 42,3 & 74,6 & 16 & 45,7 & 84,2 \\
\hline $70-79$ & 2 & 33,3 & 56,2 & 8 & 44,4 & 169,2 & 9 & 34,6 & 135,4 & 12 & 34,3 & 133,8 \\
\hline 80 e mais & 1 & 16,7 & 105,4 & 1 & 5,6 & 77,5 & 6 & 23,1 & 320,5 & 7 & 20,0 & 242,6 \\
\hline Total & 6 & 100 & 45,8 & 18 & 100 & 105,8 & 26 & 100 & 111,8 & 35 & 100 & 113,5 \\
\hline \multicolumn{13}{|c|}{ FEMININO } \\
\hline & \multicolumn{3}{|c|}{$1979-1981$} & \multicolumn{3}{|c|}{$1984-1986$} & \multicolumn{3}{|c|}{ 1990-1992 } & \multicolumn{3}{|c|}{ 1996-1998 } \\
\hline Idade & $\mathrm{n}^{\mathbf{o}}$ & $\%$ & coef & $\mathrm{n}^{\mathbf{0}}$ & $\%$ & coef & $\mathrm{n}^{\mathrm{o}}$ & $\%$ & coef & $\mathrm{n}^{\mathbf{o}}$ & $\%$ & coef \\
\hline $60-69$ & 10 & 76,9 & 118,0 & 8 & 40,0 & 70,9 & 18 & 39,1 & 113,3 & 20 & 35,1 & 93,8 \\
\hline $70-79$ & 3 & 23,1 & 82,5 & 10 & 50,0 & 195,6 & 21 & 45,7 & 274,4 & 17 & 29,8 & 161,5 \\
\hline 80 e mais & - & - & - & 2 & 10,0 & 106,1 & 7 & 15,2 & 267,2 & 20 & 35,1 & 481,3 \\
\hline Total & 13 & 100 & 97,8 & 20 & 100 & 110,6 & 46 & 100 & 175,8 & 57 & 100 & 158,3 \\
\hline \multicolumn{13}{|c|}{ TOTAL } \\
\hline & \multicolumn{3}{|c|}{ 1979-1981 } & \multicolumn{3}{|c|}{ 1984-1986 } & \multicolumn{3}{|c|}{ 1990-1992 } & \multicolumn{3}{|c|}{ 1996-1998 } \\
\hline Idade & $\mathrm{n}^{\mathbf{0}}$ & $\%$ & coef & $\mathrm{n}^{\mathbf{0}}$ & $\%$ & coef & $\mathrm{n}^{\mathbf{0}}$ & $\%$ & coef & $\mathrm{n}^{\mathrm{o}}$ & $\%$ & coef \\
\hline 60 e mais & 19 & 1,6 & 72,0 & 38 & 2,7 & 108,3 & 72 & 3,6 & 145,7 & 92 & 3,6 & 137,6 \\
\hline
\end{tabular}

O Gráfico 29 mostra situações distintas da tendência da mortalidade proporcional segundo o sexo. Para o masculino, no início e no final do período a tendência desse indicador praticamente não mudou, ou seja, a mortalidade 
proporcional diminuiu à medida que aumentou a idade. Para o sexo feminino, devido ao não registro de óbitos na faixa de 80 anos ou mais de idade, no triênio 1979-1981, observou-se maior concentração entre 60 e 69 anos (77\%) e no último, os óbitos se distribuíram de maneira praticamente uniforme em todas as idades, sem tendência de queda nas idades mais avançadas como foi observado para o sexo masculino (Tabela 22 e Gráfico 29).

Gráfico 29- Distribuição percentual dos óbitos em idosos, por diabetes mellitus, segundo sexo e idade, por triênios, Maringá-PR, 1979-1998.
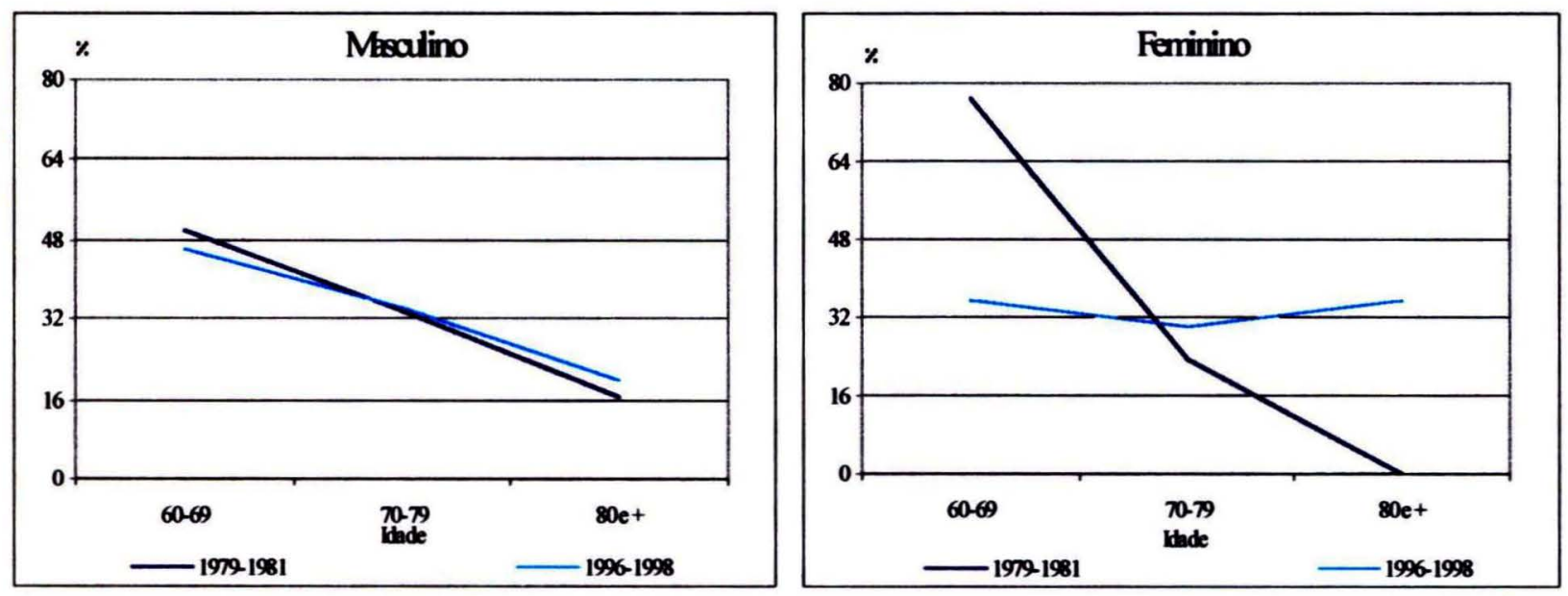

A tendência de aumento na estimativa do risco ocorreu para os dois sexos, maior nos idosos acima de 80 anos (Tabela 22 e Gráfico 30).

Gráfico 30 - Coeficientes de mortalidade em idosos (por 100.000 hab.), por diabetes mellitus, segundo sexo e idade, por triênios, Maringá-PR, 1979-1998.
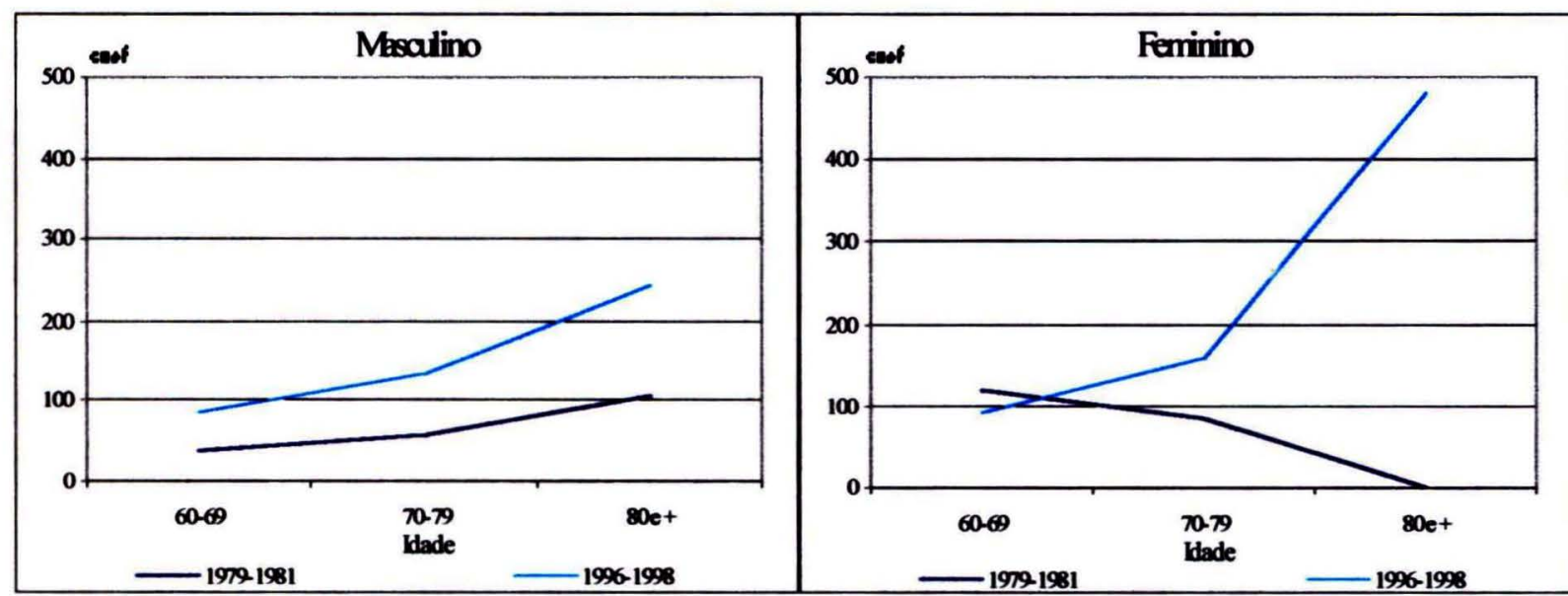
Ao mesmo tempo em que é observada queda na mortalidade geral em idosos por importantes causas como doenças infecciosas e parasitárias e doenças do aparelho circulatório, foram também registrados aumentos na mortalidade por algumas causas que evidenciam a fragilidade de parcela dessa população que está experimentando o aumento da longevidade. Ao lado do aumento nos coeficientes de mortalidade por diabetes, que tem como fator de risco principal a obesidade, observou-se aumento no risco de óbito por deficiências nutricionais, maior nas mulheres do que nos homens (Tabela 21).

Com o envelhecimento, a composição na massa corporal muda e até os $50 \mathrm{ou}$ 60 anos o acúmulo de gordura praticamente dobra (MORIGUTI e col. 2001). Por outro lado, após os 65 ou 70 anos passa a ser comum um aumento de perda de peso, mesmo em indivíduos sadios, levando a uma desnutrição proteico-energética. Embora essa perda de peso faça parte do processo natural de envelhecimento ela deve ser monitorada e investigada. As pessoas idosas que começam a perder peso têm risco aumentado de morte prematura e incapacidades, mesmo excluindo aqueles indivíduos que já apresentavam alguma doença. As possíveis causas da desnutrição, que vão desde problemas sociais de pobreza, problemas psiquiátricos, demência, depressão, alcoolismo, até a presença de outras doenças, devem ser identificadas e tratadas.

$\mathrm{O}$ risco de mortalidade por diabetes maior nas mulheres, observado para os idosos residentes em Maringá foi encontrado também para o Município de Botucatu (RUIZ 1996). FRANCO e col. (1998) analisando os óbitos de pessoas com 40 anos e mais de idade observaram que o diabetes representou aproximadamente $50 \%$ dos óbitos masculinos e quase $80 \%$ dos óbitos femininos no grupo das doenças endócrinas, nutricionais e metabólicas, para a população do Estado de São Paulo. Os autores comentam que uma possível causa para a freqüência ser maior no sexo feminino seria o melhor conhecimento do diagnóstico da doença entre as mulheres o que favoreceria a menção do diabetes na DO.

A prevalência do diabetes nos Estados Unidos e em muitos países da Europa é de aproximadamente $8 \%$ e estima-se que existam mais de 100 milhões de casos no mundo (NATHAN e col. 1997). As complicações decorrentes do diabetes são importantes, destacando-se a doença isquêmica do coração e doenças vasculares periféricas, e são as maiores causas de morbidade e mortalidade nesses pacientes em todo o mundo (LAURENTI e col. 1982, NATHAN e col. 1997). Ainda, o risco de 
morte entre as pessoas com diabetes é maior do que entre as não diabéticas e as doenças isquêmicas do coração ocorrem também mais freqüentemente entre os diabéticos do que entre os não diabéticos (FORD e De STEFANO 1991).

O primeiro censo nacional de diabetes mellitus no Brasil foi conduzido entre 1986 e 1988 em nove capitais brasileiras em uma amostra da população adulta entre 30 e 69 anos de idade. A média geral da prevalência do diabetes para as 9 capitais brasileiras estudadas foi de 7,6\%, variando de $2,7 \%$ para a população de 30 a 39 anos, até $17,4 \%$ para a população de 60 a 69 anos e que, $46 \%$ dos entrevistados não sabiam que eram diabéticos. Segundo o levantamento a prevalência de diabetes mellitus foi maior nas regiões mais industrializadas como Sudeste e Sul (MALERBI e FRANCO 1992).

Quando se analisa o diabetes mellitus como causa básica de óbito deve estar claro que existe elevada subestimação da sua importância (FRANCO e col. 1998 WHITTALL e col. 1990; WILLIAMS e col. 1995). Estudos que objetivam conhecer a real importância dessa patologia na população devem considerar todas as causas citadas na declaração de óbito captando daí, todas as vezes que o diabetes é mencionado no documento. FRANCO e col. (1998) comentam que, para a população do Estado de São Paulo, a análise do diabetes como causa básica representou apenas $1 / 3$ da sua real contribuição para o total de óbitos, sem levar em conta as limitações de qualidade do preenchimento das DO.

A despeito do diabetes ser uma doença comum entre idosos, cerca de metade dos casos não tem diagnóstico estabelecido o que deixa o idoso exposto, inicialmente à hiperinsulinemia e, posteriormente à hiperglicemia e em ambas as fases às complicações crônicas delas decorrentes (BARRETO 1997).

O ganho de peso e o índice de massa corporal são os mais importantes fatores de risco para o diabetes (MOKDAD e col. 2000) que, além de predispor à hipertensão arterial é freqüentemente o primeiro sinal de um futuro diabetes não insulinodependente.

Tem sido descrito para os Estados Unidos um alarmante crescimento da obesidade e como conseqüência um aumento na incidência do diabetes. $O$ crescimento da incidência do diabetes na década de 90 foi da ordem de $33 \%$, ou seja de 4,9\%, em 1990, passou para 6,5\%, em 1998 e com indicação de que a prevalência do diabetes estava fortemente correlacionada com a prevalência da obesidade 
(MOKDAD e col. 2000). Para o Brasil foi também relatado incremento na prevaiência da obesidade de $4,7 \%$ para $6,9 \%$, em homens e de $12 \%$ para $12,5 \%$ em mulheres, principalmente na população urbana (MONTEIRO e col. 2000).

Nesse sentido, é necessária a prevenção e tratamento precoce da obesidade com estímulo aos exercícios físicos e controle da pressão arterial, que iriam contribuir na prevenção de $50 \%$ dos casos de diabetes e de suas complicações como os acidentes vasculares, amputações, doenças renais crônicas e doenças coronarianas (BARRETO 1997). Além disso a prevenção da obesidade e o conseqüente controle do diabetes vão interferir na mortalidade por outras causas. Segundo GU e col. (1999) durante o período de 1971 a 1993, nos Estados Unidos, houve uma queda nas taxas de mortalidade por todas as causas, por doenças do coração e por doença isquêmica do coração, mais expressiva na população não diabética se comparada à diabética.

Considerando que o diabetes é mais freqüentemente diagnosticado entre $45 \mathrm{e}$ 55 anos de idade e que a população idosa no Brasil tende a aumentar, cabe aos serviços básicos de saúde grande responsabilidade na prevenção, investindo na informação com vistas ao estímulo às atividades fisicas, educação alimentar, manejo e tratamento adequado da doença de modo a evitar as complicações crônicas que reduzem sobremaneira a qualidade de vida ou mesmo a sobrevivência do diabético (BARRETO 1997).

O resultado encontrado na mortalidade em idosos residentes em Maringá, mostrando que houve aumento tanto na mortalidade por diabetes quanto por desnutrição pode parecer contraditório, já que o fator de risco mais importante para o diabetes é a obesidade. $O$ importante entretanto é perceber e reconhecer a existência de subconjuntos específicos de idosos na comunidade que apresentam problemas de saúde distintos e que somente um estudo desenhado para captar essas diferenças poderia mostrar com maior clareza tais ocorrências.

\section{- Doenças do aparelho digestivo}

As doenças do aparelho digestivo eram a quarta causa, responsáveis por $5,5 \%$ dos óbitos no primeiro triênio, passando para quinta causa com 4,6\%, no último. Tanto para o sexo masculino como para o feminino a concentração de óbitos foi maior nos idosos mais jovens com tendência de queda à medida que aumentou a 
idade: Para o sexo masculino nos dois triênios e para o feminino em 1996-1998, o maior número de óbitos ocorreu em idosos de 70 a 74 anos de idade (Gráfico 31).

Gráfico 31 - Distribuição percentual dos óbitos em idosos por doenças do aparelho digestivo, segundo sexo e idade, por triênios, Maringá-PR, 1979-1998.
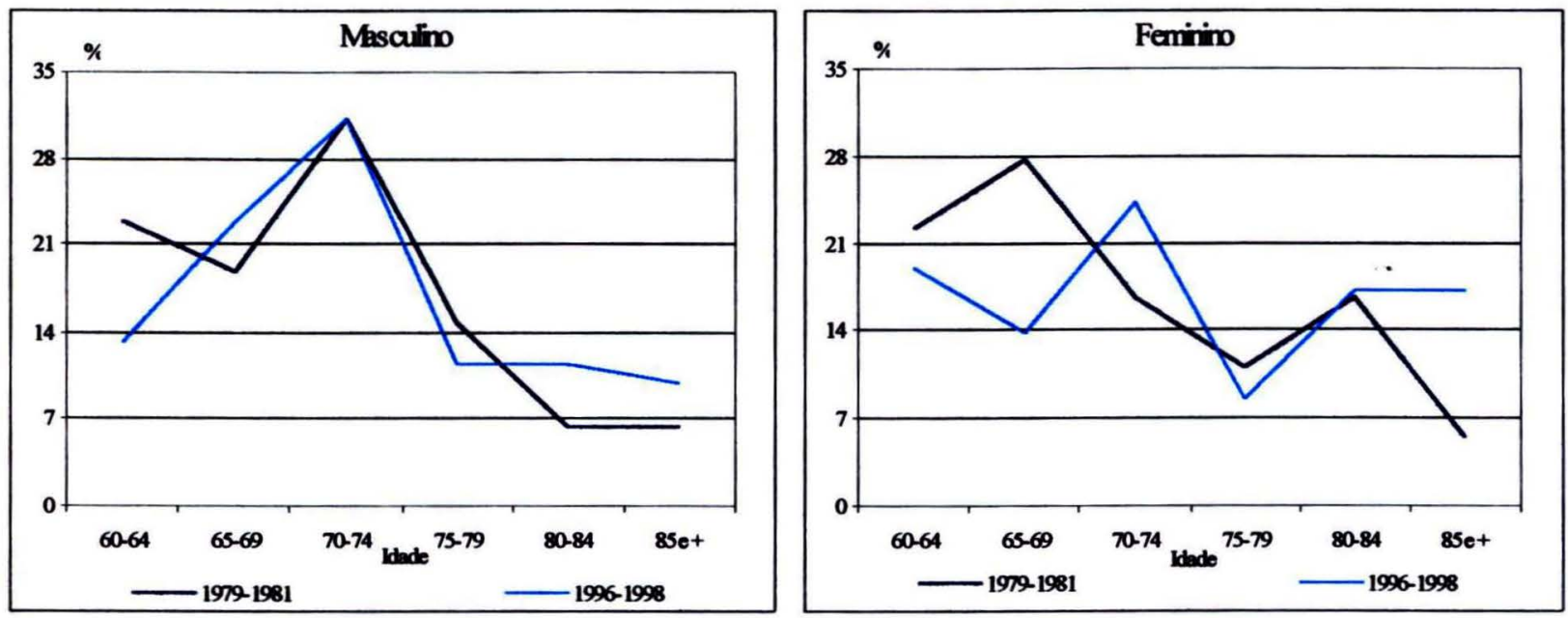

Em relação aos coeficientes de mortalidade foi verificado que de $\mathbf{2 5 0 , 2}$ diminuiu para 178 óbitos por 100.000 habitantes o que significou uma queda de $28,9 \%$. Os Gráficos 32 e 33 indicam que a estimativa do risco aumenta com a idade e tende a ser maior no sexo masculino. Entretanto, no final do período observa-se que o risco é maior para os homens nas idades intermediárias, entre 65 e 79 anos, ao passo que nas idades extremas e ligeiramente superior para o sexo feminino.

Gráfico 32 - Coeficientes de mortalidade em idosos (por 100.000 hab.) por doenças do aparelho digestivo, segundo sexo e idade, por triênios, Maringá-PR, 1979-1998.
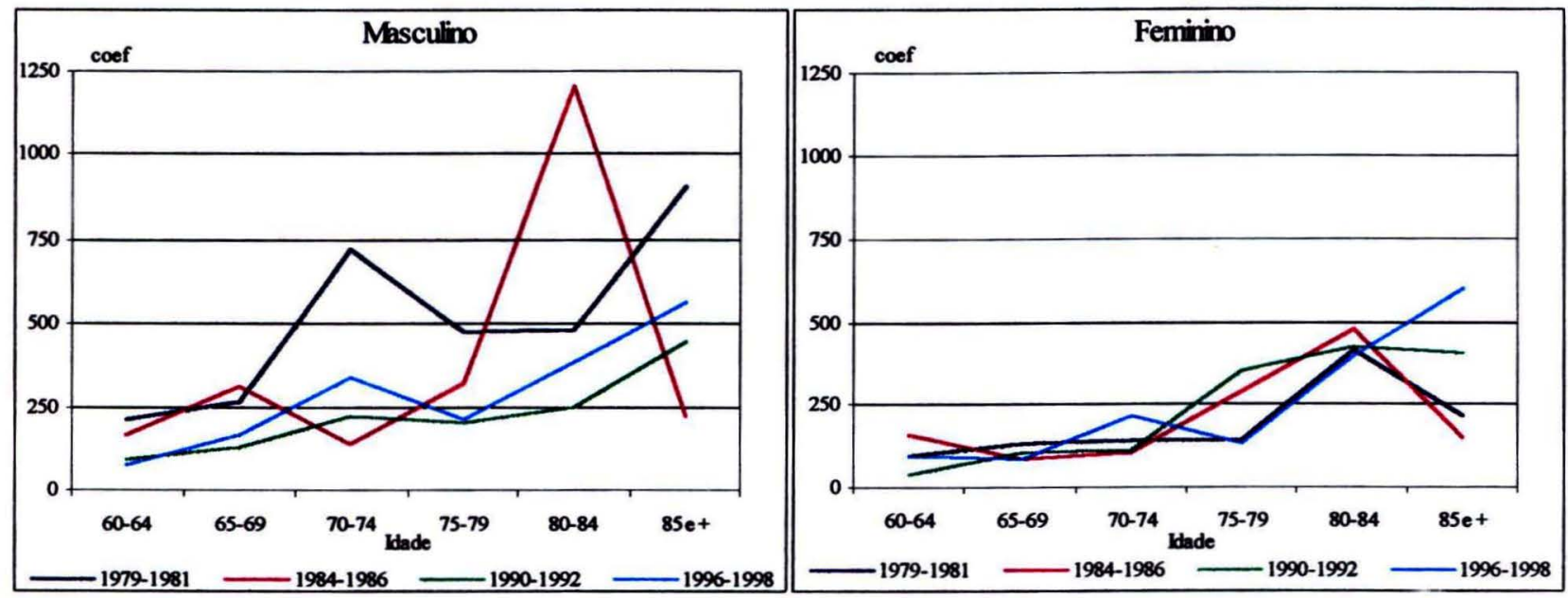
As Tabelas 23, 24 e 25 mostram o peso relativo e os coeficientes de mortalidade dos diagnósticos mais freqüentes entre as doenças do aparelho digestivo. No início do período, no sexo masculino, as doenças dos intestinos $(25 \%)$, do esôfago, estômago e duodeno $(20,8 \%)$ e doenças do figado $(20,8 \%)$ eram as mais freqüentes com valores relativos próximos entre si. No final houve um distanciamento dos percentuais devido ao aumento relativo de $104,8 \%$ das doenças do figado que passam a ser as mais freqüentes com $\mathbf{4 2 , 6 \%}$ do total de óbitos no capítulo (Tabela 23). No sexo feminino, as doenças do figado não são as mais freqüentes, embora tenha havido um aumento relativo de $\mathbf{2 3 , 9} \%$ de óbitos por esta causa entre as doenças do aparelho digestivo. Os transtornos da vesícula e das vias biliares e do pâncreas foram mais freqüentes no início do período $(33,3 \%)$ e as doenças dos intestinos no final $(24,1 \%)$ (Tabela 24$)$.

Gráfico 33 - Coeficientes de mortalidade em idosos (por 100.000 hab.), por doenças do aparelho digestivo, segundo triênios, sexo e idade, Maringá-PR, 1979-1998.
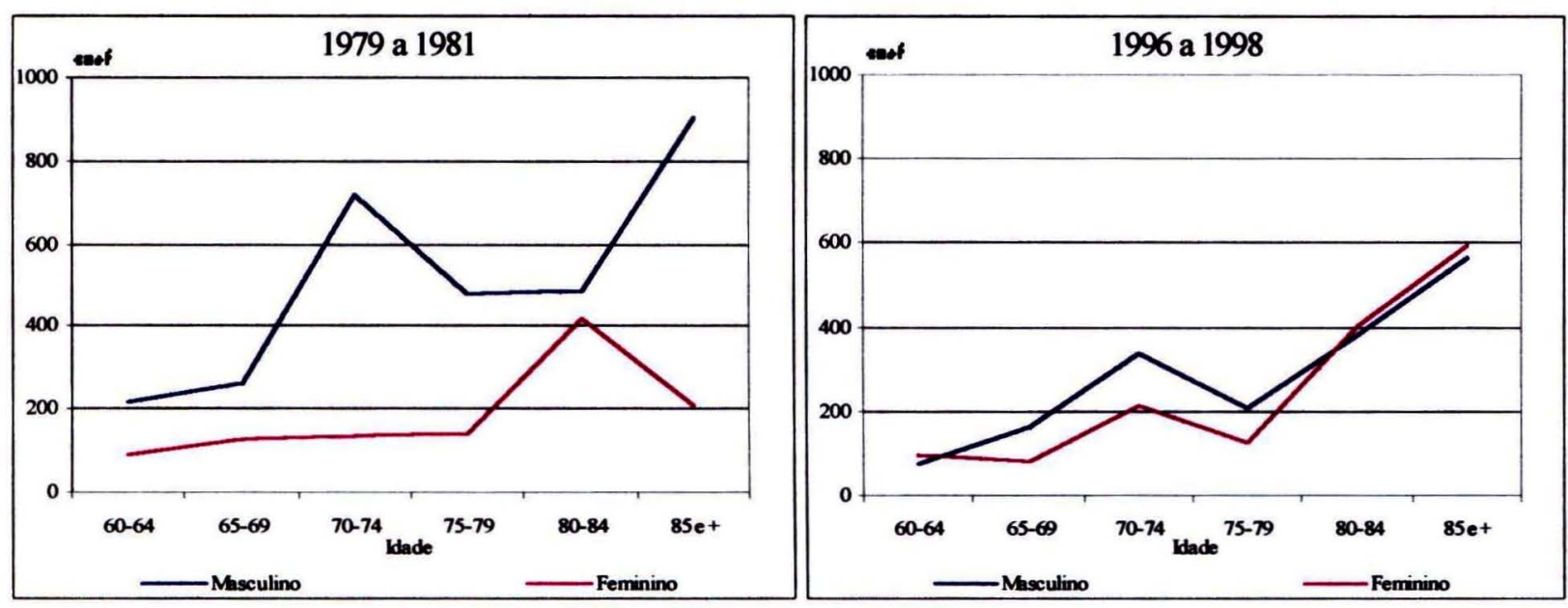

A Tabela 25 indica que houve queda na estimativa do risco para alguns diagnósticos mas que, para a hemorragia gastrintestinal e para as doenças do figado houve aumento (83,3\% e $15,2 \%$, respectivamente). Ressalta-se que o perfil de mortalidade por doenças do aparelho digestivo no triênio 1996-1998 é distinto entre os sexos. Para o sexo masculino observou-se que a estimativa do risco de óbito é maior para as doenças do figado seguida das doenças dos intestinos e da hemorragia gastrintestinal $(84,3 ; 35,7$ e 25,9 óbitos por 100.000 habitantes, respectivamențe) e 
Tabela 23 - Óbitos em idosos por doenças do aparelho digestivo, no sexo masculino, segundo principais categorias e/ou diagnósticos, por triênios, Maringá-PR, 19791998. (n⿳⺈ e \%)

\begin{tabular}{|c|c|c|c|c|c|c|c|c|c|}
\hline \multirow[b]{3}{*}{ Diagnósticos } & \multicolumn{8}{|c|}{ TRIÊNIOS } & \multirow{3}{*}{$\begin{array}{c}\text { Diferença (\%) } \\
1979 / 81-1996 / 98\end{array}$} \\
\hline & \multicolumn{2}{|c|}{$1979-1981$} & \multicolumn{2}{|c|}{$1984-1986$} & \multicolumn{2}{|c|}{$1990-1992$} & \multicolumn{2}{|c|}{$1996-1998$} & \\
\hline & $\mathrm{n}^{\circ}$ & $\%$ & $\mathrm{n}^{\circ}$ & $\%$ & $\mathrm{n}^{\circ}$ & $\%$ & $\mathrm{n}^{\circ}$ & $\%$ & \\
\hline Doenças do figado & 10 & 20,8 & 13 & 28,3 & 11 & 30,5 & 26 & 42,6 & 104,8 \\
\hline Doenças dos intestinos & 12 & 25,0 & 13 & 28,3 & 15 & 41,7 & 11 & 18,0 & $-28,0$ \\
\hline $\begin{array}{l}\text { Doenças do esôfago, } \\
\text { estômago e duodeno }\end{array}$ & 10 & 20,8 & 9 & 19,5 & 3 & 8,3 & 7 & 11,5 & $-44,7$ \\
\hline $\begin{array}{l}\text { Transtornos da vesícula e } \\
\text { vias biliares e do pâncreas }\end{array}$ & 9 & 18,8 & 5 & 10,9 & 2 & 5,5 & 6 & 9,8 & $-47,9$ \\
\hline Hemorragia gastrintestinal & 1 & 2,1 & 3 & 6,5 & 3 & 8,3 & 8 & 13,2 & 528,6 \\
\hline Demais & 6 & 12,5 & 3 & 6,5 & 2 & 5,6 & 3 & 4,9 & $-60,8$ \\
\hline TOTAL & 48 & 100 & 46 & 100 & 36 & 100 & 61 & 100 & - \\
\hline
\end{tabular}

para as mulheres a doença dos intestinos, os transtornos da vesícula e vias biliares e do pâncreas e as doenças do figado $(38,9 ; 36,1$ e 33,3 óbitos por 100.000 habitantes, respectivamente), foram as mais freqüentes.

Tabela 24 - Óbitos em idosos por doenças do aparelho digestivo, no sexo feminino, segundo principais diagnósticos, por triênios, Maringá-PR, 1979-1998. (nº e \%).

\begin{tabular}{|c|c|c|c|c|c|c|c|c|c|}
\hline \multirow[b]{3}{*}{ Diagnósticos } & \multicolumn{8}{|c|}{ TRIÊNIOS } & \multirow{3}{*}{$\begin{array}{c}\text { Diferença (\%) } \\
1979 / 81-1996 / 98\end{array}$} \\
\hline & \multicolumn{2}{|c|}{$1979-1981$} & \multicolumn{2}{|c|}{$1984-1986$} & \multicolumn{2}{|c|}{$1990-1992$} & \multicolumn{2}{|c|}{$1996-1998$} & \\
\hline & $\mathrm{n}^{\mathrm{o}}$ & $\%$ & $\mathrm{n}^{\mathrm{o}}$ & $\%$ & $\mathrm{n}^{\mathrm{o}}$ & $\%$ & $\mathrm{n}^{\circ}$ & $\%$ & \\
\hline Doenças do figado & 3 & 16,7 & 8 & 27,6 & 5 & 13,5 & 12 & 20,7 & 23,9 \\
\hline Doenças dos intestinos & 3 & 16,7 & 12 & 41,4 & 13 & 35,1 & 14 & 24,1 & 44,3 \\
\hline $\begin{array}{l}\text { Doenças do esôfago, } \\
\text { estômago e duodeno }\end{array}$ & 1 & 5,5 & 2 & 6,9 & 5 & 13,5 & 3 & 5,2 & $-5,5$ \\
\hline $\begin{array}{l}\text { Transtornos da vesícula e } \\
\text { vias biliares e do pâncreas }\end{array}$ & 6 & 33,3 & 4 & 13,8 & 9 & 24,3 & 13 & 22,4 & $-32,7$ \\
\hline Hemorragia gastrintestinal & 2 & 11,1 & 1 & 3,4 & 5 & 13,5 & 6 & 10,4 & $-6,3$ \\
\hline Demais & 3 & 16,7 & 2 & 6,9 & - & - & 10 & 17,2 & 3,0 \\
\hline TOTAL & 18 & 100 & 29 & 100 & 37 & 100 & 58 & 100 & - \\
\hline
\end{tabular}


Tabela 25 - Coeficientes de mortalidade em idosos (por 100.000 hab.) por doenças do aparelho digestivo, segundo principais diagnósticos, por triênios, Maringá-PR, 19791998.

\begin{tabular}{|c|c|c|c|c|c|c|c|c|c|c|}
\hline \multirow[b]{3}{*}{ Diagnósticos } & \multicolumn{8}{|c|}{ TRIÊNIOS } & \multirow{2}{*}{\multicolumn{2}{|c|}{$\begin{array}{c}\text { Diferença }(\%) \\
\text { 1979/81-1996/98 }\end{array}$}} \\
\hline & \multicolumn{2}{|c|}{$1979-1981$} & \multicolumn{2}{|c|}{$1984-1986$} & \multicolumn{2}{|c|}{ 1990-1992 } & \multicolumn{2}{|c|}{$1996-1998$} & & \\
\hline & $\mathrm{n}^{\circ}$ & coef & $\mathrm{n}^{\circ}$ & coef & $\mathrm{n}^{\mathrm{o}}$ & coef & $\mathrm{n}^{\circ}$ & coef & $\mathrm{n}^{0}$ & coef \\
\hline $\begin{array}{l}\text { Doenças do } \\
\text { figado }\end{array}$ & 13 & 493 & 21 & 59,8 & 16 & 324 & 38 & 56,8 & $\therefore$ & 15,2 \\
\hline $\begin{array}{l}\text { Doenças dos } \\
\text { intestinos }\end{array}$ & 15 & 56,9 & 25 & 71,2 & 28 & 56,7 & 25 & 37,4 & $\therefore$ & $-34,3$ \\
\hline $\begin{array}{l}\text { Doenças do } \\
\text { esôfago, } \\
\text { estômago e } \\
\text { duodeno }\end{array}$ & 11 & 41,7 & 11 & 31,3 & 8 & 16,2 & 10 & 15,0 & - & $-64,0$ \\
\hline $\begin{array}{l}\text { Transtomos da } \\
\text { vesícula e vias } \\
\text { biliares e do } \\
\text { pâncreas }\end{array}$ & 15 & 569 & 9 & 25,6 & 11 & 22,3 & 19 & 28,4 & $\therefore$ & $-50,1$ \\
\hline $\begin{array}{l}\text { Hemorragia } \\
\text { gastrintestinal }\end{array}$ & 3 & 11,4 & 4 & 11,4 & 8 & 16,2 & 14 & 20,9 & & 83,3 \\
\hline Demais & 9 & 34,1 & 5 & 14,2 & 2 & 4,0 & 13 & 19,4 & - & 43,1 \\
\hline TOTAL & 66 & 250,2 & 75 & 213,7 & 73 & 147,7 & 119 & 178,0 & - & $-28,9$ \\
\hline
\end{tabular}

As doenças do figado constituem importante risco de morte e salienta-se que dos 26 óbitos por essa causa no sexo masculino, no triênio 1996-1998, 19 foram por cirrose hepática e dos 12 no sexo feminino, 10 foram por esta causa. Segundo LESSA (1998c) a mortalidade proporcional em todas as regiões brasileiras, em 1994, apresentou padrão semelhante para ambos os sexos: muito elevada nos grupos de idade mais jovens (20-39 e 40-59 anos) e tendência de queda a partir dos sessenta anos. A grande maioria dos casos de cirrose hepática é atribuída ao consumo excessivo de álcool e em torno de $50 \%$ dos óbitos por doenças do aparelho digestivo são devidos a essa patologia (LESSA 1998c). Parece haver concomitantemente um forte envolvimento da infeç̧ão pelo vírus $\mathrm{B}$ da hepatite como determinante da cirrose hepática o que aponta para a necessidade de investimento em estratégias populacionais para redução do consumo de álcool e para a profilaxia da hepatite (LESSA 1998c). 
As hemorragias gastrintestinais embora de importância pequena no perfil de mortalidade em idosos, podem representar parte de um conjunto menos freqüente de causas que com o aumento da sobrevida da população idosa deve ser considerada. Segundo FARRELL e FRIEDMAN (2000) as doenças do aparelho digestivo como incontinência fecal, constipação e sangramento intestinal são causas freqüentes de morbidade e mortalidade, pois com o envelhecimento populacional, a maior possibilidade de comorbidade e o incremento no uso de medicamentos contribuem para o desenvolvimento de transtornos digestivos adversos na população idosa.

Pessoas com hemorragia gastrintestinal freqüentemente necessitam de hospitalização e como na população jovem, mais da metade dos casos nos pacientes com 60 anos e mais de idade é causado pela úlcera péptica, além do consumo freqüente de drogas antinflamatórias pelos idosos (CEBOLLERO-SANTAMARIA e col. 1999; FARRELL e FRIEDMAN 2000). GORZONI (1995) discorre sobre as conseqüências indesejáveis da utilização concomitante de medicamentos pela população idosa. Chama a atenção para a necessidade dos profissionais que atendem idosos em serviços de emergência estejam familiarizados com os principais grupos de medicamentos prescritos para esta faixa etária e também, das interações medicamentosas mais freqüentes.

Mesmo com o avanço das unidades de terapia intensiva, sofisticados procedimentos diagnósticos como a endoscopia, a mortalidade por hemorragia gastrintestinal nos últimos 40 anos se mantém inalterada (FARRELL e FRIEDMAN 2000). Se por um lado os avanços nos tratamentos têm aumentado a sobrevida, por outro têm aumentado também o número de idosos de alto risco com maiores chances de adoecer e morrer por desordens digestivas, incluindo a hemorragia o que pode ser uma explicação para o declínio pouco significativo na mortalidade por doenças do aparelho digestivo (FARRELL e FRIEDMAN 2000; PARAHYBA 1997).

É necessário portanto, que seja dispensada maior atenção aos sintomas digestivos na população idosa pois, como comentado, o uso indiscriminado de medicamentos além de complicar o diagnóstico e tratamento pode causar transtornos gastrintestinais. Ainda, é importante para a equipe de saúde estar atenta às alterações na percepção da dor que ocorre com o avanço da idade e entender que os sintomas digestivos podem se apresentar de forma distinta comparado à população mais jovem. Manifestações clínicas desde anemia sem sintomas gastrintestinais específicos, aié os 
sangramentos intestinais, devem ser cuidadosamente investigados, pois muitas vezes os idosos, devido a alguma deficiência visual ou habilidade cognitiva podem se confundir com tais ocorrências (FARRELL e FRIEDMAN 2000).

\section{- Causas externas}

A mortalidade por causas externas em idosos vem mantendo percentuais constantes no período estudado com pouca variação na mortalidade proporcional. No sexo masculino permaneceu como quarta causa mais importante e no feminino, mesmo mudando de sétimo para o sexto posto, continuam com $3 \%$ do total de óbitos em idosos. No sexo masculino os óbitos foram mais freqüentes nos idosos jovens, de até 74 anos e no feminino ocorreu o inverso, maior concentração nas faixas acima de 80 anos de idade mantendo a mesma tendência para os dois triênios extremos (Gráfico 34). Entretanto, houve modificações para a estimativa do risco que

Gráfico 34 - Distribuição percentual dos óbitos em idosos, por causas externas, segundo sexo e idade, por triênios, Maringá-PR, 1979 a 1998.
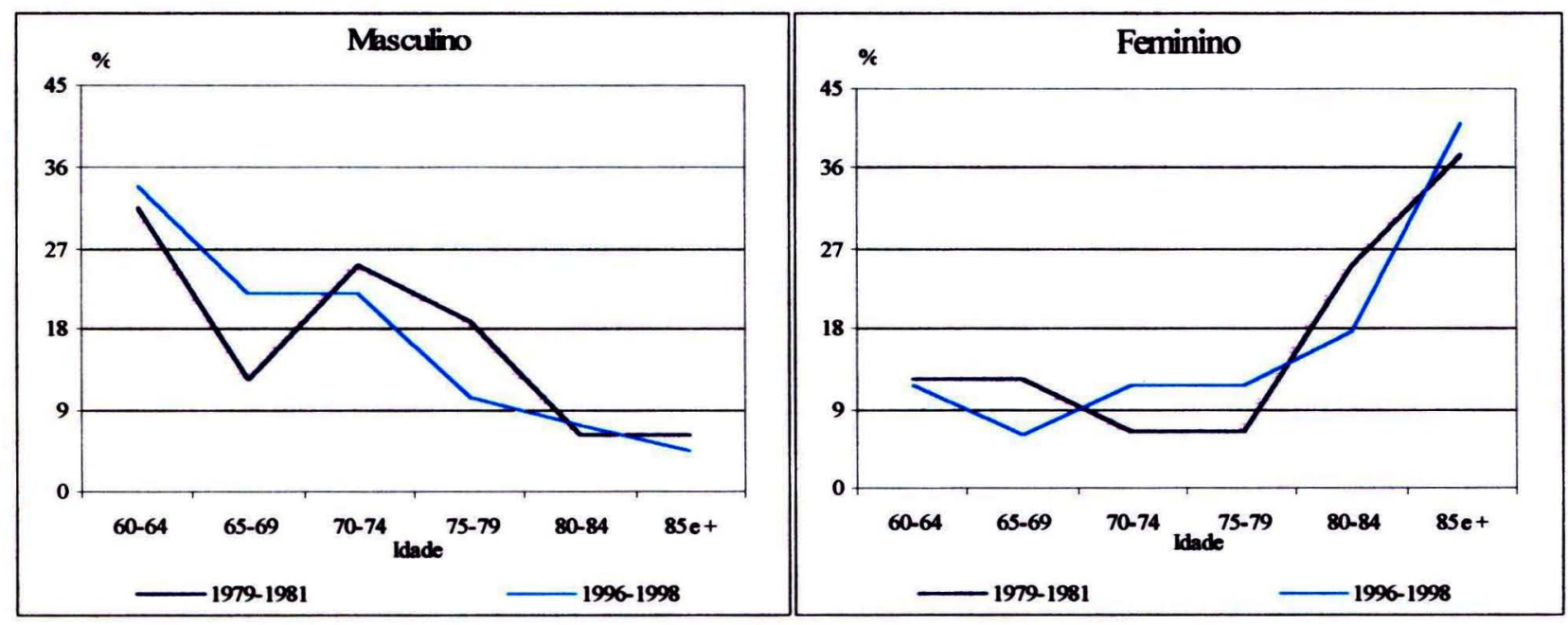

declinou, para os dois sexos, principalmente nas idades avançadas. Salienta-se que embora exista ascensão das estimativas do risco à medida que aumenta a idade ela é menos evidente no sexo masculino do que no feminino (Gráfico 35). A comparação dos coeficientes entre os sexos, nos dois triênios extremos, indica riscos maiores para os homens idosos mais jovens e só a partir de 80 anos de idade, no primeiro triệnio e de 85 anos no último, o risco passa a ser maier para as mulheres (Gráfico 36). Mesmo 
assim a sobremortalidade masculina teve um ligeiro aumento de 2,0 para 2,3 entre os triênios extremos.

Gráfico 35 - Coeficientes de mortalidade em idosos (por 100.000 hab.), por causas externas, segundo sexo e idade, por triênios, Maringá-PR, 1979 a 1998.
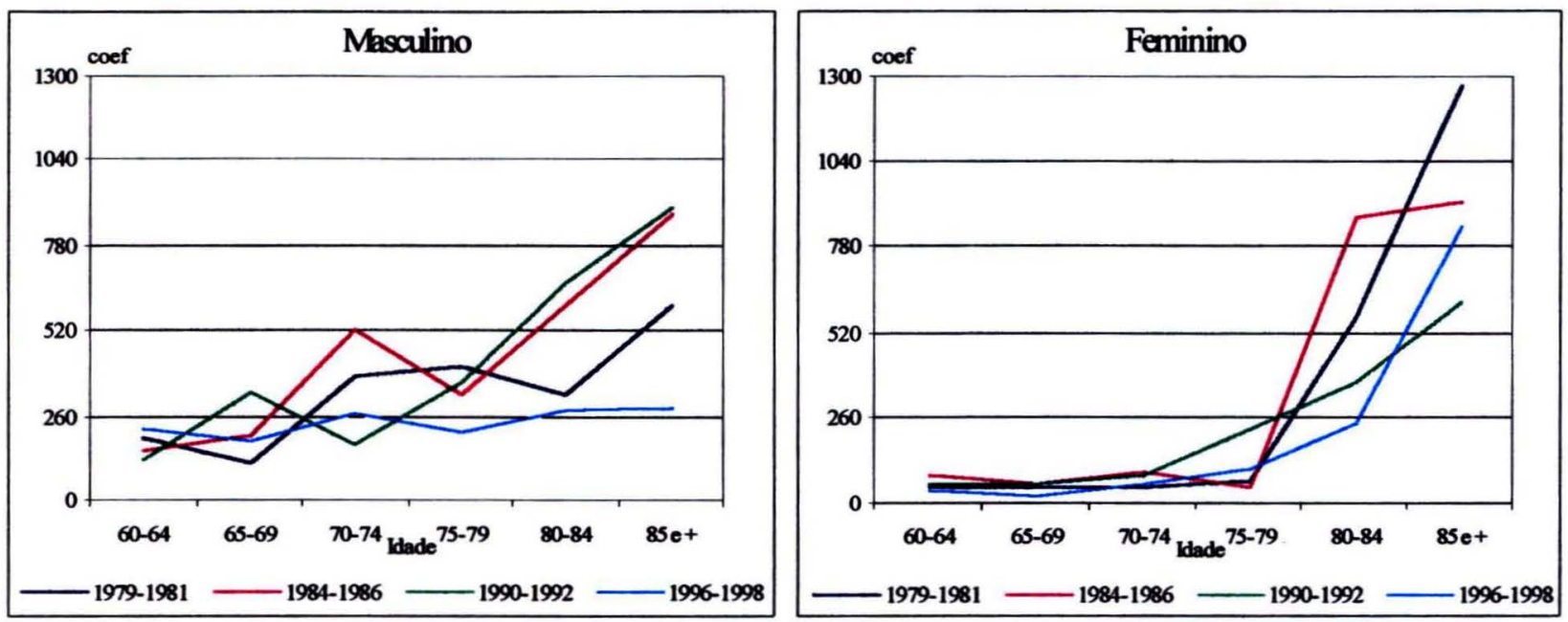

Os atropelamentos, as quedas e os outros acidentes de transporte foram os tipos de causas externas mais freqüentes nos homens, no último triênio, com $29,4 \%$, $\mathbf{2 6 , 4 \%}$ e 20,6\% respectivamente (Tabela 26). Para o sexo feminino as quedas são de longe o tipo de causa mais freqüente com $61,8 \%$ de todos os óbitos no capítulo, vindo a seguir os atropelamentos com $20,6 \%$ (Tabela 27 ).

Gráfico 36 - Coeficientes de mortalidade em idosos (por 100.000 hab.) por causas externas, segundo triênios, sexo e idade, Maringá-PR, 1979 a 1998.

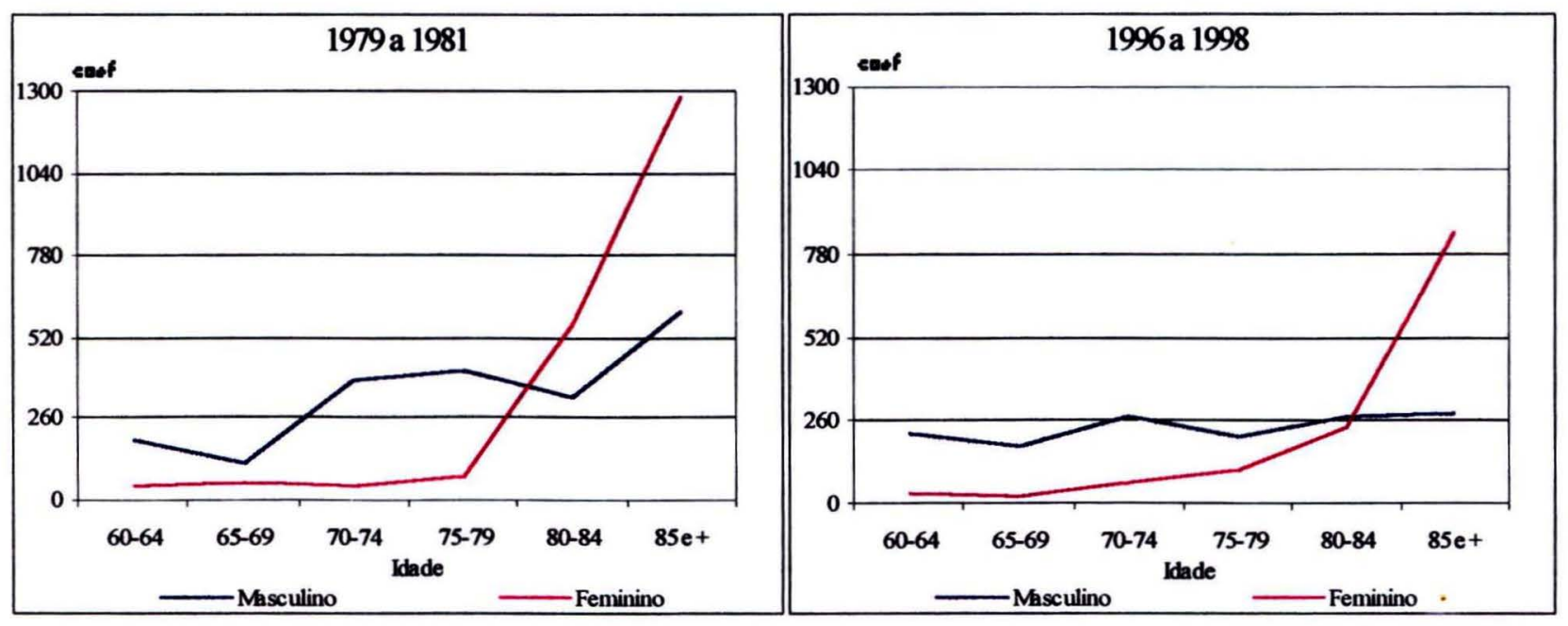


As quedas foram as causas que ganharam maior importância com aumentos relativos de $319 \%$ para os homens e de $394,4 \%$ para as mulheres e os atropelamentos aumentaram $212,8 \%$ para homens e de $227 \%$ para as mulheres (Tabelas 26 e 27 ). $\mathrm{O}$ mesmo comportamento ocorreu com os coeficientes que, para as quedas, aumentaram aproximadamente $280 \%$ para ambos os sexos e para os atropelamentos $183 \%$ no masculino e $158,7 \%$ no feminino (Tabela 28 ).

Tabela 26 - Óbitos em idosos por causas externas, no sexo masculino, segundo principais tipos, por triênios, Maringá-PR, 1979 a 1998. (nº e \%).

\begin{tabular}{|c|c|c|c|c|c|c|c|c|c|}
\hline \multirow[b]{3}{*}{ Tipos de causas externas } & \multicolumn{8}{|c|}{ TRIÊNIOS } & \multirow{3}{*}{$\begin{array}{l}\text { Diferencaa(\%) } \\
79 / 81-96 / 98\end{array}$} \\
\hline & \multicolumn{2}{|c|}{$1979-1981$} & \multicolumn{2}{|c|}{$1984-1986$} & \multirow{2}{*}{\multicolumn{2}{|c|}{$\begin{array}{c}1990-1992 \\
n^{\circ} \%\end{array}$}} & \multicolumn{2}{|c|}{ 1996-1998 } & \\
\hline & $\mathrm{n}^{\circ}$ & $\%$ & $\mathrm{n}^{\circ}$ & $\%$ & & & $\mathrm{n}^{\circ}$ & $\%$ & \\
\hline Atropelamentos & 3 & 9,4 & 11 & 22,5 & 25 & 41,0 & 20 & 29,4 & 212,8 \\
\hline Outros a & 11 & 34,4 & 17 & 34,7 & 11 & 18,0 & 14 & 20,6 & $-40,1$ \\
\hline Queda & 2 & 6,3 & 7 & 14,3 & 7 & 11,5 & 18 & 26,4 & 319,0 \\
\hline Suicídios & 3 & 9,4 & - & - & 4 & 6,5 & 5 & 7,4 & $-21,3$ \\
\hline Homicídi & 1 & 3,1 & 1 & 2,0 & 2 & 3,3 & 3 & 4,4 & 41,9 \\
\hline Lesões ig & 5 & 15,5 & 3 & 6,1 & - & - & 1 & 1,5 & -90.3 \\
\hline Outras cau & 7 & 21,9 & 10 & 20,4 & 12 & 19,7 & 7 & 10,3 & $-53,0$ \\
\hline Total & 32 & 100 & 49 & 100 & 61 & 100 & 68 & 100 & \\
\hline
\end{tabular}

*CID9 - "Lesões em que se ignora se foram acidental ou intencionalmente infligidas" (E980-E989)

*CID10 - "Eventos (Fatos) cuja intenção é indeterminada" (Y10-Y34)

Deve-se considerar que a variação das taxas de mortalidade por atropelamentos e quedas pode ter ocorrido como consequeencia da melhoria da qualidade das informações registradas na DO. De fato, puderam ser apreciados, além do declínio na estimativa do risco de morte por causas externas, de $9,9 \%$ para o sexo masculino e de $21,6 \%$ para o feminino, também declínio nos indicadores de mortalidade por "lesões em que se ignora se foram acidental ou intencionalmente infligidas", os "outros acidentes de transporte" e em "outras causas externas" (Tabelas 26, 27 e 28). Como exemplo, em análise mais detalhada foi encontrado que, no primeiro triênio, dos 18 óbitos por acidentes de transporte $78,8 \%$ (14) foram "acidentes de natureza não especificada" e no último esse percentual caiu para $23,3 \%$ (10 óbitos) mudança que deve ser considerada na interpretação dos resultados da 
mortalidade entre as categorias que compõem as causas externas, no periodo em questão.

Tabela 27 - Óbitos em idosos por causas externas, no sexo feminino, segundo principais tipos, por triênios, Maringá-PR, 1979 a 1998. (nº e \%).

\begin{tabular}{|c|c|c|c|c|c|c|c|c|c|}
\hline \multirow{2}{*}{ Tipos de causa externa } & \multicolumn{6}{|c|}{ TRIÊNIOS } & & & \multirow{2}{*}{$\begin{array}{c}\text { Diferença }(\%) \\
79 / 81-96 / 98 \\
\end{array}$} \\
\hline & \multicolumn{2}{|c|}{$1979-1981$} & \multicolumn{2}{|c|}{$1984-1986$} & \multicolumn{2}{|c|}{$1990-1992$} & \multicolumn{2}{|c|}{ 1996-1998 } & \\
\hline Atropelamentos & 1 & 6,3 & - & - & 8 & 25,0 & 7 & 20,6 & 227,0 \\
\hline Outros acidentes de transporte & 3 & 18,7 & 4 & 14,8 & 8 & 25,0 & 2 & 5,9 & $-16,9$ \\
\hline Quedas & 2 & 12,5 & 17 & 63,0 & 14 & 43,8 & 21 & 61,8 & 394,4 \\
\hline Suicídios & - & - & 1 & 3,7 & 1 & 3,1 & 1 & 2,9 & \\
\hline Lesões ignoradas* & 7 & 43,8 & 1 & 3,7 & - & - & - & - & $-100,0$ \\
\hline Outras causas externas & 3 & 18,7 & 4 & 14,8 & 1 & 3,1 & 3 & 8,8 & $-52,9$ \\
\hline Total & 16 & 100 & 27 & 100 & 32 & 100 & 34 & 100 & \\
\hline
\end{tabular}

*CID9 - "Lesões em que se ignora se foram acidental ou intencionalmente infligidas" (E980-E989)

*CID10 - "Eventos (Fatos) cuja intenção é indeterminada" (Y10-Y34)

Os acidentes de trânsito representam importante problema de saúde pública atingindo toda a sociedade e com especial gravidade para a população idosa. SOARES (1997) observou, para os pacientes de 65 anos e mais de idade hospitalizados por acidentes de trânsito no Município de Maringá, taxa de letalidade 4,1 vezes a observada para os pacientes entre 20 e 49 anos. Em outro estudo SCALASSARA e col. (1998) encontraram que os coeficientes de mortalidade por acidentes de trânsito em Maringá, em 1992, para pessoas com mais de 65 anos, representavam duas vezes os estimados para pessoas entre 20 e 49 anos.

Em geral relacionam-se os problemas de saúde dos idosos ou às incapacidades funcionais relativas ao envelhecimento às doenças crônico-degenerativas. No entanto, com o aumento crescente de pessoas acima de 60 anos de idade, atenção aos agravos conseqüentes dos acidentes de trânsito nessa parcela da população deve ser dispensada, ainda mais no caso dos atropelamentos que acometem idosos que mantêm capacidade de autonomia e independência e por isso estão caminhando pelas ruas da cidade. Os acidentes envolvendo pedestres representam especial atenção pois andar é um importante modo de locomoção para muitas pessoas acima de 60 anos. 
Tabela 28 - Coeficientes de mortalidade em idosos (por 100.000 hab.) por causas externas, segundo principais tipos e sexo, por triênios, Maringá-PR, 1979 a 1998.

\begin{tabular}{|c|c|c|c|c|c|c|c|c|c|c|}
\hline \multirow{3}{*}{$\begin{array}{l}\text { Tipo de causa } \\
\text { Externa }\end{array}$} & \multicolumn{8}{|c|}{ TRIÊNIOS } & \multirow{2}{*}{\multicolumn{2}{|c|}{$\begin{array}{l}\text { Diferença(\%) } \\
\text { 1979/81-1996/98 }\end{array}$}} \\
\hline & \multicolumn{2}{|c|}{$1979-1981$} & \multicolumn{2}{|c|}{$1984-1986$} & \multicolumn{2}{|c|}{$1990-1992$} & \multicolumn{2}{|c|}{$1996-1998$} & & \\
\hline & $\mathrm{M}$ & $F$ & $\mathrm{M}$ & $\mathrm{F}$ & $\mathrm{M}$ & $\mathrm{F}$ & $\mathrm{M}$ & $F$ & $\mathrm{M}$ & $F$ \\
\hline Atropelamentos & 22,9 & 7,5 & 64,7 & - & 107,5 & 30,6 & 64,8 & 19,4 & 183,0 & 158,7 \\
\hline Outros acidentes & & & & & & & & & & \\
\hline de transporte & 84,1 & 22,6 & 100,0 & 22,1 & 47,3 & 30,6 & 45,4 & 5,6 & $-46,5$ & $-75,2$ \\
\hline Quedas & 15,3 & 15,0 & 41,2 & 94,0 & 30,1 & 53,5 & 58,3 & 58,3 & 281,0 & 288,7 \\
\hline Suicídios & 22,9 & - & - & 5,5 & 17,2 & 3,8 & 16,2 & 2,8 & $-29,3$ & . \\
\hline Homicídios & 7,6 & - & 5,9 & - & 8,6 & - & 9,7 & - & 27,6 & - \\
\hline Lesões ignoradas* & 38,2 & 52,7 & 17,6 & 5,5 & - & - & 3,2 & - & $-91,6$ & $-100,0$ \\
\hline $\begin{array}{l}\text { Outras causas } \\
\text { externas }\end{array}$ & 53,5 & 22,6 & 58,8 & 22,1 & 51,6 & 3,8 & 22,7 & 8,3 & $-57,6$ & $-62,3$ \\
\hline Total & 244,5 & 120,4 & 288,1 & 149,3 & 262,3 & 122,3 & 220,4 & 94,4 & $-9,9$ & $-21,6$ \\
\hline
\end{tabular}

*CID9 - "Lesões em que se ignora se foram acidental ou intencionalmente infligidas" (E980-E989)

*CIDI0 - "Eventos (Fatos) cuja intenção é indeterminada" (Y10-Y34)

Em Londrina, Município próximo a Maringá ANDRADE e MELLO JORGE (2000) encontraram que os pedestres representaram as vítimas com maior probabilidade de serem internadas ou morrerem após o acidente. Para este município os autores relatam que os coeficientes de mortalidade para pedestres foi de 28,2 para idosos de 60 a 69 anos e de 39,4 óbitos para cada 100.000 habitantes, para os idosos de 70 a 79 anos. Esses resultados deixam clara a vulnerabilidade da pessoa idosa aos acidentes de trânsito, principalmente aos atropelamentos, que podem resultar em graus variados de lesões incluindo casos extremos que levam à morte. Sabe-se que os idosos acidentados têm capacidade reduzida de recuperação, ficam maior tempo hospitalizados e têm lesões mais graves do que os pacientes mais jovens, levando a seqüelas e incapacidades. Neste estudo a análise das causas de morte, vem mostrando a importância crescente dos atropelamentos que, no último triênio, entre os acidentes de transporte, foram a causa mais freqüente $(62,8 \%)$, tanto para os homens $(58,8 \%)$ como para as mulheres $(77,8 \%)$. Em relação às faixas de idade e sexo algumas características distintas foram observadas. Os acidentes de transporte por exemplo, aconteceram com mais freqüência nas idades mais jovens (Tabela 29) indicando que o idoso apresenta ainda, características da população adulta, com menos de 60 anos, como independência e autonomia, o que lhe garante uma vida ativa. Além de, no 
momento do acidente, estar em atividades de lazer, como passeios, atividades religiosas, visitas a amigos e parentes, muito provavelmente essas pessoas estão inseridas no mercado de trabalho e por isso a sua maior exposição (SOUZA 1999), principalmente os homens, cuja sobremortalidade por acidentes de transporte, no último triênio, foi de 4,4 .

Tabela 29 - Óbitos em idosos por causas externas, segundo principais tipos sexo e idade, Maringá-PR, 1996-1998. (nº \%).

\begin{tabular}{|c|c|c|c|c|c|c|c|c|c|}
\hline \multicolumn{10}{|c|}{ ACIDENTES DE TRANSPORTE } \\
\hline Sexo & \multicolumn{3}{|c|}{ Masculino } & \multicolumn{3}{|c|}{ Feminino } & \multicolumn{3}{|c|}{ Total } \\
\hline Idade & $\mathrm{n}^{\mathbf{o}}$ & $\%$ & coef & $\mathrm{n}^{\mathbf{0}}$ & $\%$ & coef & $\mathrm{n}^{\mathbf{0}}$ & $\%$ & coef \\
\hline $60-64$ & 12 & 35,3 & 38,9 & 3 & 33,3 & 8,3 & 15 & 34,9 & 22,4 \\
\hline $65-69$ & 7 & 20,6 & 22,7 & 1 & 11,1 & 2,8 & 8 & 18,6 & 12,0 \\
\hline $70-74$ & 8 & 23,5 & 25,9 & 3 & 33,3 & 8,3 & 11 & 25,6 & 16,5 \\
\hline $75-79$ & 2 & 5,9 & 6,5 & 2 & 22,2 & 5,6 & 4 & 9,3 & 6,0 \\
\hline $80-84$ & 4 & 11,8 & 13,0 & - & - & - & 4 & 9,3 & 6,0 \\
\hline 85 e mais & 1 & 2,9 & 3,2 & - & - & - & 1 & 2,3 & 1,5 \\
\hline Total & 34 & 100 & 110,2 & 9 & 100 & 25,0 & 43 & 100 & 64,3 \\
\hline \multicolumn{10}{|c|}{ ATROPELAMENTOS } \\
\hline Sexo & \multicolumn{3}{|c|}{ Masculino } & \multicolumn{3}{|c|}{ Feminino } & \multicolumn{3}{|c|}{ Total } \\
\hline Idade & $\mathrm{n}^{\mathbf{0}}$ & $\%$ & coef & $\mathrm{n}^{\mathbf{0}}$ & $\%$ & coef & $\mathrm{n}^{\mathbf{0}}$ & $\%$ & coef \\
\hline $60-64$ & 7 & 35,0 & 22,7 & 2 & 28,6 & 5,6 & 9 & 33,3 & 13,5 \\
\hline $65-69$ & 2 & 10,0 & 6,5 & 1 & 14,3 & 2,8 & 3 & 11,1 & 4,5 \\
\hline $70-74$ & 5 & 25,0 & 16,2 & 2 & 28,6 & 5,6 & 7 & 25,9 & 10,5 \\
\hline $75-79$ & 1 & 5,0 & 3,2 & 2 & 28,6 & 5,6 & 3 & 11,1 & 4,5 \\
\hline $80-84$ & 4 & 20,0 & 13,0 & - & - & - & 4 & 14,8 & 6,0 \\
\hline 85 e mais & 1 & 5,0 & 3,2 & - & - & - & 1 & 3,7 & 1,5 \\
\hline Total & 20 & 100 & 64,8 & 7 & 100 & 19,4 & 27 & 100 & 40,4 \\
\hline \multicolumn{10}{|c|}{ QUEDAS } \\
\hline Sexo & \multicolumn{3}{|c|}{ Masculino } & \multicolumn{3}{|c|}{ Feminino } & \multicolumn{3}{|c|}{ Total } \\
\hline Idade & $\mathrm{n}^{\mathbf{o}}$ & $\%$ & coef & $\mathrm{n}^{\mathrm{o}}$ & $\%$ & coef & $\mathrm{n}^{\mathbf{0}}$ & $\%$ & coef \\
\hline $60-64$ & 4 & 22,2 & 13,0 & - & - & - & 4 & 10,3 & 6,0 \\
\hline $65-69$ & 4 & 22,2 & 13,0 & 1 & 4,8 & 2,8 & 5 & 12,8 & 7,5 \\
\hline $70-74$ & 3 & 16,7 & 9,7 & 1 & 4,8 & 2,8 & 4 & 10,3 & 6,0 \\
\hline $75-79$ & 4 & 22,2 & 13,0 & 2 & 9,5 & 5,6 & 6 & 15,4 & 9,0 \\
\hline $80-84$ & 1 & 5,6 & 3,2 & 4 & 19,0 & 11,1 & 5 & 12,8 & 7,5 \\
\hline 85 e mais & 2 & 11,1 & 6,5 & 13 & 61,9 & 36,1 & 15 & 38,5 & 22,4 \\
\hline Total & 18 & 100 & 58,3 & 21 & 100 & 58,3 & 39 & 100 & 58,3 \\
\hline
\end{tabular}


A distribuição dos óbitos devido às quedas foi similar à distribuição dos óbitos por causas externas segundo o sexo e faixas de idade. Embora no último triênio, o coeficiente de mortalidade tenha sido o mesmo para os dois sexos (58,3 óbitos para cada 100.000 habitantes) foi possível observar que, para o masculino os óbitos se distribuíram mais uniformemente até 79 anos e diminuíram após essa idade. Para o sexo feminino a tendência foi inversa, observando-se concentração dos óbitos em idosas acima de 85 anos. Dos 21 óbitos por quedas, $13(61,9 \%)$ ocorreram em mulheres acima de 85 anos de idade (Tabela 29). Essa distribuição dos óbitos por quedas, desigual em relação ao sexo, faz supor a possibilidade da sua causa ser orgânica ou patológica para as mulheres e estarem ligadas a acidentes, para os homens.

As quedas compreendem um tipo de causa externa de maior importância para a pessoa idosa, pois podem causar danos variados, desde pequenas escoriações até fraturas diversas, traumas cranianos e fraturas de quadril, sendo esses últimos, muitas vezes causa de óbito.

No Município de São Paulo ROSA (1999) chama a atenção para a proporção de $31,3 \%$ de idosos que referiram ter tido pelo menos uma queda nos últimos 6 meses anteriores à entrevista, proporção que se eleva para 39,5\% entre os idosos de 80 anos e mais de idade. Em outro inquérito domiciliar realizado em Fortaleza quase um terço dos idosos entrevistados relataram, pelo menos, um episódio de queda nos últimos doze meses da entrevista, dos quais $20,3 \%$ relataram apenas um episódio e $9,6 \%$ dois ou mais episódios (COELHO FILHO e RAMOS 1999).

GRAAFMANS e col. (1996) estimam que 1\% de todas as quedas em pessoas idosas resultam em fratura de quadril, com maior freqüência nas mulheres em função das dificuldades cognitivas e de locomoção que, muitas vezes estão presentes nessa parcela da população, além do uso de medicamentos, em especial os sedativos. Em um estudo prospectivo realizado na Holanda, esses autores observaram uma população de idosos durante 28 semanas e encontraram que $36 \%$ relataram pelo menos uma queda e que a maior parte delas (79\%) ocorreu dentro de casa. Como conseqüência foram reportados $2,4 \%$ de fratura de quadril, além de outras fraturas e ferimentos menos graves. A fratura de quadril é aqui mencionada, pois a literatura registra que é uma das conseqüências graves importantes de quedas em idosos. WOLINSKY e col. (1997) relatam que, nos Estados Unidos, no ano de i990, 
aproximadamente $94 \%$ de todas as fraturas de quadril ocorreram em pessoas acima de 50 anos de idade e que, após 1 ano do evento, 24\% resultaram em óbito. Os autores afirmam que, tendo sofrido uma fratura de bacia, a probabilidade de morrer aumenta em $83 \%$ e de episódios de internação em $231 \%$, sem mencionar a diminuição da capacidade de autonomia para desenvolver as atividades de vida diárias e que, após uma fratura de quadril, a saúde do idoso deteriora significativamente. MAGAZINER e col. (1997) concluem que a fratura de quadril é um dos eventos que resultam em efeito cascata aumentando o grau de morbidade e de fragilidade na pessoa.

As causas de quedas no idoso incluem problemas ambientais, como piso e iluminação, alterações sensoriais, disfunções neurológicas e músculo-esqueléticas. Muitos medicamentos consumidos pela população idosa como os anti-anginosos, antidepressivos, anti- hipertensivos, antipsicóticos, entre outros, são potencialmente causadores de quedas (GORZONI 1995; CHAIMOWICZ e col. 2000). Como são diversos os fatores de risco, MOURA e col. (1999) recomendam intervenções preventivas abrangentes melhorando a acuidade visual, a baixa densidade mineral óssea, a baixa atividade física, a fraqueza muscular e diminuindo o medo de cair na pessoa idosa.

Vale ainda comentar a ocorrência de suicídios entre os idosos. Em Maringá no último triênio foram 6 óbitos por esta causa, 5 para o sexo masculino e 1 para o feminino (Tabelas 26 e 27). Embora ocorrência rara a população idosa pode estar mais vulnerável ao suicídio devido aos estados depressivos e às demências que são mais comuns à medida que aumenta a idade. Segundo LIRA e DRUMOND JUNIOR (2000) no Brasil, no ano de 1997 a maior concentração de suicídios $(26,3 \%)$ ocorreu em pessoas de 50 anos ou mais de idade.

\section{- Algumas doenças infecciosas e parasitárias}

As doenças infecciosas e parasitárias são consideradas mais facilmente evitáveis ou passíveis de prevenção e estão, freqüentemente relacionadas às condições de vida como habitação, educação, higiene e acesso aos serviços de saúde (WALDMAN e col. 1995; PARAHYBA 1997; PAES e SILVA 1999).

PAES e SILVA (1999) descreveram para o Brasil, na década de 80 diminuição da mortalidade por doenças infecciosas e parasitárias em praticamente 
todas as faixas de idade, particularmente em crianças menores de um ano. Para WALDMAN e col. (1995) tal fenômeno ocorreu em função sobretudo, da redução substancial das grastroenterites e das doenças imunopreveníveis. Entretanto, existe uma grande variedade de situações referentes à trajetória das doenças transmissiveis no Brasil. Além da descoberta recente de uma série de agentes infecciosos definindo quadros clínicos até então não descritos, ocorre o recrudescimento e crescente expansão de doenças já conhecidas fazendo reaquecer o debate sobre a importância das doenças infecciosas e parasitárias (BARRETO e col. 1996).

Os dados analisados neste trabalho indicam que a mortalidade proporcional e os coeficientes de mortalidade por doenças infecciosas e parasitárias em idosos residentes em Maringá também diminuiram nos vinte anos analisados. Em 1979-1981 a mortalidade proporcional era $4,6 \%$ ( $5^{\circ}$ posto) diminuindo para 3,1\% em 1996-1998 ( $7^{\circ}$ posto), ou seja, uma queda de $32,6 \%$ e, o coeficiente de mortalidade de 208,5 diminuiu para 118,2 óbitos por 100.000 habitantes, declínio de $43,3 \%$ na sua importância (Tabela 30).

Tabela 30 - Mortalidade proporcional e coeficientes de mortalidade em idosos (por 100.000 hab.), por doenças infecciosas e parasitárias, segundo sexo e triênios, Maringá-PR, 1979 a 1998.

\begin{tabular}{|c|c|c|c|c|c|c|c|c|c|}
\hline \multirow{3}{*}{$\frac{\text { Sexo }}{\text { Triênios }}$} & \multicolumn{6}{|c|}{ Mortalidade proporcional } & \multirow{2}{*}{\multicolumn{3}{|c|}{ Coeficientes }} \\
\hline & \multicolumn{2}{|c|}{$\mathrm{M}$} & \multicolumn{2}{|c|}{$\mathrm{F}$} & \multicolumn{2}{|c|}{$\mathrm{T}$} & & & \\
\hline & $\mathrm{n}^{\mathbf{o}}$ & $\%$ & $\mathrm{n}^{\mathbf{o}}$ & $\%$ & $\mathrm{n}^{\mathbf{o}}$ & $\%$ & M & $\mathrm{F}$ & $\mathrm{T}$ \\
\hline $1979-1981$ & 31 & 4,5 & 24 & 4,7 & 55 & 4,6 & 236,9 & 180,5 & 208,5 \\
\hline $1984-1986$ & 29 & 3,5 & 34 & 5,5 & 63 & 4,4 & 170,5 & 188,0 & 179,5 \\
\hline $1990-1992$ & 28 & 2,5 & 28 & 3,2 & 56 & 2,8 & 120,4 & 107,0 & 113,3 \\
\hline $1996-1998$ & 48 & 3,4 & 31 & 2,7 & 79 & 3,1 & 155,6 & 86,1 & 118.2 \\
\hline $\begin{array}{c}\text { Diferença }(\%) \\
1979 / 81-1996 / 98\end{array}$ & - & $-24,4$ & - & $-42,6$ & - & $-32,6$ & $-34,3$ & $-52,3$ & $-43,3$ \\
\hline
\end{tabular}

Em relação ao sexo e à idade, o Gráfico 37 mostra para o sexo masculino, curvas decrescentes à medida que avança a idade, indicando tendência de concentração dos óbitos em idosos mais jovens, nos dois triênios apresentados. Para o sexo feminino o mesmo comportamento não é observado havendo no primeiro triênio, maior concentração de óbitos entre 65 e 79 anos e no último, mesmo com 
Gráfico 37 - Distribuição percentual dos óbitos em idosos por doenças infecciosas e parasitárias, segundo sexo, idade e triênios, Maringá -PR, 1979-1998.
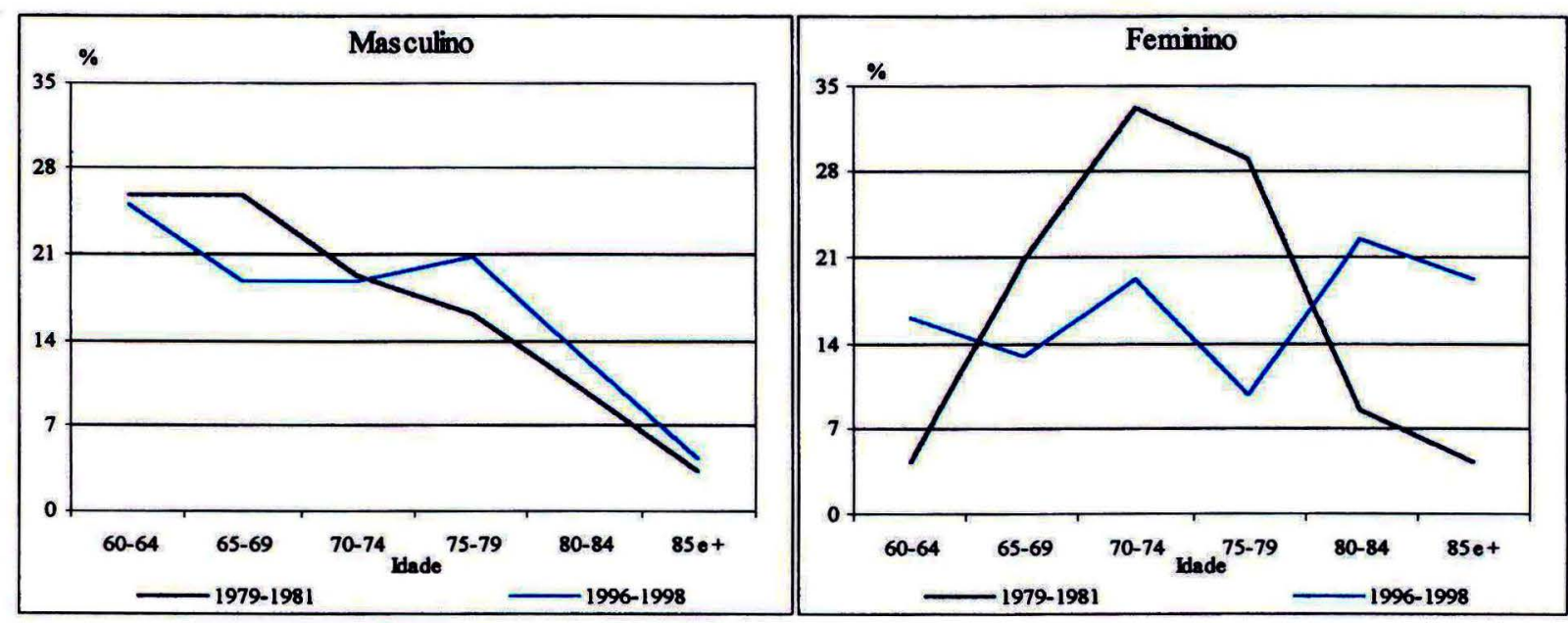

oscilação nas faixas de idade, tendência de aumento do valor relativo a partir de $\mathbf{8 0}$ anos.

Para as estimativas do risco, também com algumas oscilações nas faixas de idade, observou-se tendência de aumento em idades mais avançadas, comportamento observado para os dois sexos (Gráfico 38). O declínio nos coeficientes no período ocorreu em praticamente todas as faixas de idade, com exceção, no sexo feminino, de

Gráfico 38 - Coeficientes de mortalidade em idosos (por 100.000 hab.), por doenças infecciosas e parasitárias, segundo sexo e idade, por triênios, Maringá-PR, 19791998.
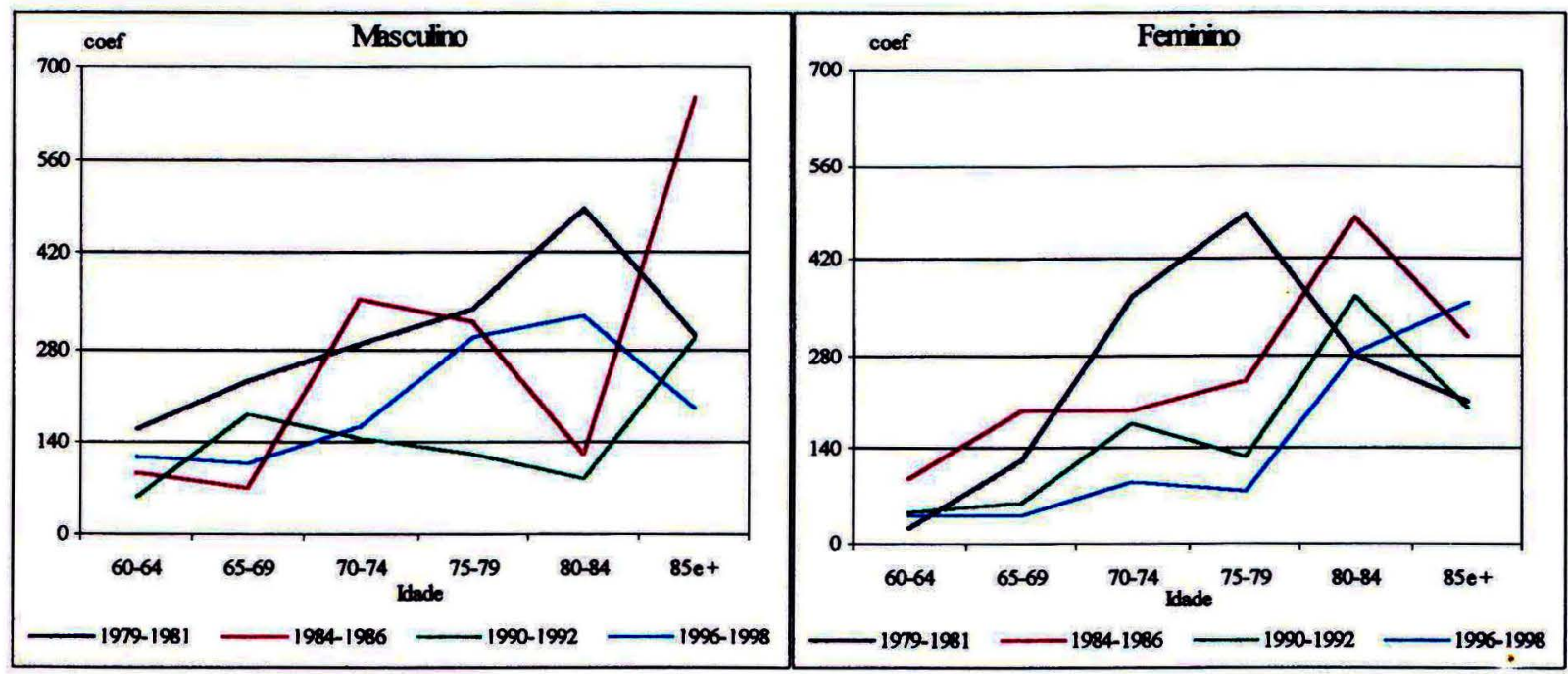
60 a 64 e 85 anos e mais de idade. No final do período o risco era maior para o sexo masculino em todas as faixas de idade (Gráfico 39), exceto para os idosos de 85 anos e mais, que foi de 189,9 e de 359,9 óbitos por 100.000 habitantes, para o feminino.

As variações por faixas de idade evidenciadas nos gráficos podem ter acontecido em razão do pequeno número de óbitos no capítulo. Assim, análise mais detalhada por categorias de diagnósticos a seguir, foi feita para os dois sexos em todas as faixas de idade na tentativa de minimizar essas oscilações.

A doença de Chagas, doenças infecciosas intestinais, septicemia e tuberculose foram os diagnósticos mais freqüentes. Destacaram-se a tendência de queda de óbitos por doenças infecciosas intestinais e por outras doenças infecciosas e parasitárias de $30,3 \%$ e $73,8 \%$, respectivamente e de aumento da septicemia e tuberculose de $99,2 \%$ e $56,2 \%$, respectivamente. Os óbitos por septicemia eram a terceira causa mais importante no primeiro triênio, com 12,7\% e com aumento de quase $100 \%$ passaram a ser a segunda com $25,3 \%$ do total de óbitos no capítulo e a tuberculose de quarto lugar (7,3\%) subiu para terceiro com 11,4\% dos óbitos (Tabela 31).

Gráfico 39 - Coeficientes de mortalidade em idosos (por 100.000 hab.), por doenças infecciosas e parasitárias, segundo triênios, idade e sexo, Maringá-PR, 1979-1998.
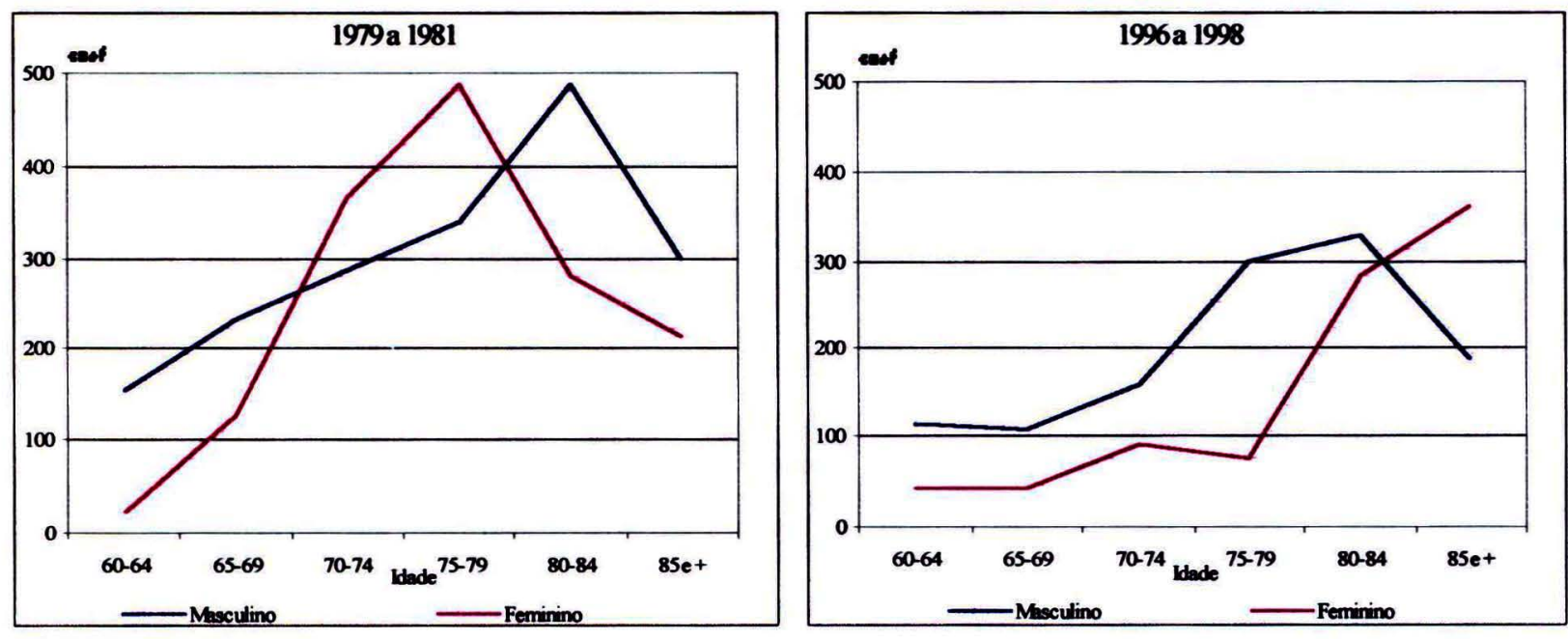

Ao observar o comportamento das estimativas do risco verificou-se que as maiores quedas ocorreram para os subgrupos das outras doenças infecciosas e parasitárias $(85,1 \%)$, doenças infecciosas intestinais $(60,4 \%)$ e doença de Chagas (45\%) como disposto na Tabela 32 Ressalta-se que a queda de 43,3\% na estimativa do risco deveu-se mais especificamente, às mudanças expressivas na mortalidade por 
doenças infecciosas intestinais e por outras doenças infecciosas e parasitárias. Os avanços tecnológicos e a ampliação dos serviços de saúde, a melhoria das medidas de saneamento, em especial ao fornecimento de água, continuam a ter impacto positivo sobre a letalidade desse grupo de doenças para as quais se dispõe de recursos para tal (BARRETO e col. 1996).

Tabela 31 - Óbitos em idosos por doenças infecciosas e parasitárias, segundo principais diagnósticos, por triênios, Maringá-PR, 1979-1998. ( $\left.\mathrm{n}^{\circ} \mathrm{e} \%\right)$.

\begin{tabular}{cccccccccc}
\hline & \multicolumn{10}{c}{ TRIÊNIOS } & \\
\cline { 2 - 8 } & $1979-1981$ & $1984-1986$ & $1990-1992$ & $1996-1998$ & Diferença(\%) \\
\hline Diagnóstico & $\mathrm{n}^{\circ}$ & $\%$ & $\mathrm{n}^{\circ}$ & $\%$ & $\mathrm{n}^{\circ}$ & $\%$ & $\mathrm{n}^{\circ}$ & $\%$ & $1979 / 81-1996 / 98$ \\
\hline Doença de Chagas & 28 & 50,9 & 39 & 61,9 & 28 & 50,0 & 39 & 49,4 & $-2,9$ \\
Dças infecciosas intestinais & 8 & 14,5 & 12 & 19,0 & 10 & 17,9 & 8 & 10,1 & $-30,3$ \\
Septicemia & 7 & 12,7 & 5 & 7,9 & 6 & 10,7 & 20 & 25,3 & 99,2 \\
Tuberculose & 4 & 7,4 & 3 & 4,8 & 3 & 5,3 & 9 & 11,4 & 56,2 \\
Outras infec. e parasitárias & 8 & 14,5 & 4 & 6,4 & 9 & 16,1 & 3 & 3,8 & $-73,8$ \\
\hline Total & 55 & 100 & 63 & 100 & 56 & 100 & 79 & 100 & - \\
\hline
\end{tabular}

A doença de Chagas caracterizada por uma doença crônica e de longa evolução, continua sendo a principal causa de óbito entre as doenças infecciosas e parasitárias em idosos residentes em Maringá. Durante todo o período houve pequena oscilação no valor relativo que ficou ao redor de $50 \%$, com exceção do triênio 1984 1986, cujo percentual foi de $61,9 \%$ do total de óbitos por doenças infecciosas e parasitárias (Tabela 31). O coeficiente de mortalidade entretanto, apresentou redução de $45 \%$ passando de 106,1 para 58,3 óbitos por 100.000 habitantes (Tabela 32).

Vinculada ao subdesenvolvimento das zonas rurais e quase que restrita ao homem do campo a doença de Chagas vem para os grandes centros urbanos a partir da intensa migração ocorrida após os anos 50 . Maringá por pertencer a uma região do Estado do Paraná colonizada a partir de meados da década de 40 , recebeu grande contingente de população, principalmente do Estado de São Paulo e de Minas Gerais, consideradas regiões endêmicas na época. Hoje essa doença tornou-se urbanizada e 
Tabela 32 - Coeficientes de mortalidade em idosos (por 100.000 hab.), por doenças infecciosas e parasitárias, segundo principais diagnósticos, por triênios, Maringá-PR, 1979-1998.

\begin{tabular}{cccccc}
\hline & \multicolumn{4}{c}{ TRIÊNIOS } & \\
\cline { 2 - 5 } & $1979-1981$ & $1984-1986$ & $1990-1992$ & $1996-1998$ & Diferença(\%) \\
\cline { 2 - 5 } Diagnóstico & Coef & coef & coef & coef & $1979 / 81-1996 / 98$ \\
\hline Doença de Chagas & 106,1 & 113,1 & 56,7 & 58,3 & $-45,0$ \\
Doenças infec. intestinais & 30,3 & 34,8 & 20,2 & 12,0 & $-60,4$ \\
Septicemia & 26,5 & 14,5 & 12,1 & 29,9 & 12,8 \\
Tuberculose & 15,2 & 8,7 & 6,1 & 13,5 & $-11,2$ \\
Outras infec. e parasitárias & 30,3 & 11,6 & 18,2 & 4,5 & $-85,1$ \\
\hline Total & 208,5 & 179,6 & 113,3 & 118,2 & $-43,3$ \\
\hline
\end{tabular}

estima-se que $65 \%$ dos chagásicos no país estejam vivendo nas grandes cidades (MEYER e col. 1996). Por outro lado a urbanização, somada às medidas de controle exercidas sobre os serviços de hemoterapia adotadas nos últimos 20 anos, significou grande impacto na trajetória da doença interrompendo drasticamente a transmissão vetorial no Brasil (WALDMAN e col. 1995; VINHARES e DIAS 2000). Os óbitos e casos internados correspondem hoje basicamente, à complicações da fase crônica instaladas tardiamente em indivíduos contaminados há muitos anos (VINHARES $\mathrm{e}$ DIAS 2000).

Informações mais detalhadas sobre a situação da doença de Chagas no Município de Maringá puderam ser obtidas através do programa de assistência ao chagásico denominado ACHEI (Atenção ao Chagásico com Educação Integral) desenvolvido por docentes da Universidade Estadual de Maringá, implantado com o objetivo de atender o paciente chagásico desde o acompanhamento laboratorial, tratamento, até o apoio psico-social. Entre os pacientes inscritos no programa 52,7\% são mulheres, $83,8 \%$ têm entre 31 e 60 anos de idade e são procedentes de Minas Gerais (33,1\%), São Paulo (31,5\%) e Paraná $(22,3 \%)$. Segundo os coordenadores do programa, com o processo de descentralização das ações de saúde e a municipalização em curso e implantação das equipes do Programa Saúde da Família abre-se a perspectiva do atendimento com ações educativas voltadas ao grupo familiar (ARAUJO e col. 2000). 
No Brasil, o número de óbitos por doença de Chagas vem apresentando redução pois de 5,2 óbitos por 100.000 habitantes em 1980, passou para 3,5 em 1997 (VINHARES e DIAS 2000), embora sua representatividade entre as doenças infecciosas e parasitárias venha aumentando, passando de 8,9\% em 1980 para 14,1\%, em 1995 (MELLO JORGE e GOTLIEB 2000). Desta forma, ainda que a transmissão da doença de Chagas tenha sido drasticamente reduzida no Brasil, segundo LIMA e COSTA e col. (2000) a mortalidade hoje, é devida a um efeito de coorte em função da exposição ao Trypanosoma cruzi no passado, indicando que suas conseqüências ainda estarão presentes em parcela da população e que ainda exigem atenção dos profissionais de saúde.

Importante salientar a participação da septicemia que, no primeiro triênio representava a terceira causa com $12,7 \%$ e no último, com acréscimo de $99,2 \%$ já representava $25,3 \%$, ficando em segundo lugar entre os óbitos por doenças infecciosas e parasitárias (Tabela 31 e 32). Estudos têm revelado que essa causa merece atenção por sua ocorrência crescente no perfil de mortalidade da população. MELLO JORGE e GOTLIEB (2000) destacam a importância da septicemia na mortalidade da população brasileira que, do total de óbitos por doenças infecciosas e parasitárias, de $8,7 \%$ em 1980, aumentou para 24,3\% em 1995. PAES e SILVA (1999) ao descreverem o comportamento dos indicadores para o Brasil, relatam que houve situação diferenciada das taxas de mortalidade por septicemia nas faixas de idade, que diminuíram no grupo de menores de um ano e tiveram leve aumento na população adulta e de forma mais importante na população mais velha. LIMA e COSTA e col. (2000) em estudo sobre a morbimortalidade em idosos no Brasil encontraram que a septicemia foi a causa mais freqüente de morte entre as doenças infecciosas e parasitárias com 38,8 e 35,9 óbitos por 100.000 idosos do sexo masculino e feminino, respectivamente. PAES e SILVA (1999) relatam também para o Brasil, que a septicemia constituiu a única causa entre as doenças infecciosas e parasitárias em que houve real aumento de risco de morte ao longo da década de 80 , para ambos os sexos.

Segundo STANLEY (1996) entre 60 e $79 \%$ de todos os óbitos por septicemia ocorrem na população idosa. Pacientes hospitalizados em terapia intensiva são os mais expostos por seu alto risco e fragilidade, somado à queda da imunidade relacionada à idade que aumenta sua suscetibilidade às infecções virais e bacter ianas. 
Além disso, as pessoas idosas apresentam outras doenças crônicas que contribuem para a mortalidade quando associadas ao quadro de septicemia. A importância da septicemia como causa de óbito nos idosos pode refletir, além da menor resistência às infecções, a possibilidade de quadros de desnutrição como comentado anteriormente, somadas às conseqüências dos avanços dos procedimentos médicos cada vez mais utilizados e às limitações do sistema de atendimento hospitalar.

Merece comentário entretanto, o uso do diagnóstico de septicemia como causa básica de óbito. MELLO JORGE e GOTLIEB (2000) discutem que devido à septicemia ser sempre conseqüente a outra doença, geralmente infecciosa, ou ser uma infecção secundária de lesões, traumatismos ou procedimentos médicos, não deveria aparecer como causa básica de morte. Nestes casos a septicemia poderia ser considerada como um indicador de preenchimento incorreto do atestado de óbito, fato que indica a necessidade de investigação para avaliação da utilização desse subgrupo de diagnóstico como causa básica, principalmente pela tendência de aumento observada no perfil de mortalidade.

Em relação à tuberculose os dados mostram uma redução do coeficiente de mortalidade de $11,2 \%$ mas o comportamento desse indicador requer análise mais detalhada. A tendência de queda observada até o ano de 1992 parece se inverter, passando de 6,1 óbitos (em 1990-1992) para 13,5 óbitos por 100.000 habitantes (em 1996-1998) o que representou um acréscimo de 121,3\% na estimativa do risco, somente entre os dois últimos triênios (Tabela 32).

A ocorrência da tuberculose é muito influenciada, de um lado, pelo nível de desenvolvimento sócio-econômico e condições de vida da população e, de outro, pela qualidade dos serviços de saúde na implementação de programas de controle (WALDMAN e col. 1995). A mortalidade, por sua vez, está associada à demora no diagnóstico, ao abandono ao tratamento, à idade avançada do paciente além, nos dias de hoje, à AIDS (OLIVEIRA e MOREIRA FILHO 2000).

Em análise da mortalidade por tuberculose no Brasil, WALDMAN e col. (1995) mostram que desde meados da década de 80 tem havido elevação nos coeficientes e que fatores como o aparecimento da AIDS e cepas multiresistentes de M. tuberculosis podem ser possíveis causas desse recrudescimento e comentam que, a inversão da tendência de queda tem merecido destaque em vários países. Segundo a 
OMS a situação epidemiológica da tuberculose é de calamidade e o Brasil é o décimo país do mundo em número de casos novos (RUFFINO-NETO e SOUZA 1999).

Para o Município de São Paulo ANTUNES e WALDMAN (1999) encontraram coeficientes de mortalidade mais elevados no grupo acima de 50 anos de idade e mostraram que nos últimos anos essa diferença tem se acentuado. Embora a mortalidade proporcional por tuberculose seja menor nesse grupo etário comparada à do grupo de 20 a 49 anos os idosos são mais suscetíveis à doença que é ainda, a principal causa de morte atribuível a um único patógeno.

Existe uma certa dificuldade em diagnosticar a tuberculose na população idosa que é atribuída à queda da imunidade e também à dificuldade de obtenção do material para exame laboratorial, menos freqüente no idoso. Tais condições retardam o diagnóstico e o início do tratamento e a presença de outras doenças aumentam a mortalidade. Segundo CHAIMOWICZ (2001) a taxa de mortalidade de 22 óbitos por 100.000 idosos de 80 anos e mais de idade sinaliza para um problema para as próximas décadas, já que é esse grupo populacional que segundo as estimativas, vai crescer mais rapidamente no futuro. De fato, o risco de morrer por tuberculose no Município de Maringá, no último triênio (1996-1998) também aumentou com a idade sendo 9,$9 ; 15,4$ e 28,4 óbitos por 100.000 idosos de 60 a 69,70 a 79 e 80 anos e mais de idade, nesta ordem.

Segundo RUFFINO-NETO e SOUZA (1999) nos últimos 20 anos acreditouse que a tuberculose seria uma doença do passado o que influenciou todo um comportamento dos serviços e dos profissionais de saúde em pensar pouco na doença e no encaminhamento de soluções para o problema. A queda na qualidade dos programas de controle e tratamento da tuberculose, o abandono ao tratamento e o agravamento das desigualdades sociais no Brasil são consideradas possíveis causas do aumento da mortalidade (ANTUNES e WALDMAN 1999; RUFFINO-NETO e SOUZA 1999). Além do mais, é preciso reconhecer as condições que necessitam de intervenção não somente médicas, mas que predispõem à tuberculose como desemprego, alcoolismo e desnutrição (OLIVEIRA e MOREIRA FILHO 2000) presentes na população idosa. Por isso novas metas foram propostas pelo Plano Nacional de Controle da Tuberculose, como diagnosticar pelo menos $92 \%$ dos casos esperados, reduzir a incidência em pelo menos $50 \%$ e a mortalidade em dois terços (RUFFINO-NETO e SOUZA 1999). 
$\dot{E}$ fato que para a tuberculose, os coeficientes de mortalidade podem representar instrumentos pouco sensíveis para avaliar sua evolução, que apresentou declínio importante na letalidade após a introdução da quimioterapia específica. Todavia, o discreto aumento do risco de mortalidade na população idosa de Maringá não difere do perfil descrito em outros estudos e pode representar apenas parte do problema ou a ponta do iceberg do possível recrudescimento da tuberculose.

\subsection{Morbidade hospitalar em idosos no período de 1995 a 1998}

O envelhecimento é um fenômeno positivo para a sociedade, significando mais anos de vida para um número cada vez maior de pessoas. No entanto, a qualidade desses anos acrescentados à vida pode não ser a melhor desejada. Existem doenças crônicas que, antes de representar um risco de vida, são uma constante ameaça à independência e à autonomia da pessoa (RAMOS e SAAD 1990).

$\mathrm{O}$ aumento nas taxas de morbidade observado nos Estados Unidos nas últimas décadas foi atribuído à maior incidência de doenças crônicas, ao diagnóstico precoce desses agravos e também ao aumento na sobrevida (VERBRUGGE 1984). Como as taxas de mortalidade estão caindo, principalmente para os idosos, essas pessoas permanecem portadoras de doenças crônicas que vão se agravando com o tempo, além de serem acrescidas outras doenças fatais e não fatais. Como conseqüência ocorre crescimento gradual nas taxas de prevalência das doenças devido às novas patologias adquiridas durante a vida significando para os idosos, a cada ano de vida adicionado, o agravamento das doenças já existentes e o desenvolvimento de outras, gerando uma demanda importante para os serviços de saúde, especificamente por hospitalizações. Daí a necessidade do conhecimento do perfil de utilização desses serviços.

Alguns comentários a respeito da utilização dos dados de morbidade hospitalar já foram feitos no início deste trabalho. Acrescenta-se que, quando as informações do banco de dados do SIH-SUS são analisadas deve-se considerar, desde a questão da qualidade dos dados relativos ao diagnóstico principal registrado nas $\mathrm{AIH}$, até os problemas mais amplos que dizem respeito à política de oferta de leitos 
hospitalares para o SUS no Brasil que cobre entre $70 \%$ a $80 \%$ das internações hospitalares (LEVCOVITZ e PEREIRA 1993; OLIVEIRA 2000).

No Município de Maringá MATHIAS e SOBOLL (1996) mostraram que em 1992, o SUS financiou 73,8\% das internações embora para Ribeirão Preto, YAZLLE ROCHA e SIMÕES (1999) tenham encontrado queda de $76 \%$ em 1986, para 51,7\% em 1996. Sabe-se entretanto, que a população idosa é a maior usuária do serviço público de saúde. A proporção de internações financiadas pelo SUS em pessoas com 60 anos e mais de idade, em Maringá, em 1992, foi de 80\% (MATHIAS e SOBOLL 1996) e em Ribeirão Preto, em 1988 de 83,4\% (GERMANO NETO 1991).

Quanto ao diagnóstico principal sabe-se que é codificado nos próprios hospitais e que em geral, esse procedimento é feito por pessoal que não recebe treinamento formal como ocorre com as codificações dos diagnósticos nas DO. Além disso, soma-se o fato do período de tempo neste estudo, abranger duas classificações diferentes. Por isso, com maior ou menor intensidade, essas questões podem influenciar as possíveis mudanças no perfil de morbidade particularmente, segundo diagnóstico de internação.

Com relação à confiabilidade, análise da tendência da assistência hospitalar no Estado do Rio de Janeiro, entre 1992 e 1995, GOUVÊA e col. (1997) observaram que houve melhora gradativa dos dados do SIH-SUS. Em Maringá a análise dos diagnósticos constatou que os mais freqüentes para os idosos, quais sejam, doenças do aparelho circulatório, respiratório, digestivo e geniturinário foram os que tiveram concordâncias satisfatórias; kappa $=0,92 ; 0,91 ; 0,86 ; 0,79$, respectivamente (MATHIAS E SOBOLL 1998).

\subsubsection{Morbidade hospitalar em idosos segundo sexo e idade}

No período de 1995 a 1998 a distribuição percentual das internações de idosos residentes em Maringá oscilou entre 22,6\%, em 1997 e 25,3\%, em 1998 (Tabela 33). Quando as internações por partos são excluídas do total a participação das população idosa aumenta de forma importante $(28,3 \% ; 27,1 \% ; 27,6 \%$ e $28,4 \%$ para cada ano, respectivamente).

O número de internações foi maior para o sexo masculino entre 1995 e 1997, mas em 1998 houve equilíbrio entre os sexos. Em relação à distribuiç̧̃ das 
internações por faixas de idade observou-se que foi mais homogênea no sexo feminino, ao contrário do masculino para o qual houve maior concentração nos idosos de até 75 anos de idade (Tabela 34).

Tabela 33 - Distribuição das internações de residentes em Maringá segundo idade e ano de ocorrência, Maringá-PR, 1995-1998. (ne \%).

\begin{tabular}{crrrrrrrr}
\hline \multicolumn{1}{r}{ Ano } & \multicolumn{1}{c}{1995} & \multicolumn{2}{c}{1996} & \multicolumn{1}{c}{1997} & \multicolumn{2}{c}{1998} \\
\hline Idade & \multicolumn{1}{c}{$\mathbf{n}^{\mathbf{0}}$} & \multicolumn{1}{c}{$\%$} & \multicolumn{1}{c}{$\mathbf{n}^{\mathbf{0}}$} & $\%$ & \multicolumn{1}{c}{$\mathbf{n}^{\mathbf{0}}$} & \multicolumn{1}{c}{$\%$} & \multicolumn{1}{c}{$\mathbf{n}^{\mathbf{0}}$} & \multicolumn{1}{c}{$\%$} \\
\hline$<1$ & 797 & 6.2 & 831 & 6,1 & 735 & 5,9 & 911 & 6,0 \\
$1-4$ & 827 & 6,5 & 903 & 6,7 & 934 & 7,5 & 1424 & 9,4 \\
$5-19$ & 1674 & 13,1 & 1820 & 13,4 & 1684 & 13,6 & 2112 & 13,9 \\
$20-59$ & 6405 & 50,2 & 6926 & 51,2 & 6118 & 49,3 & 6877 & 45,4 \\
60 e mais & 3064 & 24,0 & 3056 & 22,6 & 2935 & 23,7 & 3829 & 25,3 \\
\hline Total & 12767 & 100 & 13536 & 100 & 12406 & 100 & 15153 & 100 \\
\hline
\end{tabular}

Nos quatro anos o coeficiente de internação oscilou de 131,8 em 1997, para 163,5 internações por 1000 habitantes, em 1998. Foi observado que, para ambos os sexos, aumentou a probabilidade do idoso ser internado com o avanço da idade e que os coeficientes foram sempre superiores para os homens, com exceção do ano de 1997, na faixa de 85 anos e mais de idade (268 para as mulheres e de 265 internações por 1000 habitantes, para os homens) (Tabela 34 e Gráfico 40).

A participação da população idosa no volume de internações é variável conforme a região. COSTA e col. (2000) relatam que das internações realizadas pelo SUS em todo o Brasil, 16,3\%; 15,8\% e 18,3\% ocorreram em pessoas de mais de 60 anos, em 1995, 1996 e 1997, respectivamente. Em Ribeirão Preto, no ano de 1988, para todas as fontes de financiamento esse percentual foi de 15,5\% (GERMANO NETO 1991). Já para a população de São Carlos interior de São Paulo, em 1996, as internações em idosos representaram 18,4\% (CASELLI 1998), destacando-se que, para Maringá foram consideradas apenas as internações financiadas pelo SUS e em São Carlos e Ribeirão Preto foram estudadas todas as formas de financiamento.

Dados de internação de 1992 em Maringá revelaram que 19,8\% das internações pelo SUS foram para pessoas com 60 anos e mais de idade (MATHIAS 1994) e em 1998 , esse percentual subiu para $25,3 \%$ significando um aumento de $27,8 \%$. 
Tabela 34 - Internações em idosos (\% e coeficientes por 1000 habitantes) segundo ano, sexo e idade, Maringá-PR, 1995 a 1998.

\begin{tabular}{|c|c|c|c|c|c|c|c|c|c|}
\hline \multicolumn{10}{|c|}{1995} \\
\hline Sexo & \multicolumn{3}{|c|}{ Masculino } & \multicolumn{3}{|c|}{ Feminino } & \multicolumn{3}{|c|}{ Total } \\
\hline Idade & \begin{tabular}{l|l}
$\mathrm{n}^{\mathbf{0}}$ & \\
\end{tabular} & $\%$ & coef & \begin{tabular}{l|l}
$\mathrm{n}^{\mathbf{0}}$ \\
\end{tabular} & $\%$ & coef & $\mathrm{n}^{\mathrm{o}}$ & $\%$ & coef \\
\hline $60-64$ & 320 & 20,4 & 97,3 & 284 & 19,0 & 78,4 & 604 & 19,7 & 87,4 \\
\hline $65-69$ & 404 & 25,8 & 159,7 & 285 & 19,0 & 101,0 & 689 & 22,5 & 128 \\
\hline $70-74$ & 0 & 19,8 & & 318 & & 164,8 & 28 & 20,5 & 17 \\
\hline & 290 & 18,5 & 35,2 & 267 & 17,8 & 218,0 & 57 & 18,2 & 24 \\
\hline & 153 & 9,8 & 89,2 & 207 & 13,8 & 287,9 & 60 & 11,7 & 288,5 \\
\hline$e+$ & 90 & & 298,0 & 136 & 9,1 & 292,5 & 26 & 7,4 & 294,7 \\
\hline tal & 1567 & 100 & 167,5 & 1497 & 00 & 138,8 & 064 & 100 & 152,2 \\
\hline \multicolumn{10}{|c|}{1996} \\
\hline Sexo & \multicolumn{3}{|c|}{ Masculino } & \multicolumn{3}{|c|}{ Feminino } & \multicolumn{3}{|c|}{ Total } \\
\hline Idade & \begin{tabular}{l|l|}
$n^{\circ}$ & \\
\end{tabular} & $\%$ & coef & \begin{tabular}{l|l|}
$\mathrm{n}^{\mathbf{0}}$ & \\
\end{tabular} & $\%$ & coef & $\mathrm{n}^{\mathrm{o}}$ & $\%$ & coef \\
\hline $60-64$ & & 20,8 & & 288 & 19,8 & 76,3 & 619 & 20,3 & \\
\hline $65-69$ & 395 & 24,7 & 147,8 & 289 & 19,8 & 96,7 & 84 & 22,4 & 120,8 \\
\hline $70-74$ & 32 & 20,6 & 18 & 290 & 19,9 & 141 & 19 & 20,3 & 161,6 \\
\hline & & 15,1 & 22 & 257 & 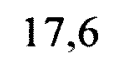 & 20 & 98 & 16,3 & 213,0 \\
\hline & 10 & 10,6 & 29 & 190 & 13,0 & 246,4 & 359 & 11,7 & 268,1 \\
\hline $85 \mathrm{e}+$ & 1 & & 409,2 & 144 & 9,9 & 283 & 77 & 9,1 & 332,5 \\
\hline & 99 & & 163,0 & 1458 & 0 & 128 & 056 & 100 & 144,3 \\
\hline \multicolumn{10}{|c|}{1997} \\
\hline Sexo & \multicolumn{3}{|c|}{ Mascu } & \multicolumn{3}{|c|}{ Femir } & \multicolumn{3}{|c|}{ Total } \\
\hline Idade & $\mathrm{n}^{\mathrm{o}}$ & $\%$ & coef & $\mathrm{n}^{\mathrm{o}}$ & $\%$ & coef & $\mathrm{n}^{\mathbf{0}}$ & $\%$ & coef \\
\hline $60-64$ & & 21,0 & & 246 & & & 570 & 19,4 & 76,6 \\
\hline & & 26,1 & & 13 & & & 716 & 24,4 & 119,5 \\
\hline & & 20,2 & & 300 & ,6 & & 613 & 20,9 & 151,2 \\
\hline & & 16,3 & 225 & 205 & & 15 & 458 & 15,6 & 187,9 \\
\hline & 162 & 10,5 & 265,6 & 174 & & 210,7 & 336 & 11,4 & 234,0 \\
\hline+ & 93 & & 265,0 & 149 & 10,7 & 268,0 & 242 & 8,2 & 266,8 \\
\hline & 550 & 100 & 150,6 & 1387 & 100 & 115,7 & 2935 & 100 & 131,8 \\
\hline \multicolumn{10}{|c|}{1998} \\
\hline Sexo & \multicolumn{3}{|c|}{ Masculino } & \multicolumn{3}{|c|}{ Feminino } & \multicolumn{3}{|c|}{ Total } \\
\hline Idade & $\mathrm{n}^{\mathrm{o}}$ & $\%$ & coef & $\mathrm{n}^{\mathbf{0}}$ & \begin{tabular}{l|l}
$\%$ \\
\end{tabular} & coef & $\mathrm{n}^{\mathrm{o}}$ & $\%$ & coef \\
\hline $60-64$ & 387 & 20,4 & 107,0 & 347 & 18,0 & 84 & 734 & 19,2 & 95,1 \\
\hline & & 21,8 & 138 & 425 & & 126,6 & 839 & 21,9 & 132,4 \\
\hline $70-74$ & 418 & 22,0 & 212,8 & 439 & 22,8 & & 857 & 22,4 & 199,7 \\
\hline $75-79$ & 337 & 17,7 & 286,8 & 319 & 16,5 & 233,2 & 656 & 17,1 & 258,0 \\
\hline $80-84$ & 189 & 9,9 & 288,5 & 170 & 8,8 & 191,9 & 359 & 9,4 & 233,0 \\
\hline $85 \mathrm{e}+$ & 155 & 8,2 & 411,1 & 229 & 11,9 & 376,6 & 384 & 10,0 & 389,8 \\
\hline Total & 1900 & 100 & 176,4 & 1929 & 100 & 152,5 & 3829 & 100 & $16 ? .5$ \\
\hline
\end{tabular}


Gráfico 40 - Coeficientes de internação em idosos (por 1000 hab.), segundo ano, sexo e idade, Maringá-PR, 1995-1998.
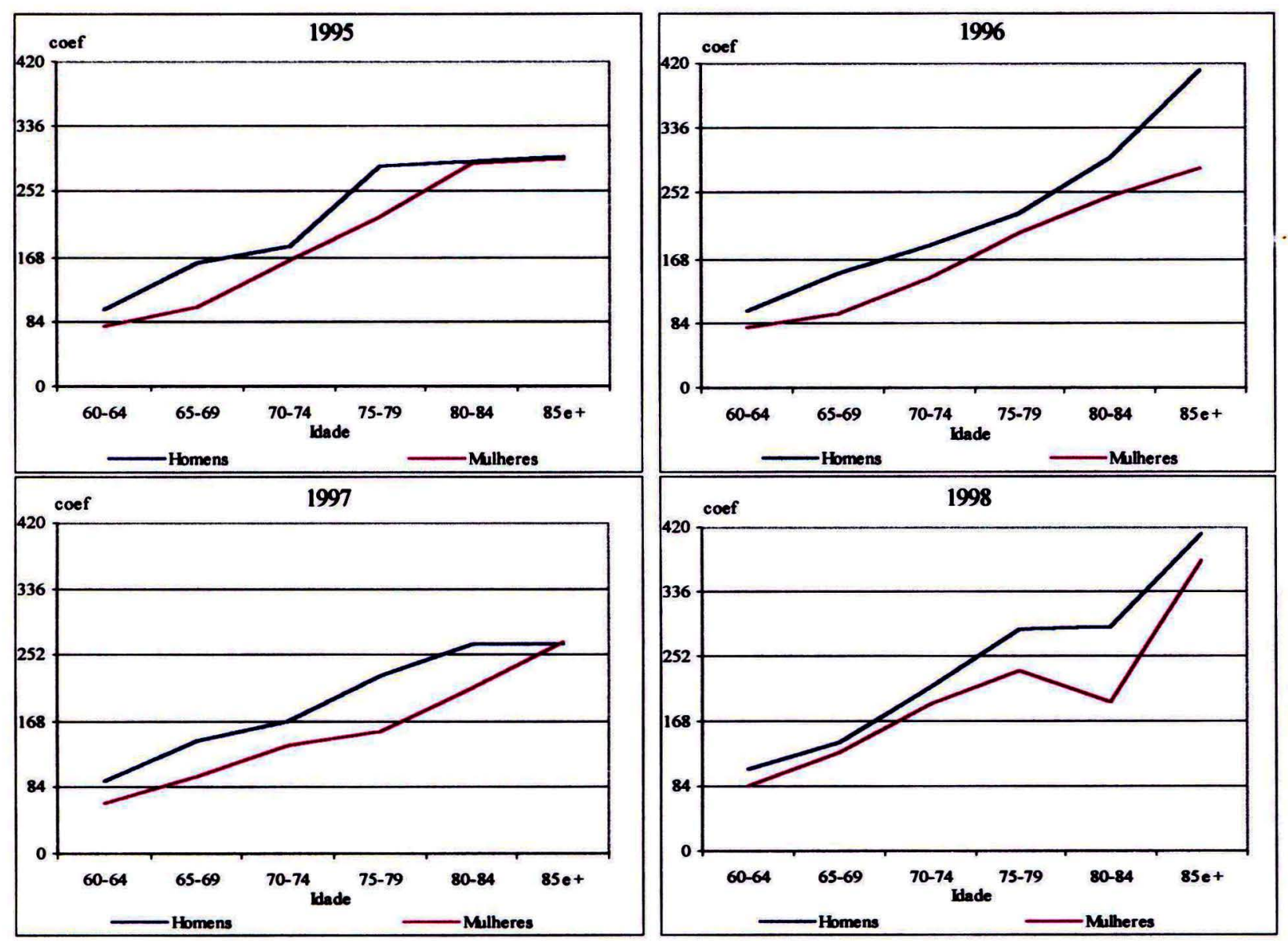

A razão entre a população e o número de internações por faixas de idade foi calculada para ilustrar a importância da utilização dos leitos hospitalares públicos pela população idosa. As crianças de zero a quatro anos e os idosos foram os que mais utilizaram os leitos hospitalares em 1998, com razão habitante/internação de 9,2 e 6,1 respectivamente, o que significa dizer que em 1998, para cada 6 idosos residentes em Maringá houve uma internação hospitalar pelo SUS. Residentes de 5 a 19 anos e de 20 a 59 anos tiveram menor taxa de utilização (37 e 22,9 internações por habitante em cada faixa de idade, respectivamente). Esses resultados mostram que a utilização dos serviços hospitalares pela população idosa é representativa, prevendo que essa demanda deva crescer substancialmente, nos próximos anos com o aumento do número de idosos no município.

Chamou a atenção o fato do risco de internação ser maior para o sexo masculino (Gráfico 40) pois, mesmo as mulheres sendo mais numerosas e longevas, 
ainda assim utilizam menos os leitos hospitalares do que os homens. Por outro lado é interessante observar que, de modo geral, estudos populacionais revelam que são as mulheres que referem maior prevalência de episódios mórbidos (RUIZ e col. 1998; CESAR e TANAKA 1996; LEBRÃO e col. 1991; BORGES-YÁÑEZ e GÓMEZDANTÉZ 1998), maior incapacidade funcional (VERAS e COUTINHO 1994) e maior utilização dos serviços ambulatoriais (COSTA e FACCHINI 1997; RASSI 1994; BORGES-YAÑEZ e GÓMEZ-DANTÉZ 1998), possivelmente pelas mudanças fisiológicas que acompanham o envelhecimento na mulher e também pela maior prevalência de algumas doenças como o diabetes (BORGES-YAÑEZ e GÓMEZDANTÉZ 1998). Se são as mulheres que referem maior número de episódios mórbidos, a maior utilização dos serviços hospitalares pela população masculina sugere que os homens nessa faixa de idade apresentam como doenças mais graves, gerando mais internações e possiveis reinternações.

\subsubsection{Morbidade hospitalar em idosos segundo diagnóstico principal de internação}

As doenças do aparelho circulatório, respiratório e digestivo, nesta ordem, foram as grandes responsáveis pelas internações na população idosa de Maringá, representando mais do que $70 \%$ de todas as saídas hospitalares nos quatro anos apresentados $(70,6 \% ; 72,9 \% ; 74,7 \%$ e $72,1 \%$ de 1995 a 1998 , respectivamente). Com relação à ordem de importância não houve modificações, mas foram observados aumentos nos indicadores para as doenças do aparelho respiratório e ligeira queda para as doenças do aparelho geniturinário, infecciosas e lesões e envenenamentos (Tabela 35).

O aumento das hospitalizações não foi homogêneo para os principais diagnósticos (Tabela 35, Anexo 6). Destacaram-se, entre 1997 e 1998, aumento nos coeficientes de internação por doenças do sistema nervoso $(372,7 \%)$, neoplasias (130\%), doenças do aparelho respiratório (63\%) e digestivo $(28,2 \%)$. As doenças do sistema nervoso apareceram em 1998, com 3,2\% e com coeficiente de 5,2 internações por 1000 habitantes. Foi observado que das 121 internações no capítulo, $108(89,3 \%)$ foram por "acidentes vasculares cerebrais isquêmicos transitórios e síndromes 
Tabela 35 - Internações (\% e coeficientes por 1000 habitantes) em idosos, segundo ano, causa* e sexo, Maringá-PR, 1995 a 1998.

\begin{tabular}{|c|c|c|c|c|c|c|c|c|c|c|c|}
\hline \multicolumn{12}{|c|}{ Masculino } \\
\hline \multicolumn{3}{|c|}{1995} & \multicolumn{3}{|c|}{1996} & \multicolumn{3}{|c|}{1997} & \multicolumn{3}{|c|}{1998} \\
\hline Causa & $\%$ & coef & Causa & $\%$ & coef & Causa & $\%$ & coef & Causa & $\%$ & coef \\
\hline Circulatório & 43,3 & 72,6 & Circulatório & 41,4 & 67,5 & Circulatório & 45,9 & 68,8 & Circulatório & 37,4 & 65,7 \\
\hline Respiratório & 17,9 & 29,9 & Respiratório & 21,9 & 35,7 & Respiratório & 20,6 & 30,8 & Respiratório & 26,6 & 46,8 \\
\hline Digestivo & 10,9 & 18,3 & Digestivo & 10,5 & 17,0 & Digestivo & 8,9 & 13,3 & Digestivo & 9,5 & 10,6 \\
\hline Geniturinário & 6,9 & 11,5 & Geniturinário & 5,6 & 9,1 & Geniturinário & 5,7 & 8,5 & Geniturinário & 4,9 & 8,6 \\
\hline Lesões & 4,3 & 7,2 & Lesões & 4,4 & 7,1 & Infecciosas & 4,2 & 6,3 & Sist nervoso & 3,9 & 6,9 \\
\hline Infecciosas & 4,0 & 6,6 & Infec & 4,3 & 7,0 & Les & 4,0 & 6,0 & & 3,0 & 5,2 \\
\hline Endócrinas & 3,3 & 5,6 & Endó & 3,6 & 5,9 & Endó & 2,5 & 3,8 & iosas & 2,6 & 4,5 \\
\hline Olho e anexos & 2,2 & 3,6 & Mal definidas & 2,9 & 4,7 & Mal definidas & 2,4 & 3,6 & $\mathrm{Neo} / \mathrm{mal}$ def & 2,1 & 3,7 \\
\hline Demais & 7,2 & 12,1 & Demais & 5,4 & 8,8 & Den & 5,6 & 8,5 & & 10,0 & 17,6 \\
\hline \multicolumn{12}{|c|}{ Feminino } \\
\hline \multicolumn{3}{|c|}{1995} & \multicolumn{3}{|c|}{1996} & \multicolumn{3}{|c|}{1997} & \multicolumn{3}{|c|}{1998} \\
\hline Causa & $\%$ & coef & & $\%$ & coef & & $\%$ & coef & & $\%$ & coef \\
\hline Circulatório & 43,6 & 60,5 & Circulatório & 43,1 & 55,2 & Circulatório & 45,2 & 51,8 & Circulatório & 35,1 & 53,2 \\
\hline Respiratório & 17,4 & 24,1 & Respiratório & 20,9 & 26,7 & Respiratório & 20,8 & 23,9 & Respir & 27,7 & 42,1 \\
\hline Digestivo & 8,1 & 11,3 & Digestivo & 8,1 & 10,4 & Digestivo & 7,9 & 9,0 & estivo & 7,9 & 12,0 \\
\hline Lesões & 7,4 & 10,3 & Endócrinas & 6,0 & 7,7 & ões & 6,3 & 7,3 & ões & 4,8 & 7,4 \\
\hline Endócrinas & 6,0 & 8,3 & Geni & 4,8 & 6,2 & Endó & 5,2 & 5,9 & asias & 3,5 & 5,3 \\
\hline Infecciosas & 3,8 & 5,3 & Lesões & 4,7 & 6,1 & ciosas & 4,5 & 5,2 & inário & 3,4 & 5,2 \\
\hline Geniturinário & 3,5 & 4,9 & Infecciosas & 3,8 & 4,9 & Genit & 3,7 & 4,3 & rinas & 3,3 & 5,1 \\
\hline Mal definidas & 2,6 & 3,6 & Osteomusc & 2,4 & 3,1 & Mal definidas & 1,8 & 2,1 & Infec/Sist nerv & 2,5 & 3,7 \\
\hline & 7,6 & 10,6 & Demais & 6,2 & 8,4 & Demais & 4,6 & 11,6 & lais & 9,3 & 17,7 \\
\hline \multicolumn{12}{|c|}{ Total } \\
\hline \multicolumn{3}{|c|}{1995} & \multicolumn{3}{|c|}{1996} & \multicolumn{3}{|c|}{1997} & \multicolumn{3}{|c|}{1998} \\
\hline Causa & $\%$ & coef & & $\%$ & coef & & $\%$ & coef & & $\%$ & coef \\
\hline Circulatório & 43,4 & 66,1 & Circulatório & 42,2 & 60,9 & Circu & 45,6 & 59,6 & tório & 36,2 & 59,0 \\
\hline Respiratório & 17,6 & 26,8 & Respiratório & 21,4 & 30,9 & Respiratório & 20,7 & 27,1 & Respiratório & 27,2 & 44,2 \\
\hline Digestivo & 9,6 & 14,5 & Digestivo & 9,3 & 13,5 & Digestivo & 8,4 & 11,0 & Digestivo & 8,7 & 14,1 \\
\hline Lesões & 5,8 & 8,8 & Geniturinário & 5,2 & 7,5 & Lesões & 5,1 & 6,7 & Geniturinário & 4,2 & 6,8 \\
\hline Geniturinário & 5,3 & 8,0 & Endócrinas & 4,8 & 6,9 & Geniturinário & 4,7 & 6,2 & Lesões & 3,9 & 6,4 \\
\hline Endócrinas & 4,6 & 7,1 & Lesões & 4,5 & 6,6 & Infecciosas & 4,4 & 5,7 & Sist. Nervoso & 3,2 & 5,2 \\
\hline Infecciosas & 3,9 & 5,9 & Infecciosas & 4,1 & 5,9 & Endócrinas & 3,8 & 4,9 & Neoplasias & 2,8 & 4,6 \\
\hline Mal definidas & 2,0 & 3,1 & Mal definidas & 2,3 & 3,3 & Mal definidas & 2,1 & 2,8 & Infec/Endóc & 2,5 & 4,1 \\
\hline Demais & 7,8 & 11,9 & Demais & 6,2 & 8,9 & Demais & 5,2 & 7,1 & Demais & 8,8 & 18,1 \\
\hline
\end{tabular}

*As lesões e envenenamentos foram analisadas em conjunto com as causas externas.

** Excluídos diagnósticos ignorados (22 em 1997 e 18 em 1998) 
correlatas" (CID10 - G45), supondo que com a introdução da CID-10 novos códigos estejam sendo utilizados.

As neoplasias, em 1995, não estavam entre as 8 principais causas e em 1998 apareceram com $2,8 \%$ do total de internações e 4,6 internações por 1000 habitantes idosos, ficando em sétimo lugar na ordem de importância. Os resultados indicaram que o coeficiente de internação foi maior para as mulheres $(5,3$ internações por 1000 habitantes, $5^{\circ}$ lugar) do que para os homens $\left(3,7\right.$ internações por 1000 habitantes, $8^{\circ}$ lugar) (Tabela 35).

LEBRÃO (1999) analisando as mudanças no perfil de morbidade hospitalar na região do Vale do Paraíba, entre 1979 e 1988, relata acréscimo de $90 \%$ nos coeficientes de internação por neoplasias e atribui esse aumento a fatores como o aumento na incidência dos cânceres, dado o envelhecimento populacional, com maior exposição aos fatores de risco (hábito de fumar, por exemplo). Além disso, a introdução de novo arsenal diagnóstico, inovações quimioterápicas proporcionando maior sobrevida e também melhor definição dos diagnósticos na $\mathrm{AIH}$, podem ter contribuido na elevação desses coeficientes. Para o presente estudo essa interpretação deve ser feita com cautela pois o período de análise não é tão longo, todavia os mesmos fatores descritos por LEBRÃO (1999) para o Vale do Paraíba podem ser também verdade para o Maringá.

Merece destaque o grupo das doenças do aparelho respiratório que foram a terceira causa com maior acréscimo no número de internações que de 603, em 1997, passaram para 1036 hospitalizações, em 1998. Entre os dois anos não houve variação na distribuição dos principais subgrupos de causa, porém a insuficiência respiratória aparece, em 1998, com 4,3\% das internações por doenças do aparelho respiratório (Tabela 36).

Enquanto que, como causa de óbito houve aumento na estimativa do risco de morrer por doenças endócrinas, nutricionais e metabólicas, para a internação os coeficientes oscilaram, registrando inclusive declínio de 42,3\% entre 1995 e 1998 (Tabela 35 ). Neste período quase $60 \%$ das internações no grupo foram por diabetes e, no ano de 1998 esse valor chegou a 64\%. Segundo LESSA e col. (1996) a demanda por hospitalização pelo paciente diabético é decorrente das complicações crônicas ou agudas que neste caso, muitas vezes, demandam por serviços de urgência. Entre as complicações mais comuns estão o pé diabético, a cegueira, a insuficiêncià renal 
crônica, além de todas as complicações decorrentes do comprometimento cardiovascular.

Tabela 36 - Internações por doenças do aparelho respiratório segundo principais diagnósticos e ano, Maringá-PR, 1997-1998. (nº \%).

\begin{tabular}{lcccc}
\hline \multirow{2}{*}{ Diagnósticos } & \multicolumn{2}{c}{1997} & \multicolumn{2}{c}{1998} \\
\cline { 2 - 5 } & $\mathrm{n}^{\mathrm{o}}$ & $\%$ & $\mathrm{n}^{\mathrm{o}}$ & $\%$ \\
\hline DPOC * & 400 & 66,3 & 669 & 64,6 \\
Pneumonia e gripe & 157 & 26,0 & 291 & 28,1 \\
Infecções vias aéreas superiores & 19 & 3,2 & 13 & 1,3 \\
Insuficiência respiratória & - & - & 43 & 4,3 \\
Demais & 27 & 4,5 & 20 & 1,9 \\
\hline Total & 603 & 100 & 1036 & 100 \\
\hline
\end{tabular}

* Doença pulmonar obstrutiva crônica

ROSENTHAL e col. (1998) afirmam que os idosos diabéticos tem 2,2 vezes mais de chance de serem hospitalizados do que os não diabéticos. Os autores encontraram que, no período de 3 anos, entre 135 idosos diabéticos na cidade de Los Angeles (EUA), 95 (70,4\%) foram hospitalizados e destes 28,4\% (27 pacientes) foram hospitalizados uma vez, o restante foi mais de uma vez tendo como principal motivo o diabetes, vindo a seguir os problemas cardíacos. Em trabalho realizado por LEBRÃO (1999) na Região do Vale do Paraíba, foi observado que entre 1975 e 1998 houve um aumento de $150 \%$ no coeficiente de hospitalização por diabetes. Um dos motivos comentados pela autora foi que a ampla disseminação do uso de insulina aumentou a sobrevida dos diabéticos insulino dependentes que após alguns anos começam a apresentar seqüelas que certamente demandarão atenção especializada.

Os dados de hospitalização por doenças endócrinas neste estudo, sugerem uma queda na utilização de leitos hospitalares por essa causa. Como em Maringá, existe em todas as 24 unidades básicas de saúde programas de atendimento ao diabético, com várias equipes de saúde da família instaladas, com disponibilidade dos medicamentos mais importantes, esse indicador poderia significar importante instrumento de avaliação da qualidade e eficácia do atendimento dispensado a esse grupo populacional. Por isso, as informações hospitalares, mesmo com to as as 
críticas conhecidas, poderiam ser melhor exploradas pelos gestores de saúde considerando que a descentralização e municipalização do atendimento básico à saúde da comunidade deveria ser sempre avaliada.

As internações referentes às lesões e envenenamentos de 8,8 em 1995, caíram para 6,4 internações por 1000 habitantes idosos, em 1998 (Tabela 35). Foi realizada análise dos diagnósticos secundários quando o motivo da internação foram as lesões e envenenamentos, embora é possível que ainda possa existir alguma dificuldade nesse registro por consistir em atividade implantada nos hospitais mais recentemente.

A Tabela 37 dispõe a relação das internações devido às lesões e envenenamentos segundo natureza da lesão e respectiva causa externa. Entre as 146 internações em idosos $45,9 \%$ foram causadas por quedas, $25,3 \%$ por exposição a forças mecânicas inanimadas e $13 \%$ por acidentes de transporte. Chama atenção que as 67 internações por quedas resultaram em $62,5 \%$ do total de traumatismos de quadril e coxa, $36 \%$ de traumatismos de membro superior, $63,2 \%$ de membro inferior, $37,5 \%$ da cabeça e pescoço e $66,7 \%$ de outras localizações, como tórax e abdome e traumatismos múltiplos. RAMOS (1997) em análise do perfil da capacidade funcional de idosos residentes em um bairro do Município de São Paulo, em 1992, encontrou que 32\% dos entrevistados referiu queda no último ano, sendo as mulheres as mais acometidas com $37 \%$ de quedas, com $7 \%$ delas resultando em fraturas. Além disso, o autor relata que as quedas figuraram entre as variáveis que aumentaram significativamente o risco de morte. Evidencia-se, mais uma vez, o problema freqüente no cotidiano do idoso que é a ocorrência de quedas já discutido na análise dos óbitos.

Foi observado também que o número de internações teve um aumento importante de 1997 para 1998, para todas as faixas de idade (Tabela 33) e para os idosos o acréscimo foi de 30,4\%. Esse ganho pode não ter ocorrido devido à melhora na oferta de leitos em Maringá, mas ser resultado de encaminhamentos para outros municípios que, ou aumentaram a oferta, ou mesmo passaram a receber esse tipo de internação como os Municípios de Itambé e Santa Fé, ambos pertencentes a $15^{\text {a }}$ Regional de Saúde da qual Maringá é sede. De fato, desde o ano de 1995, o percentual de internações para idosos residentes em Maringá ocorridas no próprio município vem sendo reduzido ano a ano, 94\%; 83\%; $81 \%$ e 67,4\% em 1995, 1996, 1997 e 1998, respectivamente. Além de outros motivos tal ocorrência pode indicar 
restrição ou dificuldade dos idosos no acesso às internações pelo SUS em hospitais de Maringá.

Tabela 37 - Internações em idosos por lesões e envenenamentos, segundo natureza da lesão e tipo de causa externa, Maringá-PR, 1998. (nº e \%).

\begin{tabular}{|c|c|c|c|c|c|c|c|c|c|c|c|c|c|c|}
\hline \multirow[b]{3}{*}{ Natureza da lesão } & \multicolumn{14}{|c|}{ Tipo de causa externa } \\
\hline & \multicolumn{2}{|c|}{ Quedas } & \multicolumn{2}{|c|}{$\begin{array}{l}\text { Exposição } \\
\text { a forças } \\
\text { mecânicas } \\
\text { inanimadas }\end{array}$} & \multicolumn{2}{|c|}{$\begin{array}{l}\text { Acidentes } \\
\text { de } \\
\text { transporte }\end{array}$} & \multicolumn{2}{|c|}{\begin{tabular}{|l|} 
Complicaçðes \\
de assistência \\
médica e \\
cirúrgica \\
\end{tabular}} & \multicolumn{2}{|c|}{$\begin{array}{l}\text { Eventos } \\
\text { cuja } \\
\text { intenção é } \\
\text { indeterminada } \\
\end{array}$} & \multicolumn{2}{|c|}{ Demais } & \multicolumn{2}{|c|}{ Total* } \\
\hline & $\mathrm{n}^{\mathbf{0}}$ & $\%$ & $n^{0}$ & $\%$ & $\mathrm{n}^{\mathbf{0}}$ & $\%$ & $\mathrm{n}^{\mathbf{0}}$ & $\%$ & $\mathrm{n}^{\mathbf{o}}$ & $\%$ & $\mathrm{n}^{\mathbf{o}}$ & $\%$ & $\mathrm{n}^{\mathbf{0}}$ & $\%$ \\
\hline $\begin{array}{l}\text { Traumatismo de } \\
\text { ombro, braço, } \\
\text { cotovelo, } \\
\text { antebraço, punho } \\
\text { e mão }\end{array}$ & 18 & 36,0 & 22 & 44,0 & 2 & 4,0 & 4 & 8,0 & 3 & 6,0 & 1 & 2,0 & 50 & 100 \\
\hline $\begin{array}{l}\text { Traumatismo de } \\
\text { quadril e coxa }\end{array}$ & 20 & 62,5 & 8 & 25,0 & - & $\therefore$ & 2 & 6,3 & 1 & 3,1 & 1 & 3,1 & 32 & 100 \\
\hline $\begin{array}{l}\text { Traumatismo de } \\
\text { joelho, perna, } \\
\text { tornozelo e pé }\end{array}$ & 12 & 63,2 & 4 & 21,1 & 2 & 10,5 & 1 & 5,3 & - & $=$ & $=$ & $\therefore$ & 19 & 100 \\
\hline $\begin{array}{l}\text { Traumatismo da } \\
\text { cabeça e pescoco }\end{array}$ & 6 & 37,5 & 1. & 6,3 & 8 & 50,0 & $=$ & $\therefore$ & 1 & 6,3 & - & $\therefore$ & 16 & 100 \\
\hline $\begin{array}{l}\text { Complicações de } \\
\text { cuidados } \\
\text { médicos }\end{array}$ & 2 & 18,2 & $\therefore$ & $\therefore$ & 2 & 18,2 & 6 & 54,5 & 1 & 9,1 & $\therefore$ & - & 11 & 100 \\
\hline $\begin{array}{l}\text { Traumatismo } \\
\text { múltiplo }\end{array}$ & 4 & 66,7 & $\therefore$ & - & 1. & 16,7 & $=$ & $\therefore$ & - & - & 1 & 16,7 & 6 & 100 \\
\hline $\begin{array}{l}\text { Traumatismo de } \\
\text { tórax e abdome }\end{array}$ & 2 & 66,7 & - & - & 1 & 33,3 & - & - & $\therefore$ & - & $\therefore$ & - & 3 & 100 \\
\hline $\begin{array}{l}\text { Traumatismo de } \\
\text { região não } \\
\text { especificada }\end{array}$ & 2 & 66,7 & $=$ & $=$ & 1 & 33,3 & - & $=$ & $=$ & $=$ & $=$ & $\therefore$ & 3 & 100 \\
\hline Demais & 1 & 16,7 & 2 & 33,3 & 2 & 33,3 & 1 & 16,7 & - & - & - & - & 6 & 100 \\
\hline Total & 67 & 45,9 & 37 & 25,3 & 19 & 13,0 & 14 & 9,6 & 6 & 4,1 & 3 & 2,1 & 146 & 100 \\
\hline
\end{tabular}

*Excluídas 3 internações cujo diagnóstico principal foi codificado como "quedas" (2 casos) e "exposição a forças mecânicas inanimadas" (1 caso).

A Tabela 38 mostra as internações realizadas em Maringá e fora de Maringá, para os anos de 1997 e 1998 . Observou-se crescimento do percentual de internações ocorridas em outros municípios para todas as causas, principalmente para as dounças 
do aparelho geniturinário $(99,6 \%)$, do aparelho respiratório $(96 \%)$ e algumas doenças infecciosas e parasitárias $(92,4 \%)$.

Mesmo com as evoluções epidemiológica e demográfica que trazem consigo mudanças na utilização dos serviços hospitalares, de acordo com LEBRÃO (1999) outros fatores concorrem para a variação na distribuição dos diagnósticos principais de hospitalização. Além dos interesses econômicos e inovações tecnológicas, sempre que existe queda nas hospitalizações por determinada causa, os leitos anteriormente ocupados por pessoas com essas doenças passam, de forma compensatória, a ser ocupados por outros tipos de internações sem que isso signifique, necessariamente, aumento real na incidência dessas doenças na população.

Tabela 38 - Internações em idosos segundo diagnósticos, local de ocorrência e ano, Maringá-PR, 1997-1998. (nº \%).

\begin{tabular}{|c|c|c|c|c|c|c|c|c|c|c|c|c|c|}
\hline \multirow[b]{3}{*}{ Diagnósticos } & \multicolumn{5}{|c|}{1997} & \multicolumn{5}{|c|}{1998} & \multicolumn{3}{|c|}{ Diferença (\%) } \\
\hline & \multicolumn{2}{|c|}{ Maringá } & \multicolumn{2}{|c|}{ Fora } & \multirow{2}{*}{\begin{tabular}{|c|} 
Total \\
$\mathrm{n}$ \\
\end{tabular}} & \multicolumn{2}{|c|}{ Maringá } & \multicolumn{2}{|c|}{ Fora } & \multirow{2}{*}{\begin{tabular}{|c|} 
Total \\
$\mathrm{n}$ \\
\end{tabular}} & $\mathrm{n}$ & \multicolumn{2}{|c|}{$\%$} \\
\hline & $\mathrm{n}$ & $\%$ & $\mathrm{n}$ & $\%$ & & $\mathrm{n}$ & $\%$ & $\mathrm{n}$ & $\%$ & & Mga Fora & Mga & Fora \\
\hline & 1151 & 86,7 & 177 & 13,3 & 1328 & 1034 & 740 & 347 & 251 & 1381 & $-10,296,0$ & $-13,6$ & \\
\hline ório & 475 & 78,8 & 128 & 21,2 & 603 & 605 & 58,4 & 431 & 416 & 1036 & $27,4236,7$ & $-25,9$ & 96,0 \\
\hline & 32 & 71,1 & 13 & 28,9 & 45 & 74 & 09 & 33 & 30,8 & 107 & $131,3 \quad 153,8$ & $-2,7$ & \\
\hline Digestivo & 176 & 71,8 & 69 & 28,2 & 245 & 233 & 70,4 & 98 & 29,6 & 331 & $32,4 \quad 42,0$ & $-2,0$ & 51 \\
\hline Lesões & & 51,0 & 73 & 49,0 & 149 & 43 & 28,9 & 106 & 71,1 & 149 & $-43,4 \quad 45,2$ & $-43,4$ & 45 , \\
\hline Geniturinário & 118 & 85,5 & 20 & 14,5 & 138 & 113 & 71,1 & 46 & 28,9 & 159 & $-4,2 \quad 130,0$ & $-16,9$ & 99,6 \\
\hline Infecciosas & 105 & 82,7 & 22 & 17,3 & 127 & 64 & $00, i$ & 32 & 33,3 & 96 & $-39,0 \quad 45,5$ & $-19,4$ & 92,4 \\
\hline Demais & 225 & 80,9 & 53 & 19,1 & 278 & 402 & 72,8 & 150 & 27,2 & 552 & $78,7 \quad 183,0$ & $-10,0$ & 42,5 \\
\hline TOTAL & 2358 & 80,9 & 555 & 19,1 & 2913 & 2568 & 67,4 & 1243 & 32,6 & 3811 & $8,9124,0$ & $-16,8$ & 71,2 \\
\hline
\end{tabular}

* Excluidos diagnósticos ignorados (22 em 1997 e 18 em 1998)

As variações nos coeficientes de morbidade hospitalar em idosos evidenciadas na Tabela 34 podem ser reflexo ainda, de mudanças nas políticas de saúde, municipais e regionais de um ano para o outro, no que se refere ao estabelecimento de regras para a utilização dos leitos hospitalares, principalmente nos hospitais privados contratados. Em Maringá, em 1997, houve mudança na administração da saúde do município, de gestão semiplena para plena e com isso aumentou o número de AIH refletindo daí, no volume de internações. 
Nos últimos anos tem sido relatada uma crescente retração na oferta dos leitos hospitalares públicos, principalmente nos grandes centros, onde houve queda no número de internações pelo SUS e concomitante elevação nas financiadas por planos de saúde (YAZLLE ROCHA e SIMÕES 1999).

Para o Município de Maringá foi também observada uma situação de escassez de leitos hospitalares para usuários do SUS. Em outras regiões do Estado do Paraná a restrição às internações tem gerado situações críticas tais como relatado por MARGARIDA e col. (1996), de "pacientes serem colocados em ambulâncias nas quais o motorista fazia a busca de vagas pelos hospitais".

Visando organizar essa oferta foram implantadas centrais informatizadas de leitos hospitalares em pontos estratégicos do Estado, com o objetivo de rastrear vagas e garantir a internação pelo SUS aos pacientes encaminhados pelas unidades básicas de saúde (SECRETARIA ESTADUAL DE SAÚDE DO PARANÁ 1995). A despeito desse esforço a escassez de leitos continua e como conseqüência, não é raro o encaminhamento de pacientes residentes em Maringá para hospitais de municípios vizinhos e também para alguns não tão vizinhos pertencentes a outras Regionais de Saúde. Essa situação remete à problemática da utilização e acesso aos serviços de saúde pela população e à garantia ao atendimento integral preconizado pelo SUS.

Os hospitais privados contratados apresentam argumentos, sendo os mais freqüentes os relativos à desatualização dos valores relativos às internações e os atrasos no reembolso. Manual do Ministério da Saúde refere haver dificuldades na relação rede conveniada e SUS, pela remuneração ser muito abaixo do patamar idealizado pela Associação Médica Brasileira, pelos freqüentes atrasos nos pagamentos (entre 60 e 90 dias) pela falta de controle sobre os pagamentos e sobre os serviços prestados ao Ministério da Saúde (MINISTÉRIO DA SAÚDE 1993).

Segundo SILVESTRE e col. (1996) o método de pagamento do governo ao hospital conveniado, que consta de um pagamento global de forma fixa, levando em conta somente uma doença ou o procedimento realizado durante a internação hospitalar, independente do número de enfermidades que o paciente possa apresentar, do tempo de permanência e dos gastos necessários de medicações e de exames complementares, pode ser uma das explicações para as dificuldades que os idosos têm em muitas cidades brasileiras, quando necessitam de uma vaga hospitalar. 
Em estudo, sobre os serviços de saúde no Brasil VIACAVA e BAHIA (1996) revelam que, segundo o número de leitos declarados para a Região Sul, a proporção era de 3,5 e para o Estado do Paraná de 4,3 por 1000 habitantes. Entretanto essa vantagem na disponibilidade de leitos descrita para a Região Sul não deve estar beneficiando todos os segmentos da população já que, para internações pelo SUS a oferta é restrita. A crescente urbanização somada à mudança no perfil demográfico com o crescente aumento da população idosa agrava esse quadro.

No Brasil o setor privado detêm a maioria da capacidade hospitalar instalada e a distribuição dos leitos é bastante diversificada nas várias regiões. SILVA e col. (1996) destacam que a redução na remuneração dos serviços levou inúmeros hospitais privados a interromperem parcial ou totalmente suas atividades se descredenciando do SUS e sempre que possível, dificultando internações que não têm interesse. Para alguns procedimentos hospitalares, geralmente os que remuneram melhor, dificilmente faltam vagas, enquanto para outros elas nunca estão disponíveis.

Em estudo realizado em Ribeirão Preto, foi encontrada importante queda nas internações financiadas pelo setor público, de 76\% em 1986 para 51,7\% em 1996 (YAZLLE ROCHA e SIMÕES 1999). Existem indícios de que se implantou uma divisão de tarefas entre os sistemas público e privado, onde o papel do primeiro é suportar a carga maior para viabilizar o segundo. $O$ que estaria acontecendo com os serviços contratados, seria a seleção da clientela com transferência dos casos não rentáveis do sistema privado, para o SUS.

Não existem dados precisos sobre a utilização da assistência médica supletiva em Maringá atualmente mas, no estudo realizado em 1992, do total de internações hospitalares no município, $26,2 \%$ foram para pacientes particulares e conveniados (MATHIAS e SOBOLL 1996). No entanto, pode-se pressupor que esse quadro tenha se modificado aumentando o contingente da população conveniada no município.

As dificuldades que os gestores das políticas municipais encontram em cumprir os requisitos mínimos de universalidade, integralidade e resolutividade da atenção à saúde ocorrem, principalmente, na oferta de serviços médicos hospitalares que vêm incorporando avanços tecnológicos de complexidade e custos crescentes (NASCIMENTO 1996). A questão crítica da assistência médica hospitalar refere-se justamente, ao relacionamento entre os setores público e privado, considerando que pertence aos hospitais privados o maior número de leitos existentes no país, 
fundamentais para a atenção médica prestada pelo setor público. O que vem sendo observado é uma tendência de incentivo à população a buscar atenção médica supletiva, os planos de medicina de grupo e seguros-saúde, o que já vem ocorrendo para parcela da população que pode pagar por eles, ou que tem acesso através das empresas onde trabalham.

Como grande parte dos idosos está fora do mercado formal de trabalho ou são aposentados ou pensionistas, certamente encontrarão maior dificuldade de acesso aos planos privados de atenção à saúde, o que pode, parcialmente, justificar sua maior utilização dos serviços públicos de saúde, em especial de leitos hospitalares. Conhecer essa realidade significa paralelamente ao estudo das características demográficas e epidemiológicas das internações, abordar uma dificuldade adicional enfrentada pela população idosa que é o acesso aos leitos hospitalares, sua maior usuária e dependente dos serviços públicos de saúde no Brasil.

\subsubsection{Morbidade hospitalar em idosos segundo duração média da internação}

A análise de indicadores de morbidade hospitalar como a duração média da internação (DMI) e o coeficiente de mortalidade hospitalar $(\mathrm{CMH})$ pode trazer informações adicionais para caracterização da estrutura etária, da procedência dos pacientes, da eficácia do diagnóstico, tratamento e da eficiência dos serviços de apoio. A análise do $\mathrm{CMH}$, por sua vez, pode informar sobre a complexidade da atenção prestada, além do cumprimento ou não da finalidade principal do hospital que é curar (LEBRÃO 1982). Neste trabalho esses dois indicadores foram analisados apenas para as internações de 1998, último ano do período.

A Tabela 39 distribui os dias de hospitalização segundo proporções acumuladas de altas. Foi observando que no quarto dia mais de $70 \%$ dos pacientes já havia recebido alta. As medianas tenderam a ser mais elevadas para os homens de até 79 anos (4,0 dias), ocorrendo o contrário para as mulheres que foi maior a partir de 70 anos de idade (4,0 dias, Tabela 39).

A duração média da internação (DMI) foi de 4,4 dias (Tabela 40), lembrando que foram excluídas as internações por transtornos mentais que certamente elevariam esse indicador. 
A variável sexo parece influenciar na DMI (D’OLEO 1991; LEBRÃO 1982) mas para os idosos residentes em Maringá não houve diferença importante no tempo de hospitalização entre os sexos (4,46 para os homens e 4,40 dias para as mulheres) (Tabela 40). Com relação às faixas de idade observou-se que as DMI foram mais elevadas nos idosos de 70-74 anos mas apresentaram tendência de queda após essa idade, para ambos os sexos.

Tabela 39 - Freqüências relativas acumuladas (\%) e medianas dos dias de hospitalização, em idosos segundo sexo e idade, Maringá-PR, 1998.

\begin{tabular}{|c|c|c|c|c|c|c|c|c|c|}
\hline \multirow[b]{2}{*}{ Dias } & \multicolumn{2}{|c|}{$60-69$} & \multicolumn{2}{|c|}{$70-79$} & \multicolumn{2}{|c|}{80 e mais } & \multicolumn{3}{|c|}{ Total } \\
\hline & M & $\mathrm{F}$ & M & $\mathrm{F}$ & M & $\mathrm{F}$ & M & $\mathrm{F}$ & Total \\
\hline 1 & 8,0 & 6,9 & 5,8 & 6,9 & 11,0 & 5,0 & 7,7 & 6,5 & 7,1 \\
\hline 2 & 23,3 & 22,3 & 21,3 & 18,9 & 25,3 & 21,3 & 22,9 & 20,7 & 21,8 \\
\hline 3 & 45,4 & 50,4 & 44,5 & 44,1 & 50,0 & 38,8 & 45,9 & 45,5 & 45,7 \\
\hline 4 & 72,8 & 74,6 & 70,6 & 73,5 & 77,0 & 72,4 & 72,7 & 73,7 & 73,2 \\
\hline 5 & 81,1 & 81,7 & 81,6 & 85,8 & 88,1 & 82,5 & 82,6 & 83,5 & 83,0 \\
\hline 6 & 86,4 & 86,1 & 85,3 & 90,5 & 91,3 & 88,7 & 86,8 & 88,4 & 87,6 \\
\hline 7 & 90,0 & 90,8 & 89,5 & 92,6 & 92,4 & 91,5 & 90,3 & 91,7 & 91,0 \\
\hline 8 & 92,6 & 92,7 & 91,5 & 94,3 & 93,9 & 93,5 & 92,4 & 93,5 & 93,0 \\
\hline 9 & 94,1 & 94,3 & 92,8 & 95,1 & 94,8 & 95,0 & 93,7 & 94,8 & 94,3 \\
\hline $10-20$ & 98,9 & 99,0 & 98,0 & 98,3 & 99,7 & 98,7 & 98,7 & 98,7 & 98,7 \\
\hline $21-30$ & 99,8 & 99,6 & 99,5 & 99,3 & 100,0 & 99,7 & 99,6 & 99,5 & 99,6 \\
\hline 31 e mais & 100 & 100 & 100 & 100 & - & 100 & 100 & 100 & 100 \\
\hline Média & 4,5 & 4,3 & 4,7 & 4,5 & 4,0 & 4,5 & 4,5 & 4,4 & 4,4 \\
\hline Mediana & 4,0 & 3,0 & 4,0 & 4,0 & 3,5 & 4,0 & 4,0 & 4,0 & 4,0 \\
\hline
\end{tabular}

Tabela 40 - Duração média da internação em idosos (em dias) segundo sexo e idade, Maringá-PR, 1998.

\begin{tabular}{cccc}
\hline Idade & Masculino & Feminino & Total \\
\hline $60-64$ & 4,55 & 4,45 & 4,51 \\
$65-69$ & 4,38 & 4,21 & 4,29 \\
$70-74$ & 4,85 & 4,52 & 4,68 \\
$75-79$ & 4,49 & 4,47 & 4,48 \\
$80-84$ & 3,78 & 4,38 & 4,06 \\
85 e mais & 4,16 & 4,35 & 4,27 \\
\hline Total & 4,46 & 4,40 & 4,43 \\
\hline
\end{tabular}


Para uma análise mais detalhada as DMI foram observadas segundo especialidade cirúrgica da internação partindo do pressuposto que estas fossem mais longas o que de fato foi constatado tanto para os homens (5,2 dias) como para as mulheres $(5,1$ dias).

O Gráfico 41 apresenta as DMI segundo sexo e idade para as duas possibilidades, quais sejam: todas as internações e com exclusão das cirurgias. Os resultados indicam que os procedimentos cirúrgicos aumentaram a DMI entre 70 e 79 anos, para ambos os sexos e entre 60 e 64 e acima de 80 anos de idade, para as mulheres. A DMI segundo diagnósticos de internação é diferente pois cada patologia é tratada como um sistema individual ou como um processo particular de cuidado. $O$ produto do processo de cuidado para a pneumonia é bem distinto do produto do cuidado de uma fratura de fềmur, por exemplo (HAND e col. 1997). Para os idosos residentes em Maringá os dados indicaram, para a maioria dos diagnósticos, que os homens ficaram mais tempo hospitalizados, exceto para as doenças do aparelho digestivo e algumas doenças infecciosas e parasitárias e neoplasias, cujas DMI foram mais elevadas para as mulheres $(5,33 ; 5,15$ e 7,78 dias, respectivamente, Tabela 41).

Gráfico 41 - Duração média da internação em idosos (em dias), total e excluídas as cirurgias, segundo sexo e idade, Maringá-PR, 1998.
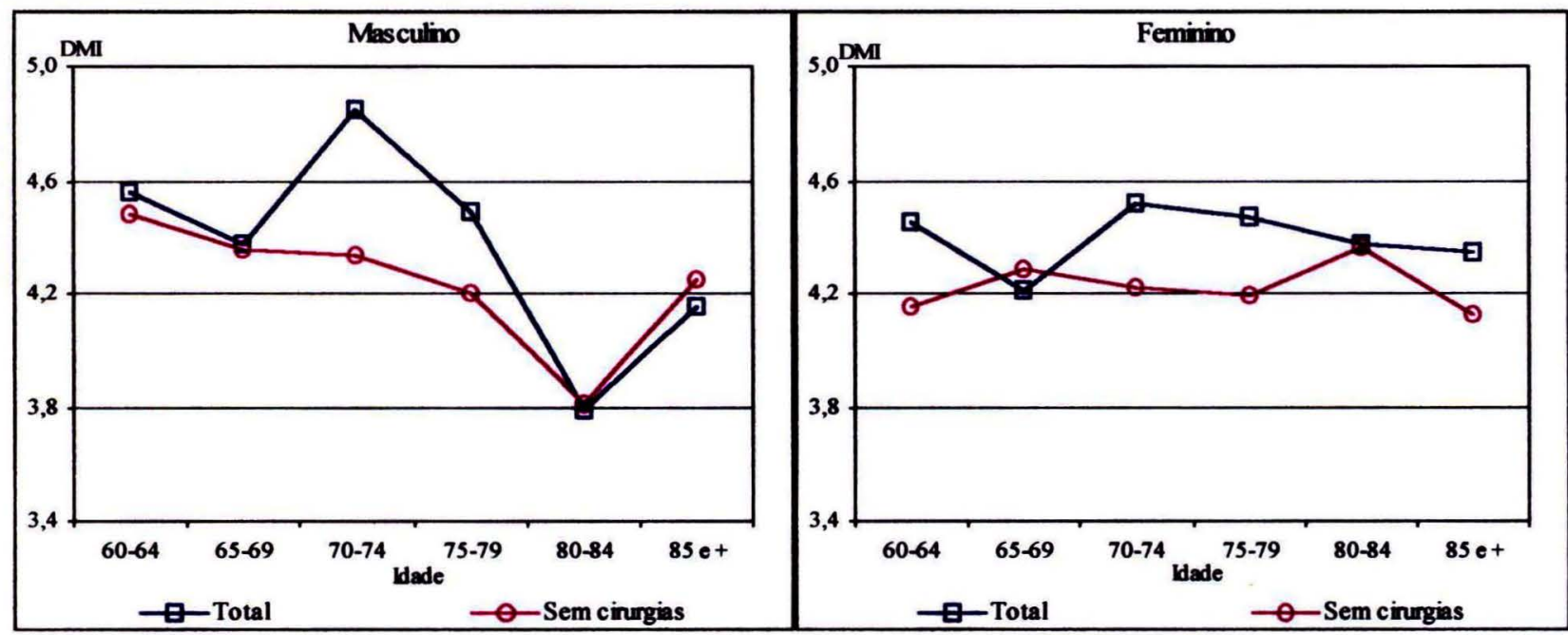

Para as doenças do aparelho circulatório a DMI não foi das mais elevadas (4,35 dias, Tabela 41) e, especificamente para as doenças cerebrovasculares a duração da internação não apresentou diferença em relação à média geral (4,41 dias). As 
hospitalizações por doenças do sistema nervoso, para as quais aproximadamente $90 \%$ ocorreram por acidente vascular cerebral e síndromes correlatas duraram, em média, 6,6 dias, possivelmente por se tratarem de quadros clínicos que justificam a necessidade de maior tempo de observação.

No grupo das doenças infecciosas e parasitárias estão incluídas as outras doenças bacterianas cuja DMI foi de 5,9 dias, possivelmente devido às septicemias que faz supor casos mais graves. Tanto para as doenças infecciosas como para as doenças do sistema nervoso o que determinou a duração da internação pode ter sido a gravidade do caso, já que para o primeiro grupo não foi realizada nenhuma cirurgia e para o segundo apenas duas, num total de 121 internações.

Tabela 41 - Duração média da internação em idosos (em dias) segundo principais diagnósticos e sexo, Maringá-PR, 1998.

\begin{tabular}{|c|c|c|c|}
\hline Diagnóstico & Masculino & Feminino & Total \\
\hline Doenças do aparelho circulatório & 4,38 & 4,32 & 4,35 \\
\hline Doenças do aparelho respiratório & 4,01 & 3,88 & 3,94 \\
\hline Doenças infecciosas & 4,74 & 5,15 & 4,94 \\
\hline Doenças do aparelho digestivo & 4,25 & 5,33 & 4,75 \\
\hline Doenças do sistema nervoso & 6,82 & 6,26 & 6,60 \\
\hline Doenças endócrinas, nutric, e metabólicas & 6,73 & 3,81 & 4,80 \\
\hline Neoplasias & 7,75 & 7,78 & 7,77 \\
\hline Doenças do aparelho geniturinário & 5,50 & 4,12 & 4,93 \\
\hline Lesões e envenenamentos & 4,54 & 4,33 & 4,40 \\
\hline Total & 4,46 & 4,40 & 4,43 \\
\hline
\end{tabular}

Em relação às doenças do aparelho geniturinário as DMI foram maiores para os homens mas a distribuição por idade foi similar para ambos os sexos (Gráfico 42), mais elevada na faixa de 70 a 74 anos, cuja média foi de 8 dias de hospitalização. Neste caso, o percentual de internações por cirurgias foi de $45,3 \%$, bem superior para os homens do que para as mulheres $(80,4 \%$ e $31 \%$, respectivamente) o que pode explicar a sua maior permanência no hospital por esse grupo de diagnósticos $(5,5$ contra 4,1 dias para as mulheres) (Tabela 41).

No caso das internações por lesões e envenenamentos o alto percentual de cirurgias $(90 \%)$ parece não ter feito elevar o tempo de hospitalização, pois a media de 
permanência não foi diferente da relativa a todas as internações $(4,40$ contra 4,43$)$ (Tabela 41).

Gráfico 42 - Duração média da internação em idosos (em dias) segundo diagnósticos, sexo e idade, Maringá-PR, 1998.

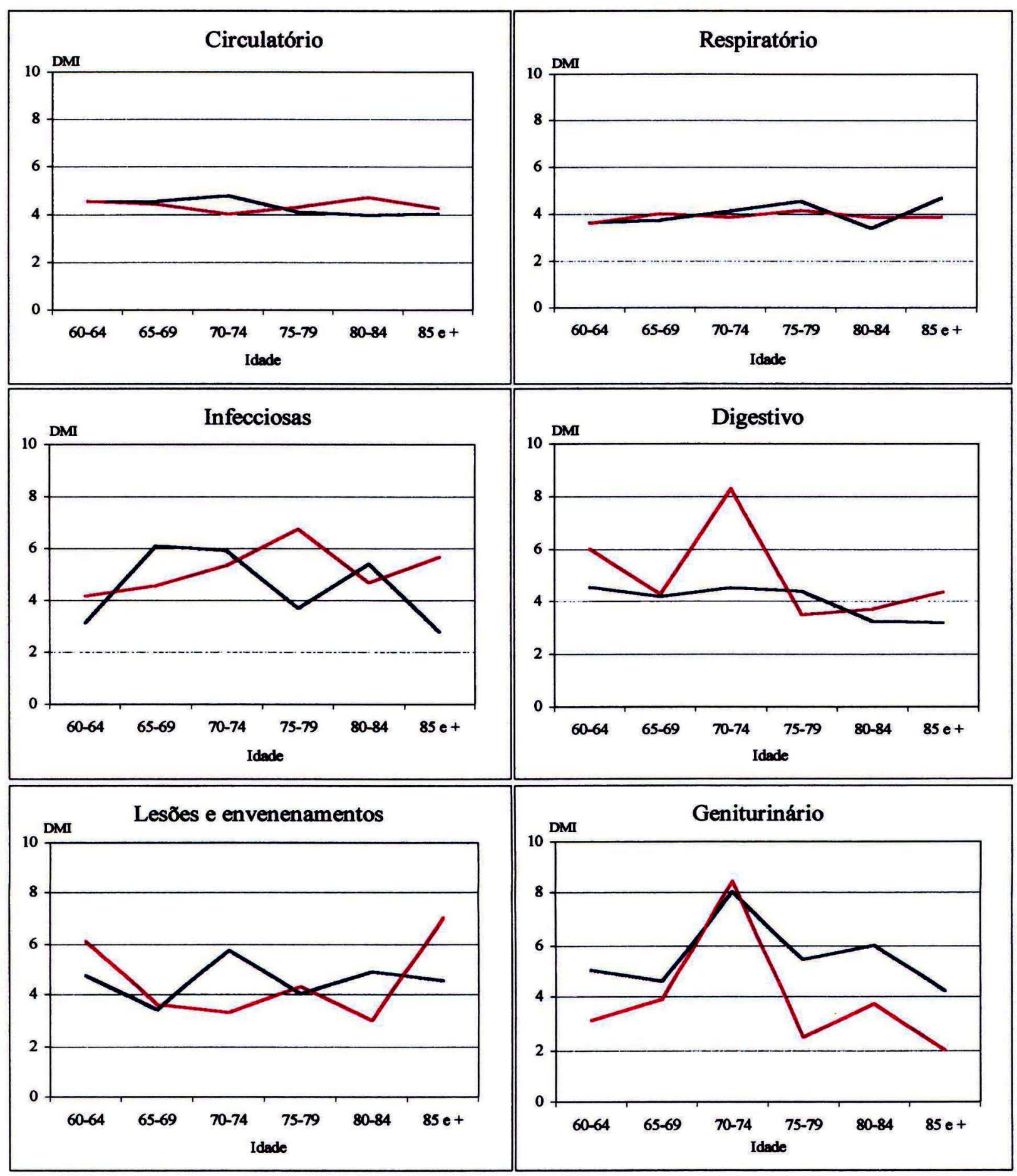

Masculino Feminino 
Mesmo não sendo um grupo de causas importante nas hospitalizações de idosos as anomalias congênitas (27 internações, ou 0,7\% do total em 1998, Anexo 6) duraram 7,5 dias em média com 93\% das internações em clínica cirúrgica. Chamou atenção que para 10 casos houve registro do diagnóstico secundário, dos quais 2 foram por fratura de fềmur (CID-10 S72) e 8 por "impacto acidental ativo causado por outros objetos" (CID-10 W22), sugerindo que os diagnósticos principais possam ter sido codificados equivocadamente.O perfil de DMI descrito neste estudo foi semelhante ao encontrado para Ribeirão Preto, em 1988 ou seja, permanência mediana de 4,0 dias tanto para os "idosos jovens" (60 a 74 anos) como para os "idosos velhos" (75 anos e mais de idade) considerada baixa pelo autor para essa faixa etária. A DMI foi de 5,63 dias não havendo diferença entre os sexos (5,63 e 5,64 para o masculino e feminino, respectivamente) (GERMANO NETO 1991). Para o Município de São Carlos em 1996, a DMI foi mais elevada do que a de Maringá mas também não apresentou diferença entre os sexos (6,1 dias) (CASELLI 1998).

Para Maringá, em 1992, foi constatado que os grupos etários com internações mais demoradas foram o das crianças menores de um ano e dos adultos acima de 50 anos de idade (MATHIAS e SOBOLL 1996). Naquela época, as DMI relativas aos adultos foram ligeiramente superiores às encontradas no presente estudo, ou seja, 4,8; 5,0 e 4,9 dias para os pacientes de 55-64; 65-74 e 75 anos e mais de idade. Foi constatado ainda que, as DMI cujas internações haviam sido financiadas pelo SUS eram $40 \%$ e $44,2 \%$ mais elevadas do que as financiadas por convênios e particulares, respectivamente (MATHIAS 1994).

O tempo de internação pode ser influenciado por intercorrências durante a internação como complicações hospitalares, por estágios mais avançados da doença no momento da admissão, ou ainda pela existência de vários diagnósticos associados (HUNT 1991). Segundo YAZZLE-ROCHA (1978) além das internações poderem ser "induzidas" pela estrutura da assistência hospitalar disponível ou pela existência de leitos, a sua duração pode receber influência do critério adotado por cada equipe médica em relação ao tratamento, à capacidade resolutiva de cada instituição e da complexidade de serviços oferecidos.

Embora tenha havido rápido aumento na proporção de pacientes mais idosos e possivelmente na gravidade dos casos hospitalizados, entre 1988 e 1993, a DMI em hospitais italianos decresceu (PAHOR e col. 1996). De acordo com o estudo, naiyuele 
país, a necessidade de diminuir a média de permanência pode ter ocorrido em razão da queda no número de leitos hospitalares e do aumento da demanda por serviços.

Em estudo realizado na Espanha TUUPONEN e col. (1993) encontraram que entre 1972 e 1986 houve aumento do número de hospitalizações, em todos os grupos de idade e que, embora a DMI seja mais elevada do que a observada em hospitais brasileiros, de 16,1 dias caiu para 9 dias para o homem e de 15 para 10 dias para a mulher. Para a Dinamarca, entre 1979 e 1993, VALLGARDA (1999) afirma que o aumento das taxas de hospitalização na população veio acompanhado da queda na média de permanência de 10 para 6 dias para todos os pacientes e de 17 para 10 dias para pacientes idosos, com 65 anos e mais de idade. Para BRAMELD e col. (1998) essa tendência pode estar relacionada às mudanças na prática médica ou melhora na qualidade do cuidado hospitalar como o crescimento dos procedimentos cirúrgicos menos invasivos resultando em altas no mesmo dia, tratamentos realizados em serviços ambulatoriais, além das restrições de ordem econômica e de mudanças no método de financiamento.

Diante da análise da média de permanência hospitalar algumas considerações relativas às internações em idosos poderiam ser destacadas. $\mathrm{O}$ presente estudo parece sinalizar para algumas mudanças importantes nas características das hospitalizações financiadas pelo SUS, durante um período relativamente curto de tempo. Entre $1995 \mathrm{e}$ 1998, das internações em idosos, o percentual dos pacientes que tinham 85 anos e mais de idade, por exemplo, cresceu $44 \%$ para o sexo masculino e $31 \%$ para o feminino. Entretanto, a DMI caiu $13,5 \%$ para o sexo masculino e $6,4 \%$ para o feminino no mesmo período, repetindo tendência descrita para outras localidades. Considerando que $46 \%$ das internações durou apenas 3 dias e que com 5 dias $83 \%$ dos idosos tinha recebido alta (Tabela 39), a queda na DMI pode indicar também, além dos fatores já relacionados, a ocorrência de desospitlizações precoces, fazendo com que este indicador esteja subestimado, já que as altas precoces poderiam resultar em sucessivas reinternações, também de curta duração.

Outro resultado que merece ser comentado consiste na menor permanência hospitalar à medida que aumenta a idade. De certa forma esse dado surpreende na medida em que esperavam-se internações mais longas com o avançar da idade em virtude de uma provável fragilidade e maior gravidade dos casos em idosos mais velhos fazendo-os permanecer maior período de tempo no hospital. 
É fato que a menor permanência hospitalar não significa necessariamente desvantagem para o paciente idoso, ao contrário, segundo GERMANO NETO (1991) provavelmente, mesmo recebendo alta precocemente, o idoso pode receber no domicílio os cuidados da família, necessários a uma boa recuperação. Sua longa permanência no hospital também poderia significar maiores riscos como quedas, infecções hospitalares, úlceras de decúbito, isolamento e até o abandono. Contudo, é preciso observar que as altas precoces antes de significar uma melhor eficiência no uso de recursos hospitalares podem sugerir ainda, a existência de hospitalizações desnecessárias (GERMANO NETO 1991).

Finalmente, qualquer que seja a razão da diminuição da média de permanência é necessário avaliar até que ponto e de que maneira tal ocorrência estaria influenciando a qualidade da assistência prestada à população e a um dos segmentos mais frágeis que é o idoso.

\subsubsection{Morbidade hospitalar em idosos segundo tipo de saída}

É objeto de discussão o uso do coeficiente de mortalidade hospitalar (CMH) como indicador de qualidade da assistência prestada. LEBRÃO e col. (1993) afirmam que as taxas de mortalidade hospitalar não ajustadas pela gravidade da doença podem refletir diferenças na composição nosológica dos pacientes admitidos mas não necessariamente na qualidade da assistência. Portanto, a análise a seguir teve como objetivo descrever o comportamento da mortalidade hospitalar em idosos de Maringá segundo sexo, idade e diagnóstico principal de internação.

No ano de 1998, entre as 3829 internações em idosos residentes em Maringá ocorreram 247 óbitos, o que representóu um $\mathrm{CMH}$ de 6,5 óbitos para cada 100 internações, maior no sexo masculino ( 7,1 contra 5,9 no feminino) e nas idades mais avançadas chegando a quase 10 óbitos para cada 100 internações em homens com 85 anos e mais de idade (Tabela 42 e Gráfico 43).

Quando analisados segundo os diagnósticos, os CMH apresentaram diferenças expressivas. Entre as causas mais importantes de letalidade hospitalar estão as doenças infecciosas $(27,1 \%)$, as doenças do sistema nervoso $(13,2 \%)$, as doenças endócrinas, nutricionais e metabólicas $(12,4 \%)$ as doenças do aparelho circulatório (7\%) e as neoplasias (6,5\%). A Tabela 43 mostra que foram as doenças infecciósas e 
parasitárias que tiveram maior CMH $(27,1 \%)$ mais do que o dobro das doenças do sistema nervoso e das doenças endócrinas, nutricionais e metabólicas $(13,2 \%$ e $12,4 \%$, respectivamente).

Tabela 42 - Internações, óbitos e coeficientes de mortalidade hospitalar em idosos (por 100 internações) segundo sexo e idade, Maringá-PR, 1998.

\begin{tabular}{|c|c|c|c|c|c|c|c|c|c|}
\hline \multirow[b]{2}{*}{ Idade } & \multicolumn{3}{|c|}{ Masculino } & \multicolumn{3}{|c|}{ Feminino } & \multicolumn{3}{|c|}{ Total } \\
\hline & $\begin{array}{l}\text { Interna } \\
\text { çőes }\end{array}$ & Óbitos & CMH & 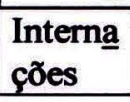 & Óbitos & CMH & \begin{tabular}{|l}
$\begin{array}{l}\text { Interna } \\
\text { çóes }\end{array}$ \\
a
\end{tabular} & Óbitos & CMH \\
\hline $60-64$ & 387 & 19 & 4,9 & 347 & 16 & 4,6 & 734 & 35 & 4,8 \\
\hline $65-69$ & 414 & 21 & 5,1 & 425 & 14 & 3,3 & 839 & 35 & 4,2 \\
\hline $70-74$ & 418 & 25 & 6,0 & 439 & 32 & 7,3 & 857 & 57 & 6,7 \\
\hline $75-79$ & 337 & 30 & 8,9 & 319 & 22 & 6,9 & 656 & 52 & 7,9 \\
\hline $80-84$ & 189 & 19 & 10,1 & 170 & 12 & 7,1 & 359 & 31 & 8,6 \\
\hline 85 e mais & 155 & 20 & 12,9 & 229 & 17 & 7,4 & 384 & 37 & 9,6 \\
\hline Total & 1900 & 134 & 7,1 & 1929 & 113 & 5,9 & 3829 & 247 & 6,5 \\
\hline
\end{tabular}

Gráfico 43 - Coeficientes de mortalidade hospitalar em idosos (por 100 internações), segundo sexo e idade, Maringá-PR, 1998.

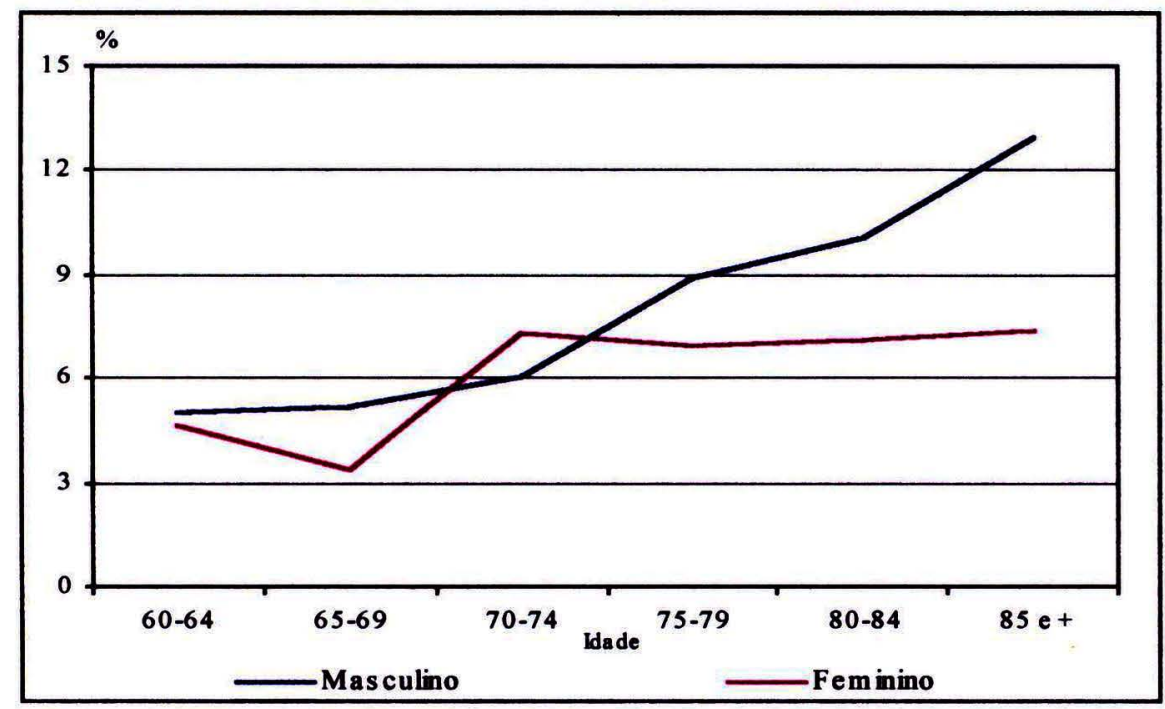

Entre as 9 principais causas de óbito os homens tiveram maior letalidade em 6 delas. O CMH todavia só teve diferença importante entre os sexos, para as doenças infecciosas e parasitárias (34,7 contra 19,1 do sexo feminino). 
Das doenças infecciosas e parasitárias 25 dos 26 óbitos ocorreram por septicemia, dos quais $64 \%$ para o sexo masculino. Já para as doenças endócrinas, nutricionais e metabólicas 50\% (6 óbitos) foram por desnutrição e 41,7\% (5 óbitos) por desidratação (Tabela 44). Entre os óbitos por doenças do aparelho circulatório $55,2 \%$ foram por outras formas de doenças do coração e destes, $96 \%$ ( 51 óbitos) por

Tabela 43 - Coeficiente de mortalidade hospitalar em idosos (por 100 internações), segundo diagnóstico e sexo, Maringá-PR, 1998.

\begin{tabular}{l|r|r|r|r|r|r|r|r|r}
\hline & \multicolumn{4}{|c|}{ Masculino } & \multicolumn{3}{c|}{ Feminino } & \multicolumn{3}{c}{ Total } \\
\cline { 2 - 11 } Diagnóstico & $\begin{array}{l}\text { Interna } \\
\text { ções }\end{array}$ & Óbitos & CMH & $\begin{array}{l}\text { Interna } \\
\text { ções }\end{array}$ & Óbitos & CMH & $\begin{array}{l}\text { Interna } \\
\text { ções }\end{array}$ & Óbitos & CMH \\
\hline Circulatório & 708 & 48 & 6,8 & 673 & 48 & 7,1 & 1381 & 96 & 7,0 \\
Respiratório & 504 & 31 & 6,2 & 532 & 24 & 4,5 & 1036 & 55 & 5,3 \\
Infecciosas & 49 & 17 & 34,7 & 47 & 9 & 19,1 & 96 & 26 & 27,1 \\
Digestivo & 179 & 9 & 5,0 & 152 & 7 & 4,6 & 331 & 16 & 4,8 \\
Sistema nervoso & 74 & 11 & 14,9 & 47 & 5 & 10,6 & 121 & 16 & 13,2 \\
Endócrinas & 33 & 4 & 12,1 & 64 & 8 & 12,5 & 97 & 12 & 12,4 \\
Neoplasias & 40 & 3 & 7,5 & 67 & 4 & 6,0 & 107 & 7 & 6,5 \\
Geniturinário & 93 & 3 & 3,2 & 66 & 3 & 4,5 & 159 & 6 & 3,8 \\
Lesões & 56 & 3 & 5,4 & 93 & 2 & 2,2 & 149 & 5 & 3,4 \\
Demais & 164 & 5 & 3,0 & 188 & 3 & 1,6 & 352 & 8 & 2,3 \\
\hline Total* & 1900 & 134 & 7,1 & 1929 & 113 & 5,9 & 3829 & 247 & 6,5 \\
\hline
\end{tabular}

insuficiência cardíaca não especificada. A doença cerebrovascular com 15 óbitos, foi a segunda mais importante com $66,7 \%$ deles no sexo masculino.

Alguns fatores importantes devem ser observados na interpretação do $\mathrm{CMH}$, como a gravidade dos casos admitidos, a estrutura etária da população e a complexidade dos serviços hospitalares oferecidos.

Foi observado que além da idade do paciente, do sexo e do diagnóstico de internação o CMH também é diferente segundo a fonte de financiamento da internação. Em Maringá, em 1992, o CMH para internações financiadas pelo SUS foi maior se comparado às conveniadas e às particulares $(3,4 ; 1,1$ e 0,4 , respectivamente) ressaltando-se entretanto, que havia diferença na distribuição por idade, sexo e diagnósticos mais freqüentes dos pacientes de acordo com a fonte pagadora (MATHIAS e SOBOLL 1996). A fonte pagadora da internação poderia ser 
então utilizada como indicador para o estudo das desigualdades das hospitalizações segundo nível sócio-econômico dos pacientes (YAZLLE-ROCHA e col 1997).

Tabela 44 - Coeficientes de mortalidade hospitalar em idosos (por 100 internações), segundo diagnóstico selecionados e sexo, Maringá-PR, 1998.

\begin{tabular}{l|rrr|rr|r|r|r|r|r}
\hline & \multicolumn{3}{|c|}{ Masculino } & \multicolumn{3}{c|}{ Feminino } & \multicolumn{3}{c}{ Total } \\
\cline { 2 - 11 } Diagnóstico & Int. & Óbitos & CMH & Int. & Óbitos & CMH & Int. & Óbitos & CMH \\
\hline Insuficiência respiratória & 31 & 17 & 54,8 & 15 & 9 & 60,0 & 46 & 26 & 56,5 \\
Outras doenças bacterianas & 31 & 16 & 51,6 & 26 & 9 & 34,6 & 57 & 25 & 43,9 \\
Desidratação & 10 & 2 & 20,0 & 8 & 3 & 37,5 & 18 & 5 & 27,8 \\
Desnutrição & 18 & 2 & 11,1 & 11 & 4 & 36,4 & 29 & 6 & 20,7 \\
Neoplasia órgãos digestivos & 17 & 2 & 11,8 & 20 & 4 & 20,0 & 37 & 6 & 16,2 \\
AVC isquêmico transitório & 65 & 11 & 16,9 & 43 & 5 & 11,6 & 108 & 16 & 14,8 \\
Outras d. aparelho digestivo & 36 & 5 & 13,9 & 22 & 2 & 9,1 & 58 & 7 & 12,1 \\
Cerebrovascular & 93 & 10 & 10,8 & 74 & 5 & 6,8 & 167 & 15 & 9,0 \\
Doença isquêmica do coração & 86 & 6 & 7,0 & 98 & 8 & 8,2 & 184 & 14 & 7,6 \\
Outras form doenças coração & 368 & 24 & 6,5 & 337 & 29 & 8,6 & 705 & 53 & 7,5 \\
D.card.pulm. e da circul. pulm. & 77 & 5 & 6,5 & 53 & 3 & 5,7 & 130 & 8 & 6,2 \\
DPOC & 315 & 8 & 2,5 & 354 & 9 & 2,5 & 669 & 17 & 2,5 \\
Pneumonia & 144 & 4 & 2,8 & 147 & 3 & 2,0 & 291 & 7 & 2,4 \\
Demais & 602 & 22 & 3,7 & 710 & 20 & 2,8 & 1312 & 42 & 3,2 \\
\hline Total & 1893 & 134 & 7,1 & 1918 & 113 & 5,9 & 3811 & 247 & 6,5 \\
\hline
\end{tabular}

Então, fatores como a possivel demora ou dificuldade no acesso à assistência médica, diagnóstico de internação (GERMANO NETO 1991), ajustados à gravidade, à idade, à fonte de financiamento e aos diagnósticos associados, devem ser considerados na interpretação do $\mathrm{CMH}$. 


\subsubsection{Morbidade hospitalar em 1998 e mortalidade em idosos no triênio} 1996-1998

Em geral os agravos crônicos prevalentes na população ou os motivos de utilização de serviços de saúde podem representar, em grande parte, os mesmos que compõem as causas de óbito, ainda que este possa ocorrer após várias décadas de convivência do indivíduo com a doença (RAMOS e SAAD 1990), fazendo com que a magnitude desses agravos ocorra de forma variável. Acrescenta-se que, além das doenças crônicas os idosos também estão expostos a alguns riscos que está exposto o restante da população, embora com intensidade e características próprias, como é o caso dos acidentes e violências. Assim, como a convivência do indivíduo com algumas doenças é longa, quando os coeficientes de morbidade hospitalar são comparados aos de mortalidade para esses agravos, certamente serão maiores os relativos às hospitalizações. Nesse sentido, foi feita análise comparativa dos coeficientes de hospitalização e de mortalidade para melhor observar o comportamento desses indicadores para a população idosa residente em Maringá.

Um primeiro aspecto que foi analisado para as hospitalizações e óbitos foi a idade. O Quadro 1 mostra que a média de idade dos idosos internados variou pouco entre 1995 e 1998, ficando em torno de 72 anos, mas também mostra que as médias de idade foram maiores para os óbitos.

Quadro 1 - Média de idade de internação e de óbito em idosos segundo sexo e ano, Maringá-PR, 1995 a 1998.

\begin{tabular}{|c|c|c|c|c|c|c|c|c|c|}
\hline & \multicolumn{3}{|c|}{ Óbito (a) } & \multicolumn{3}{c|}{ Internação (b) } & \multicolumn{3}{c|}{ Diferença (a-b) } \\
\cline { 2 - 10 } Ano & M & F & Total & M & F & Total & M & F & Total \\
\hline 1995 & 73,5 & 75,7 & 74,5 & 71,4 & 72,9 & 72,2 & 2,1 & 2,8 & 2,3 \\
1996 & 74,3 & 76,5 & 75,3 & 71,8 & 72,7 & 72,3 & 2,5 & 3,8 & 3,0 \\
1997 & 73,5 & 76,3 & 74,7 & 72,0 & 72,2 & 72,1 & 1,5 & 4,1 & 2,6 \\
1998 & 74,4 & 77,4 & 75,8 & 72,0 & 72,7 & 72,4 & 2,4 & 4,7 & 3,4 \\
\hline
\end{tabular}

Verificou-se que, em relação ao sexo, mesmo com pequena diferença, no momento da internação as mulheres têm média de idade ligeiramente mais elevada do que os homens. Para os óbitos a diferença nas médias de idade entre os sexos foi 
maior, observando-se aumento de 2,2 para 3 anos, entre 1995 e 1998, com vantagem para as mulheres.

Entre os homens, a diferença entre a média de idade na internação e óbito variou pouco no período sendo de, aproximadamente, 2 anos e entre as mulheres oscilou de 2,8 anos em 1995, para 4,7 em 1998 (Quadro 1). Embora esses resultados considerem um pequeno espaço de tempo, é razoável supor que a diferença das médias de idade para as mulheres esteja aumentando ao passo que, para os homens esse aumento não foi observado. Esses dados podem mostrar, mais uma vez, e em um curto espaço de tempo o adiamento do óbito para idades mais avançadas, principalmente para o sexo feminino. Por outro lado, parece não haver o concomitante adiamento no aparecimento da doença ou ocorrência do agravo à saúde do idoso pois a média de idade de internação, nos quatro anos estudados, praticamente não mudou. Segundo VERBRUGGE (1984) o aumento da longevidade para a população idosa pode ser explicado, em parte, pelo progresso nas técnicas médicas, principalmente na prevenção secundária da doença, que reduziram a mortalidade devido a muitas doenças, sobretudo minimizando suas complicações.

A distribuição dos diagnósticos mais freqüentes mostrou que as três primeiras causas de óbito, as doenças do aparelho circulatório, neoplasias e respiratório somaram $73 \%$ e as doenças do aparelho circulatório, respiratório e digestivo, $72,1 \%$ das internações (Tabela 45).

Entre os mais freqüentes, as neoplasias constituíram o motivo de internação que apresentou maior diferença se comparado ao padrão de distribuição das causas de óbito. O fato das neoplasias serem a segunda causa de óbito, com $18 \%$ e apenas aparecerem em sétimo lugar com $2,8 \%$ das hospitalizações, suscita algumas questões. Em primeiro lugar observa-se que o tratamento clínico ou medicamentoso das neoplasias é feito, em geral, em clínicas ou ambulatórios sem necessitar de hospitalização. De fato, das internações por neoplasias, em idosos residentes em Maringá, no ano de 1998, 86\% foram para tratamento cirúrgico, o que indica pouca utilização dos leitos hospitalares para tratamento clínico desses diagnósticos. Entretanto, pode ocorrer de internações por neoplasias serem codificadas como outros diagnósticos. Sobre essa possibilidade, a análise da concordância dos diagnósticos principais de internação registrados nas $\mathrm{AIH}$ com os registrados nos prontuários médicos, realizada em Maringá, para o ano de 1992, mostrou que o capítulo das 
Tabela 45 - Internações e óbitos em idosos (\% e coeficientes por 1000 habitantes), segundo causa e sexo, Maringá-PR, 1998 e triênio 1996-1998.

\begin{tabular}{|c|c|c|c|c|c|}
\hline \multicolumn{6}{|c|}{ Masculino } \\
\hline \multicolumn{3}{|c|}{ Internações (1998) } & \multicolumn{3}{|c|}{ Óbitos (1996-1998) } \\
\hline Diagnóstico & $\%$ & coef & Causa & $\%$ & coef \\
\hline Circulatório & 37,4 & 65,7 & Circulatório & 39,8 & 18,32 \\
\hline Respiratório & 26,6 & 46,8 & Neoplasias & 20,2 & 9,30 \\
\hline Digestivo & 9,5 & 16,6 & Respiratório & 13,2 & 6,06 \\
\hline Geniturinário & 4,9 & 8,6 & Externas & 4,8 & 2,20 \\
\hline Sist nervoso & 3,9 & 6,9 & $\begin{array}{l}\text { Digestivo } \\
\text { Endócrinas }\end{array}$ & 4,3 & 2,00 \\
\hline Lesões & 3,0 & 5,2 & Infecciosas & 3,4 & 1,56 \\
\hline Infecciosas & 2,6 & 4,5 & Geniturinário & 1,8 & 0,84 \\
\hline \multicolumn{6}{|c|}{ Feminino } \\
\hline \multicolumn{3}{|c|}{ Internações (1998) } & \multicolumn{3}{|c|}{ Óbitos (1996-1998) } \\
\hline Diagnóstico & $\%$ & coef & Causa & $\%$ & coef \\
\hline Circulatório & 35,1 & 53,2 & Circulatório & 45,3 & 14,47 \\
\hline Respiratório & 27,7 & 42,1 & Neoplasias & 15,1 & 4,83 \\
\hline Digestivo & 7,9 & 12,0 & Respiratório & 12,5 & 4,00 \\
\hline Lesões & 4,8 & 7,4 & Endócrinas & 6,3 & 2,03 \\
\hline Neoplasias & 3,5 & 5,3 & Digestivo & 5,0 & 1,61 \\
\hline Geniturinário & 3,4 & 5,2 & Externas & 3,0 & 0,94 \\
\hline Endócrinas & 3,3 & 5,1 & Infecciosas & 2,7 & 0,86 \\
\hline \multicolumn{6}{|c|}{ Total } \\
\hline \multicolumn{3}{|c|}{ Internações (1998) } & \multicolumn{3}{|c|}{ Óbitos (1996-1998) } \\
\hline Diagnóstico & $\%$ & coef & Causa & $\%$ & coef \\
\hline Circulatório & 36,2 & 59,0 & Circulatório & 42,2 & 16,24 \\
\hline Respiratório & 27,2 & 44,2 & Neoplasias & 17,9 & 6,90 \\
\hline Digestivo & 8,7 & 14,1 & Respiratório & 12,9 & 4,95 \\
\hline Geniturinário & 4,2 & 6,8 & Endócrinas & 4,7 & 1,81 \\
\hline Lesões & 3,9 & 6,4 & Digestivo & 4,6 & 1,78 \\
\hline Sist. nervoso & 3,2 & 5,2 & Externas & 4,0 & 1,53 \\
\hline Neoplasias & 2,8 & 4,6 & Infecciosas & 3,1 & 1,18 \\
\hline
\end{tabular}

*As lesões e envenenamentos foram analisadas em conjunto com as causas externas.

** Excluídos diagnósticos ignorados (22 em 1997 e 18 em 1998)

neoplasias obteve concordância considerada baixa (Kappa $=0,46)($ MATHIAS $\mathrm{e}$ SOBOLL 1998). Foi constatado que muitos dos diagnósticos desse grupo foram codificados nas AIH como afecções mal definidas (como sintomas gerais e sintomas 
relativos ao abdome e à pelve), doenças do aparelho digestivo (como gastrite) e doenças das glândulas endócrinas, da nutrição, do metabolismo e transtornos imunitários (principalmente como desidratação). Devido à subenumeração deste grupo de diagnósticos nas $\mathrm{AlH}$, para as internações daquele ano, as neoplasias ocuparam a $11^{\mathrm{a}}$ causa $(2,6 \%)$ e segundo os diagnósticos registrados nos prontuários eram a $7^{\mathrm{a}}$ causa mais freqüente $(4,5 \%)$ (MATHIAS e SOBOLL 1998).

As doenças do aparelho geniturinário, também de importância distinta entre internação e óbito foram a quarta causa com 159 hospitalizações, maior nos homens $(4,9 \%)$ do que nas mulheres $(3,4 \%)$ e na maior parte das vezes devido aos problemas renais e dos órgãos genitais masculinos e femininos. Esse grupo não representa motivo que normalmente conduz ao óbito ( $7^{\mathrm{a}}$ causa para os homens com $1,8 \%$ e $8^{\mathrm{a}}$ para as mulheres com $1,2 \%$ dos óbitos), pois muitas vezes, especificamente as doenças renais, são complicações de outras doenças crônicas como algumas doenças do aparelho circulatório ou do diabetes.

$\mathrm{O}$ aparecimento das doenças do sistema nervoso, em sexto lugar com $3,2 \%$ das internações devido, principalmente, à sua ocorrência no sexo masculino faz supor que a adoção da CID-10 com utilização do código G-45, ou acidente vascular cerebral isquêmico transitório, tenha sido determinante. Como causa de óbito esse grupo não foi importante, representando apenas 1,2\% dos óbitos no triênio 1996-1998.

Como esperado os coeficientes de internação foram bem superiores que os de óbito para todos os diagnósticos com exceção das neoplasias cujo risco de internação foi menor do que o risco de óbito. Os coeficientes foram também maiores para os homens, com exceção das internações por lesões e envenenamentos $(5,2$ contra 7,4 internações por 1000 habitantes, no sexo feminino) (Tabela 45) e por doenças endócrinas, nutricionais e metabólicas $(3,1$ contra 5,1 internações por 1000 habitantes, no sexo feminino).

No Quadro 2 foram listadas as causas de internação e óbito entre os idosos e foram feitas comparações entre os coeficientes para cada uma delas. A razão de coeficientes foi calculada para observar o comportamento ou a importância que cada diagnóstico representou como causa de internação em relação à causa de óbito. Devese salientar que como o evento doença não é único e os dados de internação não são referentes ao indivíduo e sim ao montante das internações realizadas no período, a razão entre os coeficientes tende a ser maior que 1 (um), sobretudo para as doenças de 
alta prevalência e quando o idoso é portador de doença crônica e sujeito a vários episódios de internação.

Quadro 2 - Coeficientes de internação e de óbito em idosos (por 1000 habitantes) e razão dos coeficientes segundo diagnóstico e sexo, Maringá-PR, 1998 e triênio 19961998.

\begin{tabular}{|c|r|r|r|r|r|r|r|r|r|}
\hline & \multicolumn{3}{|c|}{ Internação (a) } & \multicolumn{3}{c|}{ Óbito (b) } & \multicolumn{3}{c|}{ Razão (a/b) } \\
\hline Diagnóstico & \multicolumn{1}{|c|}{$\mathrm{M}$} & \multicolumn{1}{|c|}{$\mathrm{F}$} & $\mathrm{T}$ & $\mathrm{M}$ & $\mathrm{F}$ & $\mathrm{T}$ & $\mathrm{M}$ & \multicolumn{1}{c|}{$\mathrm{T}$} & $\mathrm{T}$ \\
\hline Circulatório & 65,7 & 53,2 & 59,0 & 18,32 & 14,47 & 16,24 & 3,6 & 3,7 & 3,6 \\
Respiratório & 46,8 & 42,1 & 44,2 & 6,06 & 4,00 & 4,95 & 7,7 & 10,5 & 8,9 \\
Digestivo & 16,6 & 12,0 & 14,1 & 2,00 & 1,61 & 1,78 & 8,3 & 7,5 & 7,9 \\
Geniturinário & 8,6 & 5,2 & 6,8 & 0,84 & 0,39 & 0,61 & 10,2 & 13,3 & 11,1 \\
Sistema Nervoso & 6,9 & 3,7 & 5,2 & 0,68 & 0,28 & 0,46 & 10,1 & 13,2 & 11,3 \\
Lesões/Causas externas & 5,2 & 7,4 & 6,4 & 2,20 & 0,94 & 1,53 & 2,4 & 7,9 & 4,2 \\
Infecciosas & 4,5 & 3,7 & 4,1 & 1,56 & 0,86 & 1,18 & 2,9 & 4,3 & 3,5 \\
Neoplasias & 3,7 & 5,3 & 4,6 & 9,30 & 4,83 & 6,90 & 0,4 & 1,1 & 0,7 \\
Endócrinas & 3,1 & 5,1 & 4,1 & 1,56 & 2,03 & 1,81 & 2,0 & 2,5 & 2,3 \\
\hline
\end{tabular}

Entre as causas de internação as doenças do sistema nervoso $(11,3)$, do aparelho geniturinário $(11,1)$, respiratório $(8,9)$, digestivo $(7,9)$, causas externas $(4,2)$ nesta ordem, foram as que apresentaram maior relação hospitalização/óbito. Significa dizer que, aproximadamente, em 1000 habitantes idosos residentes em Maringá, para cada óbito por doença do aparelho geniturinário, por exemplo, ocorreram 11,1 internações; por doenças do aparelho respiratório ocorreram 9 internações, e assim sucessivamente (Quadro 2).

A magnitude da razão dos coeficientes pode indicar, para cada diagnóstico, sua importância como causa de internação em relação ao óbito. As doenças do aparelho circulatório e respiratório, por exemplo, são reconhecidamente de alta prevalência, demandando hospitalizações e também são motivo de óbito na população idosa. Já as doenças do aparelho geniturinário, se comparadas às anteriores, não estão entre as principais causas de óbito, daí a maior relação internação/óbito $(11,1)$. Raciocínio inverso poderia ser feito em relação às razões menos importantes. Sob essa perspectiva, as neoplasias, como têm pouca importância no perfil de internações hospitalares em idosos se comparado ao perfil de mortalidade, apresentaram razão de coeficientes de 0,7 (Quadro 2). Neste caso, a menor relação, poderia também indicar maior gravidade ou quadros mais agudos da doença. Assim, a menor magnitude das 
razões para o sexo masculino observada nos Quadros 2 e 3, sugeriria maior gravidade do mesmo agravo para o homem idoso.

Quadro 3 - Internações e óbitos em idosos (n⿳⺈ e coeficientes por 10.000 habitantes, segundo diagnósticos e sexo, Maringá-PR, 1998 e triênio 1996-1998.

\begin{tabular}{|c|c|c|c|c|c|c|c|c|c|c|}
\hline \multirow[b]{3}{*}{ Diagnóstico } & \multicolumn{4}{|c|}{ Internações (1998) } & \multicolumn{4}{|c|}{ Óbitos (1996-1998) } & \multirow{2}{*}{\multicolumn{2}{|c|}{ Razão }} \\
\hline & \multicolumn{2}{|c|}{ Masculino } & \multicolumn{2}{|c|}{ Feminino } & \multicolumn{2}{|c|}{ Masculino } & \multicolumn{2}{|c|}{ Feminino } & & \\
\hline & $\mathrm{N}$ & coef & $\mathrm{n}$ & coef & $\mathrm{n}$ & coef & $\mathrm{n}$ & Coef & $\mathbf{M}$ & $\mathrm{F}$ \\
\hline Outras formas dças coração & 368 & 341,7 & 337 & 266,5 & 108 & 35,0 & 136 & 37,8 & 9,8 & 7,1 \\
\hline DPOC & 315 & 292,5 & 354 & 279,9 & 110 & 35,7 & 75 & 20,8 & 8,2 & 13,5 \\
\hline Pneumonia & 144 & 133,7 & 147 & 116,2 & 54 & 17,5 & 47 & 13,1 & 7,6 & 8,9 \\
\hline Doença isquêmica do coração & 86 & 79,8 & 98 & 77,5 & 145 & 47,0 & 129 & 35,8 & 1,7 & 2,2 \\
\hline Doença cerebrovascular & 93 & 86,3 & 74 & 58,5 & 202 & 65,5 & 153 & 42,5 & 1,3 & 1,4 \\
\hline Circulação pulmonar & 77 & 71,5 & 53 & 41,9 & 13 & 4.2 & 10 & 2,8 & 17,0 & 15,0 \\
\hline AVC isquê.síndr.correlata & 65 & 60,3 & 43 & 34,0 & - & - & - & & - & \\
\hline Hipertensão & 48 & 44,6 & 75 & 59,3 & 59 & 19,1 & 60 & 16,7 & 2,3 & 3,6 \\
\hline Doenças vesícula e pâncreas & 34 & 31,6 & 52 & 41,1 & 6 & 1,9 & 13 & 3,6 & 16,6 & 11,4 \\
\hline Doenças dos intestinos & 28 & 26,0 & 35 & 27,7 & 11 & 3,6 & 14 & 3,9 & 7,2 & 7,1 \\
\hline Diabetes & 18 & 16,7 & 44 & 34,8 & 35 & 11,4 & 57 & 15,8 & 1,5 & 2,2 \\
\hline Outras doenças ap. digestivo & 36 & 33,4 & 22 & 17,4 & 8 & 2,6 & 6 & 1,7 & 12,8 & 10,2 \\
\hline Neoplasia aparelho digestivo & 17 & 15,8 & 20 & 15,8 & 111 & 36,0 & 76 & 21,1 & 0,4 & 0,7 \\
\hline Outras doenças bacterianas & 31 & 28,8 & 26 & 20,6 & 14 & 4,5 & 6 & 1,7 & 6,3 & 12,1 \\
\hline Insuficiência respiratória & 31 & 28,8 & 15 & 11,9 & 10 & 3,2 & 8 & 2,2 & 9,0 & 5,4 \\
\hline
\end{tabular}

Esse fato é comentado por KITAGAWA (1977) e RAINA e col. (1998) que afirmam que as mulheres ficam mais doentes do que os homens e, quando doentes, estão mais debilitadas. Parte desse diferencial ocorre em função do efeito da doença que para o homem resulta na morte e para a mulher na doença. Para várias condições a mulher tem alta taxa de morbidade mas baixa taxa de mortalidade. Entretanto, uma discussão interessante relativa à maior morbidade na mulher diz respeito ao seu comportamento perante a doença, ou seja, a maior morbidade no sexo feminino poderia ser resultado do fato da mulher se sentir mais doente e relatar mais estados mórbidos que o homem. Daí, ela procura por assistência médica quando se sente doente e esse comportamento leva ao diagnóstico precoce e melhor controle dos agravos crônicos, aumentando sua sobrevida (KITAGAWA 1977). 
O grande volume de internações por doenças do aparelho circulatório pode refletir a importante prevalência dessas doenças na população idosa mas também, segundo LEBRÃO (1999) se deve, em parte, ao interesse dos centros cardiológicos que foram criados devido à pressão da indústria de equipamentos médicos que aumentou muito nas últimas décadas. Para a Região do Vale do Paraíba a autora relata que o aumento das internações por doença isquêmica do coração, por exemplo, poderia ser resumida em aumento dos cateterismos e não exatamente uma questão epidemiológica.

Comparando os coeficientes de internação e de mortalidade por causas, segundo sexo e idade, observou-se, para as internações que a tendência foi de valores ascendentes à medida que avançou a idade e foi mais evidente para as doenças do aparelho circulatório e respiratório o mesmo não ocorrendo para as doenças do aparelho digestivo e neoplasias. Para os óbitos, tal tendência ocorreu para as quatro causas, chamando atenção para o pequeno número de óbitos por doenças do aparelho digestivo que ainda assim parece obedecer o mesmo padrão (Gráfico 44).

Vale a pena comentar o comportamento das outras causas menos freqüentes de internação e de óbito, mesmo que seu impacto no perfil da saúde dos idosos seja menos importante. O Gráfico 45 mostra a distribuição dos coeficientes para as doenças do aparelho geniturinário, lesões e envenenamentos/causas externas, sistema nervoso e doenças endócrinas, nutricionais e metabólicas, para as quais houve maior variação segundo faixas de idade, em razão do menor número de eventos.

Entre as 159 internações por doenças do aparelho geniturinário 58,5\% ocorreram no sexo masculino evidenciando maior importância dos coeficientes para os homens, em todas as faixas de idade com exceção do grupo de 60 a 64 anos cujo risco de internação foi maior para as mulheres. O mesmo comentário serve para a mortalidade pois, dos 40 óbitos, $65 \%$ ocorreram no sexo masculino e se concentraram nos idosos de 85 anos e mais de idade.

Para as lesões e envenenamentos nas internações e causas externas na mortalidade, o comportamento foi diferente. Enquanto que as internações por lesões e envenenamentos foram mais numerosas para as mulheres $(62,4 \%)$, os óbitos por causas externas foram para os homens $(66,7 \%)$. Em relação à idade, o risco de internação foi mais importante a partir de 70 anos, para ambos os sexos, ao passo que 
Gráfico 44 - Coeficientes de internação e de mortalidade em idosos (por 1000 hab.) segundo causas, sexo e idade, Maringá-PR, ano de 1998 e triênio 1996-1998.
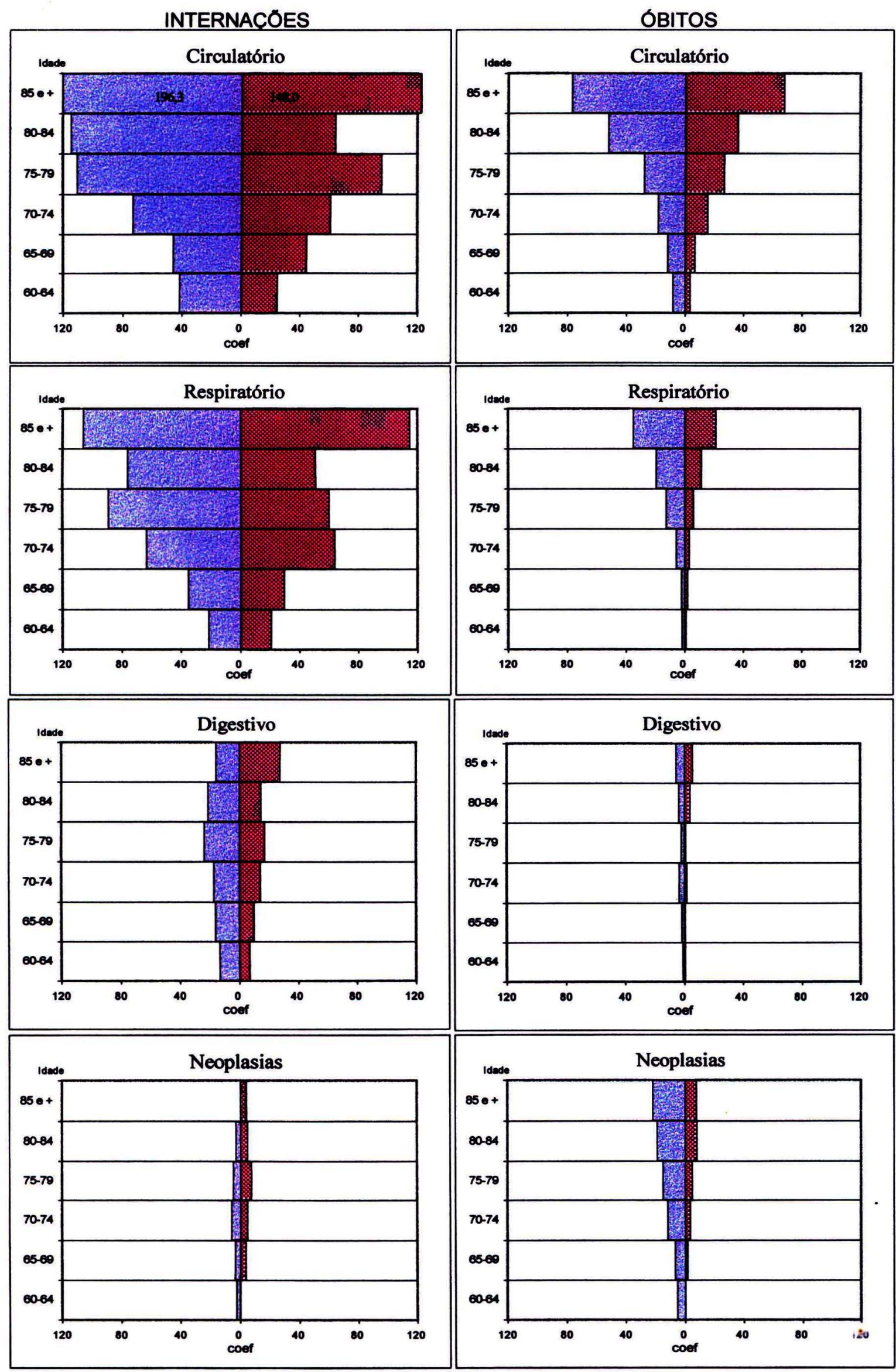
Gráfico 45 - Coeficientes de internação e de mortalidade em idosos (por 1000 hab) segundo causas, sexo e idade, Maringá-PR, ano de 1998 e triênio 1996-1998.
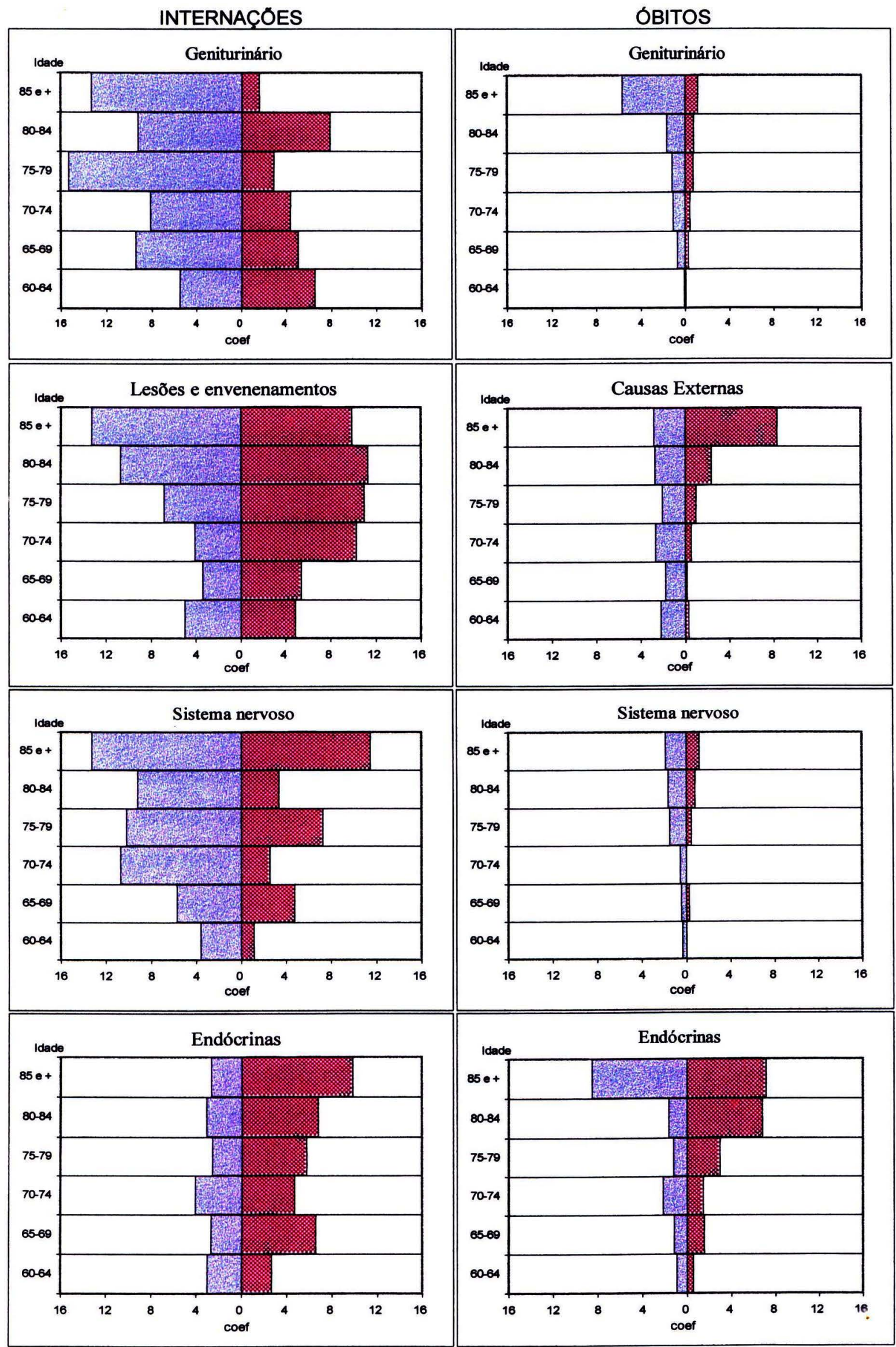
para os óbitos apenas no sexo feminino houve nítida tendência ascendente com a idade (Gráfico 45).

$\mathrm{O}$ peso relativo das doenças endócrinas, nutricionais e metabólicas foi superior no sexo feminino tanto para as internações $(66 \%)$ como para os óbitos $(60,3 \%)$. Foi evidente o maior risco de hospitalização e óbito para as mulheres de 75 anos e mais de idade. Entre os homens o risco de internação ocorreu na mesma magnitude em todas as idades, mas em relação ao óbito, assim como no sexo feminino este foi maior para os idosos em idades mais avançadas (Gráfico 45).

É importante reconhecer que o perfil de morbidade hospitalar evidencia, por um lado as doenças mais prevalentes podendo expressar as condições sociais e de vida de dada população. Por outro, retratam também a disponibilidade de recursos diagnósticos, as características próprias da prática médica, os níveis de regionalização e organização das unidades de assistência à saúde, além da sua capacidade resolutiva. O conhecimento dos dados de hospitalização pode ser útil para previsão orçamentária, planejamento de recursos materiais e humanos, principalmente considerando a atuação mais direta do município no gerenciamento das ações de saúde locais prevista pela política de descentralização e municipalização dos serviços de saúde. Já a utilização clínica das estatísticas hospitalares têm sido pequena restringindo-se às informações segundo diagnósticos, procedimentos e saídas por alta ou óbito (LEBRÃO e col. 1993).

Do ponto de vista epidemiológico essas estatísticas podem indicar a distribuição por sexo e idade das pessoas hospitalizadas. Para inferência em relação à morbidade da população a informação pode ser valiosa para aquelas condições para as quais a admissão ao hospital para tratamento é quase obrigatória, podendo até mesmo significar uma medida da incidência (LEBRÃO e col. 1993). Nesse sentido LEBRÃO e col. (1993) recomendam maiores esforços na melhora da qualidade dos registros médicos e codificação dos diagnósticos para que a interpretação dos resultados possa ser mais confiável.

Segundo VERBRUGGE (1984) a análise comparativa entre a mortalidade e morbidade poderia ser mais simples em outras épocas quando as doenças agudas eram as principais causas de doença e morte e as intervenções terapêuticas ou não existiam, ou eram pouco efetivas. Atualmente as condições crônicas são as que 
predominam e muitas vezes não são doenças que levam à morte mas antes, representam motivo de incapacidade e de utilização de serviços de saúde.

Merece ser comentado que existe um nível de atendimento médico de vital importância para o conhecimento do perfil de saúde, que são os atendimentos de urgência e os atendimentos de pronto socorro ou pronto atendimento dos hospitais. Os relativos às lesões e envenenamentos, às urgências respiratórias, circulatórias e psiquiátricas representam um contingente importante de agravos e de óbitos na população idosa. Essa é uma lacuna importante que deveria ser conhecida que, se por um lado não utiliza leitos hospitalares, por outro mostra a utilização de serviços de saúde e ocorrência expressiva na morbidade da população idosa.

A comparação da morbidade hospitalar com a mortalidade realizada neste estudo representou um exercício de análise dos indicadores de saúde na população idosa, lembrando que, como as internações pelo SUS não representam o total de internações na população por não incluírem as financiadas por seguros saúde e as particulares, pode-se considerar que os coeficientes apresentados sejam mínimos, assim como as razões hospitalização/óbito. 
5. CONSIDERAÇÕES FINAIS 
A análise descritiva do comportamento da mortalidade e da morbidade hospitalar mostrou aspectos relevantes da saúde dos idosos residentes em Maringá. A princípio destaca-se o envelhecimento populacional, também realidade em Maringá o que vem apontando para os próximos 20 ou 30 anos para uma estrutura etária provavelmente em equilíbrio com características próximas de países desenvolvidos. A queda nos coeficientes de mortalidade em pessoas acima de 60 anos é outro resultado importante levando ao aumento a expectativa de vida dos idosos, com maior importância para as mulheres.

Foram constatadas mudanças no perfil de mortalidade segundo causas, embora as doenças do aparelho circulatório, as neoplasias e as doenças do aparelho respiratório constituam ainda, as mais importantes com $70 \%$ de todos os óbitos. Todavia, se por um lado o risco de óbito por doenças do aparelho circulatório registrou queda, por neoplasias e por doenças do aparelho respiratório registrou aumento constante, tendência também observada para outras causas menos freqüentes de óbito, mas de alta prevalência na população idosa, como o diabetes mellitus. Para outras causas também menos importantes como as deficiências nutricionais, até os óbitos por septicemia e senilidade, que embora sejam considerados como diagnósticos mal definidos, os aumentos das estimativas do risco de morte podem indicar, de certa forma, a condição de maior fragilidade de parcela da população idosa. Vale destacar, entretanto, que esses aumentos não foram suficientemente grandes para que a tendência de queda no risco de morrer na população idosa fosse interrompida pois, no final do período, houve diferença negativa de $15,2 \%$.

Os dados de morbidade hospitalar indicaram maior volume de internações por doenças do aparelho circulatório e, diferentemente da mortalidade, a segunda causa mais freqüente foram as doenças do aparelho respiratório, evidenciando a grande importância dos agravos crônicos respiratórios no idoso. Observou-se que houve aumento no número de internações entre 1995 e 1998 e que outros municípios passaram a internar percentuais maiores deste contingente. Além disso a média de permanência hospitalar, embora maior do que a média nas outras faixas de idade, tende a diminuir nos idosos mais velhos.

O comportamento das principais causas de morte descrito ao longo deste trabalho foi compatível com o descrito para outras localidades. Estudos têm mostrado mudanças no perfil de mortalidade com queda nos indicadores para as doenças 
cerebrovasculares em vários paises tanto da Europa quanto das Américas (UEMURA e PISA 1988; Mc GOVERN e col. 1992; STOKES e LINDSAY 1996). Da mesma forma foram descritas quedas nos coeficientes de mortalidade por doença isquêmica do coração (SUTHERLAND e col. 1990). Estudos realizados para o Brasil (COSTA 2000) e outras localidades do país como para o Estado de são Paulo (LOTUFO 1993), para o Município de Botucatu (RUIZ 1996) também descrevem tendência de queda na mortalidade por doenças cerebrovasculares. Declínio na estimativa do risco de óbito por doença isquêmica do coração observado para a população idosa de Maringá, ocorreu para a população do Estado de São Paulo (LOTUFO 1993) e para o Município de São Paulo (LOLIO e LAURENTI 1986).

Para as neoplasias, segundo grupo de causas mais freqüentes de morte no idoso, se considerado como doença única, a tendência foi de aumento, o que está de acordo com outros autores (ROTHENBERG e KOPLAN 1990). O perfil de mortalidade por alguns tipos de câncer, com tendência de aumento para o câncer de pulmão, próstata e mama também foi compatível com o encontrado em outros estudos, como para o Brasil (MELLO JORGE e GOTLIEB 2000) e para o Estado do Rio Grande do Sul (HALLAL 2000), assim como o aumento da participação das doenças do aparelho respiratório para o Brasil (MELLO JORGE e GOTLIEB 2000) e para o Município do Rio de Janeiro (PARAHYBA 1997).

Com os resultados encontrados neste estudo algumas considerações podem ser feitas em relação à promoção à saúde e qualidade de vida da população idosa.

Um primeiro aspecto que pode ser destacado é a sobremortalidade masculina e maior utilização dos leitos hospitalares também pelos homens idosos o que é conhecido e igualmente verificado em outros estudos, é um aspecto que deveria ser melhor avaliado. Se essa realidade mostra que a população idosa é representada, sobretudo pela mulher, sem companheiro, remete também à discussão a urgência em voltar a atenção aos fatores que têm levado a menor expectativa de vida no homem. Segundo MINAYO (1995) não existe fatalidade no quadro de morbimortalidade nas comunidades, pois "para todos os problemas há um largo espaço de possibilidades para intervenções técnicas, sociais e educativas". Portanto, além de intensificar e melhorar o atendimento à saúde voltado à população feminina, é preciso implementar ações mais agressivas direcionadas aos riscos mais presentes no homem, 
principalmente à população jovem e adulta, como hábitos de vida, tabagismo e maior exposição aos acidentes e violências.

$O$ fato de estar ocorrendo menor mortalidade por doenças cardiovasculares não significa que o problema esteja menos prevalente na população idosa. No que se refere às doenças cerebrovasculares sabe-se que suas seqüelas associadas à menor imunidade aumentam a probabilidade do idoso mais debilitado adquirir e morrer por outras doenças, como as relativas ao aparelho respiratório.

Os dados mostraram também, parcela do grave problema que representa o câncer na vida do idoso. É urgente, além da implementação de ações preventivas como hábitos de vida saudáveis e campanhas de esclarecimento sobre as conseqüências do hábito de fumar, como já destacado, também melhorar os programas já existentes de deteç̧ão precoce como para o câncer de mama e do colo do útero. Os serviços públicos devem ser estruturados para atender essa demanda que é crescente e investimentos maciços devem ser feitos para que haja acesso e atendimento de qualidade, em todos os níveis, desde a detecção até o tratamento das neoplasias.

Diante dessas considerações é importante que o aumento na sobrevida da população com mais de 60 anos seja reconhecido e divulgado e que esforços sejam dispensados para que outros grupos de causas de óbito, além das doenças do aparelho circulatório, também possam contribuir para esse ganho. Nesse sentido, é imprescindível que os serviços de saúde estejam preparados, considerando que são co-responsáveis por complicações e mortes, muitas delas precoces, decorrentes do tipo de atendimento oferecido, como às doenças cardiovasculares e ao diabetes mellitus, por exemplo (LESSA 1998e).

Finalmente é importante que a sociedade acolha de braços abertos o envelhecimento encarando-o como um processo natural, colocando a saúde como fator vital para manter o bem-estar e a qualidade de vida na velhice (OPAS/OMS 1999). As medidas sociais e de saúde devem considerar as diversidades existentes no grupo das pessoas idosas e os gastos com essas medidas devem ser considerados como um investimento remetendo ao entendimento do bem estar coletivo para que o idoso continue dando sua importante contribuição à sociedade. 
6. CONCLUSÕES 
De modo geral os resultados deste estudo mostraram que houve envelhecimento da população de Maringá entre 1979 e 1998, mais importante para o sexo feminino. Em relação às causas de morte observou-se que as doenças do aparelho circulatório, neoplasias e doenças do aparelho respiratório continuam as principais causas, durante todo o período. Houve, entretanto, queda na estimativa do risco de óbito por doenças cerebrovasculares e doença isquêmica do coração fazendo com que o peso relativo das doenças do aparelho circulatório diminuísse. Por outro lado houve aumento do risco de morrer por alguns tipos de câncer como o de pulmão, próstata e mama e por doenças do aparelho respiratório como as crônicas de pulmão e pneumonias. Entre as causas menos freqüentes de óbito é importante registrar o aumento da estimativa do risco de óbito por diabetes mellitus.

A análise da morbidade revelou maior utilização dos leitos do SUS pela população idosa em relação aos residentes de outras faixas de idade e que as doenças do aparelho circulatório, respiratório e digestivo foram as grandes responsáveis por essas internações representando mais do que $70 \%$ de todas as saídas hospitalares nos quatro anos estudados. Observou-se que a média de permanência diminuiu nas idades mais avançadas e foi diferente de acordo com o sexo e também com o diagnóstico de internação.

Mais especificamente as conclusões foram as seguintes:

Entre 1979 e 1998 houve aumento relativo da população idosa no Município de Maringá que passou de $5,1 \%$ para $8,4 \%$ do total de habitantes, com diferença relativa de $62,7 \%$.

A mortalidade proporcional em idosos foi de $56,3 \%$ no sexo masculino e de $67,4 \%$ no feminino e o maior acréscimo ocorreu na faixa de 80 anos e mais de idade com uma diferença relativa de $95,6 \%$ para as mulheres e $100,3 \%$ para os homens.

A estimativa do risco de mortalidade em idosos teve queda de $15,2 \%$. Os maiores ganhos ocorreram para os homens de 65 a 79 anos e para as mulheres 70 a 84 anos de idade. Para os idosos de 85 anos e mais de idade houve acréscimo na estimativa do risco de morrer, de $2 \%$ nos homens e de $10,9 \%$ nas mulheres. 
As causas mais importantes de mortalidade foram as doenças do aparelho circulatório, neoplasias e doenças do aparelho respiratório que juntas contribuíram $\operatorname{com} 73,6 \%$ do total de óbitos, no primeiro triênio e com $73 \%$ no último. A doença cerebrovascular, a doença isquêmica do coração, as outras formas de doenças do coração, as neoplasias do aparelho digestivo e as doenças pulmonares obstrutivas crônicas foram os diagnósticos mais freqüentes de óbito em ambos os sexos.

Foi registrada queda de $43,3 \% \%$ no coeficiente de mortalidade por doenças infecciosas e parasitárias, de $35,2 \%$ por doenças do aparelho circulatório, de $28,9 \%$ por doenças do aparelho digestivo e de 16,2\% por causas externas. Por outro lado, houve aumento de $84 \%$ nos coeficientes de mortalidade por doenças do aparelho respiratório, de $64,6 \%$ por doenças endócrinas, nutricionais e metabólicas e de $22,1 \%$ por neoplasias.

Os coeficientes de internação hospitalar oscilaram de 131,8 em 1997 para 163,5 internações por 1000 habitantes, em 1998. Aumentou a probabilidade do idoso ser internado com o avançar da idade. Os coeficientes foram sempre superiores para os homens, com exceção do ano de 1997, na faixa de 85 anos e mais de idade (268 para as mulheres e 265 internações por 1000 habitantes, para os homens).

As doenças do aparelho circulatório, respiratório e digestivo, foram as grandes responsáveis pelas internações na população idosa em Maringá, representando mais de $70 \%$ de todas as saídas hospitalares nos quatro anos apresentados.

Observou-se crescimento do percentual de internações de idosos residentes em Maringá ocorridas em outros municípios para todas as causas, principalmente para as doenças do aparelho geniturinário $(99,6 \%)$, do aparelho respiratório $(96 \%)$, doenças infecciosas e parasitárias $(92,4 \%)$ e doenças do aparelho circulatório $(88,5 \%)$.

Em 1998, mais de 70\% dos pacientes havia recebido alta hospitalar com quatro dias de internação. A DMI foi de 4,4 dias sem diferença importante entre os sexos $(4,46$ para homens e 4,4 dias para as mulheres). Observou-se que as DMI foram mais elevadas nos idosos de 70 a 74 anos mas apresentaram tendência de queda após essa 
idade, para ambos os sexos. Para a maioria dos diagnósticos os homens ficaram maior tempo hospitalizados, exceto para as doenças do aparelho digestivo, algumas doenças infecciosas e parasitárias e neoplasias cujas DMI foram mais elevadas para as mulheres $(5,33,5,15$ e 7,78 dias, respectivamente).

Em 1998 o $\mathrm{CMH}$ foi de 6,5 óbitos para cada 100 internações, maior no sexo masculino (7,1 e 5,9 no feminino) e nas idades mais avançadas, chegando a quase 10 óbitos para cada 100 internações em homens com 85 anos e mais de idade. As internações com maior $\mathrm{CMH}$ foram as devidas a insuficiência respiratória $(56,5 \%)$, outras doenças bacterianas $(43,9 \%)$, desidratação $(27,8 \%)$ e desnutrição $(20,7 \%)$.

Entre 1995 e 1995, no momento da internação as mulheres tinham média de idade ligeiramente mais elevada do que os homens. Para o mesmo período observou-se que no momento do óbito a idade média da mulher foi mais elevada do que a do homem, com uma diferença de 2,2 anos em 1995 e 3 anos em 1998. Para os homens a diferença entre a média de idade da internação e do óbito foi de aproximadamente 2 anos e para as mulheres de 2,8 anos nos 4 anos estudados.

Entre as causas de internação mais freqüentes as doenças do sistema nervoso, do aparelho geniturinário, doenças do aparelho respiratório e digestivo foram as que apresentaram maior relação hospitalização/óbito. 
7. REFERÊNCIAS 
Andrade OG. Suporte ao sistema de cuidado familiar do idoso com acidente vascular cerebral a partir de uma perspectiva holística de saúde. Ribeirão Preto, 2001. [Tese de doutorado - Escola de Enfermagem de Ribeirão Preto - USP]

Andrade SM, Mello Jorge MHP. Características das vítimas por acidentes de transporte terrestre em município da Região Sul do Brasil. Rev Saúde Pública 2000; 34:149-56.

[Anonymus]. Envejecimiento e salud: un cambio de paradigma. Rev Panam Salud Pública [periódico on line] 2000; 7:60-7. Disponível em URL:http://www.scielosp.org. [2000 nov 15].

Antunes JLF, Waldman EA. Tuberculosis in the twentieth century: time-series mortality in São Paulo, Brazil, 1900-1997. Cad Saúde Pública 1999; 15: 463-76.

Araújo SM, Andó MH, Cassatotti DJ, D’Arce Mota CG, Borges SMR, Gomes ML. Programa Achei: atenção ao chagásico com educação integral no Município de Maringá e região noroeste do Paraná, Brasil. Rev Socied Bras Med Trop 2000; 33 : 565-72.

Armstrong DL, Wing SB, Tyroler HÁ. United States mortality from Ill-defined causes, 1968-1988: potential effects on heart disease mortality trends. Int J Epidemiol 1995; 24: $522-7$.

Ayres JEM. Prevalência da hipertensão arterial na cidade de Piracicaba. Arq Bras Cardiol 1991; 57:33-6.

Baeta AMC, Cruz HC. Algumas reflexões sobre o futuro da população jovem: o direito à saúde na $3^{\mathrm{a}}$ idade. In: Anais do VI Encontro Nacional de Estudos Populacionais [CD-ROM] 1988; Olinda-PE, Associação Brasileira de Estudos Populacionais, v.1, p. 437-47.

Baldijão MFA. Sistemas de informação em saúde. São Paulo Perspec 1992; 6:21-8.

Barreto ML, Carmo EH. Situação de saúde da população brasileira: tendências históricas, determinantes e implicações para as políticas de saúde. Inf Epidemiol SUS 1994; (3/4): 7-34.

Barreto ML, Carmo EH, Noronha CV, Neves RBB, Alves PC. Mudanças dos padrões de morbi-mortalidade: uma revisão crítica das abordagens epidemiológicas. Physis 1993; 3: 127-46.

Barreto ML, Carmo EH, Santos CA, Ferreira LDA. Transição epidemiológica e tendências das doenças infecciosas e parasitárias no Brasil. In: Anais do X Encontro Nacional de Estudos Populacionais [CD-ROM] 1996, Caxambú-MG. - Belo Horizonte: Associação Brasileira de Estudos Populacionais, v.4, p.2093-106. 
Barreto NDM. Diabetes mellitus na pessoa idosa. Arq Geriatr Gerontol 1997; $1: 65$ 71.

Beaglehole R. International trends in coronary heart disease mortality, morbidity, and risk factors. Epidemiol Rev 1990; 12:1-15.

Becker RA. Análise de mortalidade: delineamentos básicos. Coordenação de informações epidemiológicas. Brasilia-DF: MS/FNS; 1991, 85 p.

Benjamin EJ, Plehn JF, D'Agostino RB, Belanger AJ, Comai K, Fuller DL et al. Mitral annular calcification and the risk of stroke in an elderly cohort. N Engl J Med 1992; 327:374-9.

Berquó ES, Leite VM. Algumas considerações sobre a demografia da população idosa no Brasil. Ciên Cult 1988; 40:679-88.

Borges-Yáñez SA, Gómez Dantés H. Uso de los servicios de salud por población de 60 años y más en México. Salud Pública México 1998; 40:13-23.

Boshuizen HC, IzaksGJ, van Buuren S, Ligthart GJ. Blood pressure and mortality in elderly people aged 85 and older: community based study. BMJ 1998; 316:1780-4.

Brameld KJ, Holman CDAJ, Bass AJ, Codde JP Rouse IL. Hospitalisation of the elderly during the last year of life: an application of record linkage in Western Australia 1985-1994. J Epidemiol Community Health 1998; 52:740-4.

Brown RB. Community-acquired pneumonia: diagnosis and therapy of older adults. Geriatrics $1993 ; 48: 43-50$.

Camarano AA, Beltrão KI, Pascom ARP, Medeiros M, Carneiro IG, Goldane AM, et al. Como vai o idoso brasileiro? [periódico on line] IPEA; 1999 (Texto para discussão n 681). Disponivel em <URL:http//:www.ipea.gov.br> [1999 nov 11].

Carvalho EMF, Branco MAF. Perfil de mortalidade por doenças cardiovasculares na região metropolitana do Recife, segundo o Sistema de Informação sobre Mortalidade (SIM). Inf Epidemiol SUS 1996; (4): 61-71.

Caselli MP. A morbidade hospitalar do idoso no município de São Carlos-SP, em 1996. São Paulo; 1998. [Dissertação de Mestrado - Faculdade de Saúde Pública da USP].

Cebollero-Santamaria F, Smith J. Gioe S, Van Frank T, Mc Call R, Airhart J. et al. Selective outpatient management of upper gastrointestinal bleeding in the elderly. The Am J Gastroenterology 1999; 94:1242-7. 
Cesar CLG, Tanaka OY. Inquérito domiciliar como instrumento de avaliação de serviços de saúde: um estudo de caso na região sudoeste da área metropolitana de São Paulo, 1989-1990. Cad Saúde Pública 1996; 12 (2 Suppl):59-70.

Chaimowicz F. Age transition of tuberculosis incidence and mortality in Brazil. Rev Saúde Pública 2001; 35:81-7.

Chaimowicz F, Ferreira TJXM, Miguel A. Use of psychoactive drugs and related falls among older people living in a community in Brazil. Rev Saúde Pública 2000; $34: 631-5$.

Chor D, Fonseca MJM da, Andrade CR. Doenças cardiovasculares: comentários sobre a mortalidade precoce no Brasil. Arq Bras Cardiol 1995; 64: 15-9.

Coelho Filho JM, Ramos LR. Epidemiologia do envelhecimento no Nordeste do Brasil: resultados de inquérito domiciliar. Rev Saúde Pública 1999; 33: 445-53.

Costa NE da. Tendência da mortalidade por acidente vascular cerebral em idosos no Brasil, período de 1979 a 1995. Brasília 2000 [Dessertação de Mestrado Faculdade de Ciências da Saúde da Universidade de Brasília]

Costa JSD da, Facchini LA. Utilização de serviços ambulatoriais em Pelotas: onde a população consulta e com que freqüência. Rev Saúde Pública 1997; 31:360-9.

Costa MFFL, Guerra HL, Barreto SM, Guimarães RM. Diagnóstico da situação de saúde da população idosa brasileira: um estudo da mortalidade e das internações hospitalares públicas. Inf Epidemiol SUS 2000; 9:23-41.

Cunha EMGP da. Os neoplasmas malignos na população feminina brasileira. Anais do XI Encontro Nacional de Estudos Populacionais 1998, p. 1929-1946. Disponível em <URL:http//:www.abep.org.br> [2000 jun 20].

Cunha EMGP da. Aidar T. Avaliação da qualidade das informações de causas de morte. In: Berquó E. e Cunha EMGP da, organizadores. Morbimortalidade feminina no Brasil (1979-1995). Campinas; Editora da UNICAMP; 2000, p. 17-38.

D'Oleo RJM. Utilização dos leitos hospitalares na região de Ribeirão Preto. São Paulo; 1991. [Dissertação de Mestrado - Faculdade de Saúde Pública da USP].

Duchiade MP. População brasileira: um retrato em movimento. In: Minayo MC, organizadora. Os muitos Brasis: saúde e população na década de 80 . Rio de Janeiro: ABRASCO; 1995. p. 14-56.

Elo IT, Preston SH. Educational differentials in mortality. Soc Sci Med 1996; 42:4757. 
Escola Nacional de Saúde Pública/Fundação Oswaldo Cruz. Câncer: Mortalidade no Brasil. RADIS-Dados 1991.

Farrell JJ, Friedman LS. Gastrointestinal bleeding in older people. Gastroen Clin North Am 2000; 29:1-36.

Ferreira JMN, Faria CG. Morbidade hospitalar no Estado de São Paulo. São Paulo Perspec 1986; 2: 35-52.

[IBGE] Instituto Brasileiro de Geografia e Estatística, Conselho Nacional de Estatística. Recenseamento Geral do Brasil - Censo Demográfico do Estado do Paraná, 1950. Rio de Janeiro, 1953.

[FIBGE] Fundação IBGE. Censo demográfico de 1960-Brasil. VII Recenseamento Geral do Brasil. V 1, 1960.

[FIBGE] Fundação IBGE. Censo demográfico - Paraná 1970. VIII Recenseamento Geral 1970, V 1, tomo 19.

[FIBGE] Fundação IBGE. Censo demográfico 1980, Paraná, dados distritais. Rio de Janeiro 1982, v. 1, tomo 4, nº 19.

[FIBGE] Fundação IBGE. Censo demográfico 1991, Paraná. Rio de Janeiro 1993, $\mathrm{n}^{\mathrm{O}} 22$.

[FIBGE] Fundação IBGE. Informações estatísticas e geocientíficas. [informações on line]. Disponível em <URL:http:www.ibge.gov.br> [1998 abr 25].

[FIBGE] Fundação IBGE. Informações estatísticas e geocientíficas [informação on line]. Disponivel em <URL: http://www.ibge.gov.br> [2001 fev 1].

Fonseca LAM. A evolução das doenças neoplásicas. In: Monteiro CA, organizador. Velhos e novos males da saúde no Brasil: a evolução do país e de suas doenças. São Paulo: Hucitec/NUPENS-USP; 1995. p. 268-78.

Ford ES e DeStefano F. Risk factors for mortality from all causes and from coronary heart disease among persons with diabetes. Am J Epidemiol 1991; 133:1220-30.

Formiga MCC, Ramos PCF, Cunha MHS. Características sócio-demográficas do idoso norte-riograndense no período 1940-1991. In: Anais do X Encontro Nacional de Estudos Populacionais [CD-ROM] 1996; Caxambú-MG. Belo Horizonte: Associação Brasileira de Estudos Populacionais, v 4, p. 2355-81.

Franco LJ, Mameri C, Pagliaro H, lochida LC, Goldenberg P. Diabetes como causa básica ou associada de morte no Estado de São Paulo, Brasil, 1992. Rev Saúde Pública 1998; 32:237-45. 
Frenk J, Frejka T, Bobadilla $\mathrm{J}$, Stern C, Lozano R, Sepúlveda J, José M. La transición epidemiológica en América Latina. Bol Oficina Sanit Panam 1991; 111 : 485-496.

Fuchs FA, Moreira LB, Moraes RS, Bredemeier M, Cardozo SC. Prevalência da hipertensão arterial sistêmica e fatores associados na região urbana de Porto Alegre: estudo de base populacional. Arq Bras Cardiol 1994; 63: 473-9.

Germano Neto J. O paciente geriátrico no hospital, Ribeirão Preto, SP, 1988. Ribeirão Preto; 1991. [Dissertação de Mestrado - Faculdade de Medicina de Ribeirão Preto da USP].

Goldman L, Cook EF. The decline in heart disease mortality rates in analysis of the comparative effects of medical intervention and changes in lifestyle. Ann Intern Med $1984 ; 101: 825-36$.

Gorzoni ML. Medicamentos como desencadeantes de sintomas em idosos. Gerontologia 1995; 3:81-6.

Gouvêa CSD, Travassos C, Fernandes C. Produção de serviços e qualidade da assistência hospitalar no Estado do Rio de Janeiro, Brasil - 1992 a 1995. Rev Saúde Pública 1997; 31:601-17.

Graafmans WC, Ooms ME, Hofstee HMA, Bezemer PD, Bouter LM, Lips P. Falls in the elderly: a prospective study of risk factors and risk profiles. Am J Epidemiol 1996, 143: 1129-36.

Grassi PR, Laurenti R. Implicações da introdução da $10^{\mathrm{a}}$ Revisão da Classificação Internacional de Doenças em análise de tendência da mortalidade por causas. Inf Epidemiol SUS 1998; (3): 43-7.

Greenlee RT, Murray T, Bolden S, Wingo PA. Cancer statistics. CA Cancer J Clin [serial on-line] 2000; 50:7-33. Available from <URL: http//www.ca-journal.org> [2000 jun 1].

Gu K, Cowie CC, Harris MI. Diabetes and decline in heart disease mortality in US adults. JAMA 1999; 281: 1291-7.

Hallal ALLC. Evolução da mortalidade por neoplasias malignas no Rio Grande do Sul, 1979-1995. São Paulo; 2000. [Dissertação de Mestrado - Faculdade de Saúde Pública da USP].

Hand R, Klemka-Waldent L, Inczauskist D. Mortality and length of stay as performance indicators for pneumonia in the elderly. J Invest Med 1997; 45: 183-90.

Horiuchi S, Wilmoth JR. Age patterns of the life table aging rate for major causes of death in Japan, 1951-1990. J Gerontol 1997; 52A(1): B67-B77. 
Hunt VB. Mortality and morbidity in Wisconsin hospitals. Wis Med J 1991; 90:23-5.

Jacobs DR, McGovern PG, Blackburn H. The US decline in stroke mortality: what does ecological analysis tell us? Am J Public Health 1992; 82:1596-9.

Kalache A, Aboderin I. Stroke: the global burden. Health Policy Plann 1995; 10:121.

Kannel WB. Inferences for secular trend analysis of hypertension control. Am $\mathbf{J}$ Public Health 1992; 82: 1593-5.

Kitagawa EM. On mortality. Demography 1977; 14: 381-9.

Kohn RR. Cause of death in very old people. JAMA 1982; 247:2793-7.

Latorre MRDO. A mortalidade por câncer do estômago no Brasil: análise do período de 1977 a 1989. Cad Saúde Pública 1997; 13 (1 Suppl): 67-78.

Laurenti R. Hipertensão como problema de massa no Brasil: mortalidade por hipertensão arterial como causa básica. Ciên Cult 1983; 35:1637-42.

Laurenti R. Análise da informação em saúde: 1893-1993, cem anos de Classificação Internacional de Doenças. Rev Saúde Pública 1991; 25:407-17.

Laurenti R, Buchalla CM. Estudo da morbidade e da mortalidade perinatal em maternidades: II - Mortalidade perinatal segundo peso ao nascer, idade materna, assistência pré-natal e hábito de fumar da mãe. Rev Saúde Pública 1985; 19:225-32.

Laurenti R, Buchalla CM. Os mitos a respeito das doenças cardiovasculares. Arq Bras Cardiol 2001; 76:99-104.

Laurenti R, Buchalla CM, Mello Jorge MHP, Lebrão ML, Gotlieb SLD. Perfil epidemiológico da saúde masculina na região das Américas: uma contribuição para o enfoque de gênero. São Paulo: Centro Colaborador da OMS para a Classificação de Doenças em Português, FSP-USP; 1998.

Laurenti R, Fonseca LAM. A mortalidade por doenças cardiovasculares no Município de São Paulo em um período de 30 anos (1940-1969). Arq Bras Cardiol 1976; 29 : 85-8.

Laurenti R, Fonseca LAM, Costa Jr ML. Mortalidade por diabetes mellitus no Município de São Paulo (Brasil). Evolução em um período de 79 anos (1900-1978) e análise de alguns aspectos sobre associação de causas. Rev Saúde Pública 1982; 16:77-91.

Laurenti R. Silveira MH, Gotlieb SL. Estatísticas de morbidade hospitalar e a sua análise segundo causas múltiplas. Rev Paul Hosp 1975; 23:94-100. 
Lebrão ML. Morbidade hospitalar no Vale do Paraíba, 1975. São Paulo; 1982. [Tese de Doutorado - Faculdade de Saúde Pública da USP].

Lebrão ML. Evolução da morbidade hospitalar - Vale do Paraíba, 1975 e 1988. São Paulo; 1994. [Tese de Livre-Docência - Faculdade de Saúde Pública da USP].

Lebrão ML. Estudos de morbidade. São Paulo: EDUSP; 1997.

Lebrão ML. Determinantes da morbidade hospitalar em região do Estado de São Paulo (Brasil). Rev Saúde Pública 1999; 33:55-63.

Lebrão ML, Carandina L, Magaldi C. Análise das condições de saúde e de vida da população urbana de Botucatu, São Paulo (Brasil). IV - Morbidade referida em entrevistas domiciliárias, 1983-1984. Rev Saúde Pública 1991; 25:452-60.

Lebrão ML, Litvoc J, Figueiredo GM, Leite RM. Estudo da morbidade dos pacientes internados no Hospital das Clínicas da Faculdade de Medicina da USP-1989. Rev Hosp Clin Fac Med S Paulo 1993; 48:189-98.

Lessa I. Doenças não-transmissiveis. In: Rouquayrol MZ. Epidemiologia e saúde. $4^{\mathrm{a}}$ ed. São Paulo: MEDSI; 1994. p. 269-79.

Lessa I. O adulto brasileiro e as doenças da modernidade: epidemiologia das doenças crônicas não-transmissiveis. São Paulo/Rio de Janeiro: Hucitec/Abrasco; 1998a. Epidemiologia da hipertensão arterial; p.77-96.

Lessa I. O adulto brasileiro e as doenças da modernidade: epidemiologia das doenças crônicas não-transmissíveis. São Paulo/Rio de Janeiro: Hucitec/Abrasco; 1998b. Doenças cerebrovasculares; p.97-114.

Lessa I. $O$ adulto brasileiro e as doenças da modernidade: epidemiologia das doenças crônicas não-transmissíveis. São Paulo/Rio de Janeiro: Hucitec/Abrasco; 1998c. Outras doenças crônicas não-transmissíveis de importância social; p.181-201.

Lessa I. $O$ adulto brasileiro e as doenças da modernidade: epidemiologia das doenças crônicas não-transmissíveis. São Paulo/Rio de Janeiro: Hucitec/Abrasco; 1998d. Epidemiologia das doenças crônicas não-transmissíveis versus terceira idade; p.203-22.

Lessa I. $O$ adulto brasileiro e as doenças da modernidade: epidemiologia das doenças crônicas não-transmissíveis. São Paulo/Rio de Janeiro: Hucitec/Abrasco; 1998e. Doenças crônicas não-transmissíveis; p. 29-42.

Lessa I, Mendonça GAS, Teixeira MT. Doenças crônicas não transmissíveis no Brasil: dos fatores de risco ao impacto social. Bol Oficina Sanit Panam 1996; 120: 389-413. 
Levcovitz E, Pereira TRC. SIH-SUS (Sistema AIH): uma análise do sistema público de remuneração de internações hospitalares, 1983-1991. Rio de Janeiro:UERJ/IMS; 1993. (Série Estudos em Saúde Coletiva, nº 57).

Lima e Costa MFF, Guerra HL, Barreto SM, Guimarães RM. Diagnóstico da situação de saúde da população idosa brasileira: um estudo da mortalidade e das internações hospitalares públicas. Inf Epidemiol SUS 2000; (1):23-41.

Lira MMTA, Drumond Júnior M. A mortalidade por causas externas no Brasil no ano de 1997. Estudos epidemiológicos 2000. Brasilia-DF: MS/FNS; ago, p. 99-123.

Lolio CA. Prevalência da hipertensão arterial em Araraquara. Arq Bras Cardiol 1990; 55: 167-73.

Lolio CA, Laurenti R. Mortalidade por doença isquêmica do coração no Município de São Paulo: evolução de 1950 a 1981 e mudanças recentes na tendência. Arq Bras Cardiol 1986; 46: 153-6.

Lolio CA, Lotufo PA, Lira AC, Zanetta DMT, Massad E. Tendência da mortalidade por doença isquêmica do coração nas capitais de regiões metropolitanas do Brasil, 1979-89. Arq Bras Cardiol 1995; 64:213-6.

Lotufo PA. As doenças cardiovasculares no Brasil: estudo de caso da tendência da mortalidade no Estado de São Paulo 1970-1989. São Paulo; 1993. [Dissertação de Mestrado - Faculdade de Saúde Pública da USP].

Lotufo PA. Epidemiologia das doenças isquêmicas do coração no Brasil. In: Lessa I. $O$ adulto brasileiro e as doenças da modernidade: epidemiologia das doenças crônicas não-transmissíveis. São Paulo/Rio de Janeiro: Hucitec/Abrasco; 1998a. p. 77-96.

Lotufo PA. Mortalidade precoce por doenças do coração no Brasil. Comparação com outros países. Arq Bras Cardiol 1998b; 70:321-5.

Lotufo PA. Increasing obesity in Brazil: predicting a new peak of cardiovascular mortality. Rev Paul Med 2000; 118: 161-2.

Lotufo PA, Lolio CA. Tendências de evolução da mortalidade por doenças cardiovasculares: o caso do Estado de São Paulo. In: Monteiro CA, organizador. Velhos e novos males da saúde no Brasil: a evolução do país e de suas doenças. São Paulo: Hucitec/NUPENS-USP; 1995. p. 279-88.

Magaziner J, Lydick E, Hawkes W, Fox KM, Zimmerman SI, Epstein RS, Hebel JR. Excess mortality attributable to hip fracture in white women aged 70 years and older. Am J Public Health 1997; 87: 1630-5. 
Malerbi DA, Franco LJ. Multicenter study of the prevalence of diabetes mellitus and inpaired glucose tolerance in the urban Brazilian population aged 30-69 yr. Diabetes Care 1992; 15: 1509-16.

Marangone Camargo AB. Os idosos da região metropolitana de São Paulo. In: Anais do VI Encontro Nacional de Estudos Populacionais [CD-ROM] 1988; Olinda PE, Associação Brasileira de Estudos Populacionais, v. 1, p. 449-80.

Margarida AS, Tironi CL, Lima MG. Centrais de marcação de consultas especializadas e de leitos hospitalares. Divulg Saúde Deb 1996; 16:67-9.

Mathias TAF. Morbidade hospitalar no Município de Maringá-PR, em 1992. São Paulo; 1994. [Dissertação de Mestrado - Faculdade de Saúde Pública da USP].

Mathias TAF, Mello Jorge MHP. Sistema de informações sobre mortalidade: análise da qualidade dos dados para o Município de Maringá, Estado do Paraná, Brasil. Acta Scientiarum 2001; 23: 759-65.

Mathias TAF, Soboll MLMS. Morbidade hospitalar em município da Região Sul do Brasil em 1992. Rev Saúde Pública 1996; 30:224-32.

Mathias TAF, Soboll MLMS. Confiabilidade de diagnósticos nos formulários de autorização de internação hospitalar. Rev Saúde Pública 1998; 32:526-32.

McGovern P, Burke GL, Sprafka JM, Xue S, Folsom AR, Blackburn H. Trends in mortality, morbidity and risk factor levels for stroke from 1960 to 1990: the Minnesota Heart Survey. JAMA 1992; 268:753-9.

Mello Jorge MHP. Registro dos eventos vitais: sua importância em saúde pública. Centro Brasileiro de Classificação de Doenças, São Paulo 1990. (Série divulgação no $5)$.

Mello Jorge MHP, Gotlieb SLD. O sistema de informações de mortalidade: problemas e propostas para seu enfrentamento. Projeto de Pesquisa apresentado ao $\mathrm{CNPq}$, 1998. [mimeo].

Mello Jorge MHP, Gotlieb SLD. As condições de saúde no Brasil: retrospecto de 1979 a 1995. Rio de Janeiro: Editora FIOCRUZ ; 2000.

Mendonça GAS, Teixeira MTB. Epidemiologia do câncer no Brasil. In: Lessa I. O adulto brasileiro e as doenças da modernidade: epidemiologia das doenças crônicas não-transmissíveis. São Paulo/Rio de Janeiro: Hucitec/Abrasco; 1998. p. 155-180.

Mettlin C. Global breast cancer mortality statistics. CA Cancer J Clin [serial on line] 1999; 49:138-44. Available from URL:http://www.ca-journal.org. [2000 jun 1]. 
Meyer MA, Teixeira MG, Paim JS, Silva LMV. Mortalidade por doença de Chagas: evolução e distribuição no espaço urbano de Salvador-Bahia. Inf Epidemiol SUS 1996; (4):21-9.

Minayo MC (Nota de apresentação). Os muitos Brasis: saúde e população na década de 80. Rio de Janeiro: HUCITEC/ABRASCO; 1995. p. 9-13.

Ministério da Saúde. Doenças cardiovasculares no Brasil - Sistema Único de Saúde - SUS. Brasilia-DF: Coordenação de doenças cardiovasculares; 1993. 36 p.

Ministério da Saúde. Mortalidade: Brasil, 1994. Brasilia-DF: 1997; CENEPI/Fundação Nacional de Saúde.

Ministério da Saúde. IDB 97 Brasil. Indicadores e Dados Básicos. Rede Interagencial de informações para a Saúde - RIPSA. Brasilia-DF: - MS/OPAS/OMS; 1997.

Ministério da Saúde - DATASUS. Movimento de Autorização de Internação Hospitalar, Arquivos reduzidos [CD-ROM]; 1995, 1996, 1997 e 1998.

Ministério da Saúde - FNS/CENEPI/DATASUS. Sistema de informação sobre mortalidade, 1979-1997. [CD-ROM]; 1998.

Mokdad AH, Ford ES, Bowman BA, Nelson DE, Engelgau MM, Vinicor F, Marks JS. Diabetes trends in the U.S.: 1990-1998. Diabetes Care 2000; 23:1278-83.

Monteiro CA, Benicio MHD'A, Conde W, Popkin B. Shifting obesity trends in Brazil. Eur J Clin Nutr 2000; 54:342-6.

Monteiro CA, Benicio MHD'A, Freitas ICM. Melhoria em indicadores de saúde associados à pobreza no Brasil nos anos 90: descrição, causas e impacto sobre desigualdades regionais. São Paulo 1997. (Série: A trajetória do desenvolvimento social no Brasil, Núcleo de Pesquisas Epidemiológicas em Nutrição e Saúde, FSP/USP).

Moraes AS, Rezende MHV de, Freitas ICM de. Tendência da mortalidade por doença isquêmica do coração no Município de Goiânia-Brasil na série histórica entre 1980 e 1994. Arq Bras Cardiol 2000; 74:493-7.

Moraes MF. Câncer e velhice no Brasil. Arq Geriatr Gerontol 1997; 1: 61 -3.

Moriguti JC, Moriguti EKU, Ferriolli E, Cação JC, Iucif Junior N, Marchini JS. Involuntary weith loss in elderly individuals: assessment and treatment. Rev Paul Med 2001; 119: 72-6.

Moura RN, Santos FC, Driemeier M, Santos LM, Ramos LR. Quedas em idosos: fatores de risco associados. Gerontologia 1999; 7:15-21. 
Murray C, Lopez A. Mortality by cause for eight regions of the world: Global Burden of Disease Study. Lancet 1997; 349:1269-76.

Nascimento VB. A municipalização das ações de saúde e a assistência hospitalar: as respostas de Santo André e Diadema. Saúde Soc 1996; 5: 81-9.

Nathan DM, Meigs J, Singer DE. The epidemiology of cardiovascular disease in type 2 diabetes mellitus: how sweet it is, or is it? Lancet 1997; 350(Suppl 1): S14-S19.

Nicholls ES, Peruga A, Restrepo HE. Cardiovascular disease mortality in the Americas. Wld Hlth Stat Quart 1993; 46: 134-50.

[NEPO] Núcleo de Estudos de População-UNICAMP, 1999. Estimativa da população do Município de Maringá, 1979 a 1998.

Nunes A. Aspectos sobre a morbidade dos idosos no Brasil. Como vai? População brasileira [periódico on line] IPEA; 1999, ano IV, 2:24-36. Disponível em <URL: http//:www.ipea.gov.br> [2000 jul 20].

Oliveira DA, Rodrigues AD, Schiavon L de L, Teixeira MTB, Paula RB de. Mortalidade por doença isquêmica do coração em Juiz de Fora, 1979/1995. HU Revista 1999; 25:92-8.

Oliveira HB, Moreira Filho DC. Recidivas em tuberculose e seus fatores de risco. Rev Panam Salud Publica [periódico on line] 2000; 7:232-41. Disponível em <URL: http://www.scielosp.org > [2000 nov 15].

Oliveira LAP, Felix C. A dinâmica demográfica recente: níveis, tendências e diferenciais. In: Indicadores sociais: uma análise da década de 1980. Rio de Janeiro 1995: Fundação IBGE, p. 25-41.

Oliveira MRF. Fontes de informação complementares para vigilância epidemiológica de doenças de notificação compulsória [Editorial]. Inf Epidemiol SUS 2000; (2), p. 65.

Omran AR. The epidemiologic transition: a theory of the epidemiology of the population change. Milbank Mem Fund Q 1971; 49(Part 1): 509-38.

[OMS] Organização Mundial da Saúde. Centro Brasileiro de Classificação de Doenças em Português. Classificação Internacional de Doenças; $9^{a}$ rev. 1975. São Paulo; 1985.2 vol.

[OMS] Organização Mundial da Saúde. Centro Brasileiro de Classificação de Doenças em Português Classificação Estatística Internacional de Doenças e Problemas Relacionados à Saúde. 10ª rev. São Paulo: EDUSP; 1998. 3 vol. 
[OPAS/OMS] Organização Panamericana da Saúde/Organização Mundial da Saúde. Envelhecimento: mitos na berlinda. Ano internacional das pessoas idosas. Instituto Nacional de Envelhecimento, 1999. 7 p.

[OPS] Organización Panamericana de la Salud. Indicadores Básicos 1998. Situación de Salud en las Américas - Programa Análisis de Situación de Salud - División de Salud y Desarrollo Humano.

[OPS/OMS] Organización Panamericana de la Salud/Organización Mundiale de la Salud. Las condiciones de salud en las Américas: 1990. Washington; 1990. v.1. p. 145-52. (Publicación científica $\mathrm{n}^{\varrho}$ 524).

Osler M, Sorensen TIA, Sorensen S, Rostgaard K, Jensen G, Iversen L et al. Trends in mortality, incidence and case fatality of ischaemic heart disease in Denmark, 19821992. Int J Epidemiol 1996; 25:1 154-61.

Paes NA, Silva LAA. Doenças infecciosas e parasitárias no Brasil: uma década de transição. Rev Panam Salud Publica 1999; 6: 99-109.

Pahor M, Carosella L, Pedone C, Manto A, Carbonin P. Trends of the characteristics and appropriateness of admissions to acute geriatric and medical wars in Italy from 1988 through 1993. Eur J Epidemiol 1996; 12: 563-71.

Palloni A. Health conditions of the elderly in Latin America and the Caribbean. Washington-DC: Pan American Health Organization/WHO; 1997 (draft no 4).

Parahyba MICA. Evolução da mortalidade da população idosa no Município do Rio de Janeiro (1983-1994). Rio de Janeiro; 1997. [Dissertação de Mestrado Instituto de Medicina Social - UERJ].

Patarra NL. Transição em marcha: novas questões demográficas. Anais do $\mathbf{1}^{\mathbf{0}}$ Congresso Brasileiro de Epidemiologia; 1990 set 2-6; Campinas, Brasil. Rio de Janeiro: ABRASCO; 1990. p. 180-97.

Patarra NL. Mudanças na dinâmica demográfica. In: Monteiro CA, organizador. Velhos e novos males da saúde no Brasil. São Paulo (SP): Hucitec/Nupens/USP; 1995. p. 61-78.

Paula AMC, Evangelista Filho D, Pereira IPA, Albano AHBL, Fernandes RM. Avaliação dos dados de mortalidade, Brasil - 1979 a 1989. Inf Epidemiol SUS 1994; Publicación científica $\mathrm{n}^{0} 524$ (1): 21-41.

Pearce N. Classe social e câncer. In : Barata RB, Barreto ML, Almeida Filho N, Veras RP. Organizadores. Eqüidade e saúde: contribuições da epidemiologia. Rio de Janeiro: FIOCRUZ; 1997. P. 121-33. Série epidemiológica $n^{\circ} 1$. 
Piccini RX, Victora CG. Hipertensão arterial sistêmica em área urbana no sul do Brasil: prevalência e fatores de risco. Rev Saúde Pública 1994; 28:261-7.

Prefeitura Municipal de Maringá. Maringá sempre ecológica. Maringá-PR 1997. [Apostila de difusão cultural].

Raina P, Dudeshire S, Linsay J, Cambers LW. Chronic conditions and disabilities among seniors: an analysis of population-based health and activity limitation surveys. AEP 1998; 8: 402-9.

Ramos LR. A saúde do idoso no Brasil: uma visão clínico-epidemiológica. São Paulo; 1997. [Tese de Livre Docência - Escola Paulista de Medicina].

Ramos LR, Saad PM. Morbidade na população idosa. In: Fundação SEADE: O idoso na grande São Paulo. 1990, p. 161-172.

Ramos LR, Veras RP, Kalache A. Envelhecimento populacional: uma realidade brasileira. Rev Saúde Pública 1987; 21: 211-24.

Rassi EPM. Indicadores de saúde em idosos: o papel da Unidade Básica de Saúde. Gerontologia 1994; 2:75-81.

Rego RA, Berardo FAN, Rodrigues SSR, Oliveira ZMA, Oliveira MB, Vasconcelos C. Fatores de risco para doenças crônicas não transmissíveis: inquérito domiciliar no Município de São Paulo (Brasil). Metodologia e resultados preliminares. Rev Saúde Pública 1990; 24: 277-85.

Ribas AMM, Davanso SM. Paraná: Qualidade da informação sobre mortalidade no periodo 1974-1993. In: Anais do X Encontro Nacional de Estudos Populacionais. [CD-ROM] 1996, Caxambú- MG, Associação Brasileira de Estudos Populacionais, v.1, p. 135-49.

Rosa TEC. Determinantes da capacidade funcional de idosos residentes no distrito de São Paulo. São Paulo; 1999. [Dissertação de Mestrado - Faculdade de Saúde Pública da USP].

Rosenberg HM, Chevarley F, Powell-Griner E, Kochanek K, Feinleib M. Causes of death among the elderly: information from the death certificate. Vital and Health Statistics 1991; Procedings of 1988 International Symposium on data on aging, NCHS, n. 6, p. 35-58. (Series 5).

Rosenthal DS. Changing trends [editorial]. CA Cancer J Clin [serial on-line] 1998; 48(1): 3-4. Disponível em <URL: http://www.ca-journal.org>. [2000 jun 1].

Rosenthal MJ, Fajardo M. Morley JE, Naliboff Bd, Gilmore S. Hospitalization and mortality of diabetes in older adults. Diabetes Care 1998; 21: 231-5. 
Rouquayrol MZ, Barbosa LMM, Aderaldo LC, Moura LGX. Principais causas de morte no Brasil, 1979-1988. Inf Epidemiol SUS 1993; (5):28-37.

Rothenberg RB, Koplan JP. Chronic disease in the 1990s. Ann Rev Public Health 1990; 11:267-96.

Ruffino-Neto A, Souza AMAE. Reforma do setor saúde e controle da tuberculose no Brasil. Inf Epidemiol SUS 1999; (8):35-51.

Ruiz T. Estudo da mortalidade e dos seus preditores na população idosa do Município de Botucatu-SP. Campinas; 1996. [Tese de Doutorado - Faculdade de Ciências Médicas da UNICAMP].

Ruiz T, Barros MBA, Carandina L. Morbidade em idosos na área urbana do Município de Botucatu (SP). Gerontologia 1998; 6:59-65.

Santo AH. Equivalência entre revisões da Classificação Internacional de Doenças: causas de morte. Rev Saúde Pública 2000, 34: 21-28.

Scalassara MB, Souza RKT, Soares DFPP. Características da mortalidade por acidentes de trânsito em localidade da Região Sul do Brasil, em 1992. Rev Saúde Pública 1998; 32:125-32.

Schmuñis GA. A tripanossomiase americana e seu impacto na saúde pública das Américas. In: Brener Z, Andrade ZA, Barral-Netto M. Trypanosoma Cruzi e doença de Chagas. $2^{\text {a }}$ ed, Rio de Janeiro: Guanabara Koogan; 2000. p. 1-15.

Secretaria Estadual de Saúde do Paraná. 15a Regional de Saúde/Centro Regional de Saúde. Central de leitos $e$ informações complementares: normas de funcionamento. Versão 1/95. Maringá; 1995.

Shahar E, McGovern PG, Sprafka JM, Pankow JS, Doliszny KM, Luepker RV et al. Improved Survival of stroke patients during the 1980s. The Minnesota Stroke Survey. Stroke 1995; 26:1-6.

Silva SF, Carvalho BG, Canavese SV. Hospitais: garantia de acesso aos que realmente necessitam. In: Silva SF. A construção do SUS a partir do município: etapas para a municipalização plena da saúde. São Paulo: Hucitec; 1996. p.71-5.

Silvestre JA, Kalache A, Ramos LR, Veras RP. O envelhecimento populacional brasileiro e o setor saúde. Arq Geriatr Gerontol 1996; 0:81-9.

Simons LA. Epidemiologic considerations in cardiovascular diseases in the elderly: international comparisons and trends. Am J Cardiol 1989; 63: 5H-8H.

Smith DWE. Changing causes of death of elderly people in the United States . 19501990. Gerontology 1998; 44:331-5. 
Soares DFPP. Vítimas de acidentes de trânsito em Maringá-PR, em 1995. Londrina; 1997. [Dissertação de Mestrado - Universidade Estadual de Londrina].

Souza RKT. Aspectos da violência no trânsito na terceira idade em localidade da Região Sul do país. Maringá; 1999. [Monografia de Especialização - Universidade Estadual de Maringá-PR].

Souza RKT, Soares DFPP, Fonzar UJV. Mudanças demográficas e perfil de mortalidade do Município de Maringá-PR, entre 1980-1991. Saúde Deb 1996; (51):75-81.

Stanley M. Sepsis in the elderly. Crit Care Nurs Clin North Am 1996; 8: 1-6.

Stokes J. Lindsay J. Major causes of death and hospitalization in Canadian seniors. Chronic Dis Can 1996; 17:63-73.

Sutherland JE, Persky VW, Brody JA. Proportionate mortality trends: 1950 through 1986. JAMA 1990; 264: 3178-84.

Tuuponen T, Keistinen T, Kivelä SL. Hospital admissions for asthma in Finland during 1972-86 of adults aged 65 years and over. Age Ageing 1993; 22:97-102.

Uemura K, Pisa $\mathrm{Z}$. Trends in cardiovascular disease mortality in industrialized countries since 1950. World Health Statist Q 1988; 41:155-78.

Vallgarda S. Is old age necessarily connected with high hospital admission rates? Scand J Public Health 1999; 2: 137-42.

Vasconcelos AMN. Estatísticas de mortalidade por causas: uma avaliação da qualidade da informação. In: Anais do $X$ Encontro Nacional de Estudos Populacionais [CD-ROM] 1996, Caxambú-MG, Associação Brasileira de Estudos Populacionais, v.1, p. 151-66.

Vasconcelos AMN. A mortalidade da população idosa no Brasil. Como Vai? População Brasileira. Brasilia-DF 1998. IPEA, ano III, $\mathrm{n}^{\circ} 3$, p. 24-33. [periódico on line]. Disponivel em <URL:http//:www.ipea.gov.br> [1999 nov 11].

Veras CMT, Martins MS. A confiabilidade dos dados nos formulários de Autorização de Internação Hospitalar (AIH), Rio de Janeiro, Brasil. Cad Saúde Pública 1994; $10: 339-56$.

Veras RP, Coutinho E. Prevalência da síndrome cerebral orgânica em população de idosos de área metropolitana da região sudeste do Brasil. Rev Saúde Pública 1994; 28:26-37.

Veras RP, Ramos LR, Kalache A. Crescimento da população idosa no Brasil: transformações e conseqüências na sociedade. Rev Saúde Pública 1987; 21:225-33. 
Verbrugge LM. Longer life but worsening health? Trends in health and mortality of middle-aged and older persons. Milbank Mem Fund Q 1984; 62:475-519.

Viacava F, Bahia L. Assistência médica sanitária: os serviços de saúde segundo o IBGE. DADOS-Radis 1996: FIOCRUZ. no 20.

Vilkman S, Keistinen T, Tuuponen T, Kivelä SL. Survival and cause of death among elderly chronic obstructive pulmonary disease patients after first admission to hospital. Respiration 1997; 64: 281-4.

Vinhares MC, Dias JCP. Doença de Chagas no Brasil. Cad Saúde Pública 2000; 16 (2 Suppl):7-12.

Waldman EA, Silva LJ da, Monteiro CA. Trajetória das doenças infecciosas: da eliminação da poliomileite à reintrodução da cólera. In: Monteiro CA. Velhos e novos males da saúde no Brasil: a evolução do país e de suas doenças. São Paulo: Hucitec/NUPENS-USP; 1995. p. 195-244.

Whittall DE, Glatthaar C, Knuiman MW, Welborn TA. Deaths from diabetes are under-reported in national mortality statistics. Med J Aust 1990; 152:598-600.

Williams ES, Scott CM, Scott SM. Using mortality data to describe geographic variations in health status at sub-district level. Public Health 1995; 109:67-73.

Wolf PA. Na overview of the epidemiology of stroke. Stroke 1990; 21(II Suppl): II-4II-6.

Wolinsky FD, Fitzgerald JF, Stump TE. The effect of hip fracture on mortality, hospitalization, and functional status: a prospective study. Am J Public Health 1997; 87: 398-403.

Yazaki LM. Evolução da mortalidade da população idosa no Município de São Paulo. In: Anais do VI Encontro Nacional de Estudos Populacionais [CD-ROM] 1988; Olinda-PE, Associação Brasileira de Estudos Populacionais, v.1, p. 481-503.

Yazlle-Rocha JS. Assistência médico hospitalar em Ribeirão Preto, SP, 1972-1976: considerações para uma política de assistência médico-hospitalar. Saúde em Debate 1978; (24):186-91.

Yazlle-Rocha JS, Simões BJG. Estudo da assistência hospitalar pública e privada em bases populacionais, 1986-1996. Rev Saúde Pública 1999; 33:44-54.

Yazlle-Rocha JS, Simões BJG, Guedes GLM. Assistência hospitalar como indicador da desigualdade social. Rev Saúde Pública 1997; $31: 479-87$.

Zhang XH, Sasaki S, Kesteloot $\mathrm{H}$. The sex ratio of mortality and its secular trends. Int J Epidemiol 1995; 24:720-9. 
8. ANEXOS 


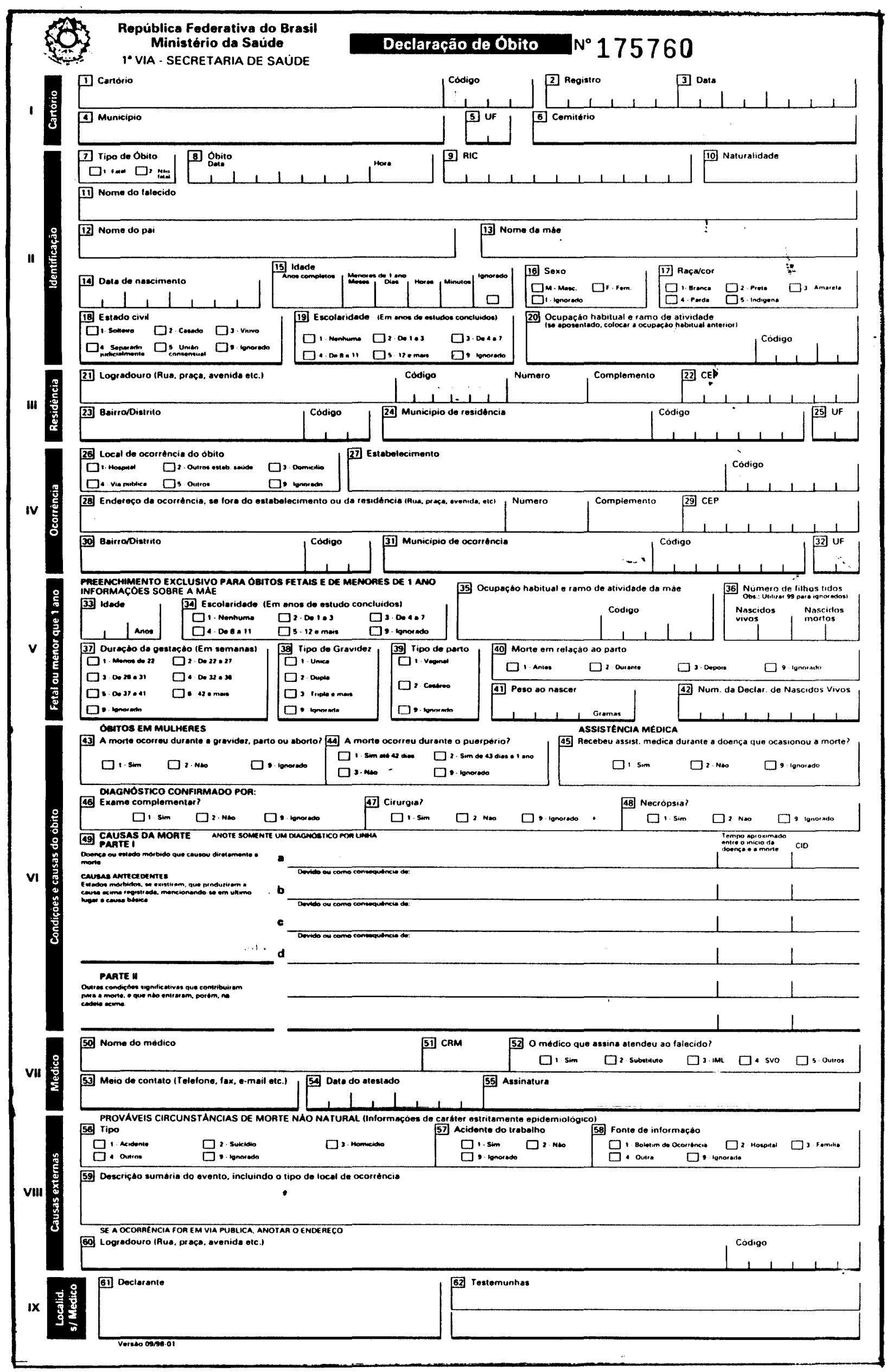




\section{ANEXO 2}

Óbitos em idosos residentes em Maringá segundo sexo, idade e ano, 1979-1998.

\begin{tabular}{|c|c|c|c|c|c|c|c|c|c|c|c|c|}
\hline & \multicolumn{12}{|c|}{ Idade } \\
\hline & \multicolumn{2}{|c|}{60 a 64} & \multicolumn{2}{|c|}{65 a 69} & \multicolumn{2}{|c|}{70 а 74} & \multicolumn{2}{|c|}{75 a 79} & \multicolumn{2}{|c|}{80 a 84} & \multicolumn{2}{|c|}{$85 \mathrm{e}$ mais } \\
\hline Ano & $\mathrm{M}$ & $\mathrm{F}$ & $\mathrm{M}$ & $\mathrm{F}$ & $M$ & $\mathrm{~F}$ & $\mathrm{M}$ & $\mathrm{F}$ & $M$ & $F$ & $\mathrm{M}$ & $F$ \\
\hline 1979 & 36 & 11 & 43 & 23 & 50 & 37 & 52 & 26 & 22 & 27 & 17 & 18 \\
\hline 1980 & 45 & 32 & 55 & 38 & 45 & 34 & 42 & 39 & 25 & 29 & 21 & 28 \\
\hline 1981 & 44 & 18 & 35 & 31 & 59 & 33 & 43 & 43 & 31 & 26 & 20 & 19 \\
\hline 1982 & 38 & 17 & 44 & 38 & 54 & 28 & 53 & 35 & 32 & 26 & 18 & 15 \\
\hline 1983 & 44 & 24 & 44 & 40 & 53 & 42 & 56 & 30 & 39 & 33 & 28 & 29 \\
\hline 1984 & 36 & 36 & 61 & 40 & 56 & 37 & 45 & 40 & 39 & 26 & 28 & 38 \\
\hline 1985 & 43 & 27 & 54 & 36 & 52 & 35 & 50 & 41 & 43 & 40 & 25 & 36 \\
\hline 1986 & 58 & 30 & 61 & 37 & 61 & 24 & 47 & 41 & 37 & 23 & 32 & 27 \\
\hline 1987 & 59 & 36 & 39 & 36 & 58 & 57 & 60 & 43 & 43 & 34 & 25 & 25 \\
\hline 1988 & 52 & 29 & 64 & 41 & 66 & 43 & 70 & 59 & 45 & 49 & 41 & 45 \\
\hline 1989 & 54 & 35 & 73 & 51 & 62 & 63 & 65 & 55 & 58 & 46 & 33 & 44 \\
\hline 1990 & 68 & 35 & 80 & 47 & 66 & 55 & 76 & 46 & 56 & 55 & 59 & 59 \\
\hline 1991 & 57 & 37 & 85 & 36 & 61 & 51 & 63 & 56 & 40 & 38 & 33 & 65 \\
\hline 1992 & 68 & 27 & 75 & 51 & 79 & 57 & 61 & 65 & 53 & 44 & 46 & 57 \\
\hline 1993 & 64 & 39 & 73 & 44 & 80 & 58 & 82 & 49 & 62 & 67 & 50 & 58 \\
\hline 1994 & 73 & 38 & 65 & 48 & 84 & 52 & 73 & 51 & 41 & 57 & 43 & 66 \\
\hline 1995 & 67 & 50 & 85 & 62 & 81 & 52 & 74 & 70 & 62 & 57 & 44 & 76 \\
\hline 1996 & 82 & 33 & 64 & 52 & 83 & 73 & 87 & 64 & 66 & 68 & 63 & 72 \\
\hline 1997 & 73 & 45 & 113 & 60 & 106 & 62 & 71 & 81 & 72 & 56 & 57 & 86 \\
\hline 1998 & 83 & 38 & 76 & 53 & 93 & 70 & 84 & 65 & 80 & 75 & 67 & 98 \\
\hline
\end{tabular}

Fonte: Ministério da Saúde 1998 


\section{ANEXO 3}

População idosa de Maringá segundo sexo, idade e ano, 1979 a 1998.

\begin{tabular}{|c|c|c|c|c|c|c|c|c|c|c|c|c|}
\hline \multicolumn{10}{|c|}{ Idade } \\
\hline & \multicolumn{1}{|c|}{$60 \mathrm{a} 64$} & \multicolumn{1}{c|}{$65 \mathrm{a} 69$} & \multicolumn{2}{c|}{$70 \mathrm{a} 74$} & \multicolumn{2}{c|}{$75 \mathrm{a} 79$} & \multicolumn{2}{c|}{$80 \mathrm{a} 84$} & \multicolumn{2}{c|}{$85 \mathrm{e}$ mais } \\
\hline Ano & $\mathrm{M}$ & $\mathrm{F}$ & $\mathrm{M}$ & $\mathrm{F}$ & $\mathrm{M}$ & $\mathrm{F}$ & $\mathrm{M}$ & $\mathrm{F}$ & $\mathrm{M}$ & $\mathrm{F}$ & $\mathrm{M}$ & $\mathrm{F}$ \\
\hline 1979 & 1633 & 1397 & 1087 & 1267 & 653 & 685 & 466 & 446 & 193 & 220 & 104 & 147 \\
1980 & 1713 & 1492 & 1145 & 1329 & 695 & 731 & 489 & 479 & 205 & 237 & 111 & 157 \\
1981 & 1797 & 1593 & 1206 & 1394 & 740 & 781 & 514 & 515 & 218 & 256 & 118 & 167 \\
1982 & 1884 & 1701 & 1271 & 1461 & 787 & 833 & 539 & 553 & 231 & 276 & 126 & 179 \\
1983 & 1976 & 1816 & 1338 & 1533 & 838 & 890 & 566 & 595 & 246 & 297 & 135 & 190 \\
1984 & 2073 & 1939 & 1410 & 1607 & 892 & 950 & 595 & 639 & 261 & 321 & 143 & 204 \\
1985 & 2174 & 2071 & 1485 & 1685 & 950 & 1015 & 625 & 687 & 277 & 346 & 153 & 218 \\
1986 & 2280 & 2211 & 1564 & 1767 & 1011 & 1083 & 656 & 738 & 294 & 373 & 163 & 233 \\
1987 & 2392 & 2361 & 1648 & 1853 & 1076 & 1157 & 689 & 793 & 313 & 403 & 173 & 249 \\
1988 & 2508 & 2521 & 1736 & 1943 & 1145 & 1235 & 724 & 852 & 332 & 434 & 185 & 266 \\
1989 & 2631 & 2692 & 1829 & 2038 & 1219 & 1319 & 760 & 916 & 353 & 468 & 196 & 285 \\
1990 & 2759 & 2874 & 1926 & 2137 & 1297 & 1409 & 798 & 984 & 375 & 505 & 209 & 304 \\
1991 & 2894 & 3069 & 2029 & 2241 & 1381 & 1504 & 838 & 1058 & 398 & 545 & 223 & 326 \\
1992 & 2988 & 3199 & 2144 & 2374 & 1452 & 1601 & 879 & 1098 & 427 & 584 & 240 & 356 \\
1993 & 3084 & 3334 & 2265 & 2515 & 1527 & 1704 & 923 & 1139 & 459 & 626 & 259 & 389 \\
1994 & 3184 & 3476 & 2393 & 2664 & 1606 & 1813 & 969 & 1181 & 493 & 671 & 280 & 425 \\
1995 & 3288 & 3623 & 2529 & 2822 & 1689 & 1930 & 1017 & 1225 & 529 & 719 & 302 & 465 \\
1996 & 3394 & 3776 & 2672 & 2990 & 1776 & 2054 & 1067 & 1271 & 568 & 771 & 325 & 508 \\
1997 & 3504 & 3936 & 2823 & 3168 & 1868 & 2186 & 1120 & 1318 & 610 & 826 & 351 & 556 \\
1998 & 3617 & 4102 & 2983 & 3356 & 1964 & 2327 & 1175 & 1368 & 655 & 886 & 377 & 608 \\
\hline
\end{tabular}

Fonte: NEPO - UNICAMP (1999). 


\section{ANEXO 4}

Mortalidade proporcional e coeficientes de mortalidade em idosos

(por 1000 hab.), segundo sexo e causas, por triênios, Maringá-PR, 1979-1998.

\begin{tabular}{|c|c|c|c|c|c|c|c|c|c|c|c|c|}
\hline \multicolumn{13}{|c|}{ MASCULINO } \\
\hline \multirow[b]{2}{*}{ Causas } & \multicolumn{3}{|c|}{ 1979-1981 } & \multicolumn{3}{|c|}{$1984-1986$} & \multicolumn{3}{|c|}{ 1990-1992 } & \multicolumn{3}{|c|}{ 1996-1998 } \\
\hline & $\mathrm{n}$ & $\%$ & coef & $\mathrm{n}$ & $\%$ & coef & $\mathrm{n}$ & $\%$ & coef & $\mathrm{n}$ & $\%$ & coef \\
\hline Infecciosas & 31 & 4,5 & 2,4 & 29 & 3,5 & 1,7 & 28 & 2,5 & 1,2 & 48 & 3,4 & 1,0 \\
\hline Neol & 91 & 13,3 & 7,0 & 126 & 15,2 & 7,4 & 191 & 17,0 & 8,2 & 287 & 20,2 & 9,3 \\
\hline Endócrinas & 12 & 1,8 & 0,9 & 28 & 3,4 & 1,6 & 34 & 3,0 & 1,5 & 48 & 3,4 & 1,6 \\
\hline Sangue & 3 & 0,4 & 0,2 & 3 & 0,4 & 0,2 & - & - & - & 6 & 0,4 & 0,2 \\
\hline Ouvidos & - & - & - & - & - & - & - & - & - & 1 & 0,1 & 0,0 \\
\hline Transtornos & - & - & - & 1 & 0,1 & 0,1 & 4 & 0,4 & 0,2 & 3 & 0,2 & 0,1 \\
\hline Sistema & 9 & 1,3 & 0,7 & 2 & 0,2 & 0,1 & 8 & 0,7 & 0,3 & 21 & 1,5 & 0,7 \\
\hline Circ & 351 & 51,2 & 26,8 & 372 & 44,92 & 21,9 & 501 & 44,5 & 21,5 & 565 & 39,8 & 18,3 \\
\hline Respir & 48 & 7,0 & 3,7 & 71 & 8,6 & 4,2 & 126 & 11,2 & 5,4 & 187 & 13,2 & 6,1 \\
\hline Dig & 48 & 7,0 & 3,7 & 46 & 5,6 & 2,7 & 36 & 3,2 & 1,5 & 61 & 4,3 & 2,0 \\
\hline Gel & 9 & 1,3 & 0,7 & 26 & 3,1 & 1,5 & 16 & 1,4 & 0,7 & 26 & 1,8 & 0,8 \\
\hline Pel & - & - & - & - & - & - & 1 & 0,1 & - & 3 & 0,2 & 0,1 \\
\hline Osteon & 2 & 0,3 & 0,2 & - & - & - & 2 & 0,2 & 0,1 & 4 & 0,3 & 0,1 \\
\hline & - & - & - & - & - & - & 2 & 0,2 & 0,1 & - & - & - \\
\hline Mal & 49 & 7,2 & 3,7 & 75 & 9,1 & 4,4 & 116 & 10,3 & 5,0 & 92 & 6,5 & 3,0 \\
\hline Causas & 32 & 4,7 & 2,4 & 49 & 5,9 & 2,9 & 61 & 5,4 & 2,6 & 68 & 4,8 & 2,2 \\
\hline Total & 685 & 100 & 52,3 & 828 & 100 & 48,7 & 1126 & 100 & 48,4 & 1420 & 100 & 46,0 \\
\hline \multicolumn{13}{|c|}{ FEMININO } \\
\hline \multirow[b]{2}{*}{ Causas } & \multicolumn{3}{|c|}{$1979-1981$} & \multicolumn{3}{|c|}{$1984-1986$} & \multicolumn{3}{|c|}{$1990-1992$} & \multicolumn{3}{|c|}{$1996-1998$} \\
\hline & $\mathrm{n}$ & $\%$ & coef & $\mathrm{n}$ & $\%$ & coef & $\mathrm{n}$ & $\%$ & coef & $\mathrm{n}$ & $\%$ & coef \\
\hline Infecciosas & 24 & 4,7 & 1,8 & 34 & 5,5 & 1,9 & 28 & 3,2 & 1,1 & 31 & 2,7 & 0,9 \\
\hline $\mathrm{Ne}$ & 58 & 11,3 & 4,4 & 89 & 14,5 & 4,9 & 120 & 13,6 & 4,6 & 174 & 15,1 & 4,8 \\
\hline Endócr & 17 & 3,3 & 1,3 & 26 & 4,2 & 1,4 & 52 & 5,9 & 2,0 & 73 & 6,3 & 2,0 \\
\hline Sang & - & - & - & 2 & 0,3 & 0,1 & - & - & - & 4 & 0,3 & 0,1 \\
\hline Tra & - & - & - & 0 & 0,0 & 0,0 & 4 & 0,5 & 0,2 & 1 & 0,1 & 0,0 \\
\hline Sistema & 3 & 0,6 & 0,2 & 4 & 0,7 & 0,2 & 9 & 1,0 & 0,3 & 10 & 0,9 & 0,3 \\
\hline Circul & 310 & 60,6 & 23,3 & 311 & 50,7 & 17,2 & 413 & 46,9 & 15,8 & 521 & 45,3 & 14,5 \\
\hline $\mathrm{Re}$ & 23 & 4,5 & 1,7 & 38 & 6,2 & 2,1 & 89 & 10,1 & 3,4 & 144 & 12,5 & 4,0 \\
\hline Dig & 18 & 3,5 & 1,4 & 29 & 4,7 & 1,6 & 37 & 4,2 & 1,4 & 58 & 5,0 & 1,6 \\
\hline Genitur & 7 & 1,4 & 0,5 & 8 & 1,3 & 0,4 & 12 & 1,4 & 0,5 & 14 & 1,2 & 0,4 \\
\hline & - & - & - & - & - & - & 1 & 0,1 & - & 3 & 0,3 & 0,1 \\
\hline Osteom & 1 & 0,2 & 0,1 & 1 & 0,2 & 0,1 & - & - & - & 6 & 0,5 & 0,2 \\
\hline Cong & - & - & - & 2 & 0,3 & 0,1 & - & - & - & - & - & - \\
\hline Mal definida & 35 & 6,8 & 2,6 & 43 & 7,0 & 2,4 & 84 & 9,5 & 3,2 & 78 & 6,8 & 2,2 \\
\hline Causas externas & 16 & 3,1 & 1,2 & 27 & 4,4 & 1,5 & 32 & 3,6 & 1,2 & 34 & 3,0 & 0,9 \\
\hline Total & 512 & 100 & 38,5 & 614 & 100 & 33,9 & 881 & 100 & 33,7 & 1151 & 100 & 32,0 \\
\hline
\end{tabular}




\section{ANEXO 5}

Mortalidade proporcional e coeficientes de mortalidade em idosos (por 100.000 hab.), segundo sexo e diagnósticos mais freqüentes, por triênios, Maringá-PR, 1979-1998.

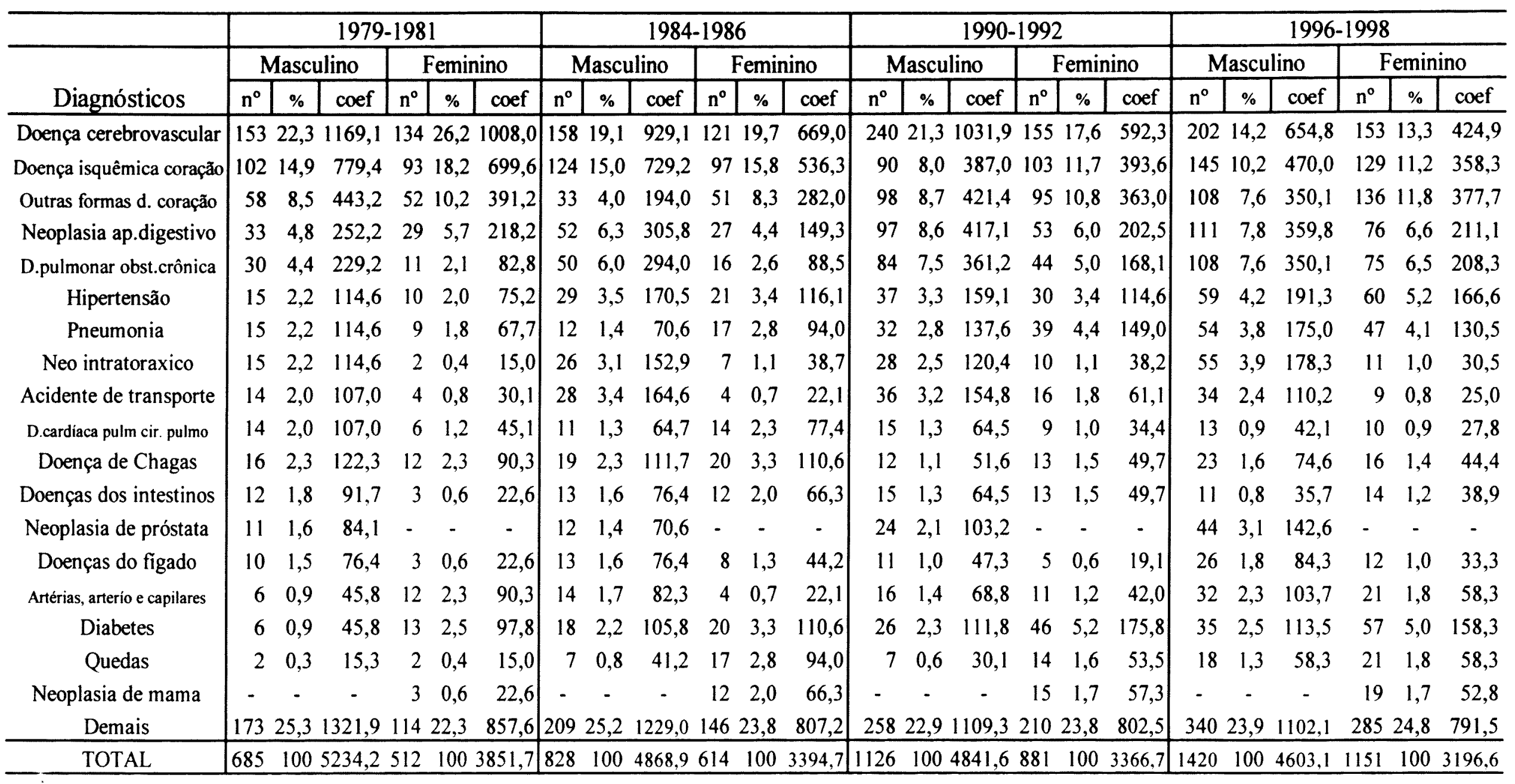


ANEXO 6

Internações ( $\mathrm{n}^{\circ} \mathrm{e} \%$ ) e coeficientes de internação em idosos (por 1000 habitantes) segundo ano, sexo e diagnóstico principal, Maringá-PR, 1995-1998.

\begin{tabular}{|c|c|c|c|c|c|c|c|c|c|c|c|c|c|c|c|c|c|c|c|c|c|c|c|c|c|c|c|c|c|c|c|c|c|c|c|}
\hline \multirow[b]{3}{*}{ Diagnóstico } & \multicolumn{9}{|c|}{1995} & \multicolumn{9}{|c|}{1996} & \multicolumn{8}{|c|}{1997} & \multicolumn{9}{|c|}{1998} \\
\hline & \multicolumn{3}{|c|}{ Masculino } & \multicolumn{3}{|c|}{ Feminino } & \multicolumn{3}{|c|}{ Total } & \multicolumn{3}{|c|}{ Masculino } & \multicolumn{3}{|c|}{ Feminino } & \multicolumn{3}{|c|}{ Total } & \multicolumn{3}{|c|}{ Masculino } & \multicolumn{2}{|c|}{ Feminino } & \multicolumn{3}{|c|}{ Total } & \multicolumn{3}{|c|}{ Masculino } & \multicolumn{3}{|c|}{ Feminino } & \multicolumn{3}{|c|}{ Total } \\
\hline & $\mathrm{n}$ & $\%$ & coef & $\mathrm{n}$ & $\%$ & coef & $\mathrm{n}$ & \begin{tabular}{|l|}
$\%$ \\
\end{tabular} & coef & \begin{tabular}{l|l}
$\mathrm{n}$ & \\
\end{tabular} & $\%$ & coef & \begin{tabular}{l|l}
$n$ & \\
\end{tabular} & $\%$ & coef & \begin{tabular}{l|l}
$\mathrm{n}$ & \\
\end{tabular} & \begin{tabular}{l|l}
$\%$ & $a$ \\
\end{tabular} & coef & \begin{tabular}{l|l}
$\mathbf{n}$ & 9 \\
\end{tabular} & \begin{tabular}{l|l}
$\%$ & co \\
\end{tabular} & oef & \begin{tabular}{|l|l|}
$\mathrm{n}$ & $\%$ \\
\end{tabular} & \begin{tabular}{l|l|} 
& coef \\
\end{tabular} & $\mathrm{n}$ & \begin{tabular}{l|l}
$\%$ & $c$ \\
\end{tabular} & $\operatorname{coef}$ & \begin{tabular}{l|l}
$\mathrm{n}$ & 9 \\
\end{tabular} & \begin{tabular}{l|l|}
$\%$ & a \\
\end{tabular} & oef & \begin{tabular}{l|l}
$n$ & \\
\end{tabular} & \begin{tabular}{l|l}
$\%$ & $\mathrm{c}$ \\
\end{tabular} & coef & \begin{tabular}{l|l}
$\mathrm{n}$ & \\
\end{tabular} & $\%$ & coef \\
\hline Infecciosas & 62 & 4,0 & 6,6 & 57 & 3,8 & 5,3 & 119 & 3,9 & 5,9 & 69 & 4,3 & 7,0 & 56 & 3,8 & 4,9 & 125 & 4,1 & 5,9 & 654 & 4,26 & 6,3 & $62 \quad 4,5$ & 5,2 & 127 & 4,4 & 5,7 & 49 & 2,6 & 4,5 & 47 & 2,5 & 3,7 & 96 & 2,5 & 4,1 \\
\hline Neoplasias & 24 & 1,5 & 2,6 & 25 & 1,7 & 2,3 & 49 & 1,6 & 2,4 & 21 & 1,3 & 2,1 & 26 & 1,8 & 2,3 & 47 & 1,5 & 2,2 & 231 & 1,5 & 2,2 & $22 \quad 1,6$ & 1,8 & 45 & 1,5 & 2,0 & 40 & 2,1 & 3,7 & 67 & 3,5 & 5,3 & 107 & 2,8 & 4,6 \\
\hline Endócrinas & 52 & 3,3 & 5,6 & 90 & 6,0 & 8,3 & 142 & 4,6 & 7,1 & 58 & 3,6 & 5,9 & 88 & 6,0 & 7,7 & 146 & 4,8 & 6,9 & 392 & 2,5 & 3,8 & $\begin{array}{ll}71 & 5,2\end{array}$ & 5,9 & 110 & 3,8 & 4,9 & 33 & 1,7 & 3,1 & 64 & 3,3 & 5,1 & 97 & 2,5 & 4,1 \\
\hline Sangue & 14 & 0,9 & 1,5 & 14 & 0,9 & 1,3 & 28 & 0,9 & 1,4 & 6 & 0,4 & 0,6 & 11 & 0,8 & 1,0 & 17 & 0,6 & 0,8 & 171 & 1,1 & 1,7 & $5 \quad 0,4$ & 0,4 & 22 & 0,8 & 1,0 & 12 & 0,6 & 1,1 & 19 & 1,0 & 1,5 & 31 & 0,8 & 1,3 \\
\hline Jho e anexos & 34 & 2,2 & 3,6 & 19 & 1,3 & 1,8 & 53 & 1,7 & 2,6 & 8 & 0,5 & 0,8 & 7 & 0,5 & 0,6 & 15 & 0,5 & 0,7 & 30 & 0,2 & 0,3 & 10,1 & 0,1 & 4 & 0,1 & 0,2 & 311 & 1,6 & 2,9 & 29 & 1,5 & 2,3 & 60 & 1,6 & 2,6 \\
\hline Duvidos & 1 & 0,1 & 0,1 & - & - & - & 1 & 0,0 & 0,0 & 2 & 0,1 & 0,2 & 1 & 0,1 & 0,1 & 3 & 0,1 & 0,1 & - & - & - & - $\quad-$ & - & - & - & - & - & - & - & 1 & 0,1 & 0,1 & 1 & 0,0 & 0,0 \\
\hline Sist nervoso & 19 & 1,2 & 2,0 & 13 & 0,9 & 1,2 & 32 & 1,0 & 1,6 & 14 & 0,9 & 1,4 & 9 & 0,6 & 0,8 & 23 & 0,8 & 1,1 & 161 & 1,0 & 1,6 & $\begin{array}{ll}9 & 0,7\end{array}$ & 0,8 & 25 & 0,9 & 1,1 & 74 & 3,9 & 6,9 & 47 & 2,5 & 3,7 & 121 & 3,2 & 5,2 \\
\hline Circulatório & 679 & 43,3 & 72,6 & 6524 & 43,6 & 60,51 & 1331 & 43,4 & 66,1 & 662 & 41,4 & 67,5 & 6284 & 43,1 & 55,21 & 12904 & $42,2 \quad 6$ & 60,9 & 70745 & $45,9 \quad 68$ & $\begin{array}{ll}68,8 & 62\end{array}$ & 2145,2 & $, 2 \quad 51,8 \quad 1$ & 1328 & 45,65 & 59,6 & 70837 & 7,46 & 55,7 & & 35,15 & 53,2 & 13813 & 36,2 & 59,0 \\
\hline Respiratório & 280 & 17,9 & 29,9 & 2601 & 17,4 & 24,1 & 540 & 17,6 & 26,8 & 350 & 21,9 & 35,7 & 30421 & 20,9 & 26,7 & 6542 & $21,4 \quad 3$ & 30,9 & 31720 & $20,6 \quad 30$ & $30,8 \quad 28$ & 8620,8 & $8 \quad 23,9$ & 603 & 20,72 & 27,1 & 50426 & $6,6 \quad 4$ & 16,8 & & 27,74 & 42,1 & 10362 & 27,2 & 44,2 \\
\hline igestivo & 171 & 10,9 & 18,3 & 122 & 8,1 & 11,3 & 293 & 9,6 & 14,5 & 167 & 10,5 & 17,0 & 118 & 8,1 & 10,4 & 285 & $9,3 \quad 1$ & 13,5 & 1378 & $\begin{array}{ll}8,9 & 13\end{array}$ & $13,3 \quad 10$ & $08 \quad 7,9$ & 9,02 & 245 & $8,4 \quad 1$ & 11,0 & 179 & $9,5 \quad 1$ & 6,6 & 152 & $7,9 \quad 1$ & 12,0 & 331 & 8,7 & 14,1 \\
\hline eniturinário & 108 & 6,9 & 11,5 & 53 & 3,5 & 4,9 & 161 & 5,3 & 8,0 & 89 & 5,6 & 9,1 & 70 & 4,8 & 6,2 & 159 & 5,2 & 7,5 & 875 & 5,7 & $8,5 \quad 5$ & $51 \quad 3,7$ & 4,3 & 138 & 4,7 & 6,2 & 93 & 4,9 & 8,6 & 66 & 3,4 & 5,2 & 159 & 4,2 & 6,8 \\
\hline Sele & 5 & 0,3 & 0,5 & 10 & 0,7 & 0,9 & 15 & 0,5 & 0,7 & 9 & 0,6 & 0,9 & 3 & 0,2 & 0,3 & 12 & 0,4 & 0,6 & 20 & 0,1 & 0,2 & $\begin{array}{ll}4 & 0,3\end{array}$ & 0,3 & 6 & 0,2 & 0,3 & 9 & 0,5 & 0,8 & 14 & 0,7 & 1,1 & 23 & 0,6 & 1,0 \\
\hline steomuscular & 25 & 1,6 & 2,7 & 24 & 1,6 & 2,2 & 49 & 1,6 & 2,4 & 20 & 1,3 & 2,0 & 352 & 2,4 & 3,1 & 55 & 1,8 & 2,6 & 161 & 1,0 & 1,6 & 18 & 1,5 & 34 & 1,2 & 1,5 & 33 & 1,7 & 3,1 & 37 & 1,9 & 2,9 & 70 & 1,8 & 3,0 \\
\hline ongênitas & 2 & 0,1 & 0,2 & 3 & 0,2 & 0,3 & 5 & 0,2 & 0,2 & 6 & 0,4 & 0,6 & 7 & 0,5 & 0,6 & 13 & 0,4 & 0,6 & 20 & 0,1 & 0,2 & 20,1 & 0,2 & 4 & 0,1 & 0,2 & 11 & 0,6 & 1,0 & 16 & 0,8 & 1,3 & 27 & 0,7 & 1,2 \\
\hline Mal definidas & 23 & 1,5 & 2,5 & 39 & 2,6 & 3,6 & 62 & 2,0 & 3,1 & 46 & 2,9 & 4,7 & 23 & 1,6 & 2,0 & 69 & 2,3 & 3,3 & 372 & 2,4 & 3,6 & $25 \quad 1,8$ & 2,1 & 62 & 2,1 & 2,8 & 39 & 2,1 & 3,6 & 40 & 2,1 & 3,2 & 79 & 2,1 & 3,4 \\
\hline Lesóes & 67 & 4,3 & 7,2 & 111 & 7,4 & 10,3 & 178 & 5,8 & 8,8 & 70 & 4,4 & 7,1 & 69 & 4,7 & 6,1 & 139 & 4,5 & 6,6 & 624 & 4,0 & 6,0 & $87 \quad 6,3$ & 7,3 & 149 & 5,1 & 6,7 & 56 & 3,0 & 5,2 & 93 & 4,8 & 7,4 & 149 & 3,9 & 6,4 \\
\hline Contatos & 1 & 0,1 & 0,1 & 5 & 0,3 & 0,5 & 6 & 0,2 & 0,3 & 1 & 0,1 & 0,1 & 3 & 0,2 & 0,3 & 4 & 0,1 & 0,2 & 90 & 0,6 & 0,9 & 20,1 & 0,2 & 11 & 0,4 & 0,5 & 22 & 1,2 & 2,0 & 21 & 1,1 & 1,7 & 43 & 1,1 & 1,8 \\
\hline Ignorado & - & - & - & - & - & - & - & - & - & - & - & - & - & - & - & - & - & - & $\begin{array}{ll}9 & 0 \\
\end{array}$ & 0,6 & 0,9 & $\begin{array}{ll}13 & 0,9 \\
\end{array}$ & 1,1 & 22 & 0,8 & 1,0 & 7 & 0,4 & 0,6 & 11 & 0,6 & 0,9 & 18 & 0,5 & 0,8 \\
\hline Total* & 1567 & 1001 & 167,5 & 14971 & 1001 & 138,8 & 3064 & 100 & 152,2 & 1598 & $100 \mathrm{I}$ & 163,014 & $1458 \quad 1$ & 1001 & 128,23 & $3056 \quad 1$ & 10014 & \begin{tabular}{|l|l|l|}
44,3 & 1 \\
\end{tabular} & 153910 & 100149 & $19,8 \quad 137$ & $74 \quad 100$ & $\begin{array}{lll}0 & 114,6 \quad 25\end{array}$ & 913 & 10013 & 30,8 & 18931 & $00 \quad 17$ & $95,7 \quad 15$ & 9181 & $100 \quad 15$ & 51,73 & 3811 & 100 & 162,7 \\
\hline
\end{tabular}

